

\section{Die Sammlung}

\section{„Rus Ratur und Geifteswelt"}

nunmebr über $s 00$ Bände umfaffend, bietet wirkliche "Einfübrungen" in abgeidloffene Wiffensgebiete für den Untertidt oder Selbftunter= rid) des Eaien nad den beutigen metbodifden Anforderungen und er: füllen fo ein Bedürfnis, Dem weder umfangreide Enjẗllopädien, nod fkizzenbafte Rbrille entipreden können. Die Bände wollen jedem geiftig

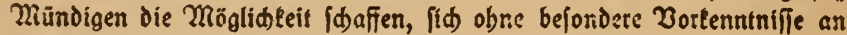
ficherfter Qucile, wie fie die Darftellung Durd berufene Betteter Der Wiffen=

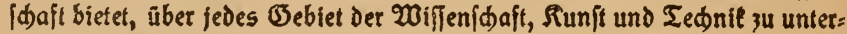
ridten. Sie wollen ihn dabei zugleid unmittelbar im $B$ er uf fördern, den Gefidtsteis ermeiternd, die Einfidt in die Bedingungen der Berujsarbeit vertiefend.

Die Sammlung bictet aber aud Dem fadmann eine rafte 3 uoer=

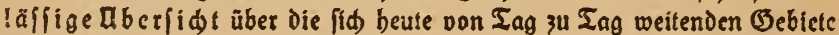
des geiftigen Eebens in weiteftem Umfang und vermag fo oor allem aud

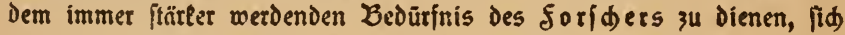
auf Den Racbargebieten auf dem laufenden zu etbalten. In den Dienft Diefer Aufgaben baben fid Darum aud in Dantenswerter Weife von Hnfang an die beften Namen geftellt, getn die Welegenbeit benukend, fich an weiteite Riteife zu menden.

Mit Gerbit 1925 tritt eine Reuerung infojern ein, als neben ben Sänden im bisberigen limfange jolde in erweitertem, etwa andettbalbfachem 34 $11 \%$ fachem Breife ausgegeben werden, weil abgeidloffene Daritellungen

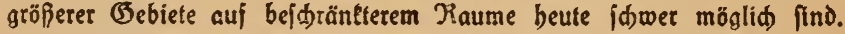
Dieje Sände, Die die Rummern oon 100 s ab tragen, erjheinen, um Die Einbeitlidbeit Der Sammlung 34 wabren. in Der gleiden Rusftattung wie die übrigen Bände. Sie fino nut auf Dem Rücentitel Duth ie ein Sterndhen über und unter der Rummer bejondets gelennzeidnet.

Plies in allem find die (d)muden, gebalívollen Bände bejonders geeignet, die freude am Bubbe zu wefen und Daran 3 gewöbnen, einen $\mathbf{B}$ ctrag, den man für Erfüllung förpetliđe't Bedũtinifle niकht anzufeben pflegt, aud

für die Zefriedigung geiftiger anzumenden.

Jever Det meift reid) illuftrierten Bände

ift in fị abgefolofien uno einzeln tãuflid)

Eeipzig, im Ottobet 1925.

B. V. Teubner 


\section{Bisber find exfbienen}

\section{3ur Ëd. u. 23öltertunde, Geologie, Meteorologie:}

Allgemeine beographie.

Seamoxpbologie. Bon kirof. Dr. f. Madatidet. Mit 33 Abbildungen. (BD.627.)

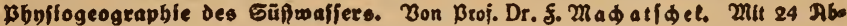
bildungen. (BD. 628.)

Das Meet, feine Exforidung und fein Reben. Bon Brofefiot Dr. O. Janfon. 3. Ruft. Mit 40 Abbildungen. (3b. 30.)

Seograpbie det Worwelt. (Balãogeograpbie.) Bon Brof. Dr. C. Dacqué. Wit 18 Siguten im Iekt. (30.619.)

Trenib und Eede. Etizen von den Wedielbeziebungen zwilden beiben. Bon Beb.

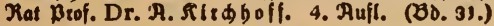

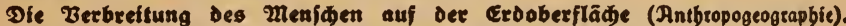

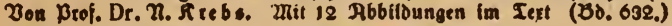

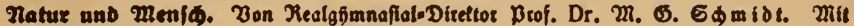
19 Abbildungen. (30. 458.)

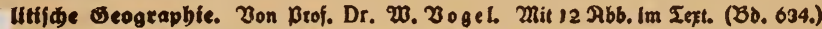
- Seitalter dex Entbedungen. Bon Brof. Dr. 5. (5 ü it welttarte. (30. 26.)

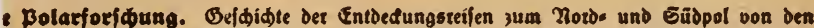
ften Beiten bis zut Eegenwart. Bon Brof. Dr. א. Baffert. 3. Rufl. Mtt 2 Abe ungen im Iezt und 2 STatten. (330. 38.)

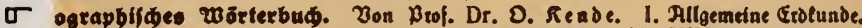
(8) भbbiloungen im Iext. (Teubners Rleine Jađwöttetbüder. 230. VIII.)

retunden.

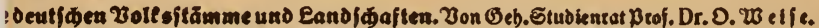
söllig umgearb. Rufh. Mat 30 Rbbildungen im Iekt und auf 20 Iafein und 1 Dialettarte itjolands. (30. 16.)

gien. כon Dr. B. OBwald. 3. Huff. Mit 4 fatten im Iezt. (38.501.)

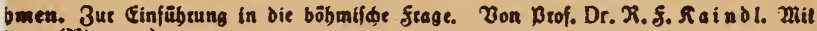
acte (30. 703.)

Baltijben Brovinzen. Bon Dr. 3. Iornius. 3. Huflage. Mit \& Abbiloungen 2 fattenftizzen. (38. 542.)

nland. Bon Eefandthaftstat J. O bquifi. (30. 700.)

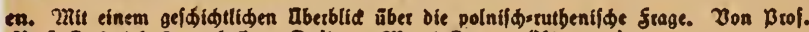
X. S. StaindL 2., oerbefferte Ruflage. Mit 6 ftarten. (30. 547.)

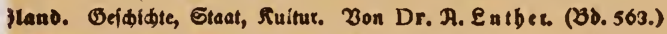

Elaweu. Bon Brof. Dr. B. Diels. (BD. 740.)

und, das Eand und das כole. Jon Brof. Dr. B. Gertman n. mit 9 Abb. (30.461.)

zeugriedenland. Won Beof. Dr. A. Geifenberg. (30.613.)

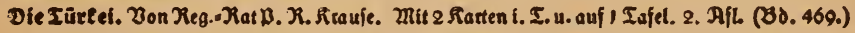

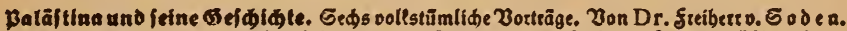
4. Rufl. ZRit, Blan oon Betufalem und 3 'Anfibten bes Geiligen Eandes. (30.6.)

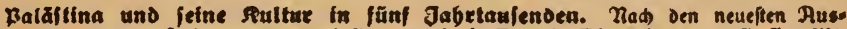
grabungen und foribungen dargeftelt oon Beof. Dr. B. Ibomfen. 2. Hufl. Mit 37 Abbildungen. (30. 200.)

3ndien. Bon profeffor Dr. 6. fion ow. (3.b. 614.)

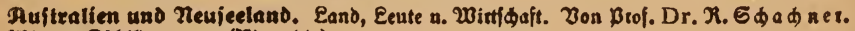
2lit 23 RbbitDungen. (20. 366.) 


\section{Antbropologie und Etbnologie.}

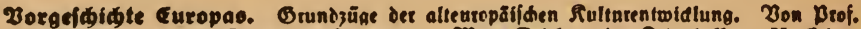

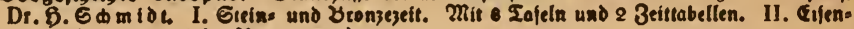
jeit. (UL. 0. Br. 1925.j (30.571/72.)

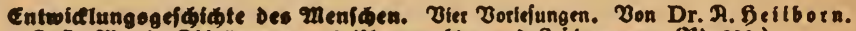
2. Rufl. Mit 6, Rbbildungen nad Dbotograpbien und 3eldnukgen. (B૪. 386.)

Det Menid Dex Uneft. Bier Botiefungen aus ber Entwidlungsgefdidte bes Menidens

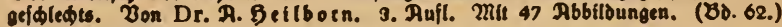

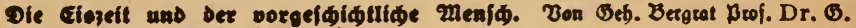
Eteinmann. 3. Rufl. (80.302.)

Rligemefne 2 z̈lectunbe. 3 Bande.

I. Seuer, Nabrungserwetb, Wobnung, Gdmud und Rleibung. Won Dr. Я. Beilborn. mit 54 Аbb. II. Waffen und Wertzeuge, Jnduftrie, Bandel und Delb, Bettebrsmittel.

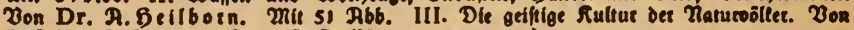

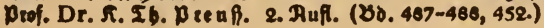

\section{Bermeffungs: und Rartenlunde.}

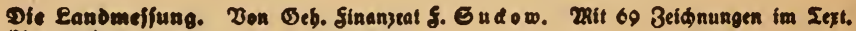
(31. 000.)

Sartentunde. Won Sinanztat Dr. Ing. भ. Coerę. I. Cinfübrung in das fartenvetfänonis 2itt 49 Hbbilbungen im $\Sigma e x t$. (Bb. 010.)

Rusgleidungsedonung nat ber metbode der tleinften Quabrate. Bon Beb. Reg.siat Beof. E. Gegeman n. Wit $\|$ Stguten im Iezt. (30.609.)

photegrammetrie. (Einfache Gteteos und Euftphotogrammetrie.) Bon Dipl. Ing. 6. Eüf由et. Mit 78 Siguren im Iext unb auf 2 Iafeln. (30.618.)

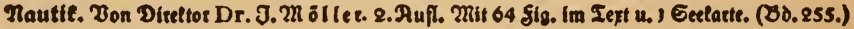

\section{Eeologie.}

Rllgemeine Eeelogie. Bon Deb. Bergrat Brof. Dr. fr. fred. 6 Bände. 3. Rufl.

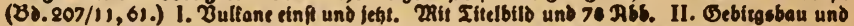

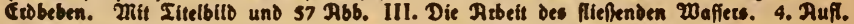
Mit 1 Iltelbitb und 50 Rbbildungen im Eept und auf 3 Iajela. IV. Die Bobenbildung,

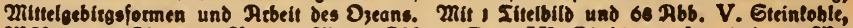

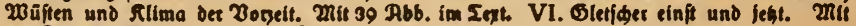
46 Rbb. im IeFt.

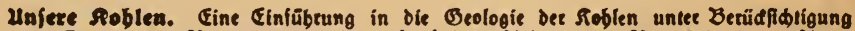
ibret Eewinnung, כetwendung und wittianaftliden Bedeutung. Won Bribatbogent bergs

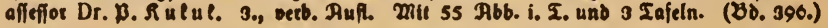

Weltentftebung in Eage uno wiffenidaft. Won Brof. Dr. ת. 3 ieglet und Brof. Dr. 5. Oppenbeim. Wit 4 Stguken im Iett. (30. 719.)

Weltuntergang in Eage und wiffenidgaft. Bon prof. Dr. R. Biegler und prof. Dr. 6. Oppen beim. (30. 780.)

Gedegifø.mineralogif 3ablteiden Rbbiloungen. (इeubnets lleine Saфwötterbüdet B̧. VI.)

\section{Theteorologie.}

Cinfübrung in Die wettecfunde. Won Brof. Dr. 2. We bet. 3. Rufl. Wht 26 Rbb. im Iext uno 3 Iafeln. (30.55.)

Infer wetter. Eine Einfübrung in die Nlimatologie Deutidlands an ber Gand von

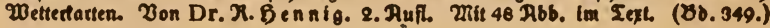

Weitere Bände befinden fíd in Vorbereitung 


\section{Aus Katur und (நeijteswelt}

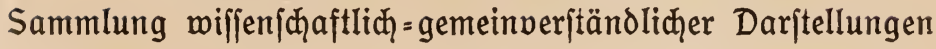
30. Bändḑen

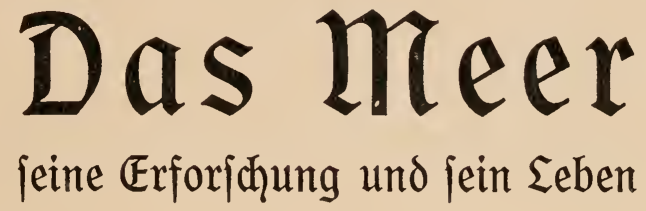

Don

Prof. Dr. Dtto Janjon

Dritte Auflage mit 40 abbildungen
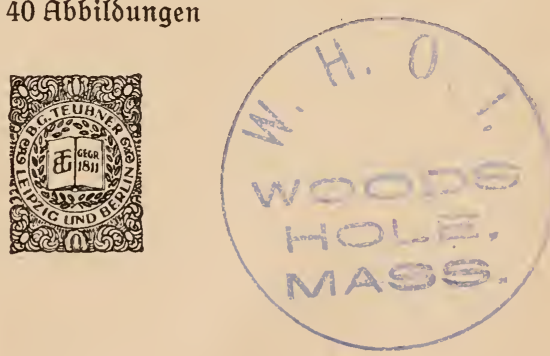

Drữ und Derlag von B. (ூ. Ceubner in Eeipzig und Berlin 1914 
Copyright 1914 by B. G. Teubner in Leipzig.

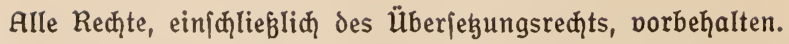




\section{Borwort 3ut erften SItffinge.}

Die Yebeten Dezennien bes vergangenen Sahrhunderts haben bie

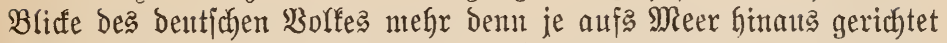

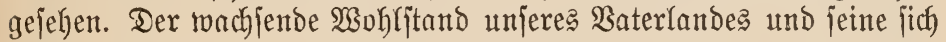

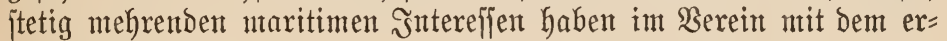

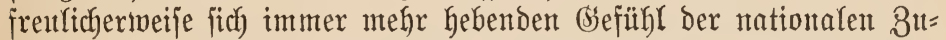
fammengehörigfeit ifm bie Pfflichtent vor 2 (ngen geführt, bie bas Stamnt= land jeinent in weiter Ferne wohnenden Ssłiedern gegenüber zu erfüflen

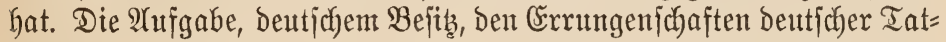
fraft und 2ftsbatter eine feite Stübe zu geben, beginnt gerabe in ber

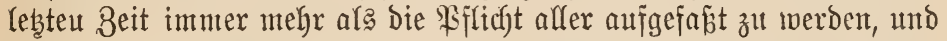

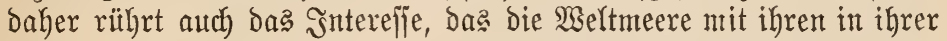

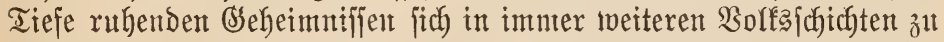

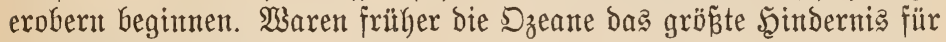

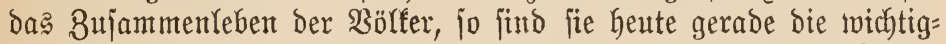
ften Bermittler fïr bie $\mathfrak{B e r b r e i t u n g ~ v o n ~ S c a n d e l ~ a n d ~ B e r f e h r , ~ S u l t u r ~}$ mo Wifjenjachajt.

Die hier gegebenen Schilderungen der twichtigiten Errfolge der mo= bernen Meeresforjchung find im affgenteiten aủ Borträgen zufanmen=

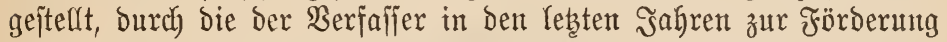
ber maritimen Bejtrebungen unjeres $\mathfrak{S o l f e} e$ jeit Scherfein beizutra= gen berfucht hat. Der zur Berfügung jtehende Raum war eng begrenzt,

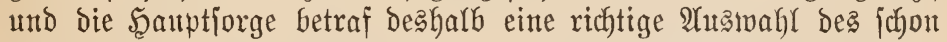
jebst äuzerit umfangreichen Stoffez, ber nach ber Bearbeitung bes vou Der Yestent Deutfchen Tiefiee= Expedition (1898/99) mitgebrachten Ma= terials jebenfalls noch bedentend anwachjent wiro. Siele twichtige Punfte

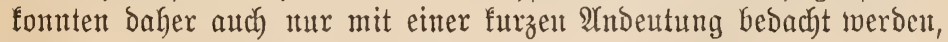

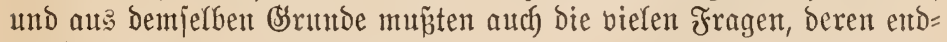
gültige Beantroortung fpäteren Sabrzehnten vorbebalten fein wiro, fich nit einem $\mathfrak{f}_{11} z e n$ Şintveis begnügen.

Dem Şerrn Serleger ipreche ich) fïr bie frentudiche Bereitwilligfeit,

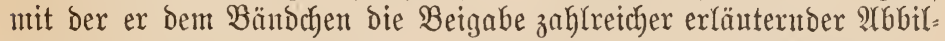
Dungent ermöglicht Gat, anth an biejer Stelle meinen Dant auts.

$\Re \ddot{0}(\mathfrak{n}$, im Mai 1902.

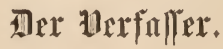




\section{Borwort jul britten 2aţlage.}

2(uch bie vorliegende britte 2 (nflage lebnt fich eng an bie erite an. Da aber bie Dzeanographie und bejonders auth bie Qehre von der Berbreitung Der Drganismen in ben Seltmeeren danf einer gropent

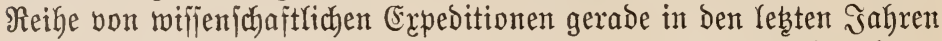
eine auperorbentfiche Förberung erfahren hat, war e马 nötig, einige Sapitel einer Durchgreifenden Untarbeitung zu unterziehen und bie neu

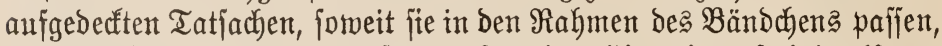
zu berïffitchtigen und einzufügen. Für ben Şintweis auf einige lunge=

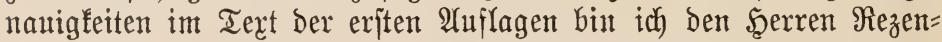
jenten, bie bem Büchlein eine fo warme Empfehlung mit auf ben $\mathfrak{S e g}$ gegeben haben, zu Danf verpflichtet.

囚öln, im Rovember 1913.

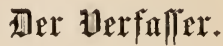

\section{Sinfaltäiberfidft}

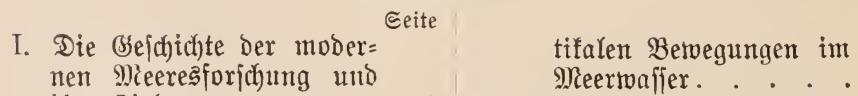
ifre Biele. . $\cdot$. $\cdot$.

II. Die Serteilung von $\mathfrak{B a j j e r}$ und Land auf ber Erbe; Die Sotwerfizenge und die Tiefen der Szeane. .

III. Die Ðberflächenform des Meereझbodens unb bie $\mathfrak{A b}=$ lagerungen ber Tieffee.

IV. Die Temperaturverfälntnifje Der Dzeane... . . 34

V. Die horizontalen und ver=

1 VI. Sidht und Drud in Der

Geite Tiefiee, Beitandteile, Didfte und Farbe des Meerwafiers . . .

9 VII. Nebe und andere Fang= merfzeuge.... 65

VIII. Die PFlanzen Des Meeres 68

16 IX. Die Tiere bes Mieeres . 76

X. Anpalfungaperjheinungen bei Den Meerestieren . 93

ธ๙һ) 


\section{2abjunitt.}

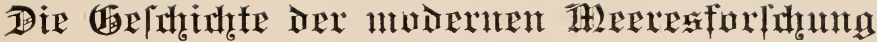 anti ilyxe Bielx.}

Es ijt Yeidht erflärlich, weshalb unter den bie Erobe betwohnenden

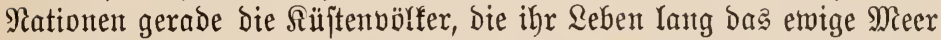

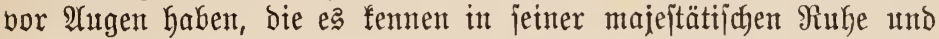
feiner alles zerftörenden Macht, bie als Fijcher oder Seeleute ihm iffren Unterhalt berbanfen und in ihm eine nie verjiegende Suelle von $\mathfrak{S}_{\mathrm{oh}}=$

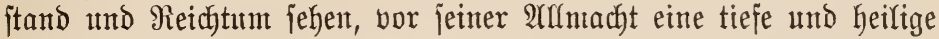
Scheu haben. 2Yber es wohnt in biefen $\mathfrak{B}$ ölfern, wie in Der Menfich heit überhaupt, von jeher neben ber tiefen, anbetenden (E)rfurcht vor ber Naturgetwalt ein unendiches Sehnen nady der Ferne, nach dem Unbe=

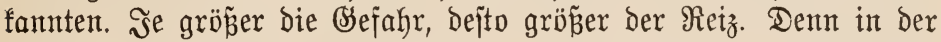

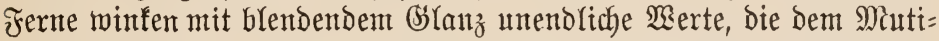
gen zufallen, der es wagt, bie Şanto banady auszanftrecfen, bie ifn tau=

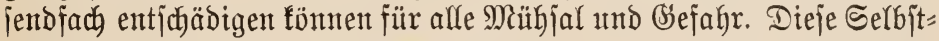
jucht, biejes Sudden nach fernent Sdyäben ijt bie Triebjeder fajt aller

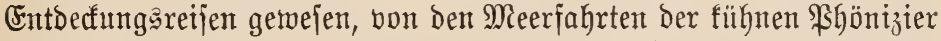
bis ztt benen unjerer Beit. Biele Sabrhunderte lang biente bas Meer

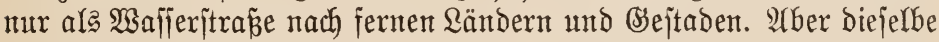
Sucht nach Bewinn trieb johon früh bie \$erlenfijider an ben Sïjten bes Jnoijuden Dzeans auch binein in bie unbefannte Tiefe des Meeres, und bie armen Schmammiucher bes Mittelmeeres troben nur ant Diejem Srumbe allen Entbefrungen und Bsefahren; Derjelbe Egoismus hat auch bie erite 2anregung zur heutigen Tiefieejorichung nit ifren überrajhenten Errfolgen gegeben.

In $\mathfrak{A}$ nregungen hatte es bereits im $\mathfrak{A n}$ fange des 19. Jahrhumberts nicht gefehrt; bie moderne Meeresforidhung nahm aber erit um bie Mitte

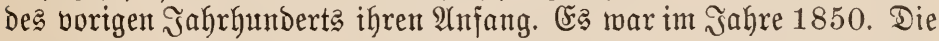
noch junge Qehre bon Der Erefeftrizität hatte bie Errindung Des Telegraphen gezeitigt, Der in weiter Ferne wohnende $\mathfrak{B}$ ölfer in $\mathfrak{A}$ trgenbliff in unmittel= bare Berïfrung zu bringen imftande ijt, und in bem genanten Sahre jollte bie erite unterjeeijiche Berbinoung jwijhen England und Frantretch hergeftellt merben. Da nan bas leitende Sabel dem unbefannten Meeres= 
grumbe anvertrauen mufste, war man gezwungen, ibu vorlyer einer ge= nauen Unterfuchung zu unterwerfen, die mandbe bis bahin geltende An= jchaung untvari und neue und äuperit benerfensiverte Tatjachen aus

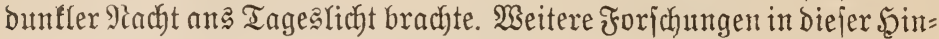

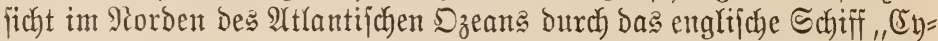

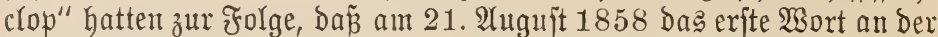
Şand des Drahtes die geheimnišbllen Meerestiefen zwijchen Sruand und

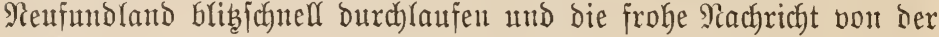
glüflich vollzogenen telegraphifhen Berbindung zweier Eroteile bringen fonnte. Brwar jollte bie Frende bon nur furzer Dauer fein, Denn bald barauf jtellte das Sabel für immer jeinte Iätigfeit ein; Die llrjache ber Störung fonnte nidgt mit Bejtimmtheit feịtgejtellt woerben. Erit fieben Sahre ipäter brachte Der "Great Eajtern" eine zmeite Berbinbung zwijchen Furopa und Amerifa zujtande. Sente liegen auj Dem Boben Der Meere Şmberttaujende von Rilometern Rabel. Sher bieje aus rein praftifchen Beweggrïnden its $\mathfrak{W e r f}$ gefebten Unternebnungen hatten den Dabei Beteiligten und bor allem Den (Selehrten bod zur

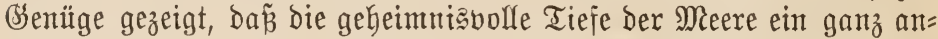
beres Bild aujreife als man bislang gemeint hatte. Fand man bod als man im Sabre 1860 das zerrifjene Sabel zwijhen Sarbinien und IIlgiex aus $3000 \mathrm{~m}$ Tiefe herauffolte, baf́ fich auf ím in brei Jabren ganze Rolonien bizher unbefannter Tiere fejtgejest hatten! Den Englän= bern, fdon Damals bem an joldhen Unternebmungen am meiften in=

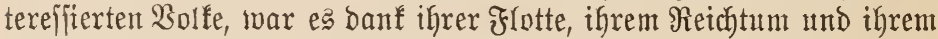
Unternehmungsgeift vorbehalten, in ben nädjten beiden Sahrzehnten das meijte zur Exforfichung Der Meerestiefen beizutragen. Männer wie Sarpenter, Ifomjon, Murray und viele andere ftellten ihre ganze firaft in Den Dienit ber Tieffeeforjanng, und die Regierung, fowie bie Das 200. Sabr ifrer Bründung feiernde "Royal Society" gaben die nï= tigen Mittel in freigebiger $\mathfrak{W e i f e}$ bazu Ger. So wurbe 1868 der fleine "Rightning" Yediglich für bie Tieffeeforjdyng ausgerïjtet; ex bradjte

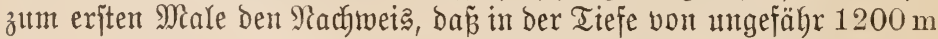
noch eit reiches Tierleben vorbanden ijt. (5s folgten $(1869-1870)$ die Fafrten bes "Porcupine" im Atrantifden Dzean und im Mittel= meer, mit Earpenter und Wyville Thomfon an Bord, von benen in Solf von Biscaya die anjelntidge Tiefe von $4453 \mathrm{~m}$ gelotet wurbe.

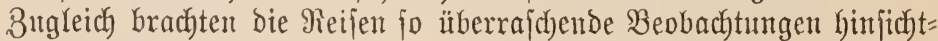
Yich Der $\mathfrak{B a ̈ r m e}=$ Drudf $=$ BDoden= und biologifachen Berhälntifje der Tief =

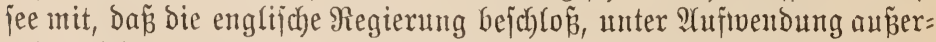

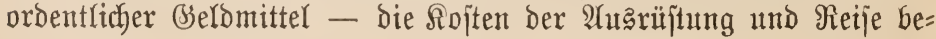


Yiefen fich auf megr als 4 Millionen Miark - ein Schiff mit allen

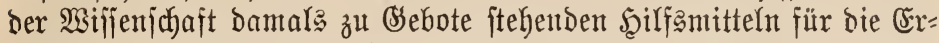

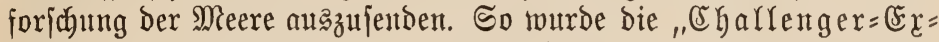
pebition" ins Reben gerufen. Das Sdjiff jelbjt, Das igr ben Mamen gegeben hat, war das sdeal eines ?aturforjhers. Da gab es alles und von allem bas Bejte und Bollfommenite, bas Wijienjafaft und Technif Der bamaligen Zeit ben unternehmungsfreudigen Belehrten mit auf

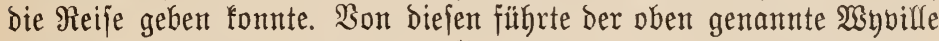
Thomion bie Reitung, Dem Der B̧eologe Murray, Der Phyjiffer und (Egemifer Buthanan und bie 3oologen Mofeley und v. Willemoës= Suhm zur Seite itanden; lebeterer erfranfte auf der Fahrt und muste zehn Monate uadh ber 2 usreife nadh Seemants 2 rat auf Den Boben Des Meeres gebettet werden. (Segen Weihnardent 1872 fubr Der "Shal= lenger" ab, freuzte den 2Ytlantifacen Szean mehrere Male und dampfte nach furzem 2 ufenthalt in Sapitadt in bas Sildoliche (Fismeer tnd nad

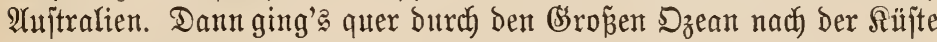

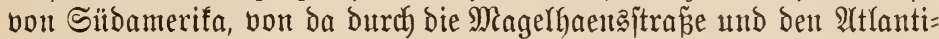

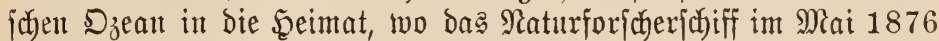
nach einer Arbmejenteit von brei Sahren und vier Monaten glüdfich wieder einlief. Into weldye Menge von neuten Tatjachen, weldye Fülle von überrajhenden Beobachtungen, wieviel jeltenes Material in Słläjern

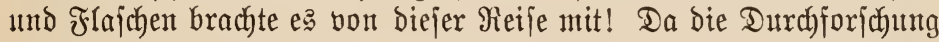
biejer wertoollen 2 Ha beute von der 2lrbeitafraft einte einzelnen For= jahers geradezu linmögliches verlangt hätte, wurbe ber Stoff verteilt, und wir bürfen ftolz fein, wenn wix Gören, Dá ein nicht geringer Teil zur Durcharbeitung in bie Scätıe beuticher Šelehrter gelegt wutroe,

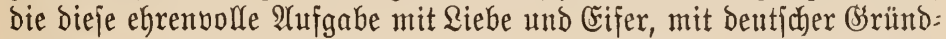
lichfeit und Wiffenfichaftrichfeit auf bas vortrefflichjte erlebigt haben. Diejer beifpiellofe Erfolg fenterte mun auth bie anderen Sulturbölfer

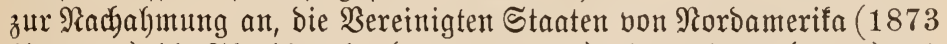
bia 1880), Die Sfandinavier $(1876$ - 1878), bie Stafienter (1880) und entolid) bie Franzojen (1880-1882); alle fonnten bie Richtigfeit ber vout "Challenger" gemachten Beobachtungen bejtätigen unt brad)ten eine reiche 2 (ntabente an neum Material mit.

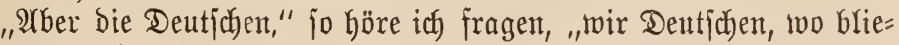
ben bent twir? Şattent wir bent gar Keinen Sinn tweder für bie ibeale

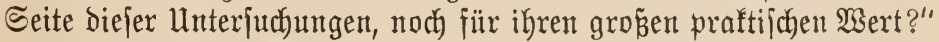

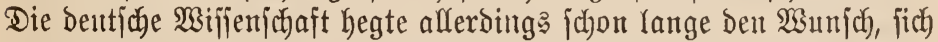

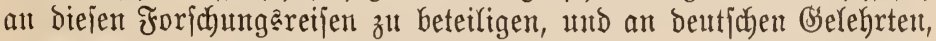
bie fich ihnen begeiftert getwiomet bätten, fehlte es, wie woir jahen, aud 


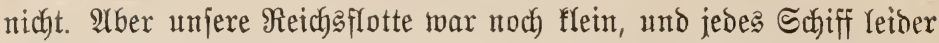

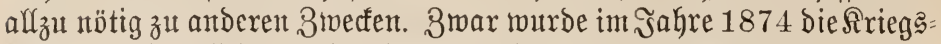
forvette "(sazelle" für bie Tiefieejorjung zmecfentiprechento ausges rïjtet; fie bereifte vom Sommer des genannten Sahres bis zum 2 tprif

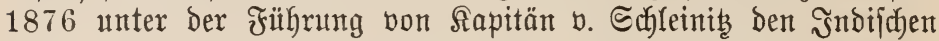
$D_{z e a n t}$ und itellte auf ifrer Fahrt nach ben Serguelen bie Tiefenver=

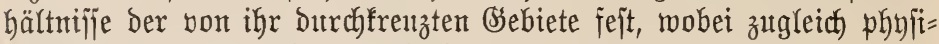
falijche und zoologilche Unteriuchungen angejtellt wurden.

Die erjte bebeutentere Fahrt eines beutichen @efiffes zur Error= jadung bes Meeres war aber bie jogenannte "Slanfton=Expebi=

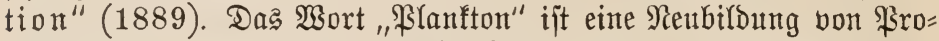

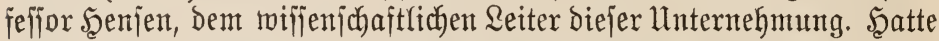

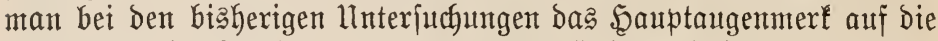
Berhältnifje ber Tieffee gerichtet, Die phyjiffalifhent und chemijahen Eigen= jichaften bes Tiefenwaliers, bie Siejtaltung bes Meeresbodens und bie eigenartigen Berwohner ber Meerestiefen fennen zu Yernen gejuctit, jo galt bei biejer Fahrt bas Эnterejie in erjter Sinie Den zahlreichent meijt

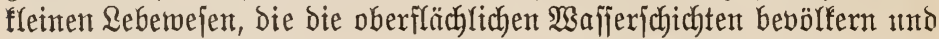
jich Dort jumebento auffalten, ein Spiel von Wind unt Wellen. Senjen

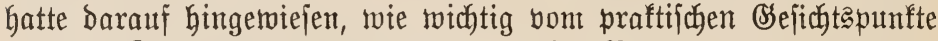
aus eine Sentntis von biejen Reberoejen bes \$lantton, von jeiter $8 \mathfrak{u}=$ fammenfekung nicht mur in qualitativer, fondern auch in quantitativer

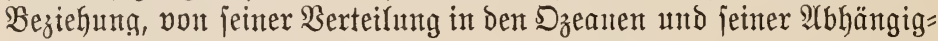

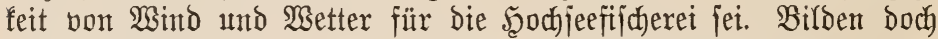
bieje Milliarben bon minzigen Algen und tierijchen Drganismen für alle anderen Meereßbetwohner bie einzige Nahrung; von ihr lebent bie zahlrojen Heinteren (bejchöpfe, und bieje werden wieber von ben grö= Berent verzehrt. Csa galt aljo bie Menge biejer Dberflächenfautua und

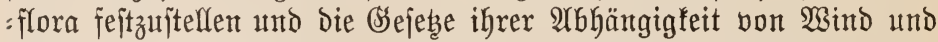

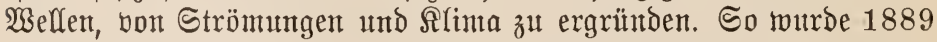

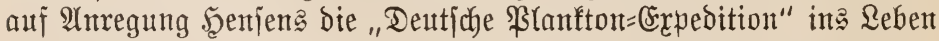
gerufen. Mitte Julti ging ber "National" von Riel atts in See. $\mathfrak{s a ̈ h}=$

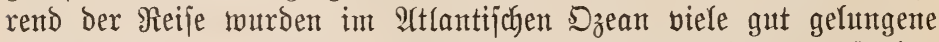

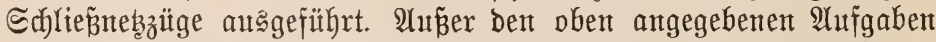
wurben auch Unterjuchungen über Windridgtung und =ftärfe, über f̧lima und \$afiate angejtellt, itber Farbe und Salzgebalt bes \$ieerwafiers und jeine Wärnteverhältuifife, über bie Meereşftrömungen und ihre $2(b=$ hängigfeit von Wind und Ealzgehalt, alles Dinge, Die offenbar für Berteilung und Berbreitunt des Flanttons von ber gröpten Beden= tung jind. Wie überbaupt auf Dem B̌ebiete ber Wijjemjhaften, jo ruft 
auth auf bem ber Meeresforichung eine einmal angejdnittene Frage Gundert andere ins Seben. Die 2lnregung wirfte nicht mur auf andere

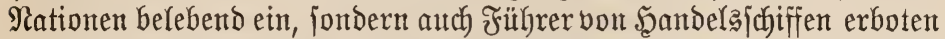

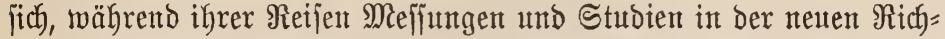
tung anzultellen, und \$rivate tritgen burch Bseldipenden und periön=

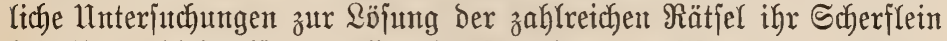
bei. Unter biejen ift bor alfem Fitrit Mrtbert von Monaco zut nemen,

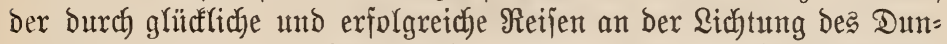
fela, das früfher über bie Berhältniffe ber Meerestiefen herrichte, fehr tätig gearbeitet hat. Seine erften $\Re e i j e n$ unternahm er 1885-1888 mit feiner Segeliacht, "Şirondelle" in Begleitung ber 8oologen Sules be

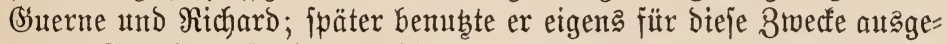

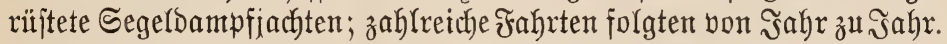

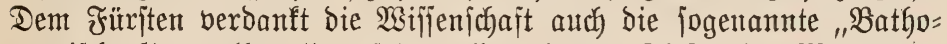
metrijche Bienteralfarte", auf ber alle geloteten Tiefen ber Meere ein= getragen fitto.

Snztwifhen ruften auch andere Nationen ntht; von ifren Fabrten

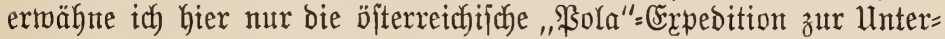
juchung der ozeanographifłen ßerhältniffe des Mittelmeeres uto des

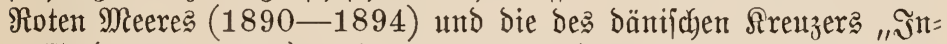

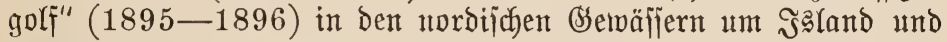

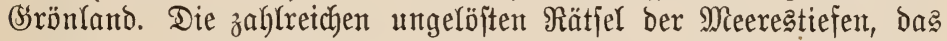
Kebhafte Jntereije, Das bentiche Forjcher biejem Şegenjtande entgegen= brachten, bie wadjenden maritimen Beziehungen mneres geeinigten Baterlandes zeigten aber auth bem beutjchen $\mathfrak{B o l f e}$ immer mefr, ba e马 bie ntoralijche Berpflichtung habe, mut aud jeinerieits zur Erforichung ber Meere, fütr bie andere Mationent fhon jo Geträchtliche Doper gebracht

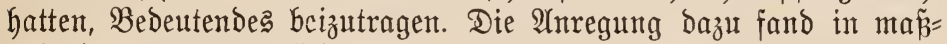
gebenden wijienfichaftlichen und regierenden Sreijen einen fruchtbaren Boden, und dant bem leb̆aften snterelïe unieres Raifers für alle Fort=

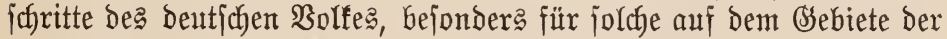

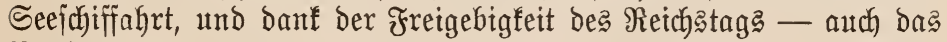

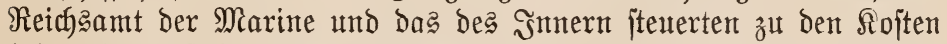

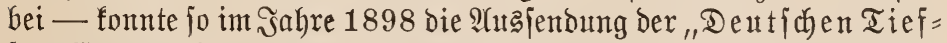
fee=Expedition" unter ber wifjenjuajtlichen Reitung bes Reipziger

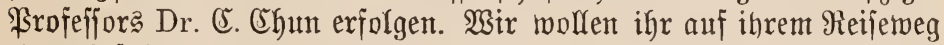
einmal forgen uno bie babei erreichtent wiffentichaftrichen Erfolge in groẻen 8 ügent vorfiübren.

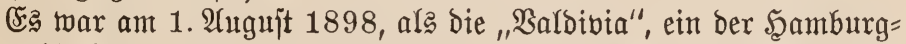
Ámerifa=2inie gehöriger Dampfer, mit allem wohl ausgerüftet, was 
zur Erreidyung ber weitgeftedten Biele nötig war, und nit den Teil=

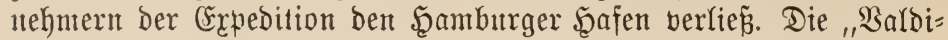
via" woar $107 \mathrm{~m}$ lang mo hatte eine Wafferverorängung von $3000 \mathrm{t}$.

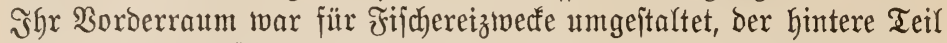

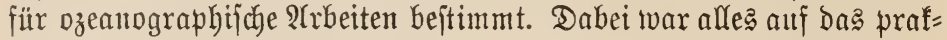
tijajte eingeridbtet; am Bord befand jich eine eleftrifane und eine Dampf= majdine für হot= und Fangzwedfe, und auß̉er ben für die Tieffeefor=

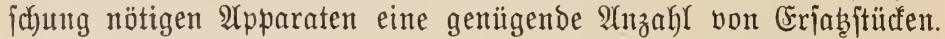

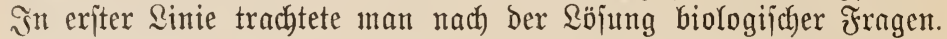
Was bildet die Rabrung der Tieffeetiere? Findet wirflid) cine $\mathfrak{W a n}=$

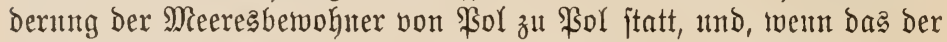
Fall ijt, wo und wann geht fie bor fich, auf Dem Meereshoden oder an ber Sberfläche? Dann galt es ferner die eigenartige Tierwelt fen= nen zu Yernen, bie fich beim Bnjammentreffen verjdieden warmer Mee= resftröme, wie z. B. jüblich vom Sap der (Suten Şoffinung, vorfindet,

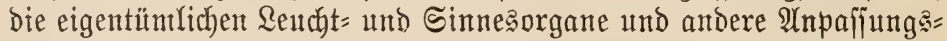
erfocinungen ber Tieffeetiere zu ftubieren und vieles andere melyr.

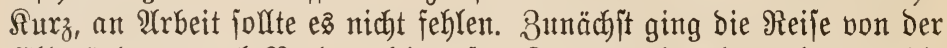
Elfmünoung nach Norben; die erjten Tage wurben bazu Genubst, bie Seijtungsfähigfeit ber mitgenommenen Seräte zu erproben und bie $\mathfrak{B e}=$

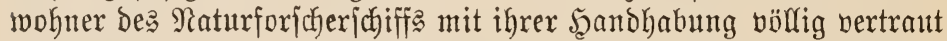

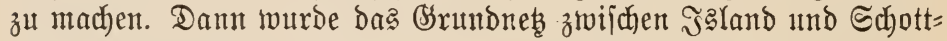
land in bas falte Tiefentwaffer ïber dem Ihomionrüten, cine Er= hebung des Meeresbodens, bie bis zur Şöbe von $500 \mathrm{~m}$ unter bem Meereśfpiegel fteigt und das falte ßolarwaffer von dem wärmeren des

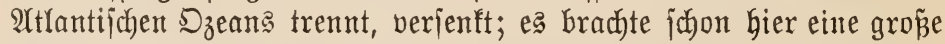
Menge von Tieffeetieren, vor allem von Sdytwämmen, ans Tageslicht.

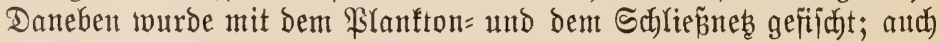
̈̈ber Den Bafteriengehalt Des Meerwafiers in grof̧en Tiefen fonnten neue Tatjachen feftgeftellt werden. Dann ging Die Fahrt nad Sitben, an ben $\mathfrak{A}$ zoren borbei nadb Teneriffa und von ba nad Weitafrifa und

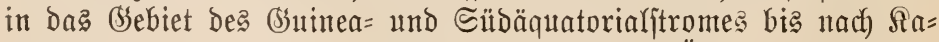
merun. Cine Rotung wenige Meilen füblich vou \&̈quator ergab eine Tiefe bon fajt $5700 \mathrm{~m}$ bei einer Bobentemperatur bon $1,9^{\circ} \mathrm{C}$. Um bie $\mathfrak{A b n a h m e ~ b e r ~} \mathfrak{B a ̈ r m e ~ m i t ~ z u n e h m e n d e r ~} \mathfrak{Z}$ affertiefe feftzuftellen, wurben bie Temperaturen des Waffers in beftimmten Âtbfänden ge= meffen, baneben dyemifhe, ozeanographifdye, biologifhe und bafterio= logifde Unterjudungen ausgeführt. Sin bejonderes Jntereffe wurbe der Fortjetzung Der Jeenfenfdyen llnterjuchungen der Planftonfantua und =flora und den Betwobnern ber mittleren 2 afferjdidyten unterbalb oer 


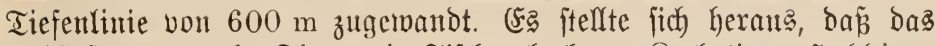

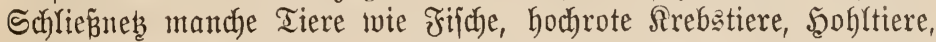
Seerwalzen u. a. an bie Sberfläche brachte, bie man vordem mur ala Bobenbetwohner gefannt hatte. Snt Santerungefiet und im weiteren Berlauf ber Fahrt entlang Der weîtafrifanifden Süfte wurben aud cinzelne 21ugflüge in bas Jntere bes Qandes unternommen. In ber Brropenen Fijafhudt, bie bei einer Rảnge von 20 Seemeilen bi zum

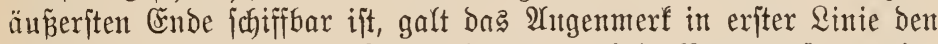
Putbitichen, benen ber aus Sitben fommende falte Benguelajtrom eine

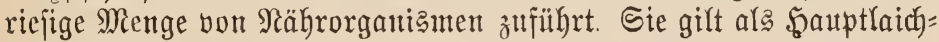

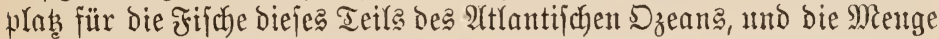

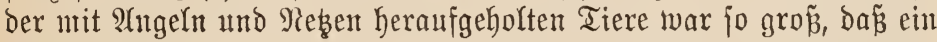
Boot burdh bie Unmaffe ber Fifiche fajt zum Sinfen gebradht wurbe.

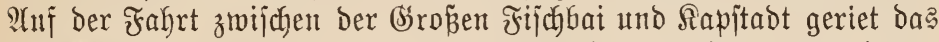
Dertifalnes in $2000 \mathrm{~m}$ Tiefe auf einte bisger unbefannte Banf, von der bas niedergelafiene Schleppneb eine grof́e $\mathfrak{A}$ tzahl Tieffeetiere her= anffolte, bie man vorher hauptläd)lich als Bewohner ber Dberflächent= idficht gefannt hatte. In Sapjtabt war ber erite Teil ber Reife be=

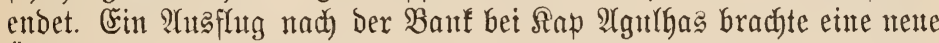
überrajdutug, Denu das Scharnebs förderte zum Erftaunen der Teit=

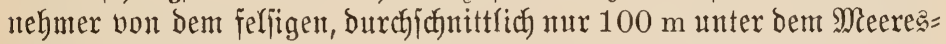

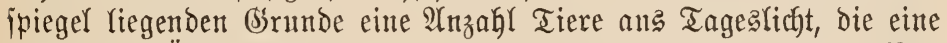

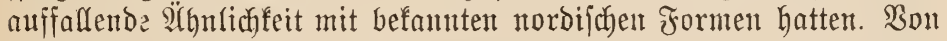

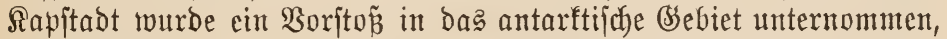

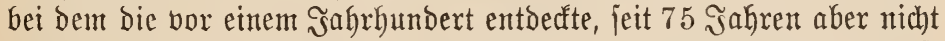

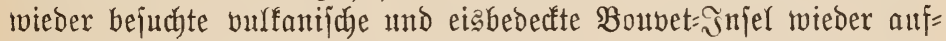
gefunden murde. Die Rotungen, bie im meiteren Berlauf der Reife ge=

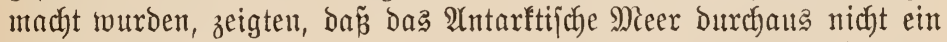
fo feichtes Becfen ift, wie man bislang angenomen hatte; Tiefent von 5000 bis $6000 \mathrm{~m}$ wurben twiederhort gelotet. Der füblithjte \$untt wurbe bei $64^{0} 14^{\prime}$ erreidft. $2(m$ Weifnadhtatage 1898 wurben bie Ser=

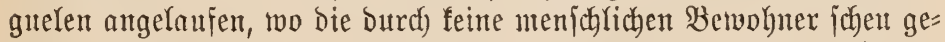

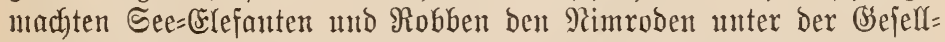
ichaft gute Bente Yieferten. Dann gintg's über Ment=2(niferoam und bie

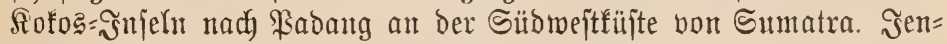

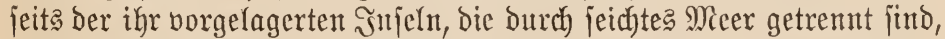
madyt fich ein bedeutender Steilabfall it ben Indifhen Dzean bemerk =

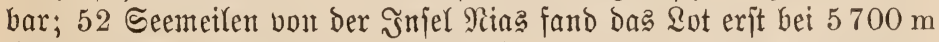
(Srunto. Bon ba fuhr bie "Walbivia" nördlid) zu bent Niffobarent, wo zmei Dredfdzïge zum Teil abjonderliche Formen ber Tieffees und Flach= 
jeefauna Keraufbradten, Fijde, Srebje, Seeipinten, Seejterne unt See= gurfen und vieles andere. Bon (Seblon wurbe über bie Malebiben und

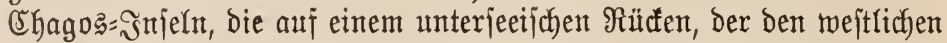
Teil bes Snbifchen Dzeans begrenzt, Yiegen, nach ben Sethelllen ge= bampit, in beren Nähe die für bieje Meere biaher befannte tiefijte Stelle von $5071 \mathrm{~m}$ gelotet wurbe. Nachoem bann unjern ojtafrifanifchen Sandzleuten in Dar es Salaant ein Bejtch abgejtattet war, murbe bie Seimreife angetreten, und am 30. 2Tpril lief bie "ßarbivia" glüaflich wieder in bie Elfe eint, wo ein begeifterter Subel bie Mitglieber ber Deutichen Tiefiee=: Expedition empfing. Die Menge ber Sotungen und Mejiungen, bie in ben Tabellen niebergelegt find, bas in Suläjern ge= jammelte Material von Meeresorganismen, bab bie Fahrt geliefert hat, ift auperordentlich grop und jtellt ben Teilnehmern und ifrem rajt= lojen Fleín ein ehrendę Zeugnis aus.

Seit der Rüuffehr ber Deutichen Tieffee=Erpedition fint nun eine ganze Reife netter Forjhungareijen ausgejandt toorden, bie unjere Senntnifje über viele Berbältnifje bedeutend erweitert haben. Biele von biejen Fabrtent hatten allerbings in eriter Sinie eine Föroberung unierer

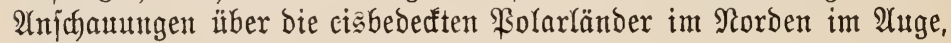

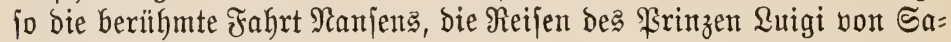
voyen auf ber "Stella Polare“, Nathorits, Sverorups, Pearys u. a.; ein bejonderes Interejie warb bejonders ben antartitichen Bjewäjjern zuteil, wo in ben lebsten Jahren viele grop̧e Expebitionen tätig waren, bie "Deutiche Sübpolarexpedition" unter E. von Drygalafi auf

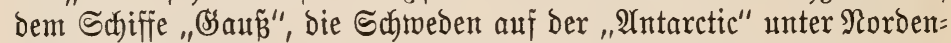
ifiöld, bie Engländer auf Der "Discobern" unter Scott, bie Schotten auf Der "Scotia" unter Bruce, Die Expebition bes Franzofent Eharcot

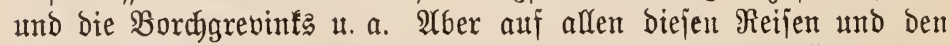
fpäteren \$olarunternehmungen bis in bie heutige Beit ber Entbefung Des Sübpola burch 2 (mumbjen (1912), bie im einzelnen anzuführen

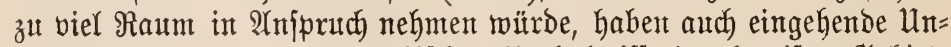
terjuchungen ber ozeanographifłen Berbältnifife Der bereijten B̌ebiete ftattgeftnden, und fo haben jich heutzutage unjere Senntrifie von biejen Berhältnifien auperorbentlich vertieft. Dazu find nach bem Borbirbe ber Deutichen 3oologifhen Station in Reapel im Raufe ber Zeiten einige Dubend andere biologifdhe Stationen an ben veridhiedeniten

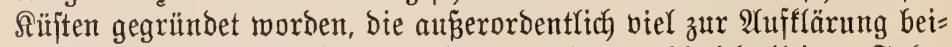
getragen haben. Endolich fint noch zu erwähnen zahlreidye fleinere $\mathfrak{F a h y}=$ ten, bie in erjter Linie praftijiche đSefichtapunfte berfolgten und im Dien=

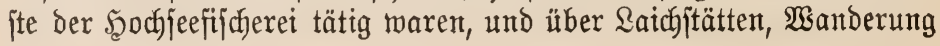




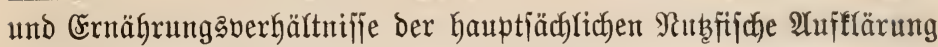

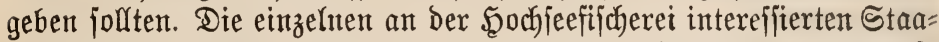
ten ftellten bejonders gebaute und ausgerüjtete Fahrzenge in ben Dienjt, bie jtänbig bie einjolägigen Fragen zu beantworten bejtrebt find und

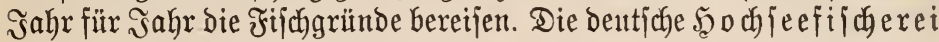
mirb hente auf 219 Fijhbampjern betrieben; von biejen jüb fajt bie Ђ̋älfte (112) in der $\mathfrak{B e j e r m u ̈ n d u n g ~ b e h e i m a t e t . ~ B e e j t e m u ̈ n d e ~ u n d ~ B r e = ~}$ merhaven find unjere größ̈łen beutichen Sূochjeefijchereipläbze; daneben fommen nod) Bremen, Scamburg, Âtona und Curbaven in Betradht.

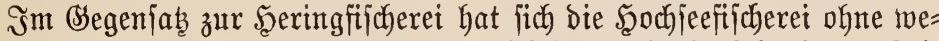
jentliche jtaatliche lunteritübung entwicfelt und ijt in fehr furzer Beit zu beträbthtidcher Şöhe gelangt. Bis zum Iahre 1884 wurde lediglich auf Segelichiffen gefijht; in biejem Sahre verlię ber erite beutiche

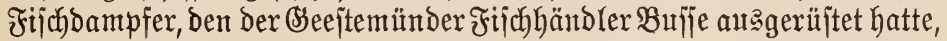

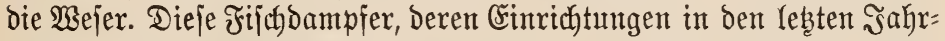
zehnten immer mehr verbeffert wutroen, fint fleine, aber feftgebaute Fahrzenge von 36 bis $40 \mathrm{~m}$ \&änge, bie eine Bejaksung von 10 bis 12 Mann haben. Sie gehen oft meit nach Norben in bie Polarwäfier, wo bie Fifcherei noch erträglidfer ijt als in näheren Ģebieten. Bsefijcht wird mit bem Sdjerbrettneb, einem tridjterförmigen Sdhleppneb, bas

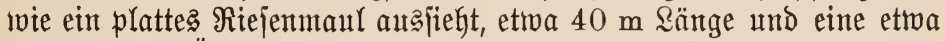
ebenjo breite D̈ff̈nntg hat; nachbem bas Neb mehrere Stunden über ben Boden geichleppt worden ijt, wirb es heraufgemunten und bie

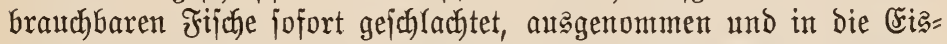
räume gebracht. Der $\mathfrak{M m j a k s ~ i m ~ ( S e e j t e m u ̈ n d e r ~ F i f c h e r e i f a f e n ~ b e t r u g ~ i m ~}$ Sahre 1909 nicht wentiger als 60 Millionen $\mathfrak{P}$ fund Seefithe.

Die Mannigfaltigfeit uno Bieljeitigfeit aller ozeanographijchen Fra: gen verlangte aber immer mehr nach einter ftreng und eintheitlich burch =

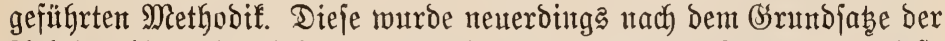

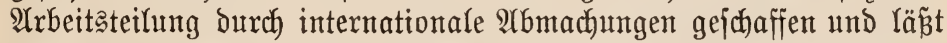
eine reiche Förberung aller 2 rrbeiten erfoffen. Der Bebante gemein=

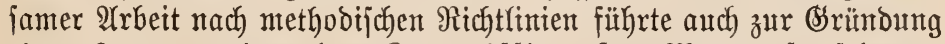
einer Jnternationalen Rommiffion für Meeresforfdung, Deren 2 (rbeit fich int erjter Linie auf Die norbijchen Meeresteife erjtredt.

\section{II. $\mathfrak{U}$ bjunith.}

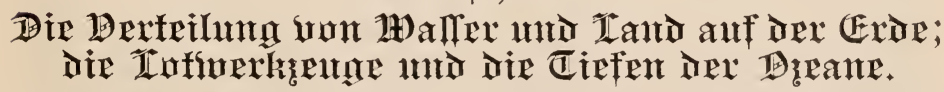

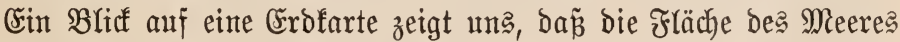

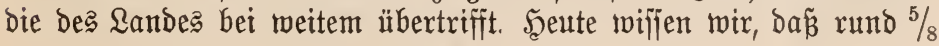


unferer Frobberfläche unter ben Fluten Des Meeres begraben füb und nur $3 / 8$ bon feitem Lande gebildet merben (arbb. 1). Die Fejtftellung genauter 8ahlen begegnet natürlid) grop̈en Edyrorigfeiten; gemöhnlid nimmt man die Tiefenlinie bon $200 \mathrm{~m}$ als bie Srenze zmifdyen Meer und Fejtland an. Rarjtens hat für bie einzelnen Dzeane folgende Zah= len ermittelt:

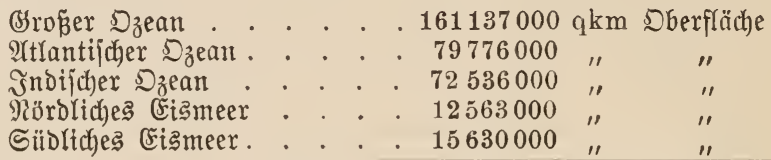

3ufammen 341642000 qkm 5 berfläd)e.

Da Sarjtens bie Dberfläche Der Binnenmeere mit $30748000 \mathrm{qkm}$ bered)net hat, fo ergibt fich eine Brejamtflädje bon 372390000 qkm Wafferbedecfung, ber runb 135500000 qkm fejten Landes gegenüber= jtehell, alfo wentiger als ber britte Teil. Nach $\mathfrak{B a g n e r}$ uno Srümmel

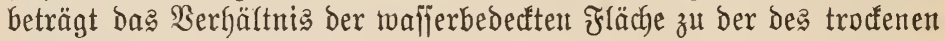

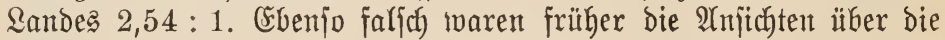
Tiefe ber Weltmeere, bie man einfach für untergründlich lyielt. Diefe

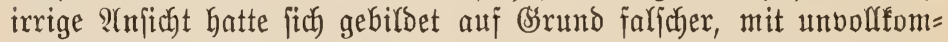
utenen 2lpparaten ausgefülbrter Rotungen; bebor wir über bie Tiefe

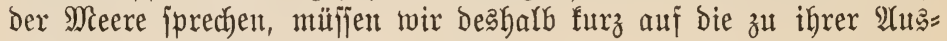
meijung nötigen $\mathfrak{B e r f z} z$ uge eingehen.

Die Tiefe eines Bsetwäffers zu mefien, jollte mant meinen, ift boch

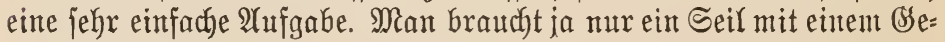
widht jo tief Ginabzulafien, bis es anf ben Bront ftöp̆t. Mit biejem ein= fachen 2 (pparat, einem höbhjtens $360 \mathrm{~m}$ Yangen und mit eintem zwölf=

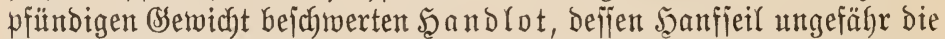
Dicfe eines Dauments hatte, wurben von alters her bie Tiefenutefingen

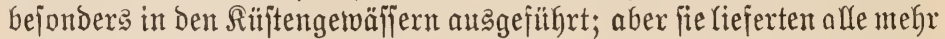
oder weniger faljache Ergebniffe, ba das Bserwicht bei etwa vorhandenen Strömungen nicht ausreichte. Was für Fehler auch bei $\mathfrak{A}$ mwendung lä̈tgerer QotYeinten bei früheren Mefinutgen vorfamen, gebt baraus her=

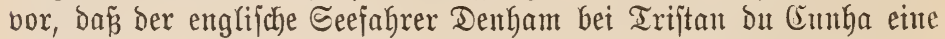
Tiefe von $14092 \mathrm{~m}$ gefundent zu habent glaubte; er beging Dabei einen

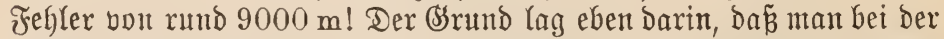

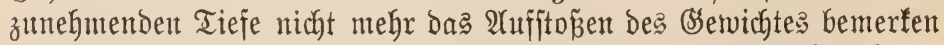
fonnte Dober aber nidgt mit ben unterjeeijchen Etrönungen gerechnet Gatte,

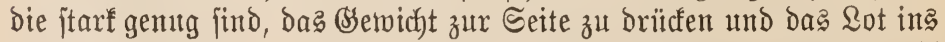
Treiben zu bringen. Leiftet deshalb ein foldyes Sandot noch heute wohl 
Dem Seefahrer, bem es bie gefahrbringenden Untiefen anzeigt, gute Dienjte, fo ijt es für bie Mefijutg groperer Tiefen nicht zu gebraucben. (F⿸尸

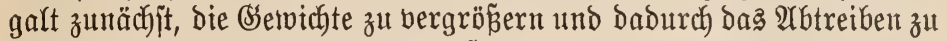
verfindern; Der Umitand fermer, bá ę bet Mefijungen größ̈erer Titefent, wie oben gefagt wurbe, nicht imnter reicft ift, an $\mathfrak{B}$ ord das $2 \mathfrak{U}$ ffito

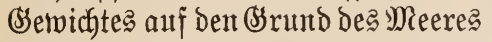
fidher wahrzunelymen, führte Broofe (1854) zur Erfintoutg bes nod) heute mit eintgen 2 (bändorungen bemubsten Tieffeelotes. Das Lot Broofes be= itand int Brinzip aus einer ichweren Eifenfugel, bie durchbohrt ijt und anf einer hofhlen Stange gleitet. Die $\Re_{\mathfrak{H}}=$ ger ijt an biejer jo befejtigt, baź beim

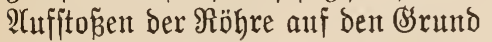
burch einen Sebefmedantismus bie

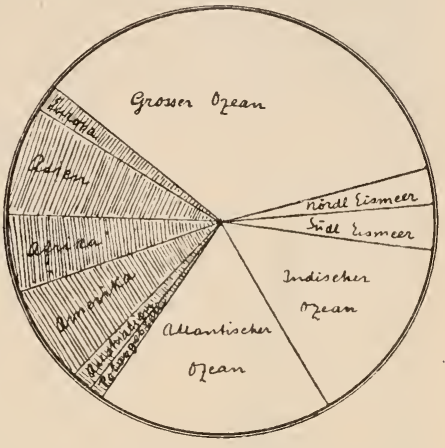

26b. 1. Die Berteilung von $\mathfrak{E a f f e x}$ uno \&and auf Der Dberfläthe ber Erob.

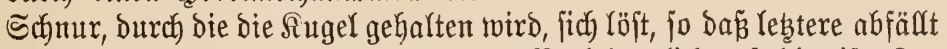
uno bie baburch Gewirfte (Entlaftung an Bord deutlich) zu fühlen ift. Zu=

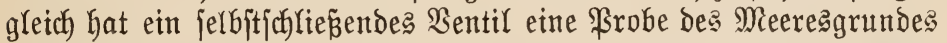
aufgenomment. Die im Raufe ber Sahre an biejem Tieffeelot vorge nommenen Sierbefierungen bejtehen in exjter Sinie Darin, da je jeit

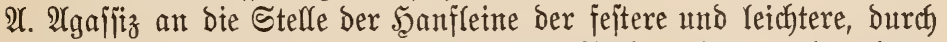
Billigfeit ttno Şandlichfeit autsgezeidnete Stahloraht trat, ber heute von einer Trommel mit Zähloorrichtung abgemidfelt wiro, und ba heute je nach ber zu erwartendent Tiefe mehrere ringfürmige Šemichte

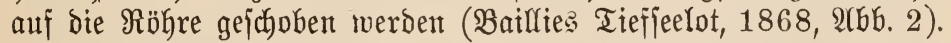
$\mathfrak{A}_{\mathfrak{u}}$ je $1800 \mathrm{~m}$ Tiefe redhnet man je einen foldyen Eijenring von un=

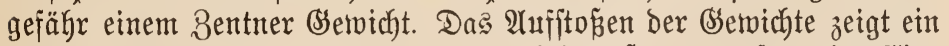
Dynamometer mit Feberzug an, ober, bei grö̈peren Tiefen, eime (Ein=

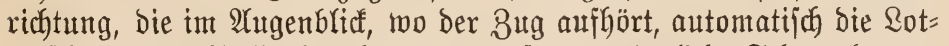
majhine zum Stillitehen bringt. Da ferner plöbliche Sdywanfungen

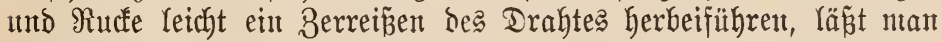
Yegeteren an Bord über eine Rolle gleiten, bie an einem Syjtem von febernden Spiralen (2rffumulator) aufgerängt ift (Sigabees Rotnta= jđine). Trob̧dem fommen Berlujte Gäufig vor. 2rYe man auf Der "Deut= ichen Tieffee=Erapebition" mit einem reuten 2 pparate einte Qotung zmi= ichen Ceylont und ben Maledivent ausfüthrte und bei $4454 \mathrm{~m}$ Tiefe

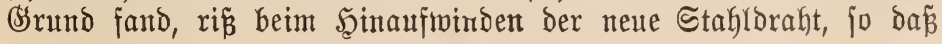


$3200 \mathrm{~m}$ jamt Thermometern, Sotröhre und ben $\mathfrak{W a j p e r j h o p p f a p p a r a t e n ~}$ verloren gingen. Mebrere andere Lotapparate find exfunden und mit

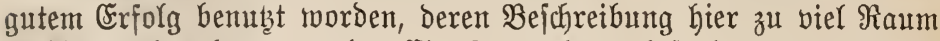

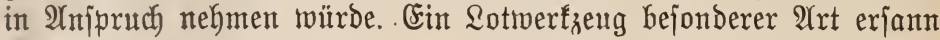
Thomjon, Der Seiter Der Ehallenger= Sxpedition. Fine Durch eine Mef $=$ finghülje gegen das Zerorücftwerden gefdübste und nur unten offene (SIasxöhre wirb in bas Waffer hinabgelaffen; je tiefer fie finft, defto mehr mirb bie Suft in ifr burch ben Wafferoruct zujammenge= $\mathfrak{A} \mathfrak{b b} .2$. preşt wexben, und befto höher wiro in ihr Tiefíeelot. Das $\mathfrak{W a j j e r ~ f t e i g e n . ~ D i e ~ M e r a ̈ n b e r u n g , ~ d i e ~}$

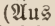
Warther.) eit in Der Röhre angebrachter Belag von Silberchromat Durch Das Seewaffer erlitten hat, läp̧st erfenten, wie tweit diefes in ihr ge=

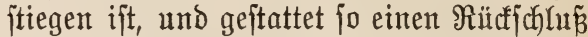
auf bie von bem 2lpparate erretchte Tiefe.

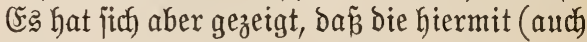
nach ber Berbefferung des Ŷpparates Durch

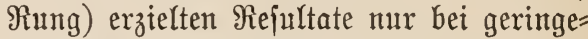
ren Tiefen von genügender Ssenautgfeit find,

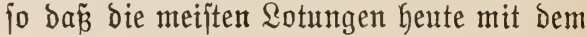
burch eine Reihe von fomplizierten (Finridy= tungen berbefferten Broofefichen $\mathfrak{A}$ (pparate ausgefübrt werden. Das হoten jelbjt ijt feine leichte $\mathfrak{A r b e i t . ~ S i t ~ b a s ~ L o t ~ i n s ~ W a f f e r ~ g e j e n f t , ~ f o ~ g e b t ~ e s ~ a n f a n g s ~ m i t ~}$

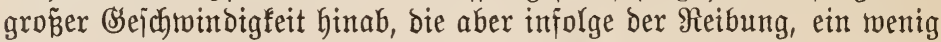
auch infolge der zunehmenden Didyte des Meerwajiers, bald nachläв̈t. Die eriten $3000 \mathrm{~m}$ werden etwa in 50 Minuten Durchlaufen. So= bald Der Srund erreicht ijt, windet bie Dampfmajdine den Draht

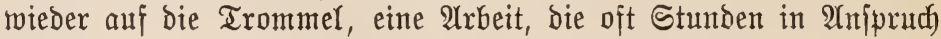
nimmt.

(5: hat jich nun die auffallende Tatiache herausgejtellt, bañ bie Stel= Yen größ̈ter Meerestiefe in Den Dzeanen nidht, wie man bod) anneh= men jollte, ungefähr in ber Mitte zu finden find, fondern in ber Nähe des Feftlandes oder inn benachbarter Snjeln, bort, wo oft jichon bas Borfommen von Bulfanen ober hart an bie Sitfte Gerantretenden Se=

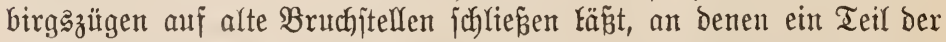
feiten Crofruite in bie Tiefe janf und bann vom Meere bebeft murbe.

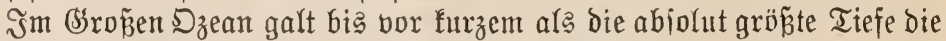
von 8513 m, die im Sahre 1874 oas amerifanijdye Sdjiff "Iuscarora" 
noch nicht $200 \mathrm{~km}$ öftlich von Den Rurilen fand, als es zur Regung

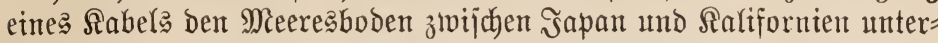

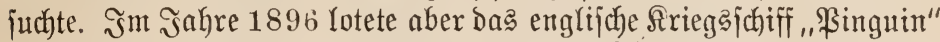

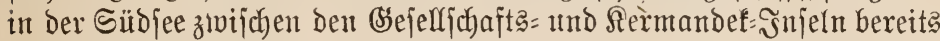
brei Tiefen über $9000 \mathrm{~m}(9184,9413,9427 \mathrm{~m})$, Sentungen, die als

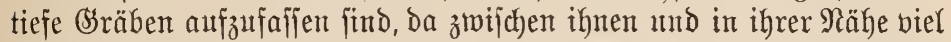
geringere Tiefen gefunden wurben, unb 1899 ftellte bas amerifanifiche

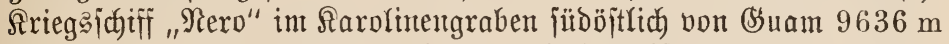
fejt. Dieje Tiefe galt bis vor furzem als vie abjolut gröpte, ift heute aber überholt Durch Die হotungen eines beutichen Bermeffungafdiffes.

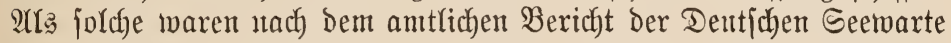
jeit 1906 der "Planet" und jeit 1911 aud die "Miöwe" tätig. Der "Planet" lotete auf Der Reije bon (Sebu nach) Termate (auf Der Molut= feninjel Dichilolo) in $9^{\circ} 56$ nördr. $\mathfrak{B r}$. und $126^{\circ} 50^{\prime}$ öjtr. \&. Die abjolut gröpite Tiefe von $9788 \mathrm{~m}$, und nod) zlweimal wurben zwifhen $5^{0}$ und $6^{0}$ nörol. Br. Tiefen bon mehr als $9000 \mathrm{~m}$ fejtgejtellt. Würó man ben höchjten Berg Der Eroe, Dent Śaurijanfar im Scimalayagebirge $(8840 \mathrm{~m})$, an Der tieffiten biefer brei Єtellen verjenfen, jo würbe man jeine Spike inmer nod fajt $1400 \mathrm{~m}$ unter bem Meeresjpiegel Yiegen. Betrachten wir bie tiefiten Gentungen in Den einzelnen Meltmeeren, fo geht aus den

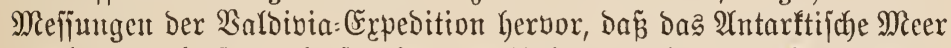
burchaus nicht fo flach ijt wie man bisher annehmen nuste; von 17

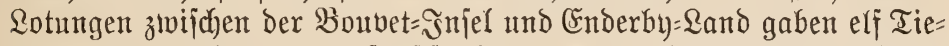
fen von 5000 bis $6000 \mathrm{~m}$, fünf foldye von 4000 bis 5000 an, während nahe der exitgenannten sniel $3080 \mathrm{~m}$ fejtgeîtellt wurdent. A̛uch für das

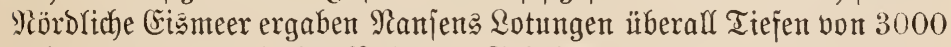

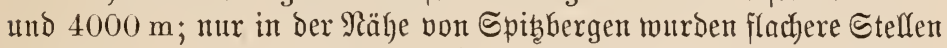
angetroffen. Die gröphte Tiefe im Xrtantijachen 5 zean wurde mit $8341 \mathrm{~m}$ fejtgeftellt; fie liegt nördlich von ben Antillen, 70 Meilen von ßortorifo

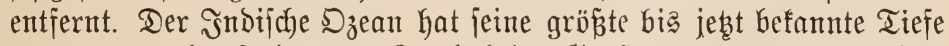
von $6205 \mathrm{~m}$ im Süben von Rombol, der Sirofie Dzean weijt die über= Gaupt tiefite Sentung von $9788 \mathrm{~m}$ auf, dic bereits erwähnt wuxbe. YAle

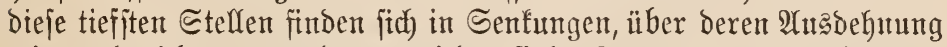
wix noch nicht genügend unterrichtet find. Cupan nennt fie Brräben;

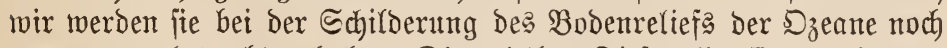
genauer zu betrachten haben. Die nittlere Tiefe aller Dzeane beträgt nach Murray $4500 \mathrm{~m}$, nach) Sarj̃tens $3900 \mathrm{~m}$, nach Sirümmel $3440 \mathrm{~m}$; fie berteilt fich, wenn wir von ben noch nicht genïgend bearbeiteten $\Omega_{0}=$ tungen der Folarländer abjehen, auf die der orei gropen Weltmeere

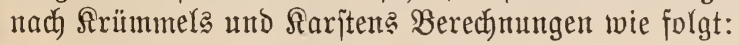

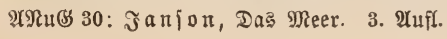




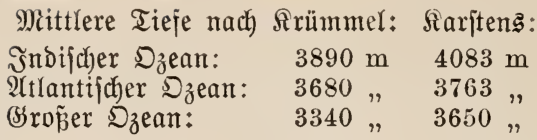

Die Schwierigfeiten joldher Bahlenangaben liegen flar auf Der Seand;

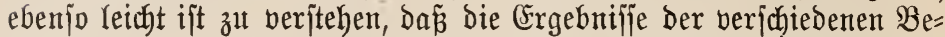
rechnungen zum Teil weit auseinandergehen, ba umjere Renntnifje von biejen Tiefentwerbältniffen teilmeife nod jehr lïcfentyaft fint.

Die $\Re$ an $\delta=$ un $b$ Binnenmeere verhalten fich Ginjidtlich der Tiefe jehr veridjieden. Die Norbjee ijt auperordentlich flach; ihre mittlere Tiefe beträgt noch nicht $90 \mathrm{~m}$. Würbe man fich ifre 2 uas behnung burch einen Bogen gewöhnliden Sdyreibpapiers baritellen, jo müroe bie Diffe diejes Bogens im $\mathfrak{S}$ ergleich zu jeiner Fläche immer noch bedeutend zu

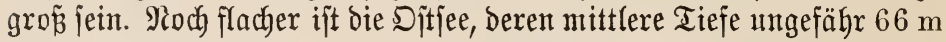
beträgt. Sie eridheint als ein nur oberflächlich unter $\mathfrak{S a f f e r ~ g e j e b z t e 马 ~}$ Stüld Binnenland, mehr als ein Bintenjee. Dagegen zeigt bas Mittel= meer, bas mehrere Einjturzbeffen barjtell, beren Lanomajien in bie Tiefe gejunfen jind, während igre Ränder jtehenblieben und beahalb Geute fteil zum Grumbe abfallen, $4400 \mathrm{~m}$; Dą Saraibijue Meer weijt bis zu $6300 \mathrm{~m}$ Tiefe auf, und in den 2Uujtral=2(jiatijchen Binneumeeren find folche über $7000 \mathrm{~m}$ gemeffen worden. Die mittlere Tiefe aller Bimtenmeere hat Siarjtens auf $1060 \mathrm{~m}$ berechnte. Alle biefe Zahlen

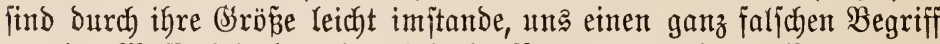

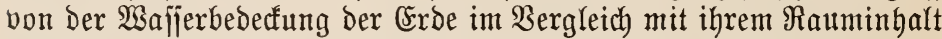
zu geben. Wenn man jich einen (S)lobus von einem Durchmefier, Der Der (Brö̈ß̈e eines erwachjenten Mannes gleichtäme, herjteflen und darauf bie Erbebungen und Sentungen ber Erboberfläche etwa aus Ton mo=

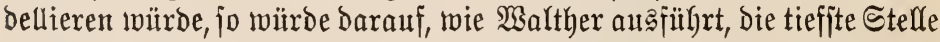
ber Meere nur einen Eindrut von weniger mebr als $1 \mathrm{~mm}$ madjen, ber hörhjte Berg aber mit feiner Spibe eine nod) ettwas geringfügigere (Ex= hebung Darjtellen. Wenn man fich ferner auf bem Meeresgrumbe alle Unebenheiten ausgeglichen und ebenjo auf bem jejten Lande alle bese birge abgetragen und bie Täler bamit auggefüllt benfen twüroe, jo twürbe

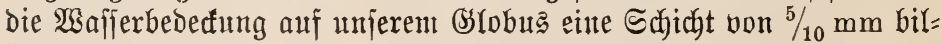

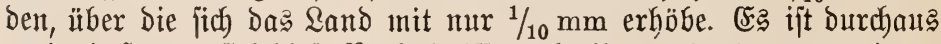

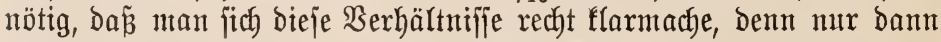

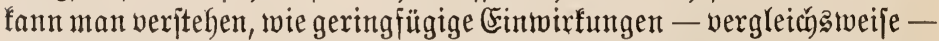
nötig find, um eine vollftänoig anbere Berteilung von Lano und waffer auf unjerer (Erbe herbeiz̆uführen. Derartige Seränderungen find nun auch, folange unjere (Erbe als abgefüflter Şimmelstörper exiftiert, auß̃er= 


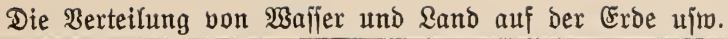

orbentlich häufig und żu allen Beiten vorgetommen und finden noch heute ftatt. Die geologifche Errforifhung ber Erorinde zeigt uns, wie bag Meer überall vor llizzeiten hier einen getwaltigen (sinbruth unternommen und bie Beichen feiner litberflutung zurïffelaffen hat, während bort durch jeinen 2 (bazug fejtes Lamb entitand, wo ehedem ein Tummel= plats von Milliarben von Meereßberwohnern war. Terrafienbildungen und Strandrinien bejonders an den Rüften höherer Breiten zeigen

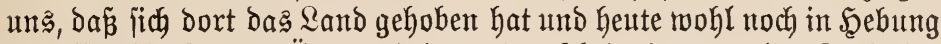

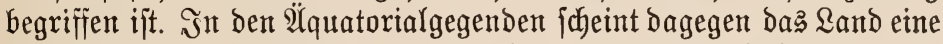
Reigung zur Senfung zu zeigen; man fennt bort zahlreiche frïffe, Deren Betten fich von ber Mündung aus nod) weit ins Meer Ginaus verfolgen Iafjelt und ehemals burd) trodfenes Land flofien, wie bas bes Indus, Branges und Rongo. Durch dieje jäfularen Schmanfungen ändert fich

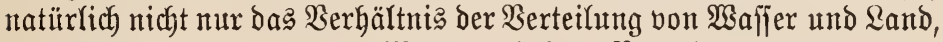
fondern aut bie Tiefen des Meere马 exfahren $\mathfrak{B}$ eränderungen.

atber aud heute, wo wir bas Meer nur als folches betradjten, wie e马 uns furzfichtigen Menichen ericheint, findet vor unferen $\mathfrak{A}$ ugen eine Derartige Beränderung Der $\mathfrak{B a f f e r b e b e c f u n g ~ i t a t t . ~ u ̈ b e r a l l ~ n a g t ~ b i e ~}$

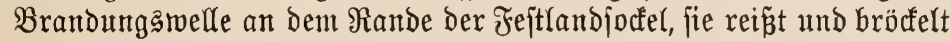
im Laufe Der Zeiten ungezählte $2 a j t e n$ von Biejtein $a \mathfrak{b}$, Die zu Bjeröll und Sand zermahlen und von ben Strömungen oft meit fortgetragen

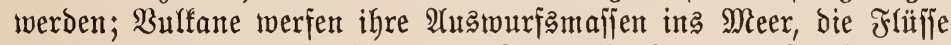
führen ifre im Lande gejammelten Sinfjtoffe ifm in gropen Mentgen zu und erböhen jeinen Boben, und an jeiner $\mathfrak{A}$ uffchüttung beteiligen fich J̧eere von Milliarden fleiner Meeresorganismen, beren winzige Salf= Doer Riejelffelette nach Dem 2rbjterben zu Boben finfen und ben Meeres= grund weit bedecfen. Dod jelbjt wenn man bieje rajtlos mirfenden Sräfte ganz auzer acht laffen wollte, würden jich noch Schwierigfeiten genug finden, wenn es jemand unternehmen wollte, bie Waffermafjen der Meere

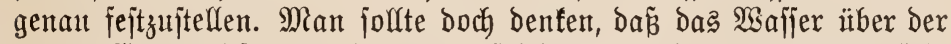

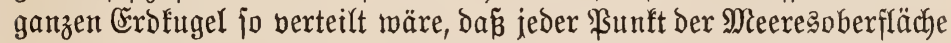
gleich weit vom Erromittelpuntt entfernt ijt. Wenn wir aber ein Błla

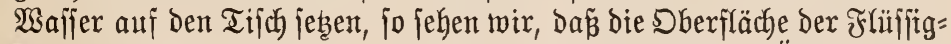

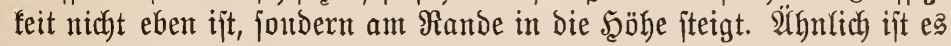

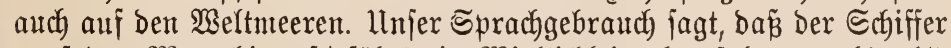
"auf bas Meer hinauf" fährt; in Wirfflichfeit aber fährt er "hinab",

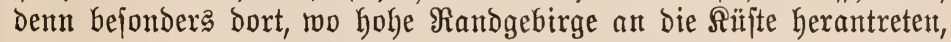

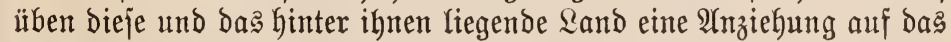

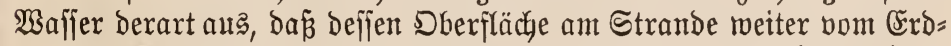
mittelpunft entfernt ijt als auf hoher See. Folgende Sfizze (2Ibb. 3) er= 
läutert bieje Berbältnifie, bie ntatïrlid jtarf itbertrieben Dargejtellt twer= Den muñten. Intmerbin fönnen biefe durch bie jogenannte Sontinentalmelfe

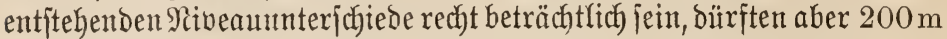
nie itberiteigen; frühere höbere $\mathfrak{A}$ ngaben bernfen auf ungenauen $\mathfrak{B} e=$ obachtungen und Beredhnngen, Die zum Teil barauf zurürfzufüthren

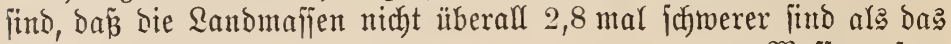

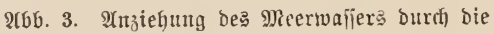
Feitlanomaīen.

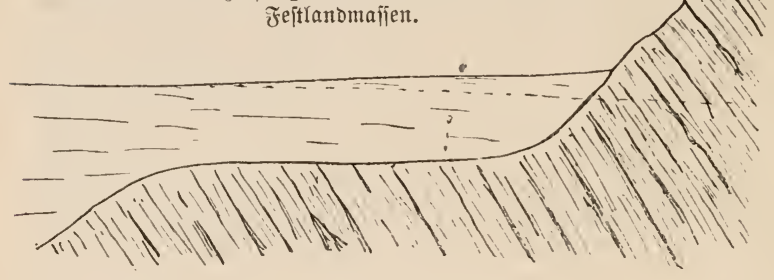

Wafier, jout= Dern innere Sęhlräume bejisen, biebie Anziehyng: fraft vermin= Dern. IYuth bie Bezeiten, E.bbe und Ffitt, wirfen

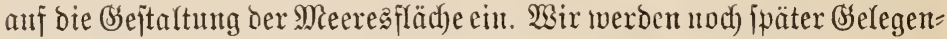

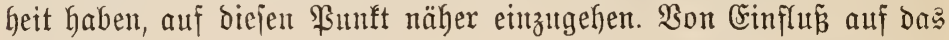
Meeresniveau ift aud Das Borherrfdyen von be fimmten Wintridgtungen,

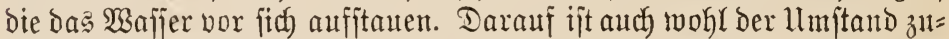

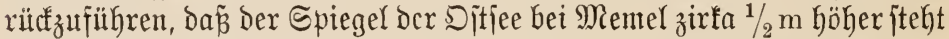

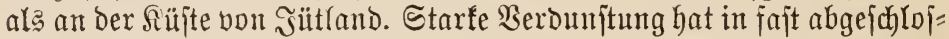
jenten Meeresteilen, z. B. im Roten Meere, eine Senfung des $\mathfrak{B a f j e r =}$

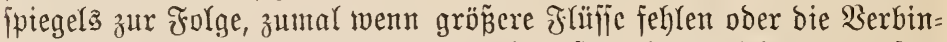

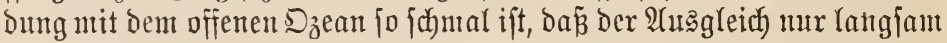

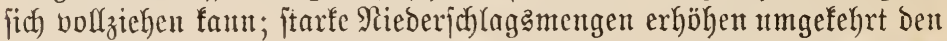

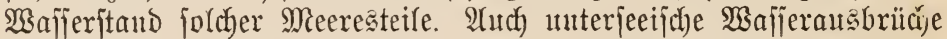

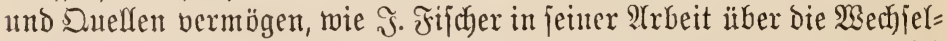
wirfung von Meer und. Binnengewäffern uachgewiejen hat, gelegentlid) Den Wafferftand Der Binnenmecre zu verältdern. Bou fehr geringem Einflús ift cublidy) auch der auf dem

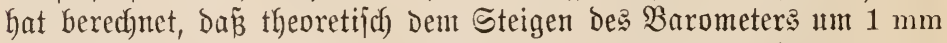
eine Ernteorigung Des Meeresfpiegels um 13,6 mm entipridbt.

\section{III. :(bjonnitt.}

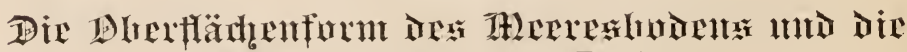

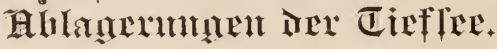

Den zahlreichen Rotungen, bie in Den leb̧ten Эahrzefnten ausgeführt

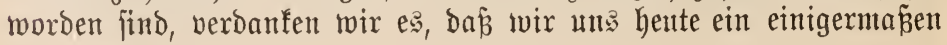


richtiges Bild von ber Sejtaltung bes Meeresbobents uthen fönnen. Den Brund zu biejer Erforjautg des Bodenreliefs legte vor ungefähr

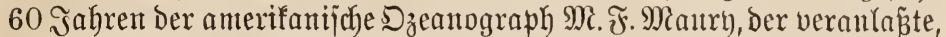

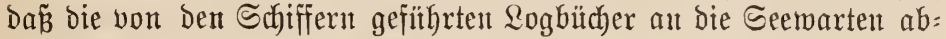
geliefert wurben, too bas auf zahl(reichen Seefahrten gejammelte Mrate= rial twiffenjchaftlich verarbeitet werben follte. Seit biejer Beit wifjen

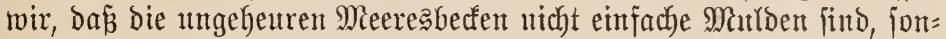

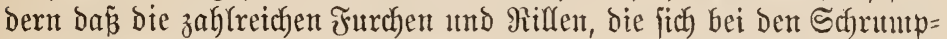
fungşorgang ber erfaltenden Erde bildeten und unjere heutigen (se= birge entjteben Yieß̃en, fich, wie zu ertwarten war, aud auf bent Meeres= boben wieberfinben. Sin allgenteinen bietet die Fläd)e der Meeresgrïnde eiu Bild grop̧er CEnförnigfeit. Die ungeheure Qäıge ber Beit hat mit Den untuterbrodben fid) abjebenden Sinfitoffen viele jaroffe liber=

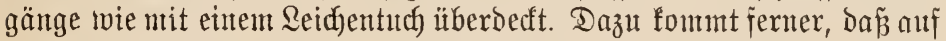
Dem Meeresboden fajt alle die Siräfte fehlen, die unjere Feftlandsmafïen

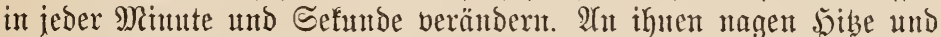

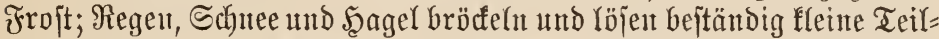

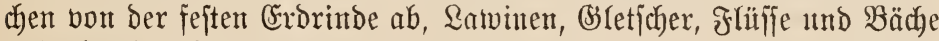
vollenden das Berjtörungswerf, fübren lier die Trümuer fort und tragen fie bort an. Bejteht jo ant Dem Fejtlande Das Bejtreben, bas Bejtehende

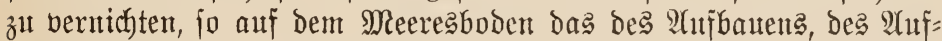

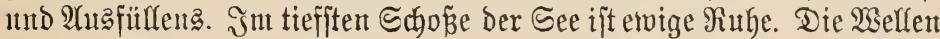
Des wütenditen Sturntes, die ein ftolzes Erbiff mit Reidtigleit zertrüm= mern fönnen, verlieren jđon in geritger Tiefe ifren Einflǘ. Sirože Miveaunterichiede finden wir alfo auf Dent Meeresboden bor allem uabe Den Rüjten ober Dort, to vulfanijue Erkebungen jtattgefunden oder die Sorallen ifre Bauten erridytet haben; fonjt aber herrjat dort in allge= meinen eine ermitbende (sleichförmigleit in Der Bobengejtaltung. Alber bas gilt bod nux ganz im allgemeinten. So viele Tiefenlotungen bishnng

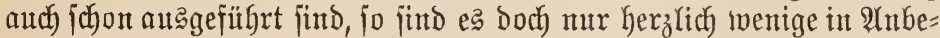
tracht Des grofien Raumes, auf Den fie verteilt fint. Wie vermödjten tvir vergleidyztweife Durch einige wentige Rotungen aus Dem Ruftballon ein Bils bon ber Dberflädengejtaltung ber Sdłvetz getwinnen? Je mebr bie Rotungen fich häufen, bejto mehr l̈berrajchungen bieten jich und

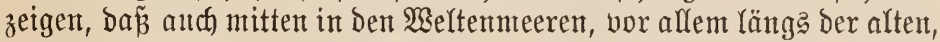
Geute von ber See bededten Urgebirge, Steilränder utb jaheinbar un= vermittelte tiefe Senfungen vorbanden fut So befinden fich in Ssolf von Uden zwijhen Szöhen dę Seebodens von mux 800-900 m Meeres:= tiefe plöbzlich Sentungen von $4800-5000 \mathrm{~m}$ Tiefe.

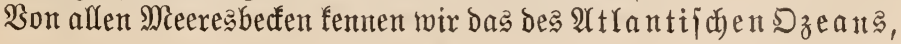




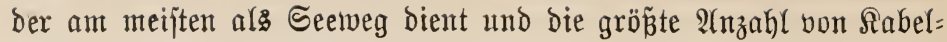
leitungen in jeinen Tiefen beherbergt, naturgemän am beiten. Noch immer ift bas Froblem ber Altantis, nady dem der Boben diefes Melt= meeres einen verjunfenen Froteil barjtelle, ntngelöft. Ein mächtiger

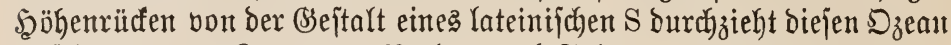

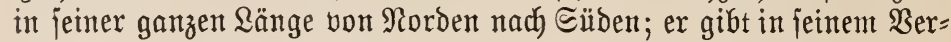

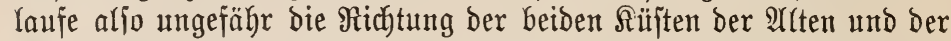

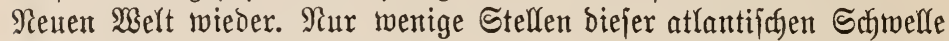
ragen aus dem Waffer empor, bas find die S̃njeln des $\mathfrak{A} z$ orenplateaus, die Feljen von St. Paul, alzenjion und Trijtan ba Eunha. Man hat diejer atlantijdyen Bodenjdyelle verjdyiedene Namen gegeben; es joheint aber, dẩ fie einte einheitliche Crgebung mit einer mittleren Tiefe von wentger als $3000 \mathrm{~m}$ ijt, bie an Der St. \$aulgllippe am idhmalften ijt

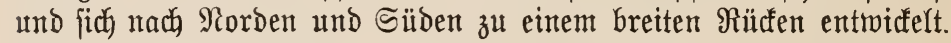
Durch bieje Schwelle wird ber Sirund unferes Szeans in eine oftatlan= tijche und eine roejtatlantijace Rinne geteilt, von benen die lebstere bie. tiefere ift; im nordamerifanifden Beden haben twir in ber Sirginentiefe eine Senfung von $8340 \mathrm{~m}$, im brafilianijhen Becten eine foldye von

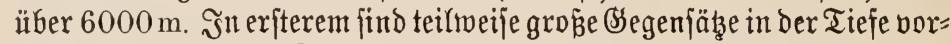
handen; fo bilben die Sileinen Antillen die höbjten Spiben eines unterjee= ijchen Ssebirgşzuges, ber Durbjichnittlich 500-1000 m tief liegt, an ber

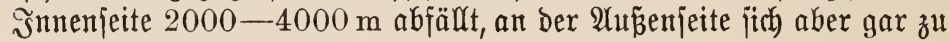
Tiefen von $6000-8000 \mathrm{~m}$ [enft. Aud in ber oitatlantijchen Murbe fönnen wix zmei flacke Becfen unterjheiden, bas norbafrifanijhe mit $6300 \mathrm{~m}$ Tiefe wejtlich von Ferro und das weftafrifanijche. Bemerfens=

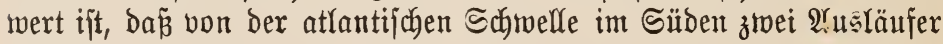

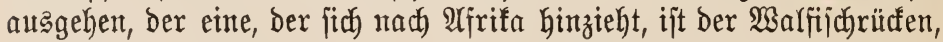

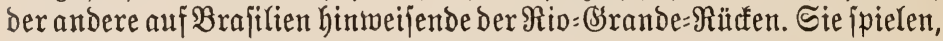
bejonders der erjtere, im jübatlantifanen Dzean eine widtige Rolle, und twir werden fie bei Betradjtung ber $\mathfrak{B a ̈ r m e b e r b a ̈ l t n i f f e ~ u n d ~ b e r ~ B e r = ~}$ breitung ber Tierwelt noch ertwähnen müffen.

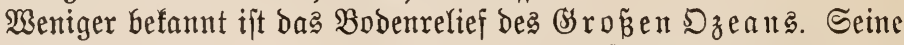
Siüften unterfaciben fich in einer Beziehung wejentlich von benen bes

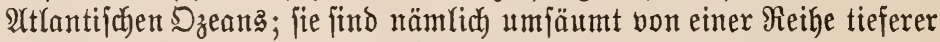
Randbedfen und einem bidhten Rranze nod tätiger und erlojdener $\mathfrak{B u l}=$

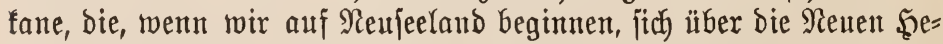
briben, die Galomon= Snfeln und über die girlandenartig ber ganzen

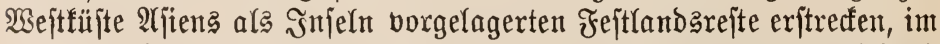
Norben fich über die ArYeuten fortjeben und auf ber $\mathfrak{W e j t f u ̈ j t e ~ v o n ~ M i t t e l = ~}$

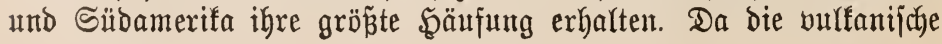


Das Relief Des Meereşbodens und die Atblagerungen Der Tieffee 19

Tätigfeit fich fajt nur bort zu groß̃er Mächtigfeit entfaltet lyat, wo Brudd)= ftellen in umferer fejten Erorinde eine Berbindung zmijchen Dberfläche

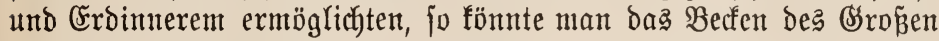

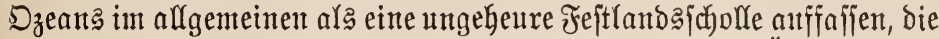
abgejunfen und bann vom Meere bedecft worden ift. Die libergänge in biejes Becfen vom Feftlande her find zum Teil felgr fdyroff; ben be= beutendften Steifabfall finden wir Yängs ben Rurilen und ben nördlidłen

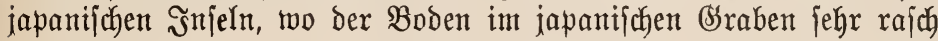
eine Tiefe von $8500 \mathrm{~m}$ und mebr erhält, ferner im ArTentengraben

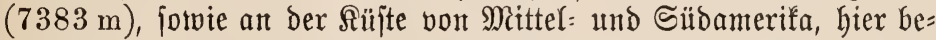
fonders im jüblichen Teile, wo im 2ltacamagraben $(7635 \mathrm{~m})$ an ber

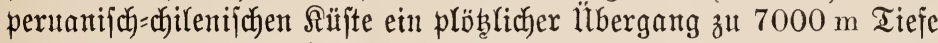
und mehr jtatfintet. Banz bejonders reich geftaltet ift ber Boben bes Sropen $D_{z e a n s}$ in ben bem auftralijeden Feftlande vorgelagerten (Se $=$

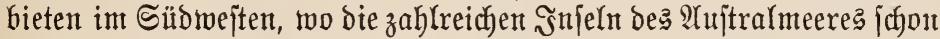
im vorats eine reidje Ssliederung bes Bodens erraten laffen. Seier liegt ber aus vier Becfen fich zujammenjeksende Tonga = mo Siermandef= graben mit ber jajon erwähnten Tiefe von $9427 \mathrm{~m}$, zwijhen den $\mathfrak{M a}=$ rianen und ben Rarolinen der farolinengraben mit Der ebenfalla be= reits genannten Tiefe von $9636 \mathrm{~m}$ nake ber S̃njel Błıam.

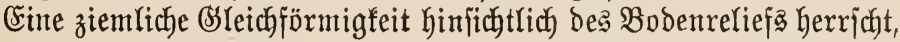

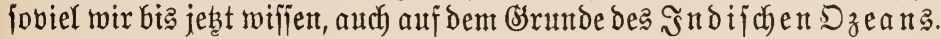

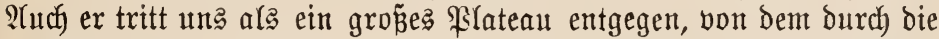

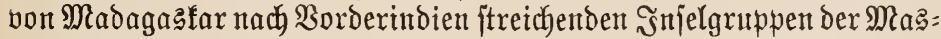

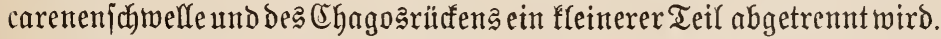
Die größ̄ten Senfungen finden fich in Süben, wo, wie die Deutjche Tiefiee=Expedition nadyies, Depreffionen über $5500 \mathrm{~m}$ vorfommen, bie größ̈te Tiefe aber im Norben, am Steilabfall bes jabanifichen Int

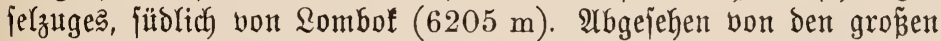

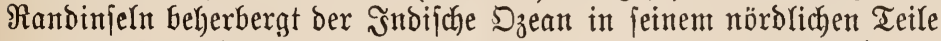

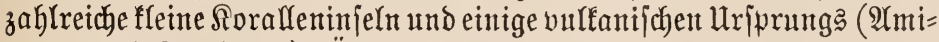
ranten und Seychellen). Über bas Bodenrelief ber beiden $\mathfrak{B}$ olarmeere ijt autzer Dem bereits Bsejagten bis jebt noch ntichts Sidjeres befaunt.

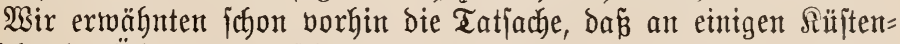
ftrichen der l̈̈bergang zwijden Feftland und Meeresboden ein jebr fteiler

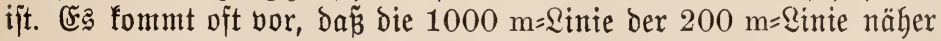

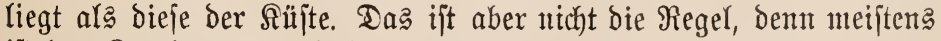
ijt ben Sontinenten und ben Inifeln ein flacher Meeresboden vorge lagert, und erjt bann geht biejer fannell z̆ größ̈eren Tiejen über. Maan

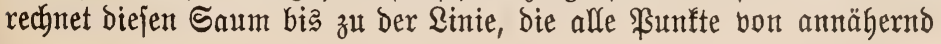


$200 \mathrm{~m}$ Tiefe verbindet, und nemut ifn beshalb die $200 \mathrm{~m}=$ Stufe. Stel= rentweife reicht er aber unt bis zur Tiefe von $80 \mathrm{~m}$, währent utan ihn andererfeits mandfmal bis zutr Tiefentinie von $800 \mathrm{~m}$ berfolgen fann. Dieje auth wohl $\Omega_{0}$ ntinentalplatean oder Fejtandjocfel genannte

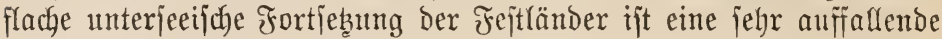

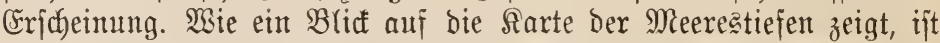

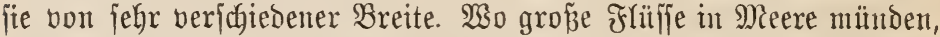
bie non Strömungen wentg heimgejutht werben, two alfo bie aus bent Qande mitgeführten Sinfítoffe ungehindert zu Boden fallen fönnen,

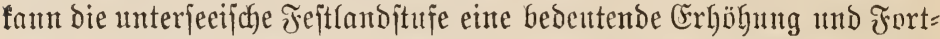
feb̧ung erhalten. Das ijt z. B. Der Fall bei Dent Şoangho, befien gelfe Schmemmitoffe von \&ö̈ß bem Meeresteil, in bem jie abgelagert wer= Den, befanntfich Die Bezeichnung bes (Belben Meeres eingetragen haben. Y(ud) der $\mathfrak{A}$ mazonenftrom füfrt ungeheure Maffen von Edyemmitoffen dem Meere zu, wie man auggeredynet hat, in jeber Stunde $80000 \mathrm{cbm}$.

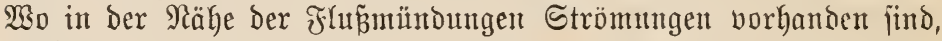
da füfrren bieje bie Einfjtoffe mit fich ub laffen fie zu Bodent fallen, fobald burd) irgendeinen lumitand ifr Lanf verzögert wirb. Ân vielen anderen Sü̈ftenjtrichen, wo wir eine fehr breite Feftlanditufe vorfinden,

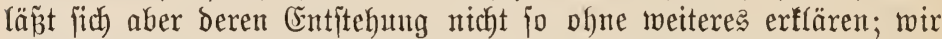

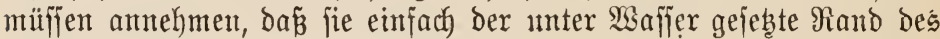

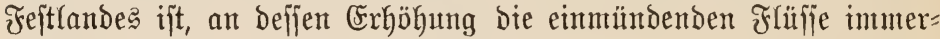

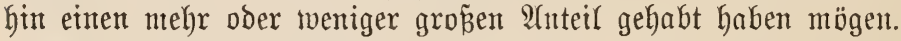

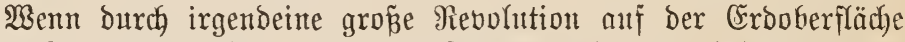

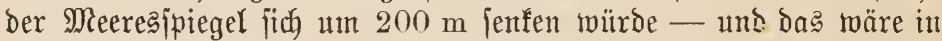

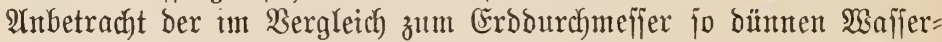
jujicht nur eine fefre unbedeutende Beränderıng —, jo wärde unjere Erofarte mit einem Schlage ein ganz anderes Biro bieten. Die Bri=

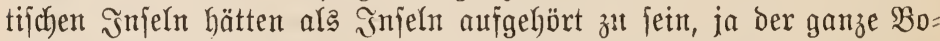

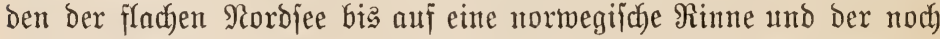
flacheren Sitfee wäre trocfengelegt. Der Djtrand $\mathfrak{A}$ merifą wäre im Sitbent bei \$atagonien und im Morden bei Reufunbland weit Ginaus= gejchobert, Das amerifanifiche Mittelmeer wäre nur noch burdy einige

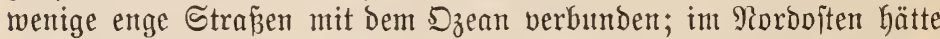
Der Siontintent burdh bie Trocfenlegunt der gropen Bänfe von Sieufund=

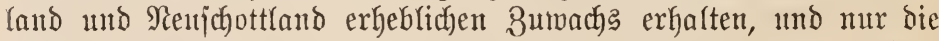
Wejtieite wïrde annäherno daşjelbe 2Utsjehen zeigen wie heute. Cine Greite Landbrücfe, Der Boden des heutigen Beringsmeeres, würde dann 2(merifa mit bem afiatijifen Sontinente verbinden, Der nod) baburd)

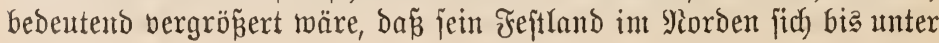


Das Relief Des Meereşbodens und die Rtblagerungen Der Tieffee 21

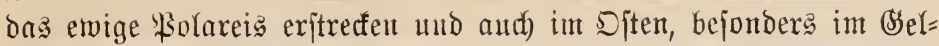

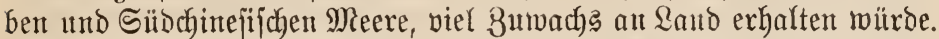
Nur eit jchmałer Meeresarm wïrbe e马 von S(tujtralient trentent, bas

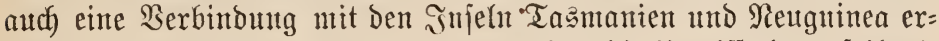
Galten haben würbe. $2(m$ wenigften wiurden bie lluriffe ber afrifani= idjen Fejtrandafdjolle burch eine berartige Revolution verändert; nur ifre Spibe twïrbe ein wenig nad, Siiben vorgejdyoben werben. Der=

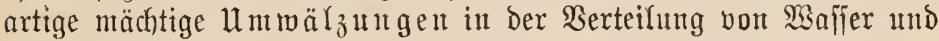

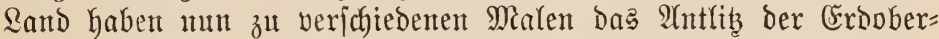
fläche von Brutut aus geändert und babei bie BSejteinsformationen ge=

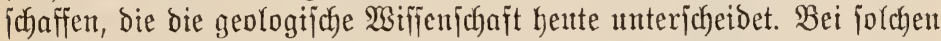
ummälzutgen birbeten jith bie Eimjturzbecfen der Mittelmeere, fotwohl bes europäijchen als auch bes auterifanifden mo des aujtral=aitati= ichen. Die ieder Sorjtellumg unjererjeits fpottenden gewaltigen Sräfte ruhen aber attch hente noch nicht; fie gebon tns bei Erobeben burch

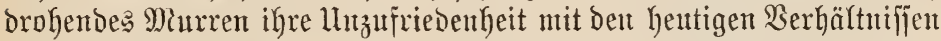
auf Der Erobberfläche zu erfenten und zeigen unß intsbejondere burch

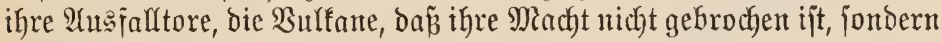

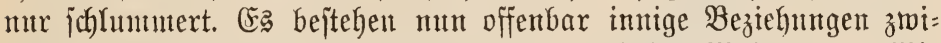

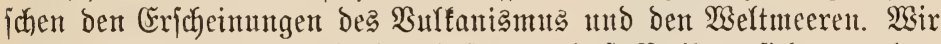
miffen bereits aus bem früher Bsejagten, dá̉ Sulfane fich vornehm= (ich) an Den hentigen Doer ehemaligen Fejtlandzrändern, z. B. anf Den

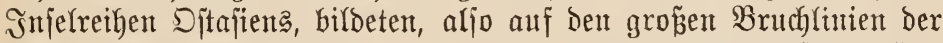
feiten Erorinde, offenbar, weil dort dem 2Yuabruche des fliiffigen Ero =

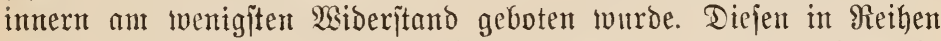

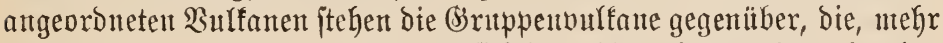
im Sntmern ber $D_{z e a n e}$ entitanden, fich dem 2 unge hente ala mehr oder

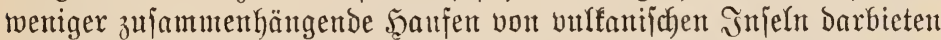

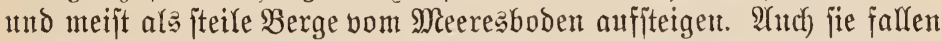
allmählich der Zeritürung Durch Wind und $\mathfrak{B e t t e r , ~ b u r c h ~ b i e ~ B r a n = ~}$

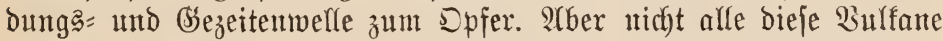

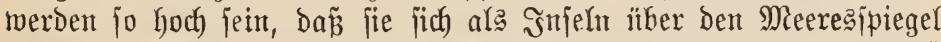

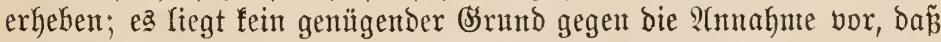

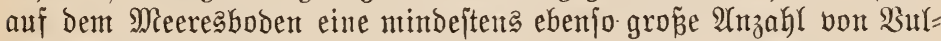

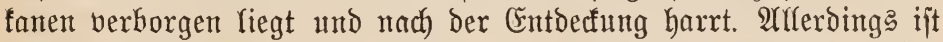
unfere Rentnis von vielen Teifen bes Meerboben Gejonders int (Se =

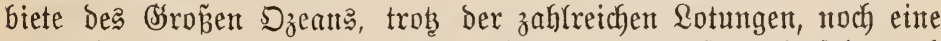

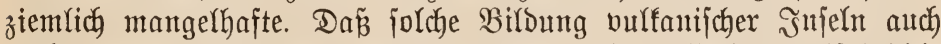
noch zu unjerer Beit vor fich ger)t, dafür ijt ein treffende马 Beifpiel bie

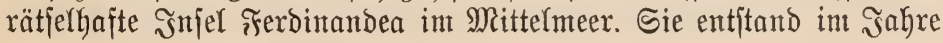


1831 zwijhen Sizilien uno ber Injel ßantellaria burch vulfanifdje

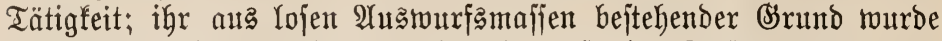
allerbings noch in bemielben Jahre ein SDper ber Beritörungstwut der

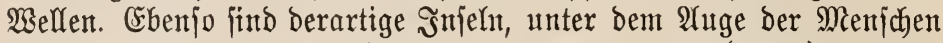
entitanden und wieder gefdyunden, von ben $\mathfrak{A}_{z}$ oren (1811), von ber

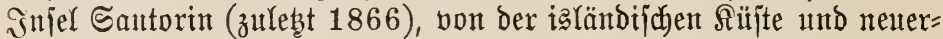
bings vom Meerbufen von Bentgalen utd zwifchen Trimidad und ber

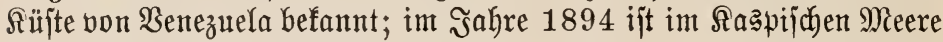
ein unterfeetidjer Bulfan aufgefunden worben, ber bicfe Schlamm=

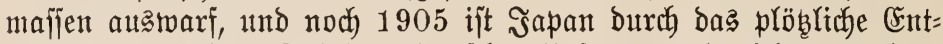

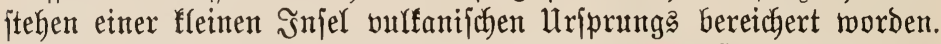
Weitere Unterjuchungen werden jedenfalls fejtitellen, bá berartige, went

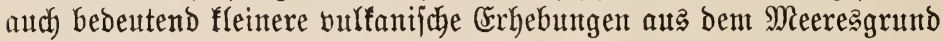

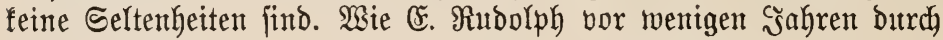

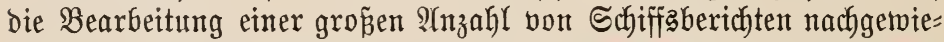
jent hat, find manthe Segenden bes Meeresgrundes ganz bejonders vul=

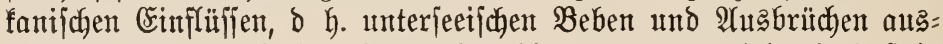
gejebzt. Das ijt nidft jo jehr merfwiurdig, menn man bedenft, baj ja audb auf bem Feftlande bie $\mathfrak{B u l f a n e}$ fich an ganz bejonderen Stellen häufen. Esin foldhes B̧ebiet ftellt nach Rutbolph bie äquatoriale Bone

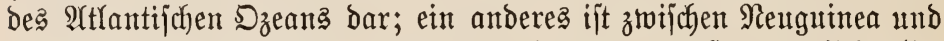

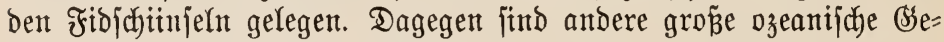
biete geradezu als erobebenfrei zu bezeidnnen. Jebenfalls war ę ein Berdienjt $\mathfrak{W}$. Srebs', als er auf ber 75. Naturforicherberfammlung 1903 in Saffel Darauf fintwies, wie wenig wir über bie Beziefungen des Meeres zum Bulfanismus wiffen, und wie notwendig eine plan=

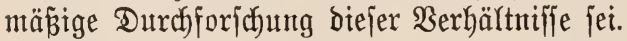

Die Frage nach dem Crinflué bes Bulfanißmus auf bie Bodenge= ftalt ber $\bigvee_{z}$ eane hängt mit einer anderen wijienjidyaftlichen Streitfrage zufamment, bie aud hente noch nidht ale völlig gelöjt angejehen wer=

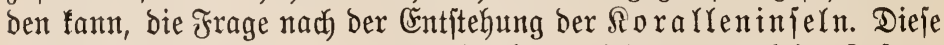

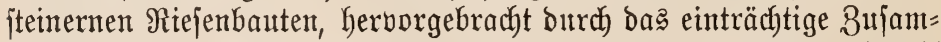
menleben und = wirfen unzähliger winziger Tierd)en, erheben fich fteil anjteigend von bem Meeresgrumbe oft aus beträbthticher Tiefe bis an ben Mieereşpiegel. Wiederholt finto räumlith nahe beieinander liegende Tiefenunterjatiebe von $3000-4000 \mathrm{~m}$ in Roralfengebieten beobach)= tet worben. Wenn ber Meeresjpiegel fajt erreidht ift, arbeitet Wind,

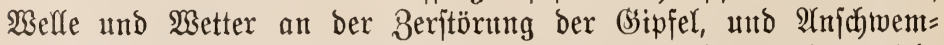
mungen fafffen jo eine Şumusbecfe für eine melyr ober wentger reidhe Begetation. Die Siorallen gehören befanntfich zu Den Şohytieren oder 


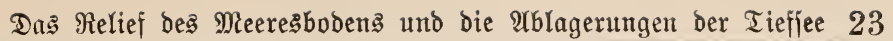

Cölenteraten; ihr jtrahlig gebauter, jacfförmiger Rörper, befien Wanto inten gejartet erjocheint, trägt um ben Mund fechs bis acht feine Arrme,

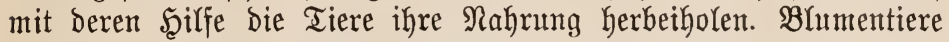
nannte man jie mohl, als ifre tierifhe Satur allgemeine $2 \mathfrak{d}$ erfent= nung* gefunden Gatte. Die Rorallenitöfe bilden bas Bujdyert des Meereşbodens bejonders an ben Rüjten. Starr jtreçen fie ihre bräun=

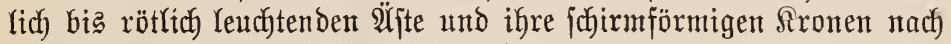
allen Seiten aus, ein Sdyirm fteht neben und ither bem anderen, fo dá bas Şanze terraffenförmig anjteigt uno bie B̧ejamt= mafie der Ralfbauten ferbjt der wilden Brandung einen unbefiegbaren Sall ent= gegenftellt. 2 m befauntejten von biejen tierifhen Baumeiftern ift wohl die Edel= foralle (Corallium rubrum) bes Mittel= meeres und der Moroweitfüfte âfirifas

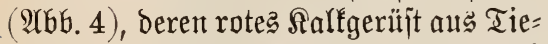
fen bis zu $200 \mathrm{~m}$ heraufgeholt unt nach)

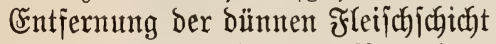
hauptfächlich in Rivorno, Seapel und (S)enta zu allerlei Schmutơgegenjtänden verarbeitet wirb. Sie birbet aber mur fleine Stöcfe mit vergleid) șeife mentigen Einzeltieren. Ungleich maffigere Bauten

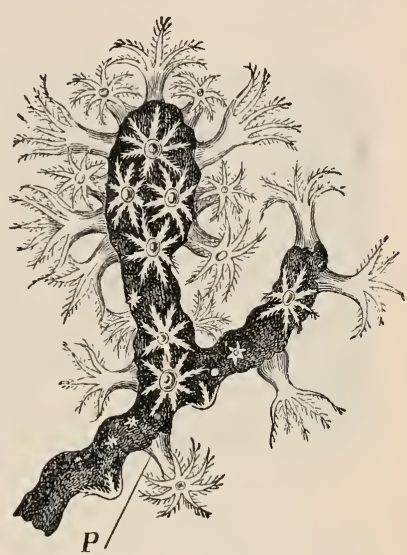

)rbb. 4. Edeltoralfe.

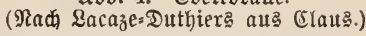
von baum=, ;ujirm= ober fugelförmiger Bseptalt ftellen bie riffbildenden Rorallen her. Bor allem gefjören bahin bie \&öcherforallen oder Madre= porarien (Porites, Madrepora [AGb. 5], Turbinaria u. a.), ferner bie mafitgen, tiefer lebenden Sternforallen oder 2(jtraeen unt bie gropenen, meijt einzeln Yebenden Fungien. Daneben wirfen bei biejen Bauten, bie,

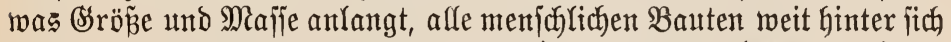
lafien, auch nod) 2Urcyontarien (Heliopora) unb $\mathfrak{P o l y p e n}$ (Millepora), jo= wie von pflanzlichen (Sebilden bie Salfalgen (Lithothamnium) mit, von

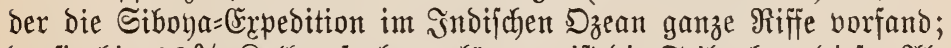
ba jie bis $90 \%$ Ralf anfnehmen fönnen, ift bie Teilnahme biejer $2 \mathfrak{l}=$ gen am 2 uffbau bes Meeresgrundes aljo burchaus nicht gering. Die zarten und mannigfaltigen Farben Der Sorallen rufen ben Findruft unterjeeijher Şärten ober Błumentwiejen herbor. Johaunes Walther,

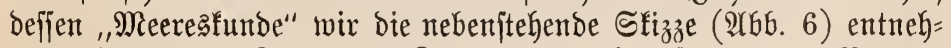
men, ein genauter Sentuer ber Roralfen unb iGrer jubmarinen Bauten, gibt von biejen Särten folgende Scfilderung: „Bon bem fleinen Drte 


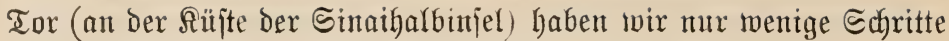
bis zum Meer. Ein jmaragogrüner Saum von $300 \mathrm{~m}$ Breite zieht fich längs des lljers hin, es ijt das Siorallentriff, bas an dem dunflen

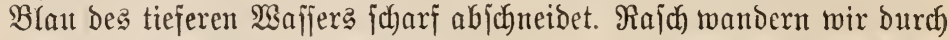

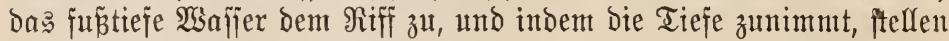

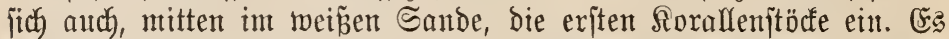

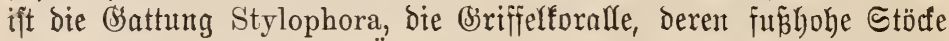

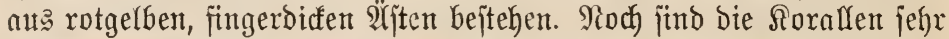

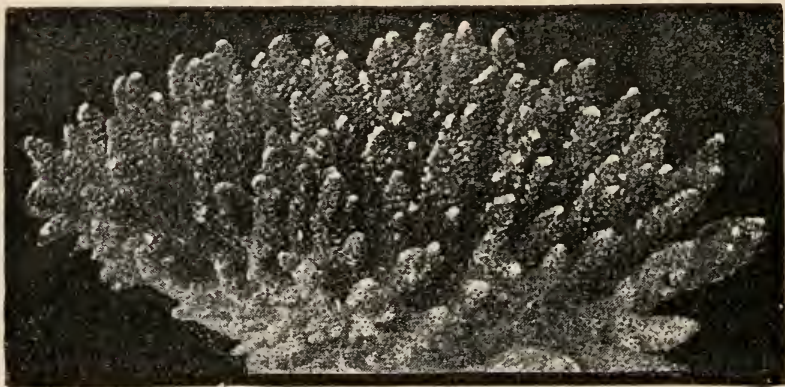

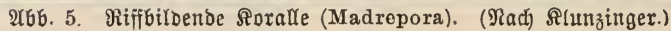

vereinzelt, und żwi $=$ forentignen auf bent Sande be= merfentrir Taujende bott idjtuarzelt Seeigeln, Deren Sta $=$ dyeln leidyt in unteren

Juñ bringen, toeshalb wir langiam und vorjichtig weiteridyreiten. Da Wajfer wird metertief, und die Sorallenjtöcfe tverden zahlreicher uto mannigfaltiger. Sier jehen wir die olivenbraunen Schirme der Madrepora ( $\mathfrak{A b}$ b. 5 ), dort die flumpenförmige braune, mit ipangrünen Streifen ver: fehene fiolonie einer Coeloria. Itnd während die Stylophora immer jel=

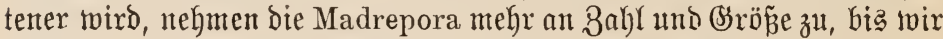
entich in einem bunten Sorallengarten ftehen. Wie in einem eng=

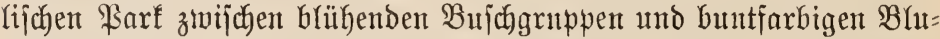

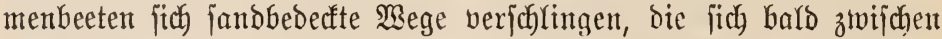
hohen Büjchen verichmälern, bald zu fiesbedecften ł̧äßsen ertweitern ober in ente juattige Srotte münden, jo verhalten jich bie janbbebed:

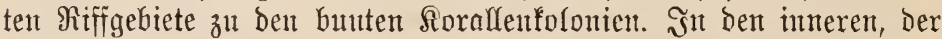
Sïjte naben Riffteilen wandelt man zwifdsen flachen Sorallenbeeten

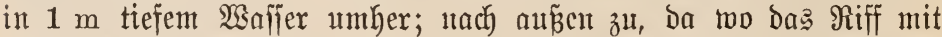
Iteiler Siante gegen bas tiefere Meer abftürzt, werden bie Sorallenfolo= nien zu 2 bis 3 m hohen Sruppen, und der Sand nimnt engere Räume eit." Zu Dem Ssedeihen der Siorallen ijt eine gemiffe Wafferwärme nötig; deshalb fommen fie nux bort vor, wo bieje nicht unter $20^{\circ}$ finft. Der 25. Breitengrad ungefähr bildet in Norden und Sitden bes 


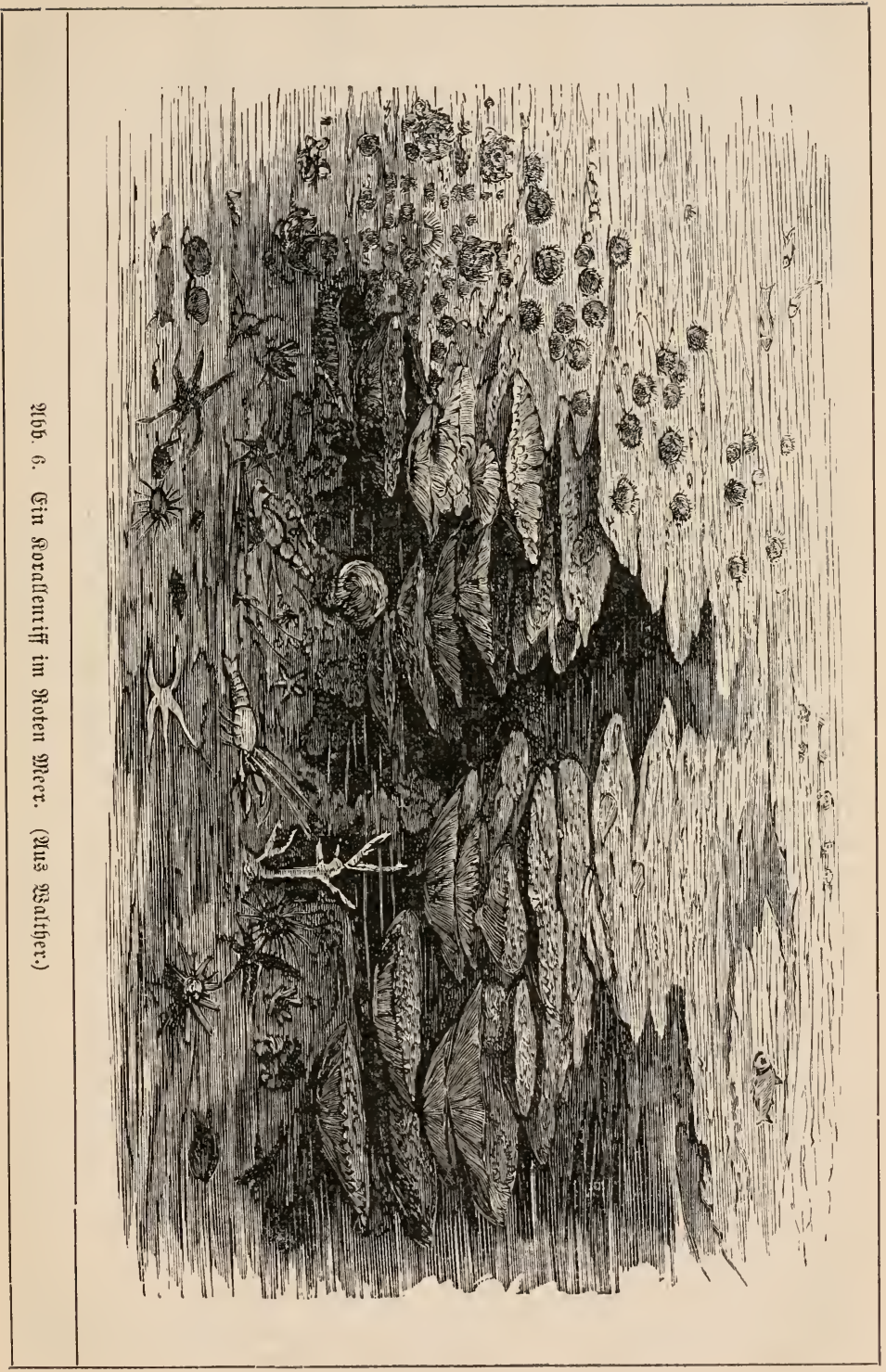


Äquators die Sirenze ifres $\mathfrak{B e r b r e i t u n g s g e b i e t e s ; ~ n u r ~ b a , ~ t o o ~ r a r m e ~}$ Dberflächenftröme die Temperatur des Waffers erhöhen, wie im Diten bes amerifanijchen und ajiatifdyen Fejtlandes, verjojiebt fich dieje Brenze poltwärtz, während wegen Der falten Wafjer bes ßeru= und Benguela=

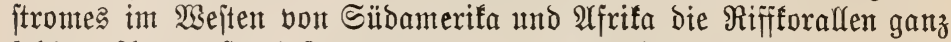

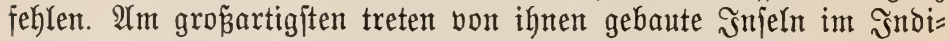

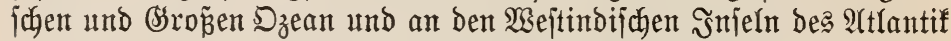
auf. Die Tiere lieben flares, betwegtes Waj̃er, bas innen frijhe Artem= luft und Nahrung zuführt, und leben in einer Tiefe big zu $40 \mathrm{~m}$. In ber Tieffee fommen zwar aud Sorallen vor, aber fie find entwes der Einzeltiere oder bilben meift nux fleine Stöcfe. Fungia symmetrica wurbe vom "Ehallenger" aus einer Tiefe von über $3200 \mathrm{~m}$ her= aufgeholt, aber auch grope riffartige Stöcfe bilbenbe forallen fommen, wie bie Baldivia=Erpebition zeigte, noch in $3000 \mathrm{~m}$ Tiefe vor.

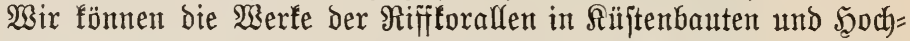
jeebauten einteilen, erftere wieber nach Darming Borichlag in Saum= und Dammriffe. Shre Bilbung gebt im Bergleich mit ber ber Tief= jeeablagerungen in viel fürzerer Beit vor fich; ein im Sndijhen Dzean

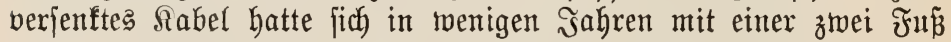
hohen Schidgt von Rorallenfarl bedecft. Betrachten wir zunächjt bie Süftenbauten, fo erbeben fich die Saumriffe nake dem Strande und wachjen vom Sirunde bis in die Nähe bes Meeresfpiegels. Der= artige Caumxiffe finden fich befonders ausgebildet an ben Siüften bes Roten Meeres, tov die Ralfmaffen von Porites solida u. a. zum ફ̧ä山= ferbau Berwendung finden, ferner bei Sevlon, Florida und ben গilfo= baren. Wo Flüffe ihr Süp̧waffer ins Meer jenben, finden fich হücen, ba bie Sorallen fich bort nidgt anfiedeln. Die Damm= ober Wallriffe

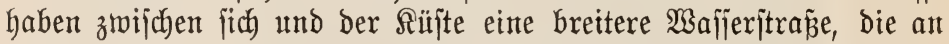

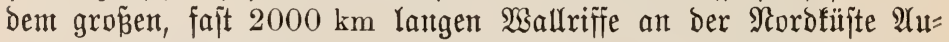
ftraliens ftellenmeije $75 \mathrm{big} 90 \mathrm{~km}$ breit ift. Sie erbeben fich 3 bis $4 \mathrm{~m}$ über bas Meer, tragen bort, wo bie Flut eine \$umusfchidgt ge= ichaffen hat, oft reichen Pflanzenwuchs und find bann auch betwohnt. Die Qücen in ben meift jteil aus Dem Meere aufiteigenden Wallriffen

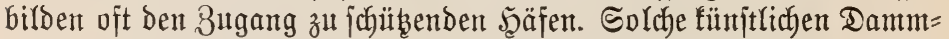

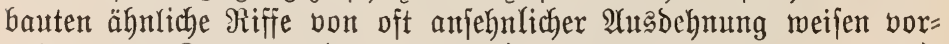

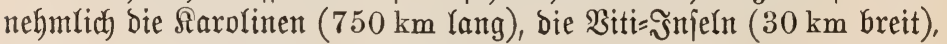
die (sejellida afts= Injeln u. a. auf.

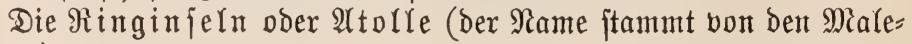
biven) find Şodjfeebauten. Sie jind fteil aus bem Meere aufiteigende

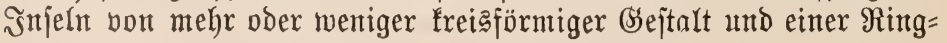


Dả Relief Des Meeresbodents und Die Ablagerungen der Tieffee 27

breite von 1000 bis $1300 \mathrm{~m}$. Sm Snmern findet bie Senfung alf= mählid jtatt und geft in eine Lagume ïber. Meift ragent mur fleine Teile bes Ringes aus der Flut empor; fie jind zuweilen an der $\mathfrak{W}_{\text {etter }}=$ jeite mit einer mäpigen Bodenjujicht bebecft und dant aud öfters be $=$ wohnt. Bon Den 2(tollen weift Der Stille $D_{z}$ ean etwa 300 auf, bon benen allein 70 bis 80 auf ben $\mathfrak{B a u m o t u = 2}$ rechipel fommen; bie grö $\tilde{\beta}=$ ten find bie Malediven und Laffadiven im Indijđen Dzean. - Die Frage nach ber (entitehung Der 2 (tolfe ijt audh heute noch nidgt gelöjt.

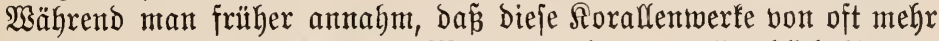
als $1000 \mathrm{~m}$ Meächtigfeit vom Meeresgrunde aus allmählich bis zur

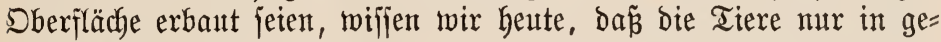
ringer Tiefe zu leben vermögen. Die erfte mo bald barauf ganz all= gemein angenommene Erffärung ihrer Entjtebung gab Darwin, ber im Jahre 1837 auf feiner Seltumjegelung mit Fizaroy die Sofos= Snjeln im Sübmejten ber Sundajtrape unterjucht hatte. Die ringför=

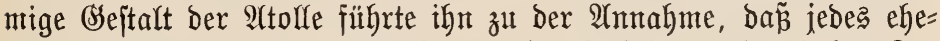
mals ein Rüjtenriff gemejen jei, das eine Эniel ungeben habe. Im Saufe ber Zeiten hätten ber Meeresboden und mit ihm bie Snjelberge jiłch allmählich gejenft, unb biejer Senfung hätten bie Rorallen Sdyritt für Sd)ritt nadhgearbeitet, bis bie Injel unter bem Wajijerjpiegel ver=

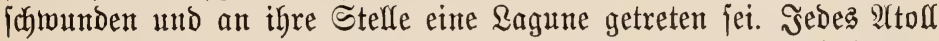
ift aljo nach Dartwin bas Dentmal einer entichiwumbenen Snjel. Sames

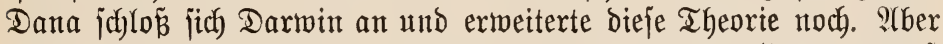

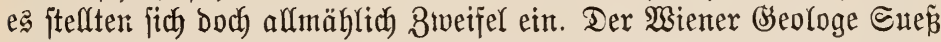
behauptete gerabe das (Segenteil: nicht der SSrunt des Meeres habe jid gejentt, jondern jein Spieger habe fich geboben; ein Landsmann

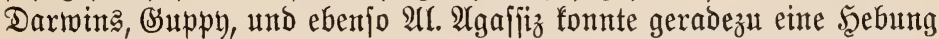

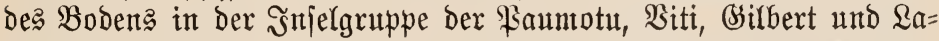
bronen nachmeijen, und Semper fogar bas gleidfzettige Borfommen

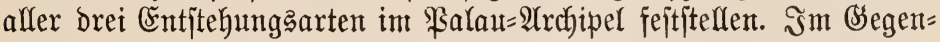

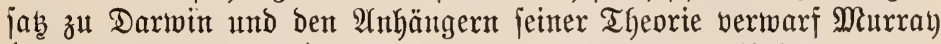
(und vor ifm Shamijio) jede Scebung oder Senfung des Bobens; unter=

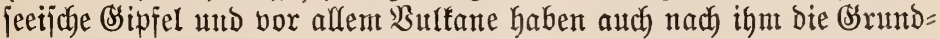
lagen für bie Siebelungen ber Rorallentiere abgegeben, aber erjt nach=

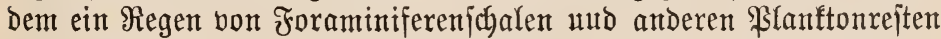
ihren Ssipjel jo weit erhöht hatte, baz bie Sorallen ihre Tätigfeit in bem nunmefr jeichten Wafjer beginnen fonnten. Bon ben Lagunen

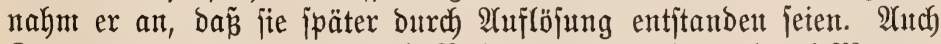

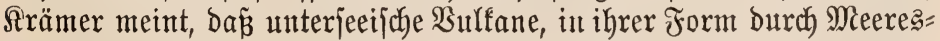
ftrömungen verändert, Den Untergruno ber meijten Atolle bilden. $\mathfrak{A} \mathfrak{n}=$ 
bere nette Unterjucher, wie Bserland und Dahl, geben barin, das bie snieln jidh gejenft haben, teilmeife wieder Darwin redt, allerbing? nicht ganz in bemfelben Sinne. Şatte leb̧terer angenommen, baz ber ganze Meereaboden eine jolche Sentung erfahren habe, jo behauptet

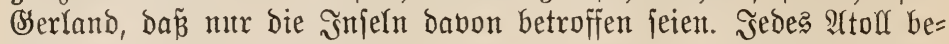
findet fitch nach rebzterem Beobachter auf eintem Bulfan, ber bei jeinen

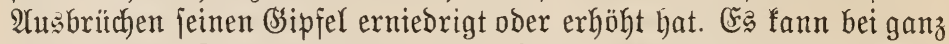

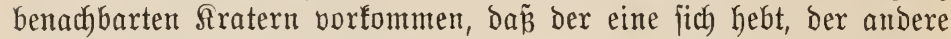
fich fenft, wie Berland an ber Baumotu=-Gruppe nadheifen fomte.

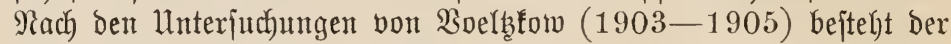
Ilntergrumb ber von ifm unterjuchten Soralleninjeln im wejtlichen in= bijoben $D_{z}$ ean nicht aus vulfunifhem Bsejteit, fondern aus zoogenem,

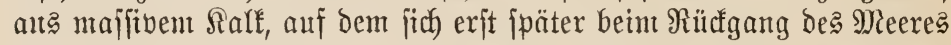
die Soralfen anjitedelten. - Sebenfalls iprechent bei ber Entitehung

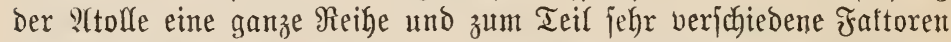
mit, beren 8 ujammenfaffung und Sdyeidung ipäteren lunterjuchungen

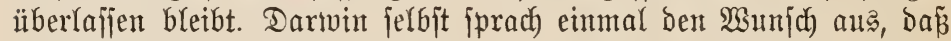
irgendeit reidfer Mann fich finden möbdte, ber auf einer Siorallen=

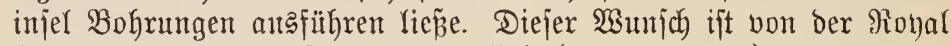
Society) in Rondon exfüllt, uno es find (1893-1896) Expeditionen nach) Funafutti, einter ber Laguneninjeln der Südjee $\left(9^{0}\right.$ jübl. $\mathfrak{B r}$., $179^{0}$ wejtl. \&.), gejanot worben, bie bort im Sorallenfalf Bohrungen an= ftelfen und criblich eine S? ntwort auf bie Frage geben follten, ob bie Atolle auf Bulfanen aufgebant fins, oder ob auch unter ber Tiefen= linie, bis zu ber bie Sorallen zu Yeben vermögen, Sorallenfalf ange= troffen wirb, und wie tief er reidft. Die 2 (rbeiten, bie anfangs mit manthem Miñgefdict zut fämpfen hatten, find bis $340 \mathrm{~m}$ Tiefe fort=

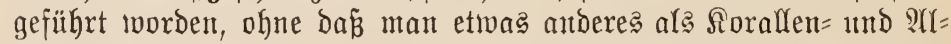

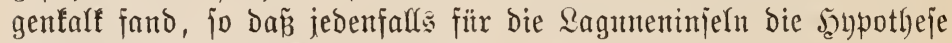
Darmints recht zu befalten fdheint.

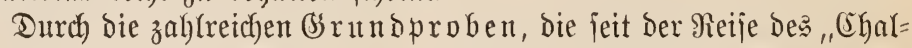
renger" aus ben Tiefen ber Dzeante an bas Tugeslidyt gebracht wor= ben find, find wir heute in ben Stand gefebt, uns and iiber bie $3 \mathfrak{U}=$ jammenfebung ber Bobendecfe ein im alfgenteinen ridhtiges bild zu machen. Ridgt nur bei Belegenheit Der Rotungen bringt Der ßeifftoff eine Probe bes von ifm berülrten Bobenz Gerauf, fondern aud bie

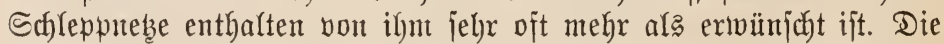

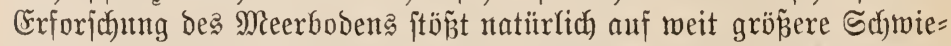
rigfeiten al: bie ber Feptlande; Der ,fubutarime" (Beologe fann nicht

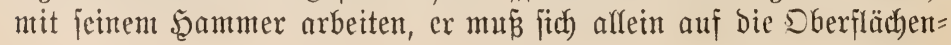




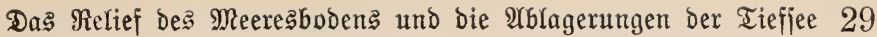

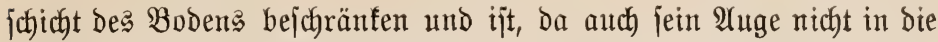
finteren Tiejen zu Dringen vermag, in bezug auf bie Alsbreitung einer

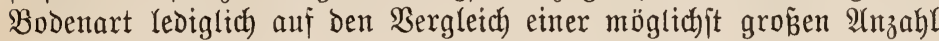
von Sirunoproben angetwie ent. Alf ganz Diejelben Schwierigfeiten wïrbe vergleichswetje jemand jtö̧en, Der es unternahme, von einem in ber

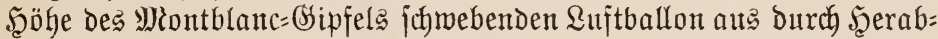

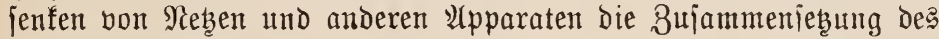

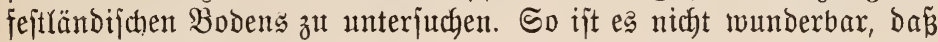

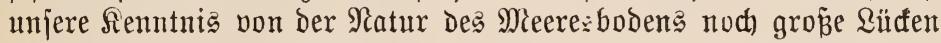
aufmeijt und noch viele ungelöjte Fragen in fich birgt. Jumerhin find uns aber heute gemilje Bobenbezirfe in biejer Scinjicht genauer befannt als manche jobtwer zugänglichen Sebiete auf Dem Fejtlande. überall finden wir in Den Sirunoproben die Refte Der Siere und \$flanzen, Die in Den Dberflächenjohichten Yebten, nach dem Tode hinabjanfen und Dort ihr Srab fanden. Wo ihre \&etber noch nicht völlig zerjebst jind, liefert Der mit ignen gebüngte $B$ Doen eine vorzügliche Futterjtelle für allerlei Mujcheltiere und andere Srunbbemohner, bie von ber in ibm aufgebäuften organifoch Nabrung leben und ihr folgen, wenn jie burch Ströntungen weggetragen wiro. Die Wanderungen mandjer (Srund= bewobner mögen jo ihre Erflärung finden.

Die Ilnterjudung des Bobens jelbit exfolgt mit eigens für biejen 3weaf gebauten Werfzeugen, die an Den sotorabt befejtigt werden; ent=

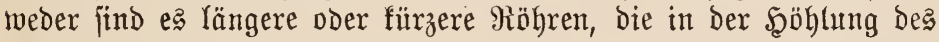
Sotbleis herabgelaffen werben und armtief in ben Boden einoringen fömen, oder eigenartig geitaltete Schöpflöffel, um Deren $B$ au bejonbers Der Fürit von Monaio fich verbient gemacht hat.

Die 2 b la ger ungen auf Dem Meeresboden famn man nad Murray in fün $\mathfrak{A}$ rten einteilen, die man als fï̈tenablagerungen, SBlobigerinen= jd) lamm, Diatomeenjalamm, Rabiolarienidblamm und verjdieden ge= färbte Ione unterjobidet. Tazu fommen noch als mebr lofale Sedi=

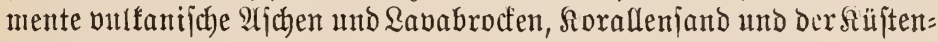

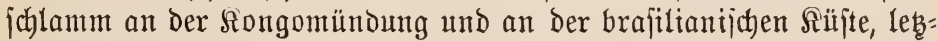

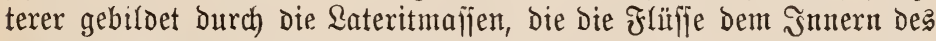
Landes entjühren. Was zunädjt die $\Re$ ü fte a b lagerungen anbetrifft,

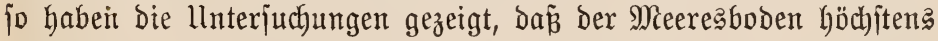

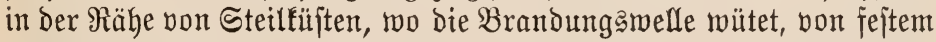
anjehendem Sejtein gebildet wirb. Soujt jest fich ber Seeboden in

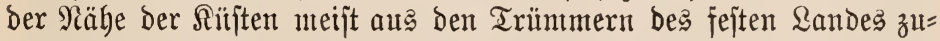
jammen, die die Flut oder die Brandung loggerijןen hat, ober aus ben

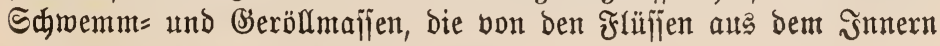


Des হandes mitgeführt wurben und jich an beren Mündung zu Boden jebten. Nicht immer aber fallen fie jhon bort nieber, fondern mand mal fann biejer terrejtriface Detritue burch Strömungen tweit fortge=

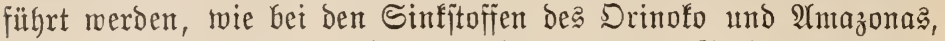

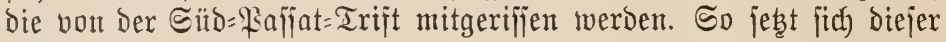
Schliff atts Den Trïmmern alfer Der verichtedenten Sejteite zufammen, bie bie Fejtränder alfweifen, untermifht mit ben Sfelettrejten zahl= reider Tiere Der Rïitenfauna. Ein Froduft biejer B̧ejteingtrïmmer ijt ein Sdylamm, Der jeiner Farbe wegen blauer Sand ober Tonjidylamm genannt wirb, eine weiche Majie, bie an ber \&uft bald braun wirb. se megr wir uns von ber Ritite entfernen und uns ben Mitten der Dzeane nähern, dejto anders gejtaltet fich die Bujammenjebzung dę Meeresbodenz; nicht mehr ber Schutt ber Lamomajien ijt ę, ber ihn bilbet, fondern bäufig bejtegt er, zumeilen gemijht mit ben Schalen

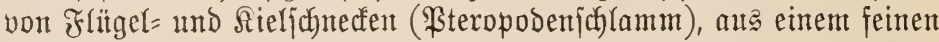

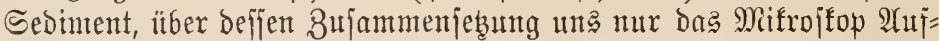

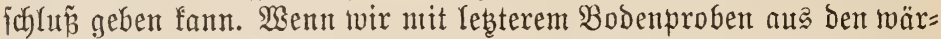
meren Teifen bes 2atlantijchen $D_{z}$ eans unterjuchen, fo finden wir, ba ber Dort allgentein verbreitete gelbbraume, Hebrige Schlamm, ber ge=

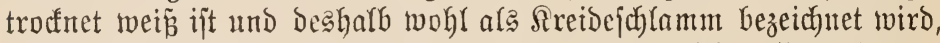

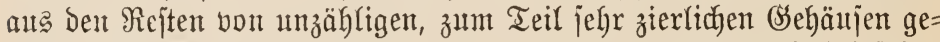
bilbet wird, bie Schnedenfäujern ober 2 mmoniten ganz ähnlid jehen uno früber autb dafïr gehalten wurben. Dả find die Echalen der Fora=

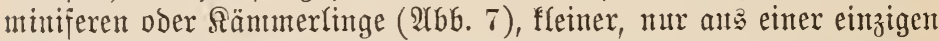
Belle bejtehender und Deahalb zu Den \$rotozoen ober Urtieren gehören= Der Wejen, bie während igres Rebenz imitande jind, den im Meerroafjer gelöften fohlenjautren Salf in jich aufzutehmen und auf ihrer Dber=

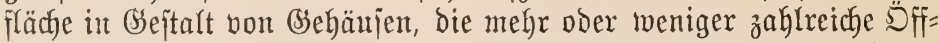
tungen uno oit aud itrahlig nad) allen Seiten auseinambergebenoe

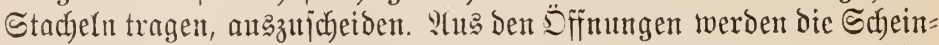

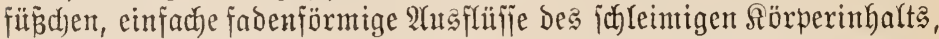
mit benten bieje Wejen ifre Rahrung ergreifen, autsgejtrecft. Da eine Form biejer Formaniferen, bie Oslobigerinen, mit ifyren Echalen ben meitaıs gröp̃ten 2Ynteil aut der Bildung biejce Bobenabjakes hat, be= zeichnet mant ifn alfgemein als (Slobigerinenjichlamm. Die Zahl biejer Sarfidalen ipottet jeber bejareibung. So fand Bjimbel in $1 \mathrm{cem}$ bes Schlanmtes nach unöglichjit genauer Bähflutg 225000 Sdhalen biejer Tiere ober Rejte bavon; fie jind bermijht mit Sand= und Mineral= förnern, Salt= und Siejeljtäbdhen anderer Tiere und winzigen Teildhen fosmijhen Staubes, unb gelegentlich finden fith aud barunter zahl= 
Das Relief Des Mekreßbobens und die Mblagerungen ber Tieffee 31

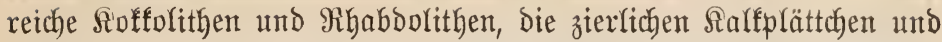
= ftäbdyen einzelliger Drganismen aus der Slafie Der Shryjomonadinen. Der (Slobigeritemichlanm bebedt nach ungefährer Schäbung $2 / 5$ des beutigen Meeresbobens und findet fich nach Murray erjt 75 bis 100 $\mathrm{km}$ von Der Sitjte entfernt, uto ztwax in Tiefen bis etma $3500 \mathrm{~m}$; er bededt einen grofien Teil bes Artlantijchen Dzeans, to jein Siebiet infolge des (ssolfitromes weiter nach Yorben reicht als nach Sitben. S̃n fülteren Meeren tritt aut fei= ne Stelle zumeilen ber Bilocu=

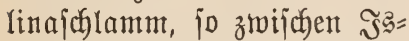
land und Epibzergen. Diejer Sämmerling lebt, ebenjo toie andere Foramintieren, bie die Balbivia auf Der : (gulbasbanf erbeutete, auf Dem Meeresbo= Den, bie Sslobigerina und ifre Bertwanden jind aber Betwoh= ner bes freien Wafjers, in Den fie fich mittels ifrer langen Fortiäbe joblvebend exhalten; jobald jie in fälteres Maffer gelangen, fterben fie ab und jin= fen ihre 巨abalen langiam zu Boden. Ein untunterbrodyener Regen diejer Ralfichalen, went dies Bild hier gebraudht werben

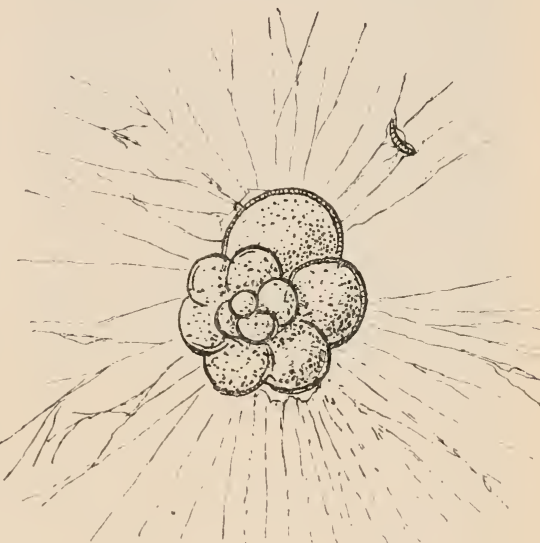
barf, riejelt arjo auf Dent Meeresboden hernieber. Er ift eine entzige rie= fige Begräbnisjtätte; wie auf einem Friebhofe lagern fier die Slelette vou Freund und Feind bidyt nebeneinander. Bei neneren Unter[uthungen

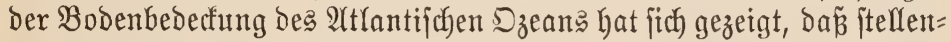

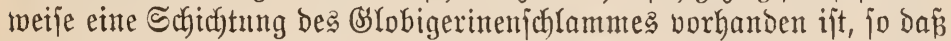

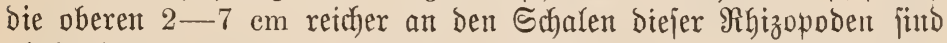
als bie barunter liegenden. Woher bieje ऽ bichtung ber Sinkftoffe fommt, die juct) jebenfalls während langer Beiträume vollzogen hat, mifjen wix

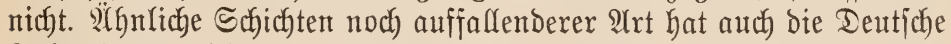
Sitopolarexpedition fejtgejtellt. Die Foraminiferen haben einen nicht unbedeutenden 2 nteil au ber Bildung unjerer fejten Crorinde gehabt; ganze Siebirge find ans ifren Shalen aufgebaut. So find bie Siretbe= berge Rïgens fajt ganz von ifnen gebildet; bie Schalen eines anderen fämmerlings, der Miliola, haben zunteijt Den fialfboden des Seine= 
becfens gejhaffen und einem gropen Teile von Paris bie Baujteine geliejert. Jahrtaujendelang haben jidh bie 2ublagerungen joldber $\Re a l f=$ jafalen auf bem Boden ber ehemaligen Meere angejammelt, ber Druft

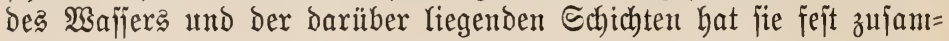
mengepré̃ rinde bie Serteilung von Land und $\mathfrak{B a j j e r}$ eine andere wurbe, ver= härtete jich bie ganze Majie zu dem heutigen B̈ebilde. - Sn je grö: Bere Meerestiejen wir hinabjteigen, bejto mehr nehmen allmählich bie Foraminiferenjchalen $\mathfrak{a b}$. Früber mahm man an, da Tiefe und bem fteigenden Drud̆ zunehmende Soblenjäuregehalt jei, der

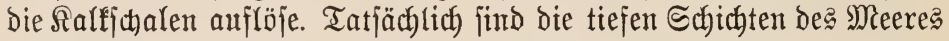
auffăllend falfarm, ber Şrumb hiervon ijt ung aber, wie wir fpäter jehen werben, zurzeit nod) nicht recht befaunt. 2 n bie Stelle ber Frora= miniferen treten im Snoifchen und auth in einigen Teilen bes Stiflen Ðzeans, jowie vornehmlich in ben $\mathfrak{B}_{0}$ larmeeren in eitter mittleren Tieje von $2700 \mathrm{~m}$ bie Riejelichalen ber Diatomeen. Dies find befannt= (id) mifrojtopijd fleine, auth free im Wajier idyebende, einzellige $2(1=$ gen, von gelblicher bis brauner Färbung, bie im Leben bie im $\mathfrak{W} a$ fjer gelöjte ßiejeljäure aujnehment fönten und fie in Bsejtalt von febr zier= lichen Riejelpanzern abjobeiden. Das Mifrojtop zeigt uns oft ïber= rajchend idjöne Formen von Schiffdhen, Scheiben und Stäbchen, aus zwei Teilen wie eine Schadhtel gebildet, deren flächen wie in getrie=

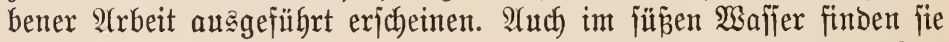

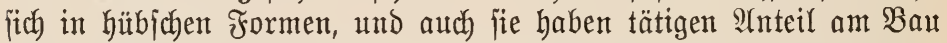
unjerer Erorinde genommen; auf foldher Diatomeenerbe fteht befannt= (idf) ein Teil ber Stadt Berlin.

Eine andere 2Hblagerung von $\Re$ iejelpanzenn ftellt ber $\Re$ a biolarien=

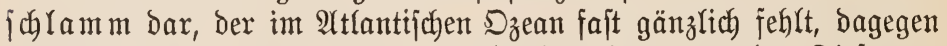
im Wejten und in ber Mitte Des Griópen Dzeans in Der Tiefe von meift mehr als $5000 \mathrm{~m}$ grop̃e Teile bes Mieeresbodens bedectit. Er

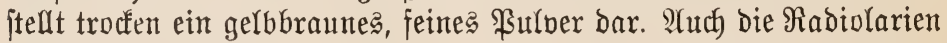

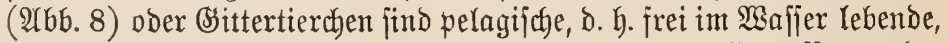
einzellige Urtiere. Siele von innen zeigen einen fugeligen Bau; aber auch andere febr hübjiche Formen jind häufig vertreten. Der zarte $\Re \ddot{o r}=$ per biejer Tierchen wirb burch) Sitejelftrahlen, bie vom Innern auš =

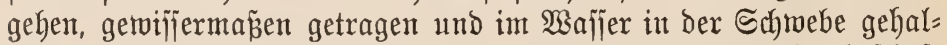
ten; innere und äuzere Sapjeln jtüben bieje Strablenbüichel und jhaf=

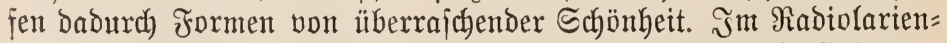

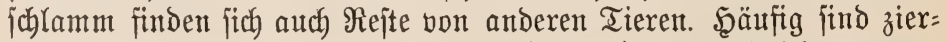

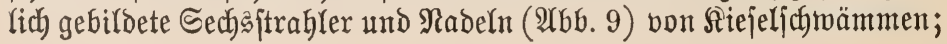


Das Relief des Meeresbodens und die 2(blagerungen der Tieffee 33

jo famben bie Srumbnebe ber Barbivia ein $5 \mathrm{~mm}$ bicfés Bruct)= ftücf einer Riejelnadel eines zur Błattung Monorhaphis gehörigen Schrommes, befien uripring= lide Qünge auf $3 \mathrm{~m}$ geichäb̧t werben farm.

Den grö̈̄ten Teil Des Bodeñ bejonber ber Meere ber bär= meren Slimate bebecfen aber von etra $5000 \mathrm{~m}$ an big zll den tief= ften Etellen Echichten von ganz anderer 3ujanmenjebutug, ber rote Tiefiecton (red clay), eine burch Eijettoryd und Man= gan bald heller, bald bunfler ge= färbte Majie, bie an ber Luft hart wie Töpferton wirb. Die Foraminiferenjualen jind bier fajt völlig verichwumben; ifre

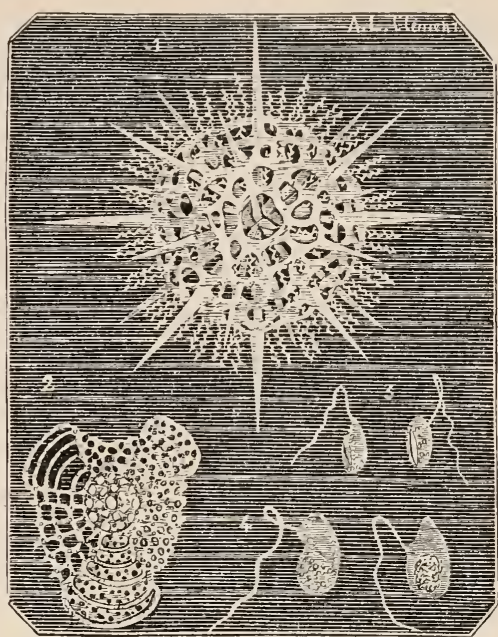

भGb. 8. গabiolarien aus bem Dberflächen:

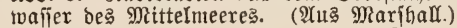
1. Lychnaspis, 2. Euchitonia, 3. 4. Sporent.

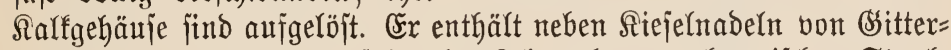
tierchent und Schwämmen jehr feine Fłttterchen von fosmijchem Staub,

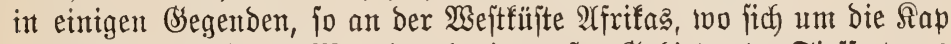

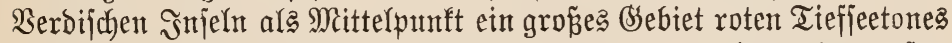
findet, Staubmajien aus ber wejttichen Sahara, in anderen in gropent

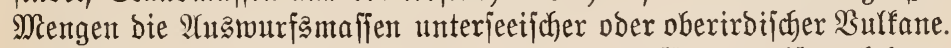
Die Şerfunft biejes fo weit verbreiteten roten Tieffeetones ift autb heute nochnichtganz flar; wäbrend Thomion für ifn ebertfalls eine animali= iche Entite= hutg anneh= meก zน müij̄en glaubte, ftellte Marray die heute wohlam meijten gel= tende $\mathfrak{A}$ njictyt

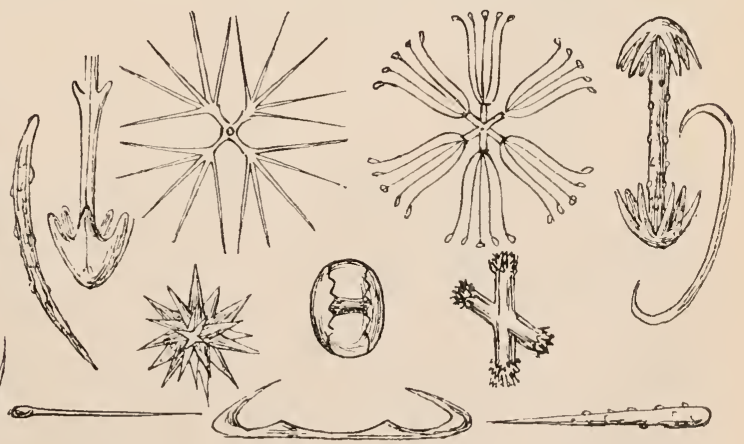

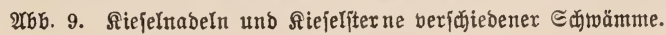




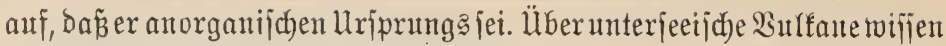
wir, twie wir bereits fahen, nichts Feftjtelyendes; wahrjobeinlid ijt ifre Ber=

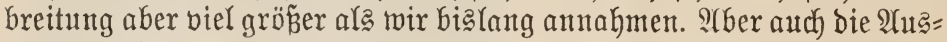

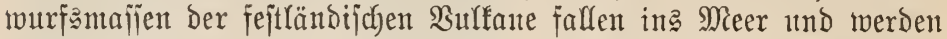

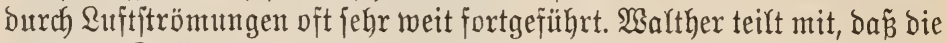

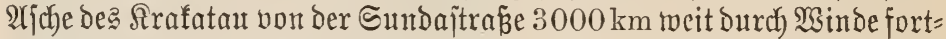
getragen wurbe. Dießildung diejes roten Tiefieetones mun aber ungeheuer langiam vor fich gehen; tobhl sahrtaufende find nötig, un ben Boden in eine nux wenige Finger bicfe Schicht einzubüllen. Durch nichts wirb die langiame (sntjtehung diejer unterjeeijchen Bodenjobicht jo gut erläutert als Durch bas bemerfenștwerte $\mathfrak{B}$ orfommen von Wirbeltierreften in ifr.

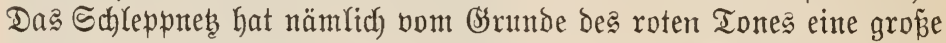
Menge von Şaifijdzähnen, von den jeften, über faujtgropen runben fnochen aus ben Felfenbeinen ber Waltiere, jotwie Sieböriteine von Sinochenfijdhen heraujgebradyt. Die Scaififdzähne gebörten zum Teił Formen an, die hente nicht mehr Yeben und ung fonit nur als $\mathfrak{B} e r=$ jteinerungen des Tertiär: Ŝnde von längít entjchwundenen Beiten ge=

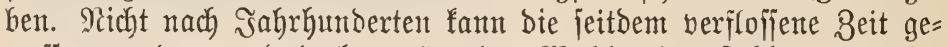
mejien werben, und boch genügt das 2 ühlen des Schleppnebes im weichen Meeresboden, un fie freizulegen. Sie find oftmals ichalenför mig ungeben von einem fejten, Brauntein und Eifenoxhb enthalten= ben Ton und bilben bann bie jogenannten Manganfnollen, die von

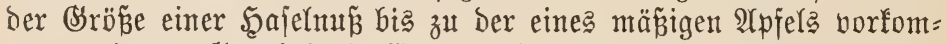
men und von Sïmbel als Erzeugnifje mnterieeijcher Sprubelquellen angejehen werden. Aluch vulfanijobe Bimsjteinftücficn und Mineral= förndyen fönten als Serne biejer Inollen auftreten, die ftellentueije den Meeresboden bidgt bebecfen. So hat bie Mieeresforjaung auch auf bie Seologie fehr belebent eingemirt.

\section{IV. $\mathfrak{A} \mathfrak{b}$ janitt.}

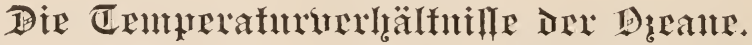

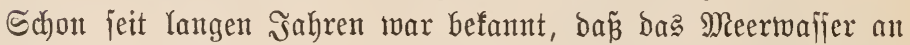
ber sberfläche verichiebene Temperaturen hat, mo man wusite auth,

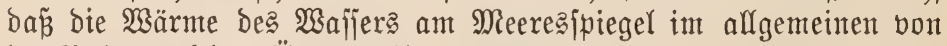
ben $\mathfrak{F o l e n}$ nach bem 2 (quator Gin zunelyme. Die neweren Unterjuchungen haben diefe 2Injicht bejtätigt. Zur Feftitellung ber Dberflächententpera= tur bedarf man nux eines genau gebenden $\mathfrak{I}$ hermometers. ANners ver= bält es fich mit ber Wärmemeffung ber Tiefiee. Nooch Serjobel ftellte 


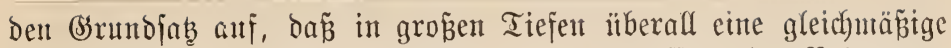
Temperatur von ca. $4^{0}$ C herridye. Die Shamejing ber Bobentem= peratur int Meere ftellte aber audf ungleich viel

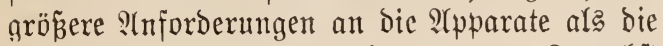
Beptimmung der Dberflächentuärme. Zunächjt handelte ez fich Darum, Ihermometer herzu= ftellen, bie ben auperorbentlichen Druff in ben Tiejen anahalten und trobedem genate ?Yugaben machen. Der "Challenger" hatte Tiefieethermo= meter an Bord, Die einen Druff don $3500 \mathrm{~kg}$ auf den Duabratzoll aushielten, was dem (setwichte ciner etwa $4800 \mathrm{~m}$ hohen $\mathfrak{B a j i j e r j a ̈ u l e ~ e n t j p r i d g t . ~}$ arfa wun einjt bie Snflitrumente in fajt $7000 \mathrm{~m}$ Tiefe verienft wurben, famen zwei von ifnen zer=

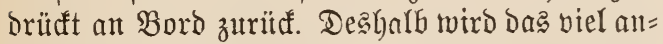
gewanto Tiefieethermometer von Mitfer $=$ Cajella auth in eine feite Sapjel gejtecft, und der Raum ztwifhen biejer und bem eigentlichen Thermometex

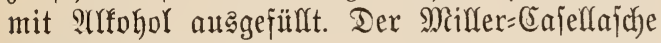
2lpparat ift im Srunde genommen ein Marimum = und Minimum=Thermometer, bas burch ztwei Schimimer bie höd)ite und niebrigite erreidyte Iemperatux jelbftändig aufzeidynet. Mit Scilfe biejes Thermometers fonnte man aljo feitiftellen, welches Der niebrigite Märmegrad war, ben bie Bajjerjäule an bent Srte erreichte, wo es verjenft murbe. Es fommt aber bei den Temtperaturmef= jungen bes Meerwajiers in vielen Fällen meniger

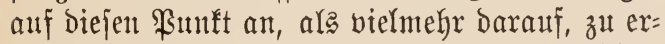
fahren, wie jich bie Temperatur in ben verjohie: Denen übereinander Yiegenden Mieeresfichichten ver= teilt, weldhe in biejer, weldhe in jener herridgt. Fitr bieje Mejiungen geeigute Thermometer (2rbb. 10) verfertigen feit Jahren Miegretti uno Zambra in Rondon. Sha Şauptunteridjed vou ben jonft gebräuchlichen bejteht barin, bã bą Rohr oberhalb des gueffijtberbehältuifies, "wo zu=

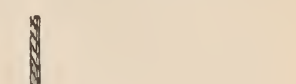
gleich fein Şohlraum fich verengert, einen finieförmigen Inicf erhalten lyat. Stellt man ein joldhes Thermometer auf ben Sopf, jo reiṕst aut der verengten Stelle ber Duecfiłlberfaden ab und behält bis auf ganz ge= 


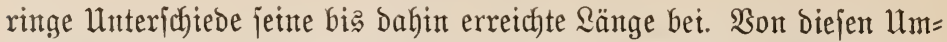

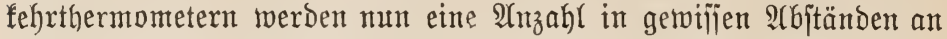
Dem Sotungsoraht befeftigt und in bie gewünjhte Tiefe verfenft. Dann werben Durch Semichte, bie ntan hinabgleiten läß̧t, Durch einten ein= fachen Medhanismus die Ihermometer Der Reihe nach herumgedreht, und fie verbleiben in biejer Stellung, bis jie heraufgeholt werben. (5马

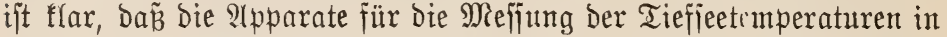
bezug auf Drucf und হeijtungşfähigfeit jehr genau gearbeitet jein müfïen und auch öfterer Nachprüfung bedürfen. - Yach einer anceren Me=

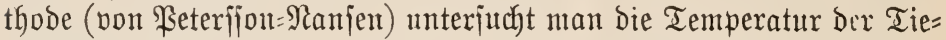
fentwaj̃er erjt an Borb, nadyom man eine Brobe in bejondern, eine

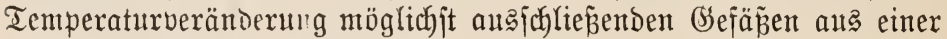
gewiffen Tiefe heraugefolt hat.

Wir wenden uts jeb̧t zu den $\mathfrak{B a ̈ r m e v e r h a ̈ r t n i j j e n ~ i n ~ M e e r e ~}$

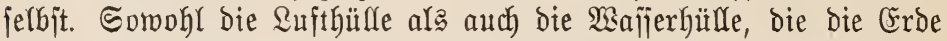
umgibt, erbäĺt ihre Wärme von ber Sonte. Shre marmen Strahlen werben entweder von ber Crd= ober $\mathfrak{S a j j e r o b e r f l a ̈ d j e ~ a u f g e j o g e n , ~ o d e r ~}$ zurücfgemorfen und wieber abgegeben. Die Suft wirb aljo von unten her Durch Augftrahlung erwärmt, während Dą Meer von oben her eine $\mathfrak{B a ̈ r m e z u f u h r ~ e r b a ̈ l t , ~ b i e ~ i n ~ e r j t e r ~ S i n t e ~ b a b u r c h ~ h e r v o r g e r u f e n ~}$

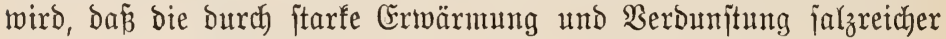
geroorbenen Wafjermafjen fortwähreno herabjutfen. Deshalb jeben mir,

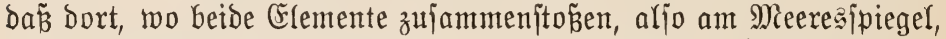
beibe annäherno diejelbe Wärme haben; Die Suft ijt (abgejehen von

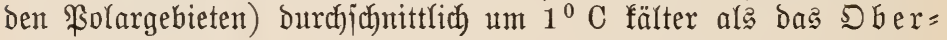
flädentwajfer. Se weiter wir uns von ber gemeinfamen Wärme=

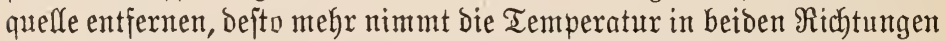
ab. Die Bedentung ber Dberflächentärme des Meerwaj̄ers für dasె

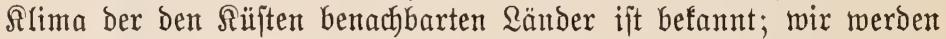
bei der Befprechung ber Meeresitrömungen noch näher barauf eingehen müif̈en. Das Meerwafjer erwärmt jïh langiamer als bie Sandmaifen, fühlt fich aber auch langiamer ab als bieje und wirft fomit ausglei= dhent. Wenn wir auf eine Sarte bliffen, auf ber bie Jabresijothermen

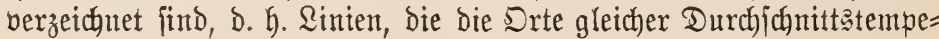
ratur im Jahre verbinben, fo jehen wix, dấ dieje auf Den Dzeanen

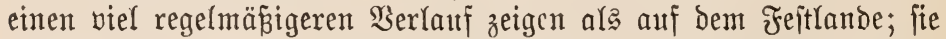
nehmen bort, fomeit jie nidht Durch @trömungen beeinf(uñt werden, fajt parallele Richtung an. Die Temperaturgegenfäkse am Tage und Die Sahresfichanfungen find aljo auf dent offenen Mleere viel geringer als auf bem feiten Lande. Sie betragen z. B. auf Dem Attantijden 
$\bigvee_{z}$ ean unter $35^{0}$ nörblicher $\mathfrak{B r e t t e}$ nur $7,3^{\circ}$; im Februar ift bie Durch=

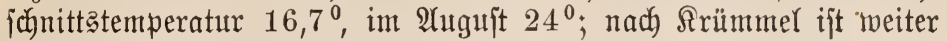
füolich) in $10^{\circ}$ nörolicher Breite die tieffite Temperatur imt Meärz $24,8^{\circ}$, bie hödjite im September $27,5^{\circ}$, was eine $\mathfrak{B a ̈ r m e j d y a n f u n g ~ v o n ~ m u r ~}$ $2,7^{\circ}$ bedentet. Minima und Maxima ber Errwärmung treten auf Dem Meere viel jpäter ein alg auf bem Feptlande; erftere erft int Februtar oder März, lebztere im 2 luguft ober September. Sm allgemeinen find

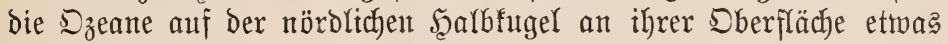

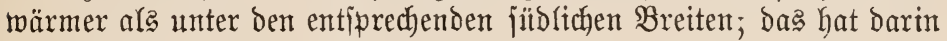

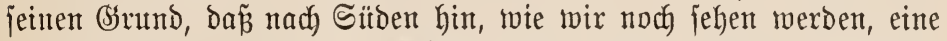
offentere Berbindung mit Dem falten Sübpolarwafier befteht. Die Deut=

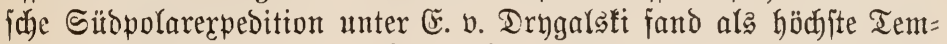

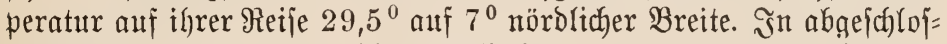
jenen Meeresteilen fann bie Dberflädentemperatur aber nod höher

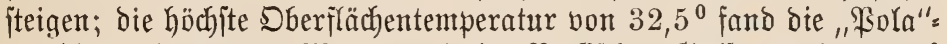
expebition im Roten Meere, und im Reritichent (Solfe wurbe $35,6^{\circ}$ angetroffen.

Die verjujieben erwärmten oberen Schichten ber Meere ïben auf

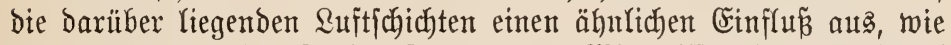

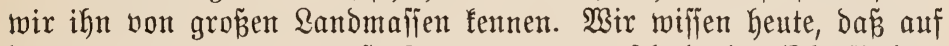
Den Dzeanen bort, wo grop̉e Temperaturunterichiede bes Dberfläd)en= wafiers fich vorfinden, aud bie Seimat ber Stïrme ift. Biele von

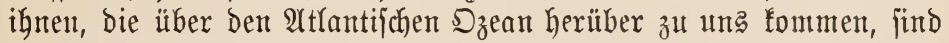

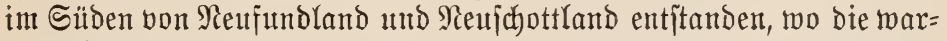
men B̧emälifer bes Bsolfijtromes einen auffallenden Temperaturgegen=

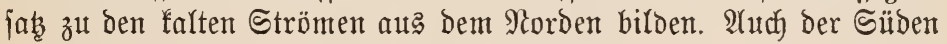

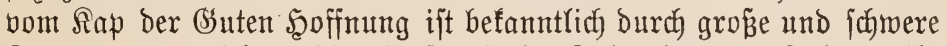
Stitrme ansgezeichnt, bie ebenfo wie im Sübmejten von Sïbamerifa und im Norbojten von Japan joldben Temperaturgegenjäken ihre Ent= itebung verbanfen.

Ein volftändiger umichwung hat fich infolge ber Tieffeeforjachung mit unferen $\mathfrak{2}$ njichten aber über bie $\mathfrak{W a ̈ r m e v e r t e i l u n g ~ i n ~ b e n ~ t i e ~}$

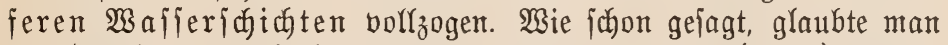
auf Brrund ber Beobachtungen von Iumont b'Urville (1826), Wilfę

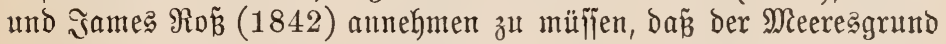
von einer gewiffjen Tiefe an überall eine gleichmäp̈ige Wärme von

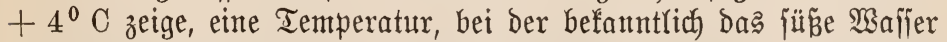

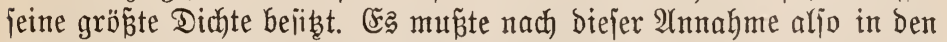
Polarmeeren nach der Tiefe eine 3tmahme der $\mathfrak{B a ̈ r m e ~ b i s ~}+4^{0}$ itatt= finden, in Den $2 \ddot{q u a t o r i a l g e g e n d e n ~ e i n e ~ e n t j p r e d y e n d e ~} 2$ (bnahme. 3twi= 
fichen beiden follte auf jeder Şalbftngel ein (s)ürtel vorhanden jein, auf bem dả Meer von oben bis unten bie gleiche Wärme habe, bie "homb= therme Grumbjhicht", Die Norb und Süb beide Male wie eine Maner

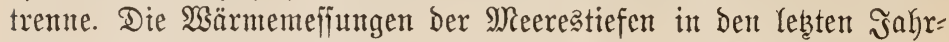
zehnten Gaben bieje Borjtellung, bie jich alfgenteiner 2lnerfennutg er= freute, ganz über ben Şaufen getoorfen. Aaflerbings bringen bie wär= menden $\mathfrak{B i r f u n g e n ~ b e r ~ S o m m e n t r a h l e n ~ i n ~ m u r ~ j e f h r ~ g e r i n g e ~ T i e f e n ~ e i n , ~}$

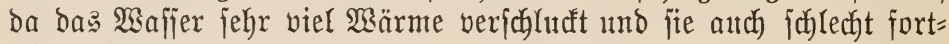

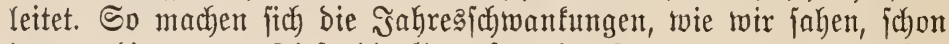
in 150 bis $200 \mathrm{~m}$ Tiefe, bie Gregenfäbe Der Tagestemperaturen fichon in geringerer Tiefe nidht mehr bemerfbar. Im Roten Meere ijt ber

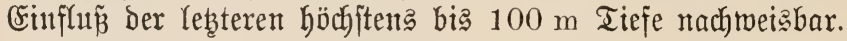

Die zahlreichen Reihentemperaturen, die zur Feitftellung ber jenfrechten $\mathfrak{B a ̈ r m e v e r t e i l u n g ~ g e m e j i ̄ e n ~ w o r b e n ~ f i n d , ~ h a b e n ~ b e m g e m a ̈ ß ~}$

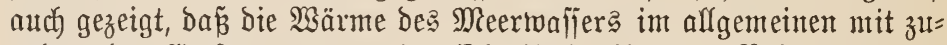
nehmender Entfernung von ber Dberfläche bis zum Boden Gin ab= nimmt. Diefe 2lbnafme erfolgt innerbalb ber erften 300 m jehr raja, bann langjamer bis zur Tiefe von ungefähr $1100 \mathrm{~m}$. Bon hier bi

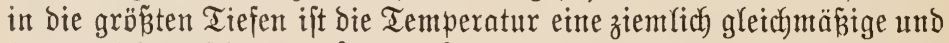
berwegt fith ztwifiden $+2{ }^{0}$ und $0^{0}$; in ben Polargegenden fant fie auf Dem (Srunbe infolge der falten Schmelzmäfjer aud unter $0^{\circ}$ jinfen.

Die nebenjtehende graphijdye Daritellung (2Hbb.11) Der Temperatur=

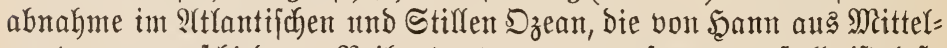
werten aus veridjiedenen $\Re$ eigentemperaturen zufammengejtellt ift, läp̈t bie Berbältniffe bentlich erfenten. Dautad verläuft bie Wärmeabnahme im äquatorialen Teil bes Stiflen $D_{z}$ eans zwijhen ben beiben Breiten= graben von $3^{0}$ folgendermásen:

\begin{tabular}{|c|c|c|c|c|c|}
\hline $\begin{array}{l}\text { Tiefe } \\
\text { in } \mathrm{m} \text { : }\end{array}$ & Temperatur: & $\begin{array}{l}\text { Unter= } \\
\text { (id)iebe: }\end{array}$ & $\begin{array}{l}\text { Tiefe } \\
\text { in } \mathrm{m} \text { : }\end{array}$ & Temperatur: & $\begin{array}{l}\text { Unter }= \\
\text { j(biede: }\end{array}$ \\
\hline 0 & $28,0^{\circ} \mathrm{C}$ & $6=0 \mathrm{C}$ & 1440 & $3,0^{\circ} \mathrm{C}$ & \\
\hline 180 & 21,7 & $6,3^{\circ} \mathrm{C}$ & 1620 & 2,5 & $0,5^{\circ} \mathrm{C}$ \\
\hline 360 & 10,0 & $\begin{array}{r}11,7 \\
2,5\end{array}$ & 1800 & 2,2 & 0,3 \\
\hline 540 & 7,5 & 2,5 & 1980 & 2,0 & 0,2 \\
\hline 720 & 6,2 & 1,3 & 2160 & 1,9 & 0,1 \\
\hline 900 & 5,0 & $\begin{array}{l}1,2 \\
08\end{array}$ & 2340 & 1,8 & 0,1 \\
\hline 1080 & 4,2 & 0,7 & 2520 & 1,7 & $\begin{array}{l}0,1 \\
0,1\end{array}$ \\
\hline 1260 & 3,5 & 0,5 & 2700 & 1,6 & \\
\hline 1440 & 3,0 & & & & \\
\hline
\end{tabular}

Anfautgs mad)t fich Demuadh nodh bie Sberflädyentwärme bemerfbar bann aber erfolgt bie Temperaturabuahme jehr rajch, uto Die Surve fällt fteił; je tiefer wir aber gelangen, bejto geringer werbent bie lln= terfobiede, bis fie jullieşlich fajt ummerffich find. 
von $+1^{0}$ bis $+2^{0}$ an, erjt bei weiterer $\mathfrak{A m t a ̈ h e r u n g ~ a n d ~ b i e ~} \mathfrak{P o l a r}=$ meere wïrbe es $0^{0}$ bis $-1,5^{0}$ zeigen, bis wir in biefen felbit bas Minimum von $-2^{0}$ bis $-2,5^{0}$ voriänden. 2rrjo nidht unter bem Äquator finden wir bie wärmiten Bobenfichichten, fondern nörolich von

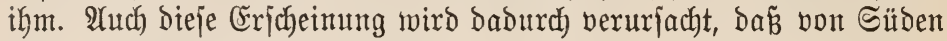
her falte Bodenjtröme ungehindert in bie $\$_{3}$ eante eintoringen fönnen,

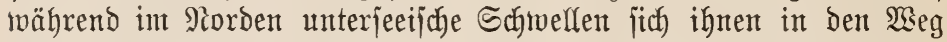
ftellen. Dieie haben aljo auf bie wärmeberbältnifje ber Tiefiee ben=

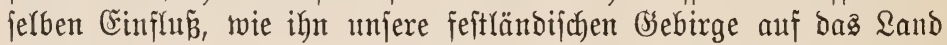

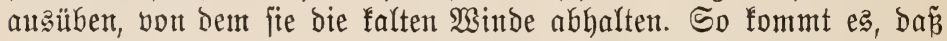

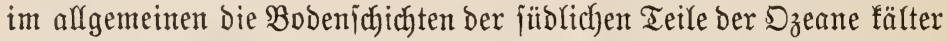
finto als bie unter gleichen Breiten befindlichen nörblichen. Im $\mathfrak{A} t=$ lantif fand bie "Baldivia" auf ihrer Reife nach Dem Eiident folgende Bobentemperaturen:

unter bem :̈quator

unter bem jüblidfen Sendefreije.

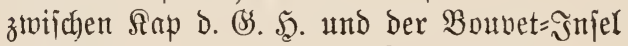

zwifhen Dem 55. und 64. Breitengrade.

$+1,7^{\circ} \mathrm{C}$

$+1,0^{0} \mathrm{C}$

$+0,4^{0} \mathrm{C}$

$-0,4^{0} \mathrm{C}$

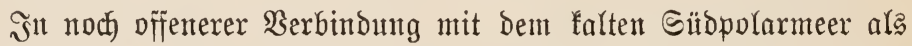

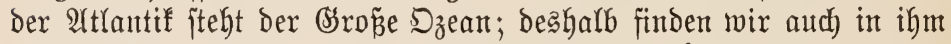
in Der Tiefe bon $2700 \mathrm{~m}$ แno mehr eine um $1^{0}$ geringere Tempe= ratur als in jenem. Sehrreich jind auth folgente Beifpiele. Der jüb=

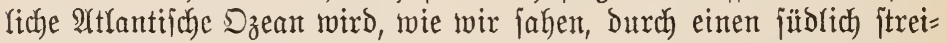

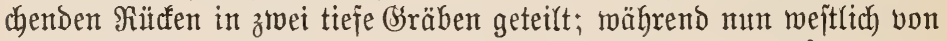
biejem im brajilijchen Becfen eine Bodentoärme von $-0,6^{0}$ gemefijent wurbe, zeigt ber biftidje Şraben eine Tiefententperatur von $+1,9^{\circ}$, alfo einen Unteridhied von $2,5^{\circ}$, weil Dort ein vom Maffitv Des Rüufents

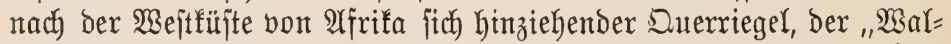

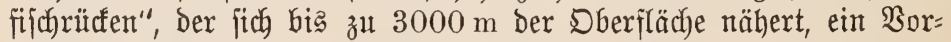
bringen ber falten Bodentwafier von Sïben her verfindert, was bei

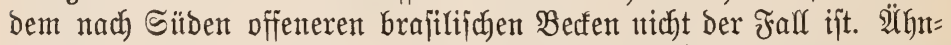

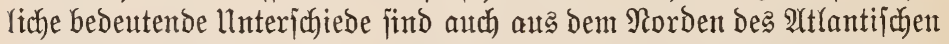
Dzeans befannt, wo eine unterjeeijobe Erbebung ziwijhen Schottlant,

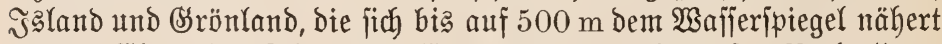

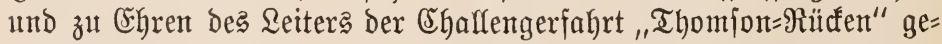
nannt wird, bie falten Bobenwaffer bes Polarmeeres von ben wär=

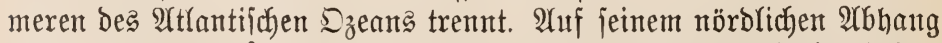

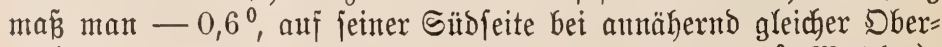
flächentemperatur und in Derjelben Tiefe +6 bis $+10^{\circ}$ (Waarther); 
während im Rorben eine reine Polarfauna angetroffen wurde, fehlten

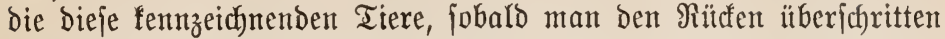
Gatte. Derartige $\mathfrak{A}$ b weich angen von ben allgemein geltenden Sirund = fäbsen fönnen aber aud baburch herborgerufen werben, bá bie täl= teren Bodenjtröne beim 3 uammentreffen mit anderen entporgepreżt werben oder burch andere ipäter zu extwähnende Finfliffie jteigen und jich Dann über twärmere Ströme hintwegichieben tönnen. Das in eine jolḑe Srbichtung von wärmerem mb tälterem Waffer hinabgelafjente Thermometer łann natürlich nidht bie fonit beftebende allmählich zu= nehmende Temperaturerniedrigung vorfinden. So zeigten bie Thermo= meter \$. Mohns 1877 im Norben der ffandinavijhen Sealbinjel unter bem 79. Breitengrad:

\begin{tabular}{|c|c|c|c|c|c|c|c|}
\hline \multicolumn{3}{|c|}{ Sberfläche $\quad 11,6{ }^{\circ} \mathrm{C}$ ) } & \multirow{6}{*}{ Albnafume. } & \multicolumn{3}{|c|}{ in $183 \mathrm{~m}$ Tieje $2,6{ }^{\circ} \mathrm{C}$, } & \multirow{5}{*}{ Bunahme. } \\
\hline in $18 \mathrm{~m}$ & Tiefe & 7,4 & & " $201, "$ & " & 2,8 & \\
\hline 37 & 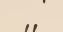 & 5,5 & & " 219 " & " & 3,7 & \\
\hline " $73 "$ & $"$ & 4,9 & & $" 274 "$ " & $" \prime$ & 4,0 & \\
\hline " 110 & " & 3,7 & & $" 411 "$ & $"$ & 4,0 & \\
\hline " 146 , & $\prime \prime$ & 2,9 & & & & & \\
\hline " 183 " & $"$ & 2,6 & & & & & \\
\hline
\end{tabular}

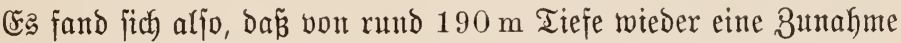
ber Temperatul jtattfand. Áber es fann, wie aus bem vorbin Siejagten

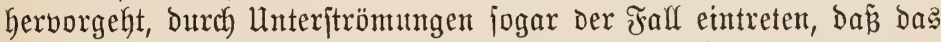

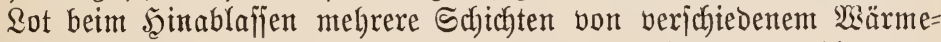
grad durchläuft; fo murbe von der antarftijden Expedition, die 1892 Das jübliche ßolarmeer auf jeine (Ergiefigfeit hinjichtlich bes Walfifd)=

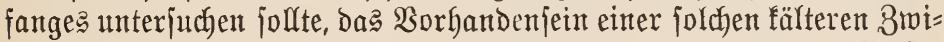

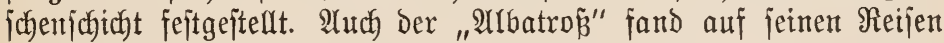
(1890-1895) im Beringmeer eine rajdye UGnahme ber Temperatur bis $100 \mathrm{~m}$, dann eine Bunahute bis $400 \mathrm{~m}$, von ba bis $800 \mathrm{~m}$ eine fajt gleiche Wärme 1 nto von $800 \mathrm{~m}$ bis zum (Sirunde $(2129 \mathrm{~m})$ eine bejtändige Ybnabme bis zu $1,5^{\circ}$. Spätere Unterjutchungen baben noch

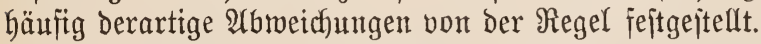

In Meeresteilen, toolin bie falten Bodenjtröme nidjt gelangen fön= nen, twird die Tiejentemperatur eine höhere fein. Dffenbar ift die Be= wegung ber erjteren nur jebr gering, ba jie fonjt bie unterjeeijchen

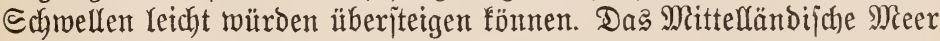
ijt Durch bie noch nidyt $13 \frac{1}{2} \mathrm{~km}$ Greite Schmelle bei Sibraltar, Die fich ztwijchen Rap Trajalgar und $\{a p$ Spartel bis auf $311 \mathrm{~m}$ bem Meereşipiegel nähert, fajt ganz vom At Uantijchen Dzean abgejd)lofien. Sn erjterem nimmt im Sommer die Temperatur jehr rajch bis etro $100 \mathrm{~m}$ Tiefe $\mathfrak{a b}$, am janeljten zwijoben 30 und $70 \mathrm{~m}$, bann immer 
langjamer, von $400 \mathrm{~m}$ bis $1000 \mathrm{~m}$ mur nod) um ca. ${ }^{1 / 2}{ }^{0} \mathrm{C}$. Bon $1000 \mathrm{~m}$ an abtoärts findet feine nennensıerte $\mathfrak{B a ̈ r m e a b n a h m e ~ m e h r ~ i t a t t , ~ u n d ~}$

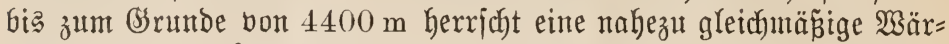
me von ca. $13,5^{\circ}$. Im Winter fülylen fich aud bie jonjt wärmeren

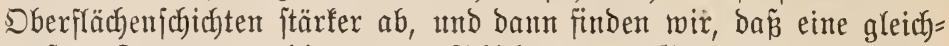
mäp̃ige Temperatur die ganzen Edjichten vom Ornumbe bis zur Dber=

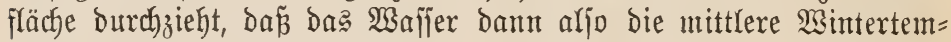
peratur ber Rüjtengebiete zeigt.

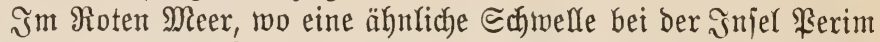

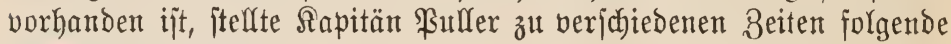
Temperaturen fept:

an Der Sberfläche . $\quad 26-30^{0} \mathrm{C}$,
in $731 \mathrm{~m}$ Tiefe . .
in $1243 \mathrm{~m}$ Tiefe.
in .

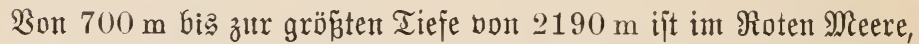

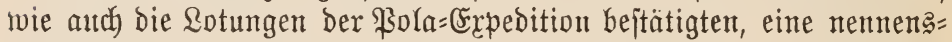
werte Temperaturabnahme nicht mehr nadymeişbar. Die gleidymääige

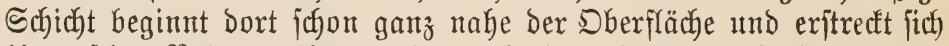

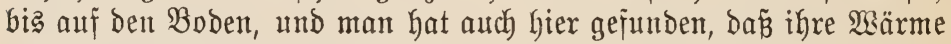

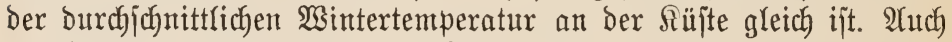
im Solf von Merifo und im Raraibijan Meerbujen herricht bon $1300 \mathrm{~m}$ an bis in bie Tiejen von $6000 \mathrm{~m}$ eine gleidje $\mathfrak{W a f j e r t b a ̈ r m e ~}$ von über $4^{0}$. 2̇̈hnliche Berbältniffe fönnen aljo aud eintreten, went eit Teil bes Meerbodens jich becfenförnig eingejenft hat und von trennen=

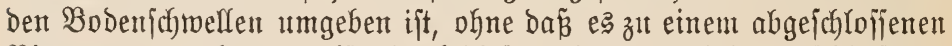
Binnenmeere gefonmen ijt. Âth bieje mehr ober minder gejchlofijenen Wälle tverben fältere Bodentwäffer abhalten, und von ber Linie igrer mittleren Erhebung an biz auf dent Bsnund Der Becfen roird. Deshalb cine annähernd gleichmäpigige Temperatur herrichen. Diejer Mangel an Birfulation fachafft bemnach it ben melyx Doer mentiger vom $\mathfrak{B}$ elt=

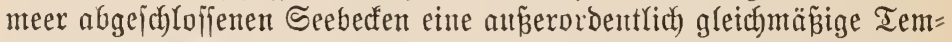
peratur bes Wafjers; jo finden wir z. B. in der 3 ulu= Eee eine gleid $=$

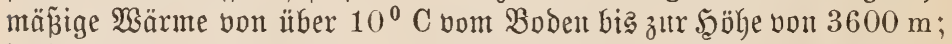

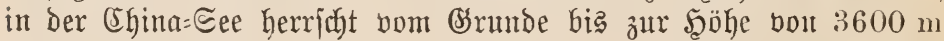

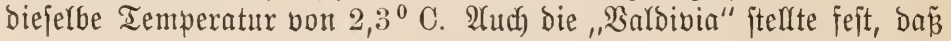
im fumatranifiden oder Montamei=ßecfen von $900 \mathrm{~m}$ Tiefe an biejelbe

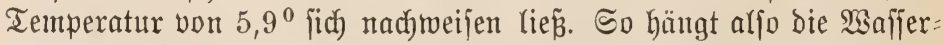
twärme Der Mieerbecfen in grö̈ß̄eren Tiefen auf bả engite mit ber mehr oder wentiger innigen Berührung mit den falten Bodenjtrömen zulammen. 


\section{V. $\mathfrak{Q}(\mathfrak{b} j$ d}

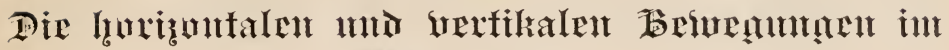 1t2extuallex.}

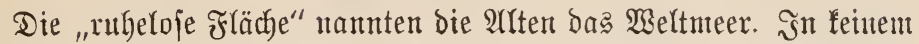
Angenbliffe find bie riefigen $\mathfrak{W} a$ ffermafjen ber $D$ zeane in träger $\mathfrak{B}$ emegungălofigfeit. Die burd) bie Sberflächenverdunjtung jalzreicher und

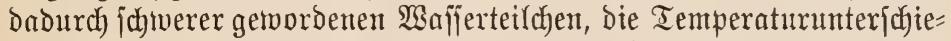

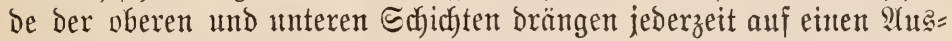

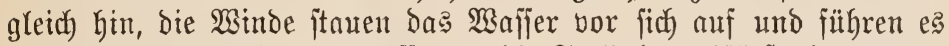
fort, und andere Mengen müffen an bie Stelle ber abfliez̃enden treten.

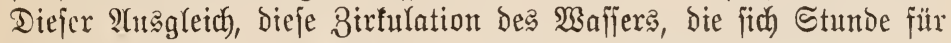
Stunde fowohl in wageredhter als aud in jenfred)ter Ridjtung voll= zieht, ijt nidyt mur für bie Exijtenz Der Drganismen bes Meeres von

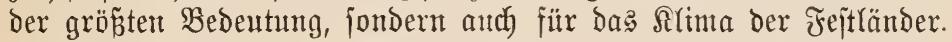

Selbjt bie jonjt mu langiam betwegten Tiejenjchicften werben -

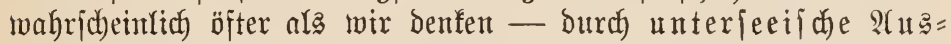

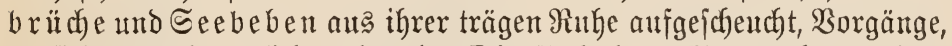
bie jich mur gelegentlidy and an der Dberfläd)e bemerfbar machen merben,

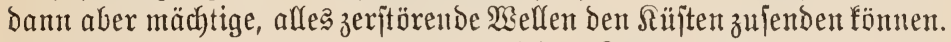
J̦m Samtar 1898 fand an ber ijtrijhen Riijte zwijhben Siola und Sapo d'Sïtria ein jtarfes Meerbeben jtatt; bas Meer trat mebrutals

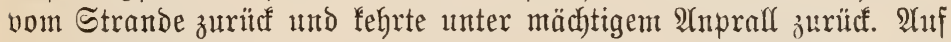
offenem Meere find berartige (Erbjtö̈ze je nach ihrer Stärfe entmeder

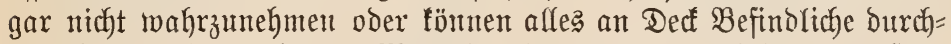
einander twerfen und bas Meer it eine Bewegung brittgen, baj wallt und iprubelt wie fodjendes Wajfer. Mandje Segenton jind, wie wir jahen, Derartigen jubmarinen Erobeben mo Eruptionen ganz bejonoers ausgejebt. Das ijt leidjt zu exflären, ba ja auth auf bem Fejtlande vulfaniface Exicheinungen hauptjächlich auf ganz bejtimmte

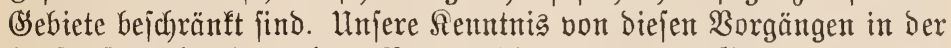
Tiefe ijt nod) felyr gering. Bon weldh elementarer Bsetwalt berartige vulfantiche $\mathfrak{A}$ usbrüche find, bavou zengen folgende Artgaben. Durch Das Crobbeben, Das im Salhre 1854 Simoda in Sapan zerftörte, ent=

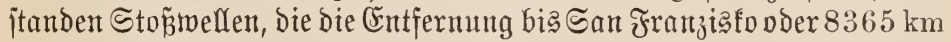
in etrua $12^{2} / 3$ Stumben zuriicflegten, aljo ftündlich megr ala $660 \mathrm{~km}$. Das ijt ungefähr bie Entfermung von Berlin bis jur belgifdyen (Brenze, zu Der Der Sdynellzug aber mehr ara 11 Stutben gebrantht. Die $\mathfrak{S e l}=$ lenberge folgten einander in 2 (bjtänoen von je 35 Mimuten. Bei Dem 


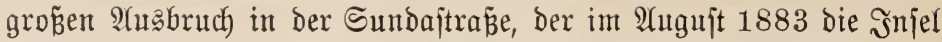

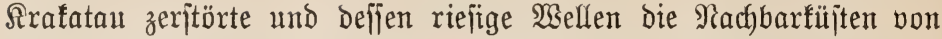
Sava und Eumatra bermirfteten, legten erjtere nach wharton die rund $9000 \mathrm{~km}$ betragende Strecfe bis an bie Sï̈jte Djtafrifas mit einer

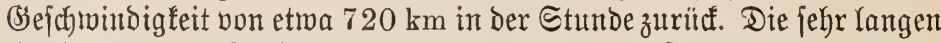
Wellen famen in 3wijchenräumen von etro einer Stumbe an und hatten

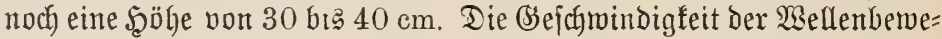

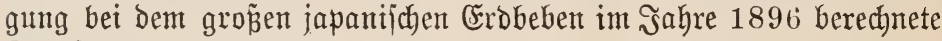
Davifon auf $748 \mathrm{~km}$ [tündridy.

Eine andere 2lrt ber Bemegung ber Bafiermafjen ruft bie Ein= wirfung der B̈ejtirne hervor. Die Ericheinung des periobijchen $\mathfrak{A} u \tilde{F}=$ und Niederiteigens bes Meeresipiegels, bie jich bejonders an Den fïjten bemertbar madht, bezeidnen wir befanntlich als (3) ez eitent oder Ti i en. Zweintal täglich findet biejes âtmen bes Meeres jtatt, bie auffteigende Bewegung nennen wir Flut, bie abjteigende Ebbe. Seit ber bentmür= Digen Feftlegung ber (Sejebe Der (Sravitation Durch Nerwton wifijen wir,

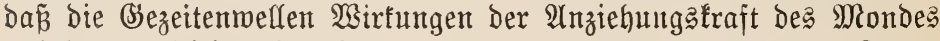
und der ungleich viel gröpéeren, aber 387 mal weiter entfernten Eomne

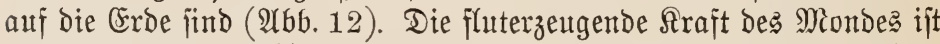

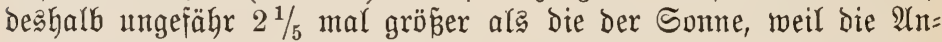
ziehung mit bem Duabrate ber (Entfernungen abnimmt. Durch bie $\mathfrak{A} \mathfrak{n}=$ ziehung biejer Şimmeläb̈rper wird auf ber ifnen zugewandten Seite

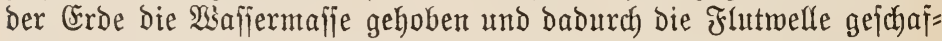
fen, während auf der abgemandten Seite infolge ber Rotation ber

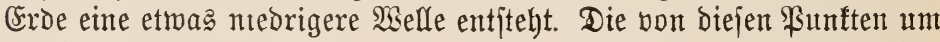
90 Rängengrabe entjernten Drte Gaben zu gleicher Zeit Niebrigmafjer voer (Ebbe. Täglich zmeimal umlälf̈t aljo bie Erbe in einer Beit von 24 Stunden 48 Minuten - im allgemeinen in einer ifrer $\mathfrak{A}$ (d)jen=

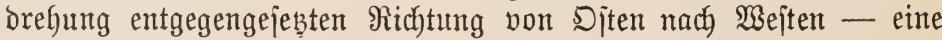
Monbflut und in einem Beitraum von ca. 24 Stmonen eine Sonnen=

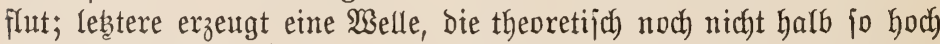
ift wie bie eritere (20bb. 13). Wirfen Miond und Sonne zujammen,

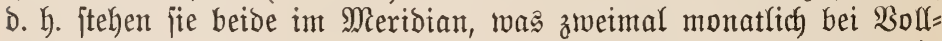
uno Reumond eintritt, fo entftegen bie Epringfluten (2Hbb. 12, I, II);

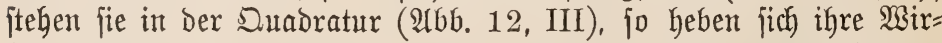
fungen teilmeije auf, und wir haben eine taube ober Sitppflut. Der Şöben=

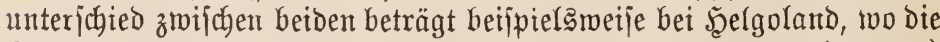

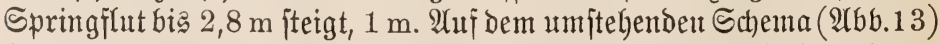

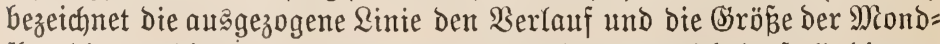
flut, bie punftierte bie ber Sonnenflut, und bie gejtrichelte ftellt bie aus 
Die horizontalen und vertifalen Berwegungen im Meerwajier 45

beiben rejultierende Flut innerhalb 12 Stunden Dar. Der Interjated

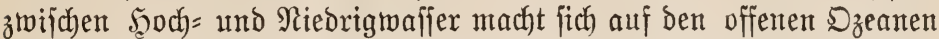
nur wenig benterfbar; er beträgt nach Srümmel bei Tabiti $40 \mathrm{~cm}$, bei Ascention $60 \mathrm{~cm}$, bei St. Şelena $90 \mathrm{~cm}$, in Sübgeorgien $80 \mathrm{~cm}$, bewegt fich alfo auf Den offenen Weltmeeren meift zroijhen 0,5 und $1,0 \mathrm{~m}$. Anders aber, wenn die Flutwelle auf grop̧e ฉanomajןen und

I
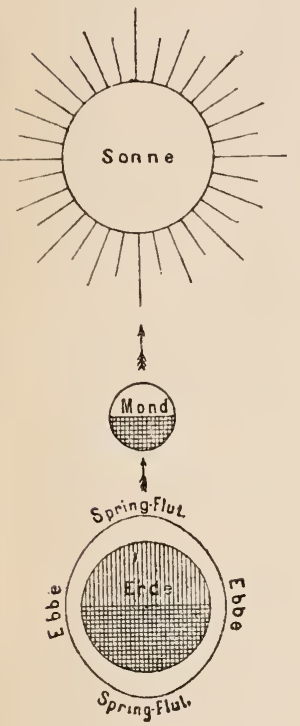

II
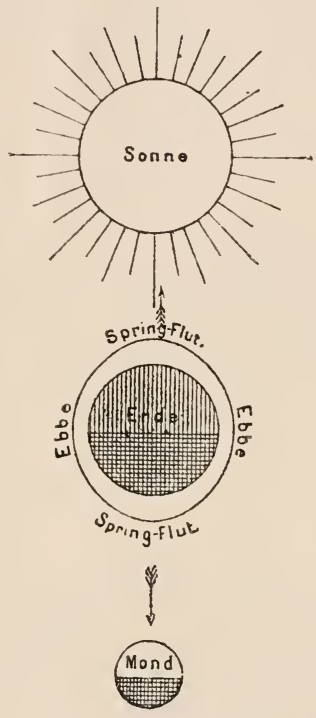

III
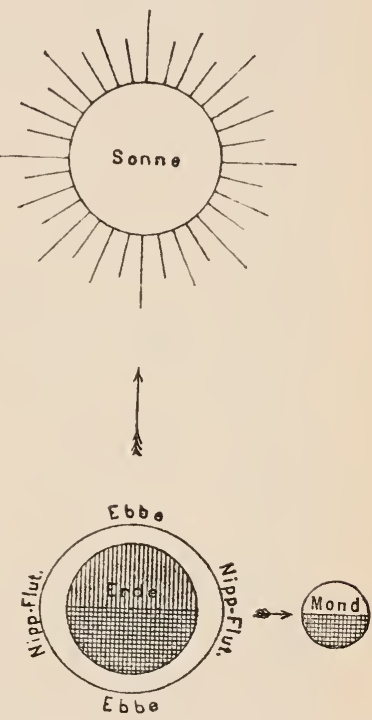

भKb. 12. Entitefung Der Spring= und Tippfuten.

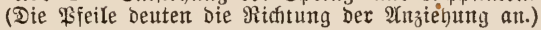

dabei auf Steilfüften trifft, und vor allem, wenn fie in enger werdende Solfe zu laufen gezmungen wird, wie in ben Briftolfanal uno bejon=

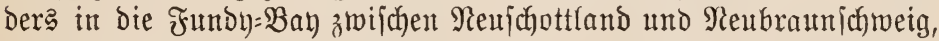
to die Epringflut nach Srïmmel bis $21,3 \mathrm{~m}$ hod fteigt; im Cobiac= Fluffe werden jogar $20 \mathrm{~m}$ Flutböhe angegeben. Dabei ipielt aud die gerabe herridjende Windridytung eitte großße Rolle. Tas Sindringent Der Flut in Fluf́münoungen fchafft beijpielsmeife in ber Bsaronne, im Ulmaznas, wo fie noch $800 \mathrm{~km}$ aufroärts nadjweisbar ift, im $8 \mathrm{am}=$

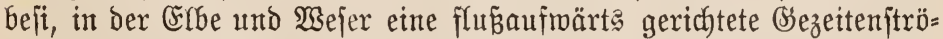
mung, die Das Sindringen von Seefbiffen weit ins Qand finein ex= möglidyt und jo das Borbandenjein wichtiger Şäfen (Şamburg, Bremen, 


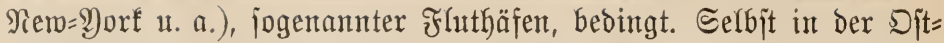

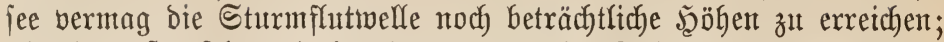

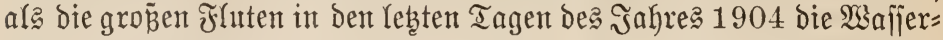
maffen nad) Diten aufgejtant hatten, wurben fie bei umfpringendem

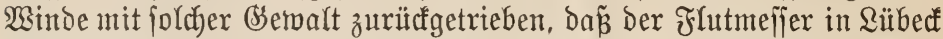

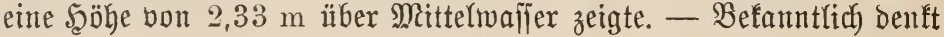

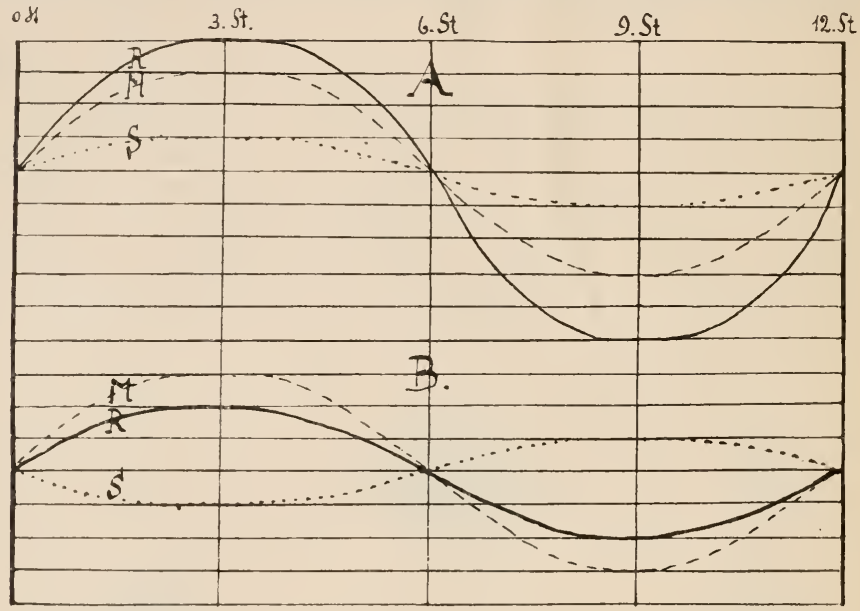

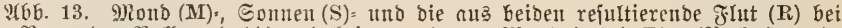

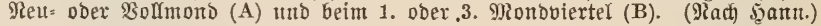

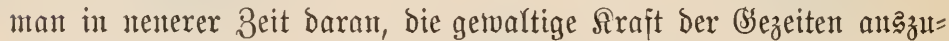
muben, indem man entweder ifren Drut zu verwerten ober aber bie von iłr zugeführten Waffermaffen in Sammelteichen auffängt und zum Treiben von Mïflen Doer Turbinen zut vermenden juttyt.

Wenn die ganze Erbe von einer gleichmäpigen $\mathfrak{S a f f e r j a j i c h t ~ u m = ~}$ geben wäre, fo miiñte die Scauptflut jedesmal bei bem Durchgang des Mondes Durch den Meribian bes Drtes jtattfinton, ס. h. jedesmal nadh 12 Stumben 25 Minuten. YUf Den weiten $\bigvee_{z}$ eanen fann bie Flut=

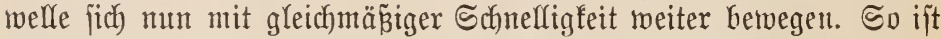

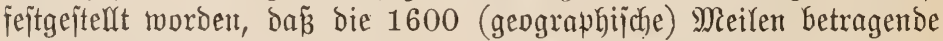
Entfermung zwifhen der Sild fiijte 2(ujtrafieng mo dem Sap ber guten f̧offunth in 12 Stunden zurüfgelegt miro. Sobald aber bie Ffut= melle auf Ranomaffen ftöß̈t, tritt eitte Q̈̈nderung und Berlangiamung

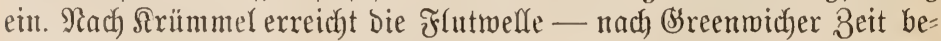
rechnet - แm $2^{\text {h }}$ Siap Finiaterre, trifft $u m 4^{\text {h }}$ am Eingang zum 
S̈̈rmel= Sanal ein und fommt weitere zwei Stunden fpäter butrch bie Strape von Dover und zugleich int Norden um bie Şebriben herum

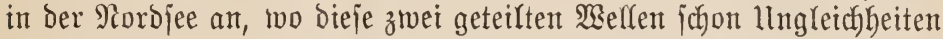
hervorrufen. Den Unterichied ztwijhen Rulmintation des Miondes und

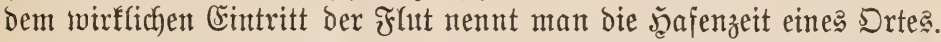

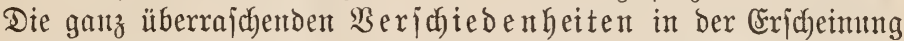
Der Bsezeiten beruhen, wie twir heute aus den Unterjuchutgen von

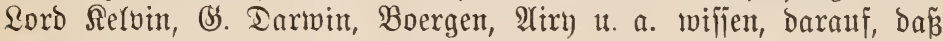

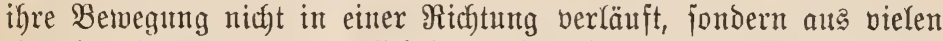
einander begegnendent und fid freuzenton Welfen und Weflenjujtemen bejteht. Die Şafenzeit eines Drtes Durch Borautarechnm ficher zu be= ftimmen, ijt nach unjerer heutigen Renntnis unmöglich. Rebent ber Stellung ron Mond und Sonnte twirfen anf. Die Flutwellen aujer ben

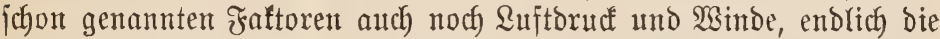
Scebung bes Meeresgrundes und das dadurch flacher werdende $\mathfrak{B a f j e r}$

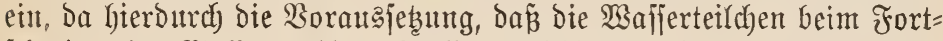

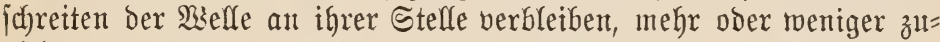

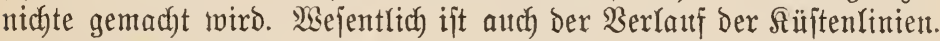
Un ber Sïbmejtfüite Englands erreid)t nach Wharton bie Flut eine

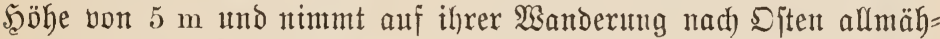
lich bis Poole $(2 \mathrm{~m}) \mathfrak{a} \mathfrak{b}$; von ba exfäbrt jie eine Steigerung bis Şa ting $\mathfrak{S}(8 \mathrm{~m})$, und weiter nach Ditent wird fie wieder fleiner. Da

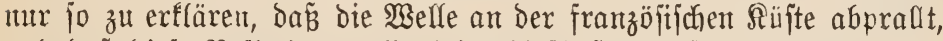

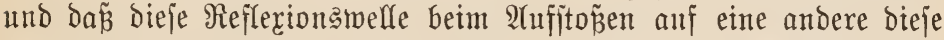

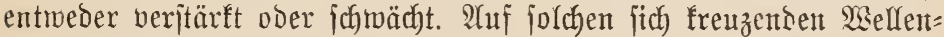

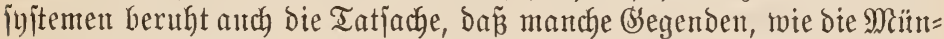
bung des Miffififitppi, uur einte Flut täglich haben, antere, z. B. Die Ditfüjte von Echottland, melgr als jivei inmerhalb 24 Stunden, uäm= lich alle vier Stundelt bent Eintritt einer Flut ermarten fönten. Rach

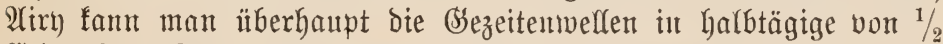
Eroımfang \&äıge, ganztägige, einen Eroumfang lange, uno britten? folche, bie int noch längeren 3wijh)enträımen (14 oder 29 Tage, $1 / 2$ und ein Sahr) anftreten, einteilen. Dabei joll nicht vout ber Salto getwie=

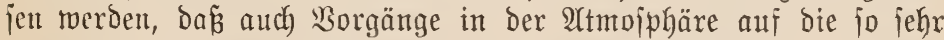

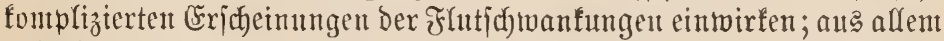

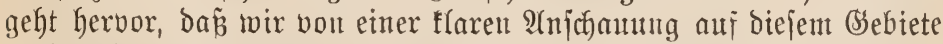
noch recht weit entjernt jind. SUd bie Binnentmeere haben igre natürfich kleineren - Ffutmellen; int Mittelmeer erreicht bie Spring= flut bei Toulon $14 \mathrm{~cm}$, bei Ticapel $34 \mathrm{~cm}$; gans j (d)wad) ijt jie in Der Ditfee ( Siel $7 \mathrm{~cm}$, Miemel nod) nicht $1 \mathrm{~cm}$ ), unto Spuren finden fict) 


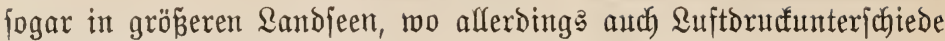
mitbeftimmento find.

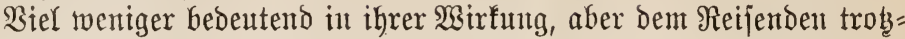
Dem auffallender ijt bie Erricheinung bes Seeganges. Nur jelten ijt bas Meer ipiegelglatt; bei jeder \&uftbetwegung twerben burch ben un= gleichen Druff bes Wsindes auf bie Dberfläche bie $\mathfrak{S a f f e r t e i l d y e n ~ i n ~}$

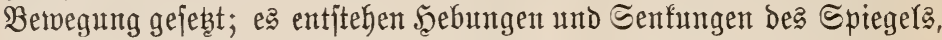

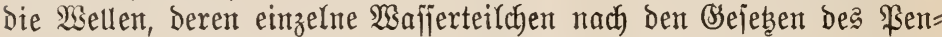

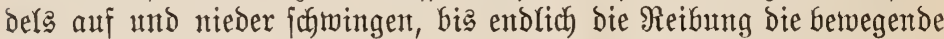
Sraft verzebrt. Die Sommandoz der beutichen Maritefahrzenge fint jeit eintiger Beit angewiejen, Beobachtungen über Şöhe, Länge, Periobe und

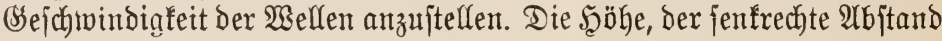

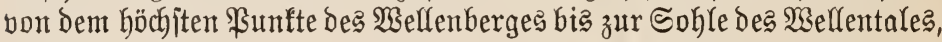
twird Yeicht ïberichäbt; fie richtet jich nach der Stärfe bes Wintos und Der Dauer feiner Eintwinfung und bürfte auch beim heftigiten Sturme auf offentem Meere jelten mehr ala $10 \mathrm{~m}$ betragen, und Mejpungen, Die bỉ zu $15 \mathrm{~m}$ Şöhe fejtitellten, find auf unzulängliche Miethoden

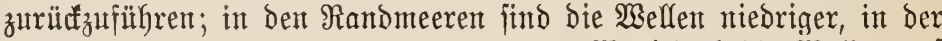
Norbjee z. B. wohl im Marimum $6 \mathrm{~m}$. Wo jedoch bie $\mathfrak{\text { Wellen }}$ auf feiten Miderjtand itopen, jest jich ifre wageredyte Beregung in eine

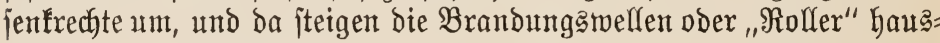

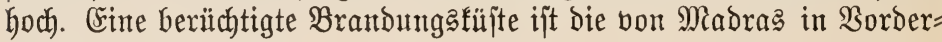
indien.

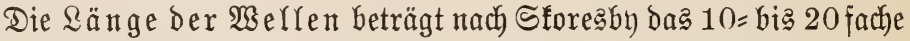
ifrer Şöhe, ein Berhältnis, das fich nach anderen Beobachtungen bis zum 33 fachen erböhen fant. Nach Sapitän Stanley entipricht einer Wellenthöhe von rund $6 \mathrm{~m}$ eine länge von $90 \mathrm{~m}$ unt eine Sejefbin= bigkeit von jtündlich $46 \mathrm{~km}, \delta$. i. etroa $12,8 \mathrm{~m}$ in einer Sefunde. Bei biejer johnellent Fortpflanzung ber Bewegung bleiben bie Wafferteil=

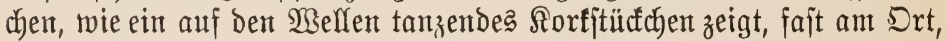
fie geben ben erfaltenen $\mathfrak{A}$ njto $\tilde{\beta}$ mur weiter und bewegen fich in ber Sauptiache utr auf und nieber in ber Bagn einer Trochoide, b. i. ber=

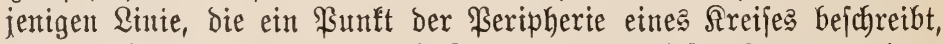
Der auf einem andern rollt. Die Fortpflanzung biejer Bervegung fam

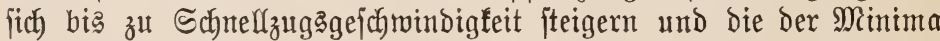

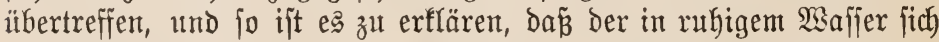
fortfebende Seegang Dber bie zurürffleibende Dünung von einem ver= Geerenden Drfan, ber vielleicht Taufende von Seemeilen entfernt tobt Deer getwïtet hat, Beugnis geben und den Schiffern geradezu als Warn= zeichent bienen fant. - Der Fortpflanzung ber Mellenbetwegung in 
Die horizontalen und bertifalen Bemegungen im Meerwaffer

bie Tiefe find biel engere Sdyranfen gejebst. Shre Srrenze liegt, wie man auf theoretifher (Sirundlage beredhnet hat, $350 \mathrm{mal}$ tiefer als bie

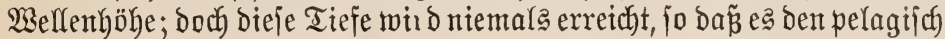
lebenden Tieren Yeidyt ift, fich vor einem nahen Untwetter in bie rubigen tieferen B̧rïnde zurïđżziehen.

Die wutnderbare (Erjheiunt ber Dberfrädenjtröme im Meere, gleidffam ber Berwegung von Frififien in Den Dzeanen mit oft beutlich erfennbaren llfern, bebeutend wärmerem ober fälterem Saffer, verän= Dertem Salzgehalt, abweichender Färbuntg und anderem Tier= und $\mathfrak{P f l a n =}$

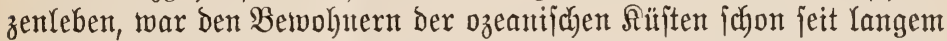
befannt - bie erfte Sarte Der Meereşitrömungen zeidnnete SYthanafius

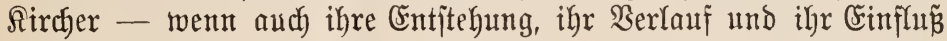
auf bas Slima ber Feftländer erft viel fä̈ter genauter erjoricht und er= fannt wurbe. Şolzitüiffe und andere angefdrwemmte Dinge, bie nicht bem heimatlichen Boden entitammen fonten, madhten mohl zuerjt auf biefe merfwüroigen horizontalen Berwegungen bes Meeres aufmerf: jam; joldhe Funbjitüfe waren aud ber erjte Seintweis auf jente Drift von

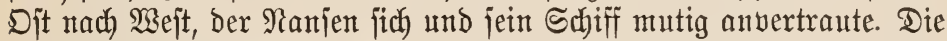
Strönungen machten fich be马 weiteren aber ben Seeleuten noch bemert:

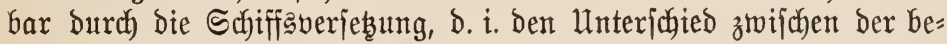

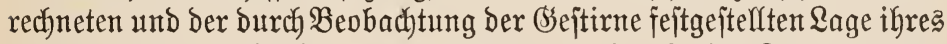
Fahrzenges, eine (Erjheinung, bie man mur burch eine Strömung er= flären fonnte. Die Sdjiffer fürdyteten fie lange Zeit, ba fie in ifnen bie Sicherheit ber Leitung verloren; erit fpät erfannte man bie Borteile, bie bie Driften ben reijenden Schiffen bieten, und jeitbem bentust man fie nach Meöglichleit.

Cinen britten Beweis für bie Betwegung ber $\mathfrak{W a f j e r m a f f e n ~ i n ~ h o r i = ~}$

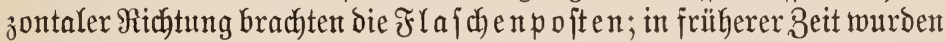

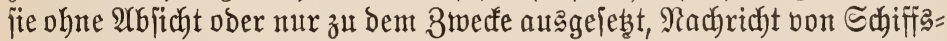
unfällen auf hoher See zu geben. Şeute bebient fïch die moberne Meeress= funde ifrer mit Erfolg zur Erforichung ber Meeresftrömungen, und

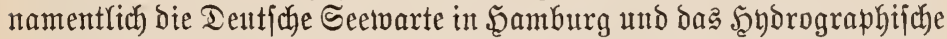

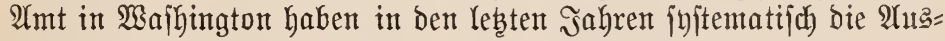

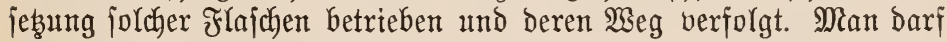
bei ber Beurteilung bes WSertes Derartiger Flajhenpojten aber nicht ver=

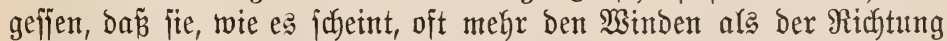

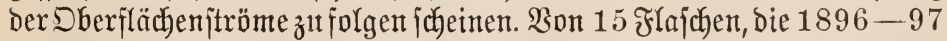
im Diten des aujtralijeben Feftlandes aufgefunden wurben, waren nur brei bem von Norden herfommenden Ditaujtralijchen હtrom gefolgt;

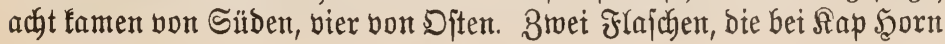




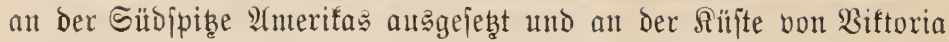
aufgefundent worben waren, hatten 9000 Seenteilen, act)t bis zehnt täg=

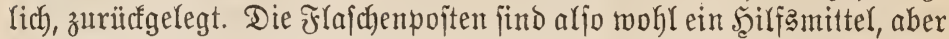
fein allzu zuberläfïtges, mo immer nod) find Thermometer zur $\mathfrak{B} e=$ ftinmung ber abweichenden Temperatur und $\mathfrak{A}$ räometer zur Feftftellung bes burd) Den veränberten Salzgehalt vermehrtent ober vermintorten

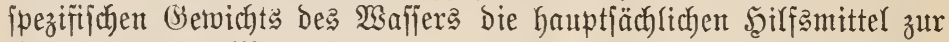
Erforidhung der Meeresfitröme.

Man untericheibet im allgemeinen oberflächliche Strömungen, her= vorgerufent burch) (Ebbe und Flut, burch bie Qand= und Seetwinte, bie

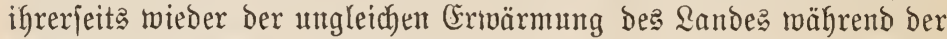
Tag = und Nachtzeit ifre Entjtehung verbanfen, ferner bie eigentlichen Meeresftrömutugen und bie Tiefenftröme. Für bie Entjtehung ber bei= Den echten Meeresjtrönungen jint nadh ber befanten Theorte bes

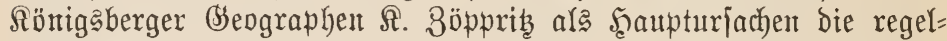

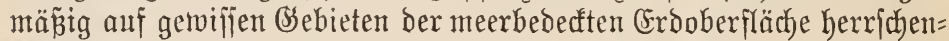

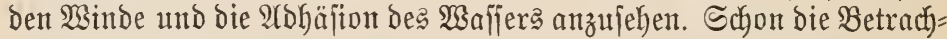
tung einer fiarte zeigt bent engen 3 ulammentang zwijchen den Windrich = tungen und den Meeresftrömungen. Die Sebiete zu beiben Seiten bes

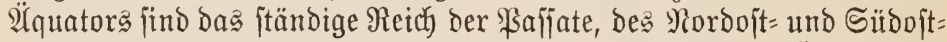

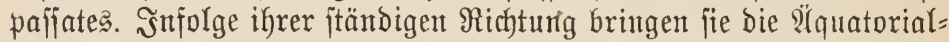

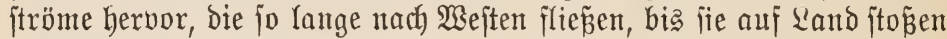

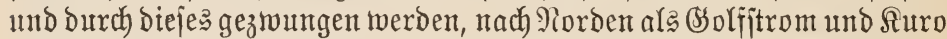

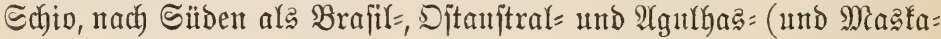
retten=) Stron auszuweichen. Aur im S̈ebiet des Snbijhen Dzeanz fommt Der Norbäquatorialftrom nicht fo recht zur $\mathfrak{A}$ usbildung; hier erzeugen

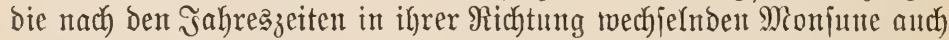

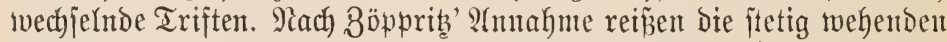

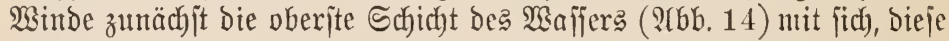

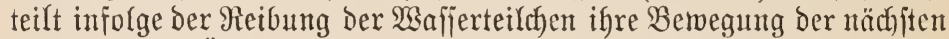
mit, unt biefe übertragung jeşt fich entiprechend ber Stärfe ber urfädd)= richen Bemegutg von Shicht zu Schicht bis zu verichiebener Tiefe fort. Nun Gleift aber in Wirfidfefeit weber bie Ridytung nod) bie Sraft ber Winde jtändig biejelbe; aber bieje Beränderungent fömten mur auj bie

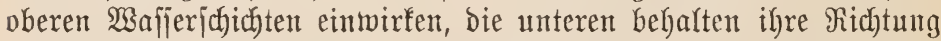
bei, Denn bie Strönung ift nidht bas Erzengnis eines gerabe hente herr=

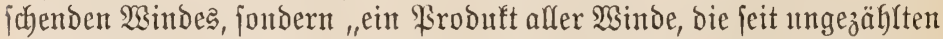
sabrtaufenden iiber bie betreffenden "Segenden hintueggeftrichen find" (Supan). Radh Böpprits' Beredymung witrde eine hente begimuende und jtetig we hende Quffjtrömutg erjt nach 239 sahren igre Wirfutg bis in 
die Tiefe von $100 \mathrm{~m}$ fortpflanzen. Somit toären alङ 5̧aupturiachen für bie Meeresjtrömungen bie ftändig wehenden Paffate der Ÿlquatorial= gegenden und die Wejtwinde ber höheren Bretten anzujeben. Dbjobn

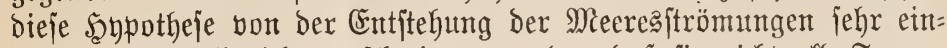
leuchtens ijt, foll nicht verjobtwiegen werben, bafis fie nicht alle Fragen flar beantwortet und Deshalb aud Wideriprud gefutben bat. Eine Ánzahl von 5 zeanographen jehen z. B. Die Şaupturjachen bex Meeres=

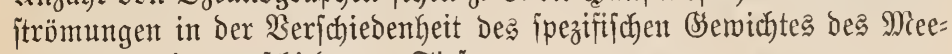
restwafiers in verichiedenent Tiefen.

गanjen glaubt oreiganzandere Uriachent für bie Sntitehung die= fer auffallenden Strömultg ber= antwortlich ma= chen zu müffen: die Eigentwär= ne Der Erde, Die

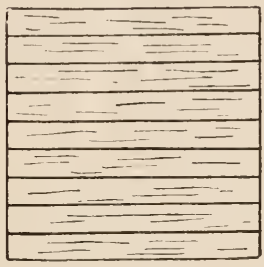

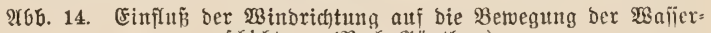
(d)ichten. (Mach Bituther.) anziehende Siraft der Şiumelsförper, aljo vornehmlich des Mendes, vor allent aber bie $\mathfrak{W a ̈ r m e j t r a b l u n g ~ b e r ~ S o n n e , ~ d i e ~ d i e ~ W i n d e ~ e r z e u g t , ~ e i n e ~}$ ungleiche Erwörmung ber 5 berfläche hervorruft und das Waffer verjchie=

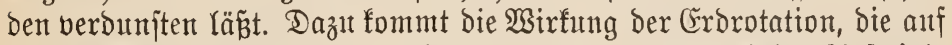
ber nörolichen .̧albfugel als nach Siten ablenft, Dann bie lalten

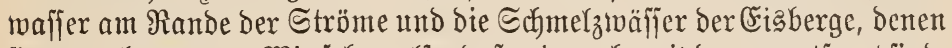
fie etwa begegnen. Wir jehen aljo, baj wir noch weit bavon entfernt find, Die Erjobeinung Der Strönungen flar zu erfennen. Se tweiter die Ströme, vom Sitrande ber Fejtlandsmaffen geleitet, fich vom ঐ̈lquator entfernen, bejto mehr bïben fie an Wärme ein und bejto fdywerer twird infolge ber Berbunitung ifr $\mathfrak{W a f f e r}$; in ben mittleren Breiten nehnen bie Dort berx= ichenden Weftwinde bie Bewegung ber Strömmung auf und beföroern fie

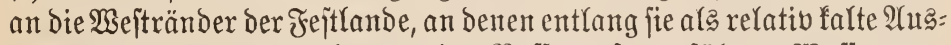
gleichitröme zux Dectung ber von ben Paffaten fortgeführten Waffermen=

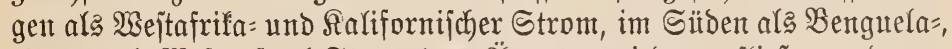

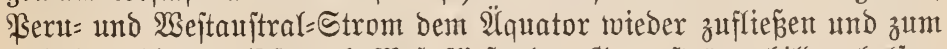

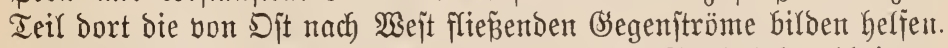
Bejonders die eben genannten $\mathfrak{A} u$ glelechjtröme der Süblhalbfugel bringen grof̉e Maffen falten Waffers in niebere Breiten; Der Stifle Dzean Dagegen

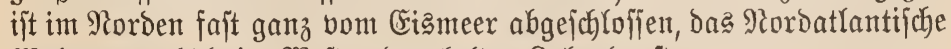
Weltmeer erbält im $\mathfrak{W e j t e n ~ d e n ~ f a l t e n ~} \mathfrak{a}$ bradorjtrom. 


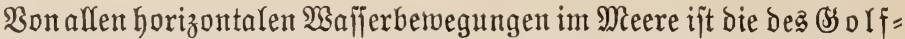
ftromes am längiten und am beften befannt, bejonders burch ältere

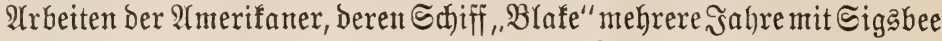
und Barlett an Bord ber Exjorjaung biefes Stromes gedient hat, Dann aber vornehmlich Durch die neuejten Interjuchungen von @ chott u. a. Die Einwirfung des Ssolfiptromes auf bas Âlima Europas ijt befannt. Seinten

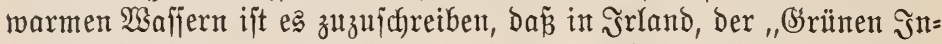

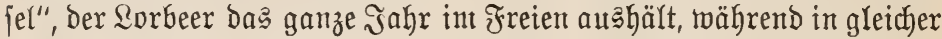

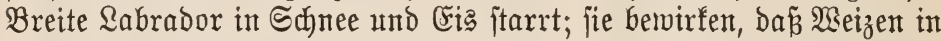
Normegen bis zum 64. Breitengrad, Serpte gar bis zum 70. angebaut

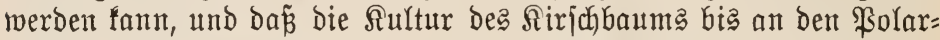
freis heranreicht. Da wix an biejem wärmejpendenden Strom alle bie Erfbeinungen, bie aud bei anderen vorfommen, an bejten fennen lernen fönnen, wollen wix uns jeinen Berlauj einmal etroa näher vor Alugen führen. Die beiben vereintgten $\mathscr{A} q u a t o r i a l j t r o ̈ m u n g e n ~ b e s ~ \mathfrak{Y}$ tlantif treten

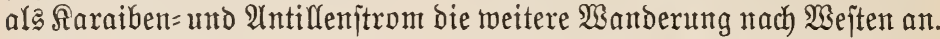
Erjterer, mit einer mittleren Tiefe von etwa $180 \mathrm{~m}$, zloängt fich burch

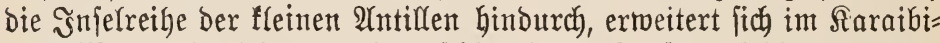

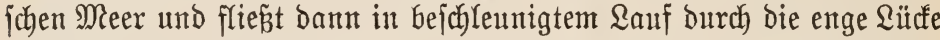

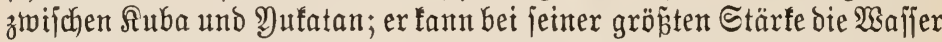

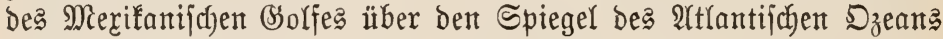
erheben. Geine Sejdnindigfeit hängt ab von ber Stärfe der Winde, die feinen $\Omega a u f$ unterftüben, ub erjtere forvie feine Srrenzen werben be=

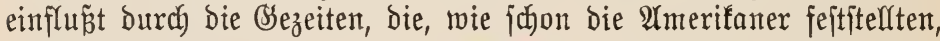

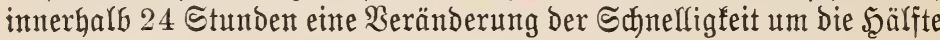
betwirfen tönnen. Der eigentlid)e (Solfitrom ijt feine unmittelbare Fort= jebung Des Saraibenjtromes, jondern er nimmt jeinen $\mathfrak{A n f a n g}$ im Meri= fanifden Ssolf. Nieberjaläge und Flüfje vermebren fier die : menge. Bon lebsteren Yiefert allein ber Mijififippi einen grof́nen Teil;

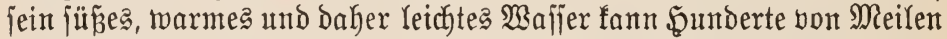
weit im Bsolf verfolgt werden. Bon ber Floridajtraß̄e an begiunt ber eigentliche Ssolfitrom; bei einer Ränge von mehr als 6000 gengraphi

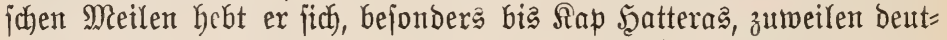

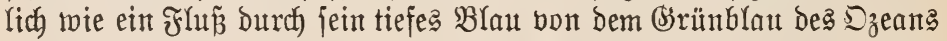

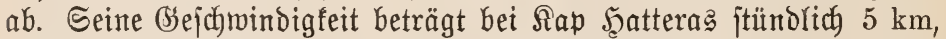
nimmt aber raid) ab: auf Der Breite von Nem Yorf beträgt fie $2 \mathrm{~km}$,

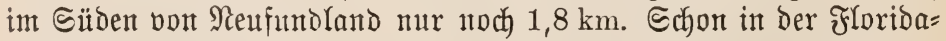

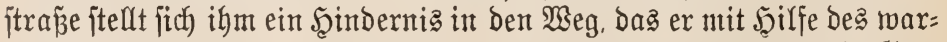
men Antillenjtromes, ber fich mit ifm verbindet, überwindet; fein Seg=

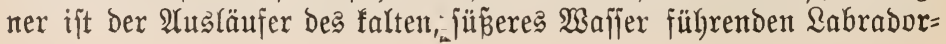




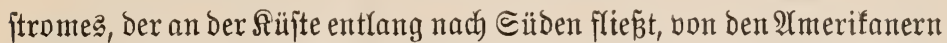
bie "falte Mauer" genamnt. 2Auffallend ijt bie $\mathfrak{W a ̈ r m e ~ b e z ~ B j o l f i f t r o m e s ; ~}$

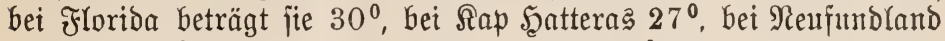
nur noch $20^{\circ} \mathrm{C}$; fie ift hier aber immer noch $15^{\circ}$ höher als bie bes um=

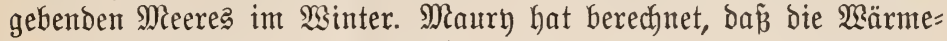
mengent bes (3) lfiftromes imftande fein wiurden, einen Strom auz flüffigem

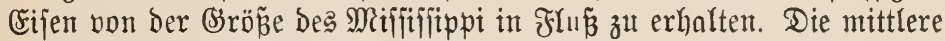
Dberflächentemperatur des ganzen ভtromes mirb auf $26,5^{\circ} \mathrm{C}$ angegeben. Seine mittlere Tieje mag $300 \mathrm{~m}$ und mehr betragen; bei Sap Şattera马 ift bie warme @chicht etwa $200 \mathrm{~m}$ mächtig. Bei Neufundland gelangt ber Bsolffitrom in bas Bsebiet ber Polarmaffer. Bugleich breitet er jich noch weiter fächerförmig atz und bejteft bon ba an aus meilenbreiten Streifen fayten und warmen Wafferę, bie jich autch durch ifre Farbe zu erfennen geben. So trifft er in einem Winfer mit bem falten $\& a b r a b o r=$ ftrom zufammen, ber aus der Bereintgutg des Srönlanditromes und Der ebenjo falten $\mathfrak{B a f f e r}$ aus Der Baffinbai und Daviabai gebildet wirb und feine größ̈te Mädftigfeit im Sommer entfaltet. Da fein $\mathfrak{S a f j e r ~}$ falzreicher ift als bie falten vom $\mathfrak{F o l}$ her fommendent, fo tautcht er all= mählich unter, und zmar am frühejten in ber Davisjtraß̧e, viel fpäter

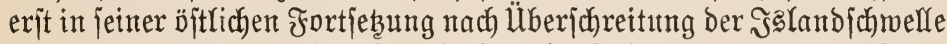

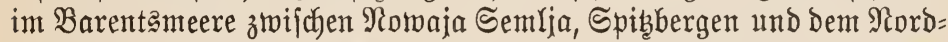
fap, und fest endlich feinen Rauf biz zum völligen $\mathfrak{A}$ ufgehen in ben

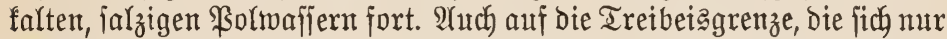
in feltenen Fällen bis zıtm $40^{\circ} \mathrm{n}$. Br. verichieben fann, obrobhl man ver= einzelte (siaberge auch nod unter bem 37. Breitengrad angetroffen hat, wirft ber (Solffitrom ein, intoem er fie weit nach Siorden zutrüđoröngt.

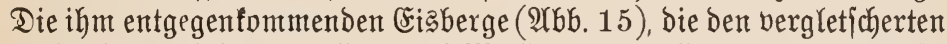

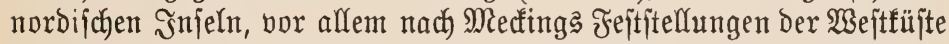
Şrönlands in der Umgebung Der Diśfobucht entiftammen und Deren mit=

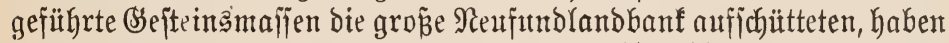
oft eine böbe bis zu $100 \mathrm{~m}$ und ragen, ba mur $1 / 8-1 / 10$ aut bem $\mathfrak{B a f j e r}$ herausfieht, mit mebreren Şundert Metern nach unten. So fönten jie beim Sdhmelzen eine gro gegenfab der Strömungen erzeltgt bei ifrem Bufammenjtoź iene biçten Neber, Die fajt immer bie Renfumblandbanf bebecfen unt ber Echiffahrt jo gefährlich find. Einem foldhen Eisberg fiel auch im Eommer 1912 bas Riejenfochiff, die Titanic, zum Dpfer. Zwar foll ein auffallendes Sinfen Der Dberflächentemperatur Den Schiffer yor bem Seerannahen von Eismafifen warnen, aber foldyes Sinfen der Temperatur beobachtet

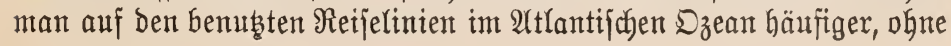




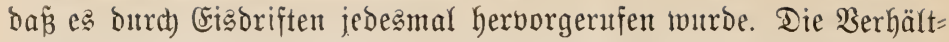

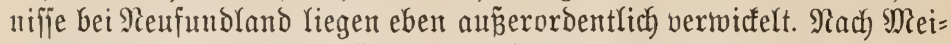

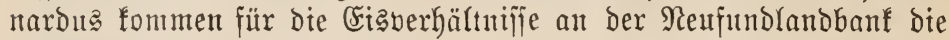

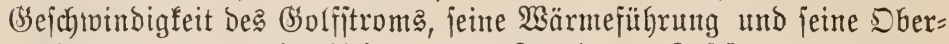
flächentemperatur, bie Ritchtung uno Stärfe Der \&uffttrömungen über

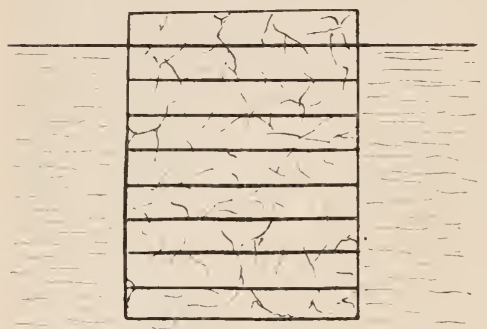

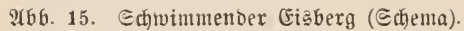

ihn, wentigftens im $\mathfrak{B i n t e r}_{\text {, }}$ in Betradyt, und alle bieje Faftorell fint mieber voneinander abhän= gig. Wie bą Jahr 1912 wegen ber Eisnerbältniffe ein bejonoer? ungüntiges für bie Sdifffahrt war, fo twar e马 auth das Jahr

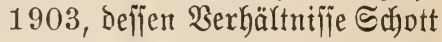
genauer unterjutdt hat. Nach bie= jen Unterjutchungen ijt bie abnor= me Eisorift des Jahres 1903 Durch eine in ben Monaten vor= her eingetretene ftarfe Brolfitrom= brift, bie aud den ifgr in bie Flan=

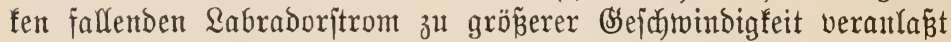
hat, wenn nicht hervorgerufen worden, jo boch begünjtigt.

Schon in der ફ̧öhe bes 43. Breitengrabes tritt eine Brabelung unjeres Stromes cin; ber eine $\mathfrak{A}$ jt, "bie Byblfitrombrift", jebst jeinen Lauf, wie wir fahen, Wärme fpendent, nach Norben fort, ber andere wendet jith nach Süben, umfreift bie Sargaffofee und fließ̄t an ben Rapperbent alz Meftafrifajtrom zum S̈lquator zurürf, um ba ben Sreisłauf von vorne

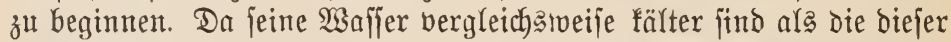

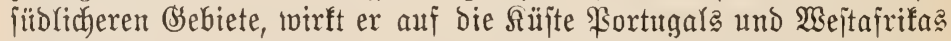
abfüblend ein. Dent $\mathfrak{B e g}$ von Floriba bis Enropa legt biejer Strom in etwa $5 \frac{1}{2}$ Monaten zurü̆f; ber ganze Sreislanf wiro inach Şumboldot? Berechnung in etwa 34 Monaten vollendet. Cine bei Sap Berbe im Mai 1887 ausgelebte Flajdhe landete erft nach fajt brei Jahren an ber

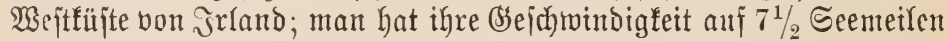
pro $\mathfrak{T} a g$ oder ftünolich faft $1 / 2 \mathrm{~km}$ für ben Fall berechntet, bá̃ fie itgren Weg wirffich Durch bae Raraibifhe Meer und bie Straß̉e von Floriba genommen hat.

Die Tiefen it röme ber Dzeane lyaben im allgemeinen bie ungefehrte

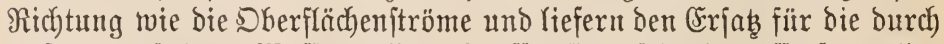
dieje toeggefülyrten $\mathfrak{B a f f e r m a f f e n . ~ T r e f f e n ~ f i e ~ a u f ~ S ̧ i n d e r n i f f e , ~ f o ~ q u e l l e n ~}$

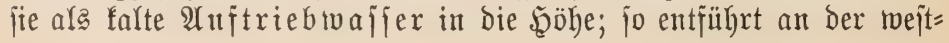


Die horizontalen und vertifalen Bemegungen im Meerwaffer 55

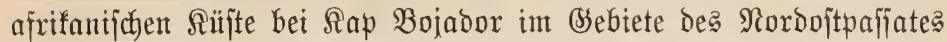

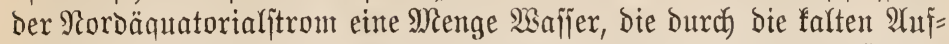
triebroffer erjeßzt wiro. Wo die Tiefenjtrönte burch enge Strẩen zu fließ̈en geztwungen find, fömen fie oft einen ichnelleren হauf annehmen als bie Dberjtröme. Das beobachtete betjpielmeife $\mathfrak{B h a r t o n}$ an Den Unterftrom, Der Dem aus dem Schwarzen Meer dutrch Den Bosports in Das Marmara=Meer und von ba burdy bie Darbanellen ins Mittelmeer fich

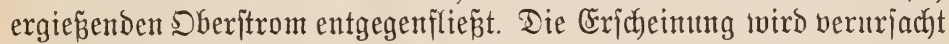

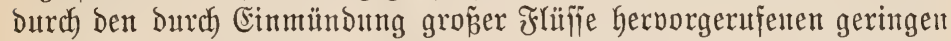
Salzgehalt Des Sdywarzen Meeres; die Dbermaffer find faft jü̈j, die

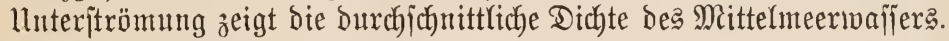
Auct) an Der Meftpforte Des Mittelmeeres, in ber $111 \mathrm{x} 311 \mathrm{~m}$ tiefen

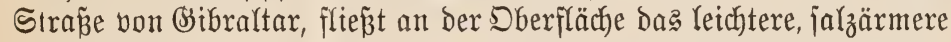
Wafier des YYtlantifchen Dzeans in Das Mittelmeer hiuein, während das

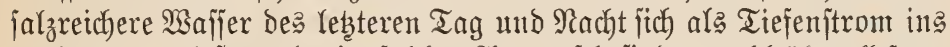

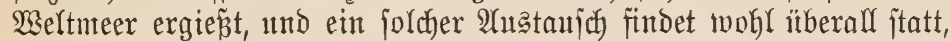
two zwoe Meerbecten von ungleicher Wajjerbichte Durch eine enge \$Fforte miteinander in Berbindung ftehen, fo auch zwifhen Norb= und Ditjee Durch Sfagerraf und Rattegatt; Diefe Unterivajieritrömung ift es auch,

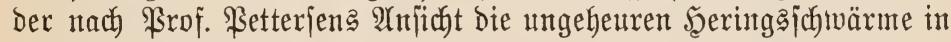
bie Sitfee folgen.

Wie in Den genannten Binnenmeeren, jo wälzen fich aud beftändig auf Dem Sirumbe ber offenen Dzeane die falten 2 hagleidftwaffer von ben

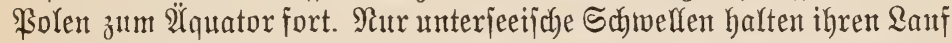

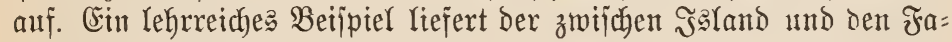

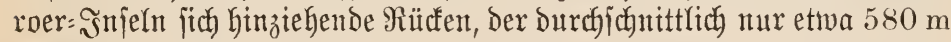

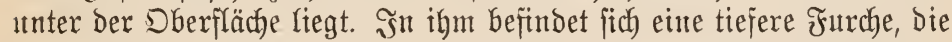
Faroer=shetland= Rimne, die die mehr als eisfalten Polarmajier auf ihren Drängen nach Sitden geid)affen haben. Suer burch jie zieht aber

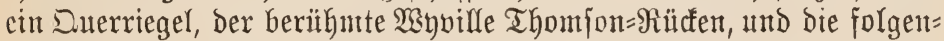
Den Temperaturen, die Prof. Sdyott auf Der Balbivia fand, zeigen, wie

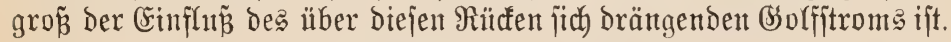

\begin{tabular}{|c|c|c|c|c|c|}
\hline & & $\begin{array}{c}\text { Sitolid } \\
\text { vom }\end{array}$ & Thomion=? & $\begin{array}{l}\text { Räroblich } \\
\text { iücten }\end{array}$ & \\
\hline $0 \mathrm{~m}$ & Tiefe & $10,9^{\circ}$ & & $98^{0}$ & \\
\hline 100 & 2.10 & $9,7^{0}$ & & $7,8^{0}$ & \\
\hline 200 & " & $9,7^{\circ}$ & & $7,6^{0}$ & \\
\hline 300 & 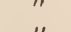 & $9.6^{0}$ & & $68^{0}$ & \\
\hline 400 & 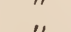 & $\left.9,6^{0}\right)$ & Warnter & $3,2^{0}$ & Ralter \\
\hline 500 & " & $\left.9,0^{\circ}\right\}$ & llnterftrom & $\left.0,4^{0}\right\} 1$ & llnteritron \\
\hline
\end{tabular}

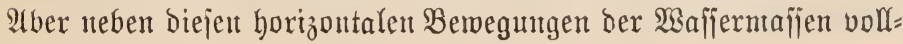


zieht fid infolge von Berdunjtung und 2rbfïhlung der Dberflächenichidbten

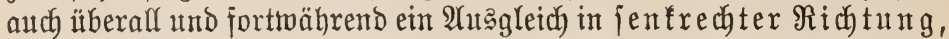
alleroings nidyt als jichtbare Strömung, fondern viel langiamer, in ber Schnelligfeit fajt unmȩ́bar. Crr bemirft zulammen mit ben eben genann=

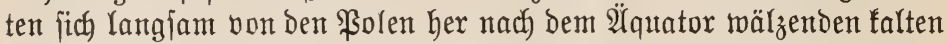
Tiefenftrömen, Durdb Das 2Uufmärtsfteigen ihres falten $\mathfrak{B a f j e r s ~ h a u p t = ~}$ jächlich in Den 2 qutatorialgegenden, jowie bort, two bie Winde bas wär= mere Dberwafier wegorücfen boer Ströme es entfüthren, bie auffallende

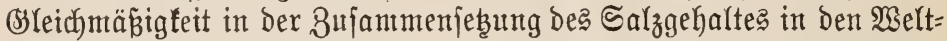

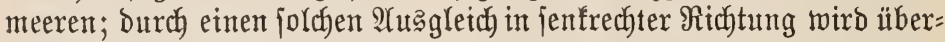
Gaupt erjt Die Exijtenz Der Tiefenbemohner möglidh, Denten bie Bertifal=

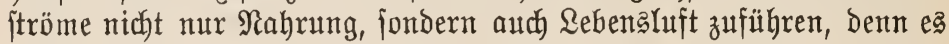
hat fich Gerausgeitellt, Dás bie Tiefentwafjer genau fo viel \&uft enthalten wie bie ber Ðberflädhe, einte Erjobeinung, bie uns mit Notwentsigfeit zu

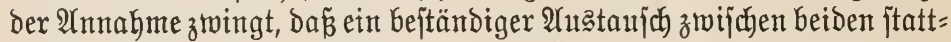
finden muz und, wie wir fahen, auth mirflich ftattfindet.

\section{VI. $\mathfrak{A b j u n i t t . ~}$}

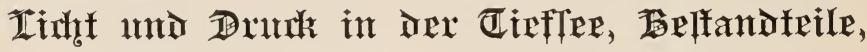

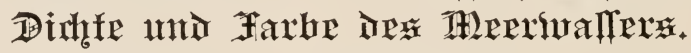

"Einer Der widhtigiten und tätigiten $\mathfrak{A}$ rbeiter im grof́en $2 a b o r a=$

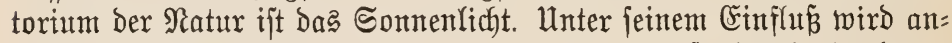
organifhe Materie in organijhe umgejebt, und jo berufht in Yebgter Linie alles Reben auf Erben auf jeiner (Segentwart" (Marjhal). Unt= terfuchungen über bie Richtberbältniffe der Tieffee wurben bereita in Den vierziger Jahren angejtellt. Je tiefer wir ing Meer hinabjteigen,

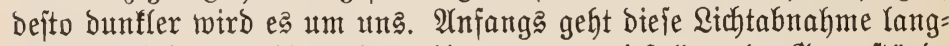

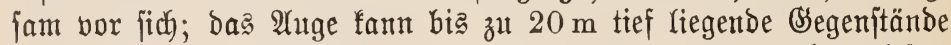
noch erfennen, vermöchte dort unter umitänden fogar noch zu lejent. In Diejen geringen Tiefen enthüllt fich Dem 2 Atge die ganze Farben=

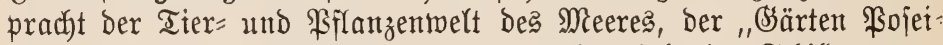
Dons"; wer fentut nidht bie begeifterten, farbenglïhenton Echildoerungent

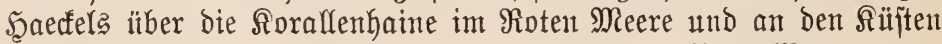
von Ceylon? Nur aumahmatweife, bei bejondera ruthigem Wetter, guter

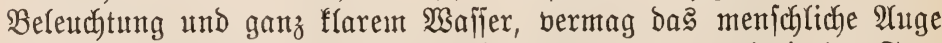
nod) tiefer, etro bỉ zur äuserjten (Srenze von $60 \mathrm{~m}$, wie in ber Sar= gaffofee beobadftet wurbe, zu bringen und größ̄ere Bsegenftände am Boden wahrzunehmen. 


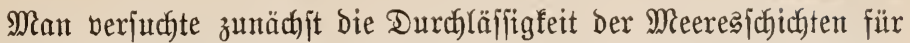
bas $2 i c h t$ burdy Serjenfen von weifien und anders gefärbten ßlatten zu ermitteln. Arber bie Tiefe, in ber bie Scheiben fichtbar bleiben, ift örtlich grofenen Schroanfungen unterworfen: fie liegt im Mittelmeere zwijchen 32 und $60 \mathrm{~m}$ und jtebt natürlich in engem 8 jammenthang ntit Der Menge Der unorganijichen oder organifden im Wajfer gelöpten ober ichrwebenden Stoffe. Da bie fälteren Meere im allgemeinen reicher an jobrobenden Drganismen find und fich aud langjamer jelbit rei= nigen, find fie auch weniger Durchjichtig als bie Der tropijuch Ssebiete. Um dieje Schwanfungen fejtzujtellen, madhte vor einigen Sabren $\mathfrak{A}=$

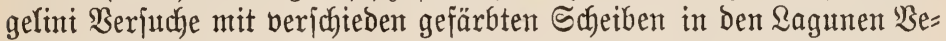

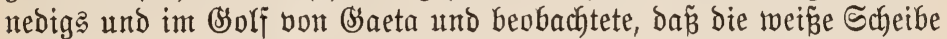
bort fachon in $2 \mathrm{~m}$ Tiefe, im Solf aber erjt viel tiefer verichmand. Bon

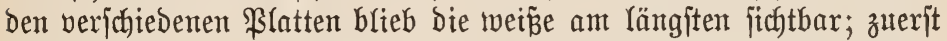
verjatwand bie rote, barauf bie blaue; das Meerwajfer verjoludt aljo bie roten Strahlen am meiften, baher erflärt jich auch jeine grünblaue Farbe. Die \$lattenverjuche find Inegen ifrer Ungenautgfeit von nur

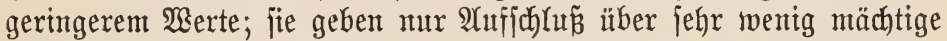
Wafferjudiden, da die Iafeln bem $\mathfrak{A}$ uge bald entrïft find. Da aber wandte Forel zuerjt im Sienfer See photographifhe \$latten an, die

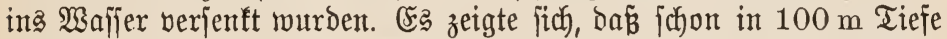
das Sicht auf die \$latten nicht mehr einmirtte. Das Mittelländijche Meer hat eine größzere Durchfichtigfeit; Berjuche, bie auf Forels $\mathfrak{A n}=$

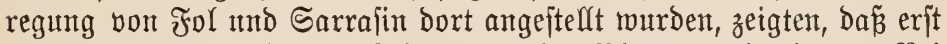
in etwa $480 \mathrm{~m}$ Tiefe feine ๔chwärzung der ßlatten mehr eintrat. Bei

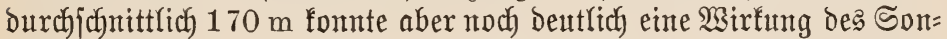
nenlichtes nachgerwiefen werben, bei $380 \mathrm{~m}$ Tiefe faum noch; es bürfte Dort Das Qicht Demnach mux io jtart jein, wie bei uns in einer Sternen= nacht zur Zeit des Neumondes. Später hat v. Beterjen einen photo= graphifden $\mathfrak{A}$ pparat hergeitellt, ber ermöglidhte, bie jehr empfindliche ßlatte in jeder beliebigen Tiefe zu exponieren; er jebste fie an einent hellen Novembertage bei Capri längere Beit in einer Tiefe von $500 \mathrm{~m}$

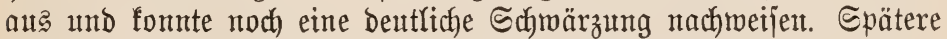

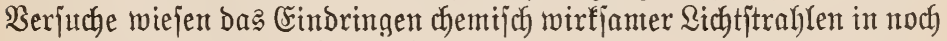
etroas gröperere Tiefen $(550 \mathrm{~m})$ nach.

Dieje geringen Ridhtmengen find aber für bie vor allem auf bas Sonnenlidyt angerwiejenen Pflanzen viel zu gering; jobn bei $150 \mathrm{~m}$ Tiefe bürfte das Bflanzenleben faft ganz aufhören, und in grözerer Tiefe würbe man nur noch farbjtoffloje niebere pflanzliche Drgantimen vor= finden. Eine $\mathfrak{A}$ unahme madyt nur die fpäter nod zu ertö̈hnende grüne 


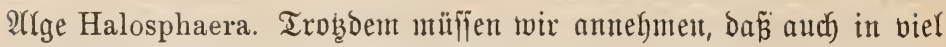
bedeutenderen Tiefen eine gewijןe Beleudhtung vorhanden ijt; die Âugen Der Tieffeetiere, ifre Farben zwingen un mit Notwendigfeit baju.

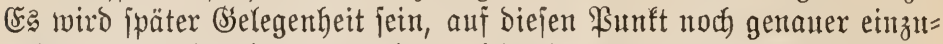

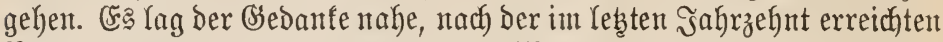
Berbolfonmuntu ber \$hotographie Momentaufuahment vou ben in geringer Tiefe rebenden Meerestieren zit madyen. Mit Šilfe twaffer=

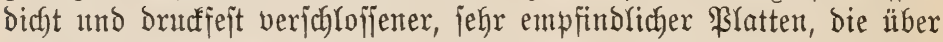

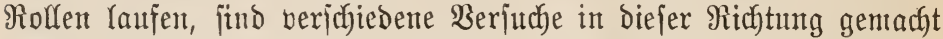
worben und haben ganz ermutigende Erfolge gehabt. Auf einer bex von feiten Der Franzojen in Banyulesur= Mer hergejtellten jubmari= nen Photographien find bor bem aufgeftellten @ifirm vorbeiziebende

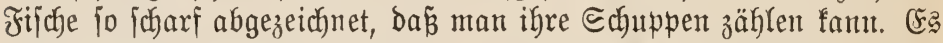
fdreint Denmady die \$hotographie bernfen zu fein, in Bufunft ein wich)=

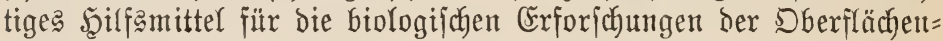
fauna zut werbent.

Den Berjuchen ter Menjchen, perīönlich in bie Tiefen de? Meeres vorzubringen und bort an Drt und Stelle fente $\mathfrak{B u n d e r ~ z u ~ b e t r a c h ~}$ ten, wirs gar bald ein energifdes Scalt zugerufen. Sinx geübte Tau= cher vermögen in größ̧ere Tiefen als $20 \mathrm{~m}$ einzudringen und bort auch mux wenig über cinte Biertelítunde zu verweilen, ba bald die

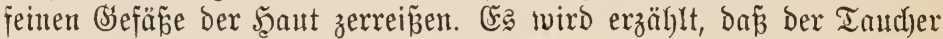
Deschamp, ber in Şahre 1866 einen $70 \mathrm{~m}$ tief gejunfenen Dampfer unterjuchen rollte, au $60 \mathrm{~m}$ Tiefe betwütlog heraufgezogen twerdent

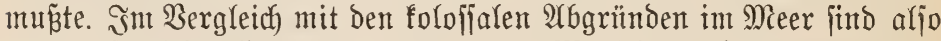
dem perjönlichen Futbringen jeitens des Menjichen äuŕserit enge Brent= zen gezogen.

Befauntlich lajtet mijere \&ufthülle auf jebem Duabratzentimeter un= jeres Sïrpers mit einem (Śewid)te von ungefähr $1 \mathrm{~kg}$; diejen $\mathfrak{D} \mathfrak{r}$ uf nenten wir futrz eine $\mathfrak{A}$ tmofphäre. Der Drud im $\mathfrak{W a j f e r ~ n i m m t ~ n u n ~}$ jefr rafdy zu. Das Meerwafier ift wegen feitte Salzgefaltes etwas

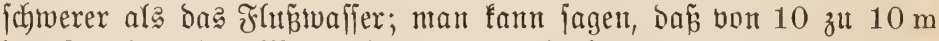
ber Drud in Den Meerestiefen unt rund eine Atmoiphäre zmimut. Das macht it $100 \mathrm{~m}$ Tiefe jdyon eiten melyr als zelumal gröperen Druaf als an ber Dberfläche, und in Den gröpjten Tiefen Der Dzeane, die ja ungefähr $9000 \mathrm{~m}$ betragen, laftet auf jeden Duabratzentimeter ein Drud von über 900 2Atmofphären. Davon fönmen wir uns jałwer

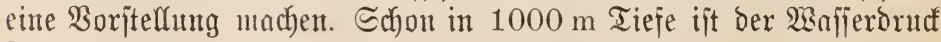

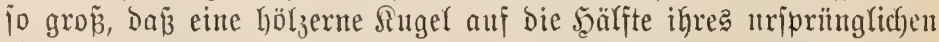

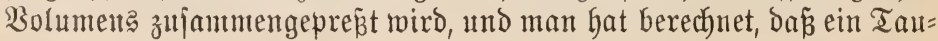


dher, ber in bie Tiefe von $3560 \mathrm{~m}$ hinabiteigen würbe, ein Ssemidyt

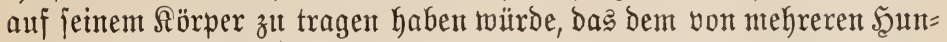
bert ber j(d)weriten ¿ofomotiven gleich)fäme. Die Tieffeeinjtrumente miiljen natürlich fïr biejen enormen $\mathfrak{W a j j e r d o u d ~ e n t j p r e c h e n d ~ e i n g e = ~}$ richtet und regufiert jein, utb boch ift e马 vorgefommen, ba $\tilde{\beta}$ bie burch metallene Sapjeln gejchübten Thermometer, bie in grope Tiefen hinab= gelafien wurben, vollitändig zertrïnmert wieber an bie Sberfläche

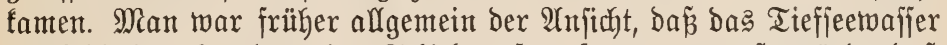

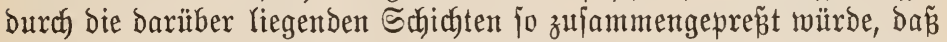

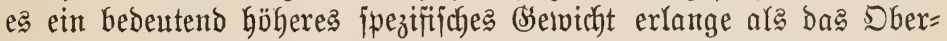

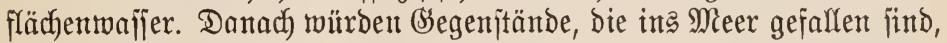
gar nicht bis auf bent Bround gelangen, jondern je nach ifrem (Šelvichte in irgend einer Sdjidgt, bie ipezifijich gerabejo jatwer wäre wie fie jelbjt, jujweben miiffen. Demgegenïber ijt aber nachgetwiejen, baź bas

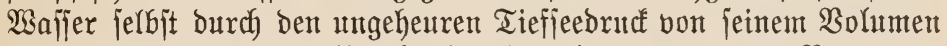
nur einen ganz geringen Brudbteil verliert, ber in $9000 \mathrm{~m}$ z. B. nur un= gefähr $1 / 24$ Getragen würde. Das Getwidht bes Tiefentwaffers ftellt aljo

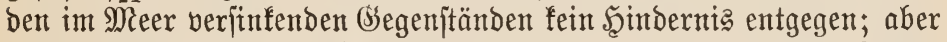
ob fie wirffich auf bem (S) rund anfommen, bas ift eine andere Frage. Die organifichen Stoffe werben wohl im Magent ber Milliarden von Meerestieren ifr Brab finden, und es ift wahricheintich, bas von den anorganifchen nur wenige auf bie Dauer ber Berjebutg burch bas See waffer und ben in ifm wirfenden d)emifhen finäften wideritehen tön= nen. Smmmerhin wiro durch biejen Druft bie Dichte bes Meerwaffers, bie gewöhnlich 1,024 bis 1,028 beträgt, in ber Tiefe von $350 \mathrm{~m}$ auf 1,0446 erhöht. - Die Tiere, bie, wie wir hente wiffen, noch in Tiefen vorfommen, bie man früher für unbemohnt halten muß̃te, föntnen bie= ien Drud beshalb ohne alle Befdwerbe aushalten, weil ifm in ihrem Sörper ein gleich groper entgegenjteht. (Es ift nutr fraglich, ob fich ber Stoffimedjel bei biejen Tieren gerabejo vollziegt wie bei benten, bie unter ungleid) geringerem Druft nahe Der Sberflädhe Yeben; aber das ift ein $\mathfrak{B}_{\text {unft, }}$ itber bem bis heute noch volffommentes Dunfel herricht

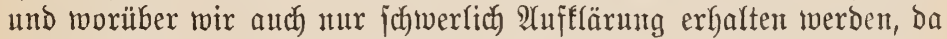
wir berartige Unterjudhungen un an heraufgebolten Tieren anjellen fönnen, bei benen ber abnehmente Drucf fajt immer alle Besetwebe zer= riffent hat.

Die Didn te bes Meerwafijers hängt in eriter Sinie, wenigitens nahe Der Sberfläche, yon jeinem ভalzgehalt ab. Stuf fie roirfent beshalb

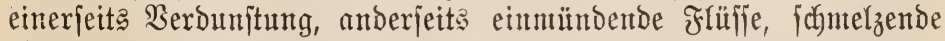

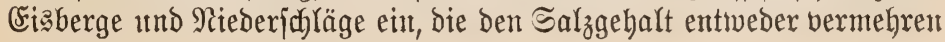




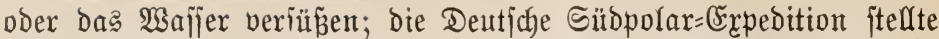

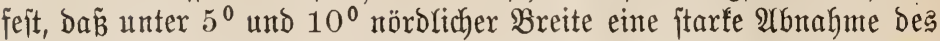
Salzgehaltes des Dberflächentwafiers infolge der bamals gerabe herr= ichenden Regenzeit eintrat. Der Salzgebalt aller Meere beträgt burch)= ichnittlich $3,53 \%$; man hat ausgerechnet, baz biejes Salz, wenn es

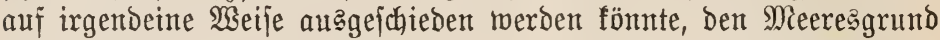
mit einer $57 \mathrm{~m}$ bicfen Schicht Kedecfent würde. Die Siiftentwajier find im allgemeinen jalzärmer, bejonders in ber Nähe ber Mämbungen

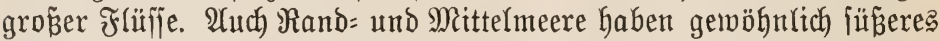
Waffer, weil die einmündenden Flüfje jolches zubringen. CFin gutes Beifpiel bietet bie Ditfee, beren Salzgefalt nach Diten immer mehr

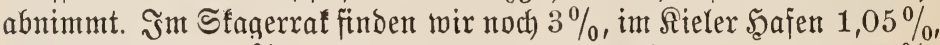
bei Bornholm $0,7 \%$, am Eingang zum Bottnifben Meerbujen 0,4\%, nno bei Sromjtabt ijt bas $\mathfrak{B a f j e r}$ mit $0,1 \%$ fajt trinfbar. 2Uuch bas Schmarze Meer hat jeiner itarfen Buflüfipe halber nur einen Salzge= halt von 1,5 bis 1,8\%. Binnenmeere bagegen, bie itarfe Berbunitung bei geringem 3 ufflú haben, find jalzreicher; fo zeigt bas Mittelmeer

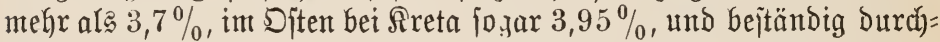

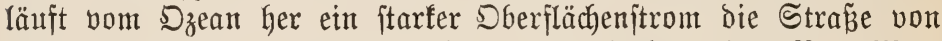
Bsibraltar, beftrebt, Den Unterichied auszugleichen. Dả Rote Meer

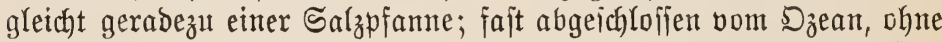
nennenswerte 3uflüfie, Dabei mit enormter Berbunjtung burch bie jen= genden Strahlen Der Sonne, hat es einen Salzgehalt von $4,08 \%$, im Suezfanal jtellenmeife jogar fajt $6 \%$. 2Uuth in ben offeren $D_{z e a n e n}$ find Salzgehalt und Didyte an ber Sberf(äche nicht itberall gleich; Die Schmantungen find hier auf biejelbe ltriache zurüdzuführen. Die von Buchanan entworfenen Sarten zeigen, Dás ber Salzgehalt in ben nie=

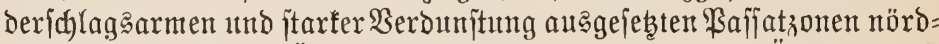
(idc) und jüblich vom L̈lquator am gröpten ift; nach bem Q̈ंquator und

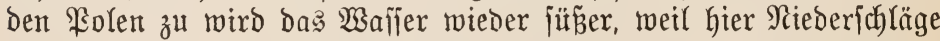
ber Berbunitung Das (S)leidfgemidyt halten oder fie gar übertreffen. Die Salz rrmut bes nördltchen Bolarmeeres wirb aber nicht allein burch

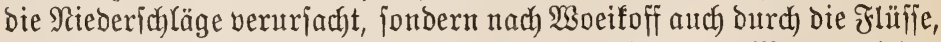
bie im Frühjahr viel Süftwafjer liefern; diejes friert im $\mathfrak{W}_{\text {sinter miedel }}$ und fann jibh beshalb mit ben jhyereren und falzhaltigen Tiejens

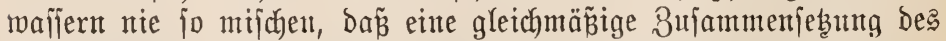
Polarwafiers eintreten fann. Die mächtigere Cnntrvidflung Der $\mathfrak{B} a$ ffiat= zonen auf Den offeneren $D_{z}$ eanen ber füblichen Şalbfugel berwirft aud),

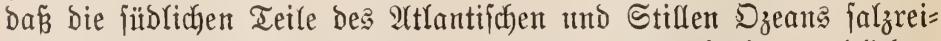
chere Sberflädyenjchichten haben als bie ihnen entiprechenden nörolichen. 
Der $\mathfrak{A}$ thantif hat in feinem norbäquatorialen Ģebiet höheren Sal $=$ gehalt als bie anteren Weltmeere wohl aud aus bem Brunde, weil

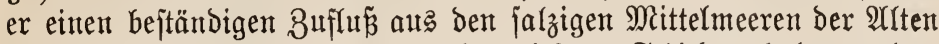

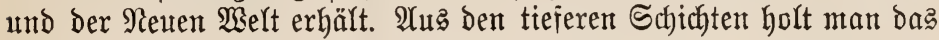
Meerwajier mit jinnreich fonjtruierten Schöpfflajchen und Schöpfap= paraten zur Unterjuchung heraus. Die Unterfichiede des Salzgehaltes an ber Dberfläche finto in einer Tiefe von wenig hundert Metern fajt

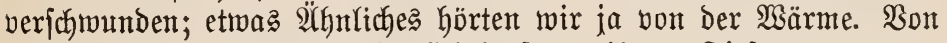
ba an bleibt ber Salzgebalt ziemlid fonjtant; bis zur Tiefe von $2000 \mathrm{~m}$ finbet eine geringe 2 (bnatgme und von ba bis zum Srande eine eben= fo geringe Bunahme jtatt. Der Salzreichtumt ber Bodenichichten ift

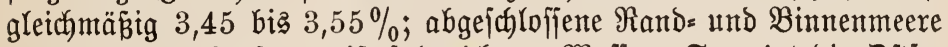
führen in ben Tiefen meift falzreicheres Waffer. So zeigt bie Ditjee bet Siel an Der Dberflärhe $1,65 \%$, in ber Tiefe etra $2,5 \%$ Salz= gehalt. Waß die Natur ber im Seewaffer aufgelöjten Stoffe anbelangt, jo hat man bis jest mehr als 30 Elemente in ihm nadgemiefen, ein= zelue allerbings nur in fehr geringen Mengen. Share Atuwejenbeit er= teilt bem Seemafjer jenen bitteren, zum Erbrechen reizenden Siejchmadf, Der es zum Trinfen untauglich madht. Sit jo ber Bsehalt an Salz recht ungleid), jo ijt boch bie $\mathfrak{A}$ rt ber 8 ulammenfebung im allgemeinen recht

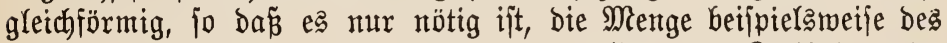

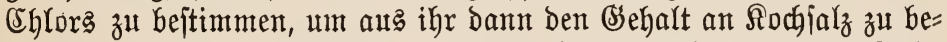
rechnen; bie anderen Stoffe fant man bei ber Beptimmung bes Salz= gehaltes bann ganz vernadbläffigent. Went man eine Menge Seemafjer

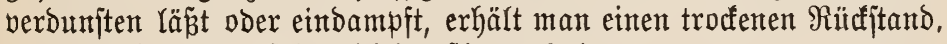
von bem je $100 \mathrm{~g}$ jehr gleichmäß̄ig enthalten:

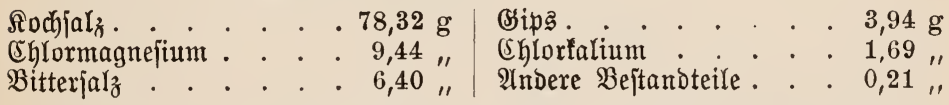

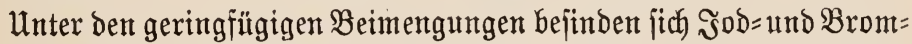
verbindungen, geringe Mengen von Mangan, Blei, Silber, Zinf, Sup= fer ufm., aber auth Sdelmetalle, wie Silber und (sold, bie wohl aus ben vom fejten Rande vom fliez̈enden Wafjer abgewajchenen Sedimen=

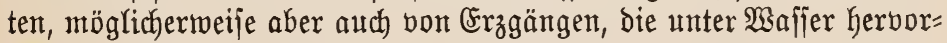
treten, herrühren. Freilich ift bie Mienge fehr gering, etwa $0,006 \mathrm{~g}$ Brold im Serte bon 1,668 Pfentig find in $1000 \mathrm{l}$ entfalten; aber man

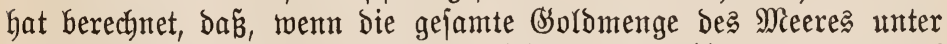
bie Crrdenberwohner verteilt würbe, auf jeden etwa $3 \frac{1}{2}$ Millidnen Marf

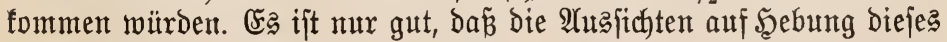

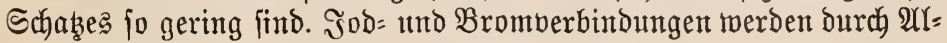


gen aufgenommen und bei beren Arbjterben am Brunde des Meeres aufgejpeichert, bon wo jie gelegentlid burch 2luftriebraffer wieder em= porgehoben werden; Yebeteres gilt aud bon ber jalpetrigen Säure ber Tiefenwajier, bie Dort aus ben Milliarden verwejender Tierleichen mit

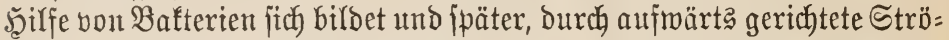

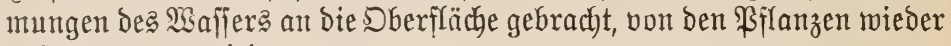
anfgenommen wirb.

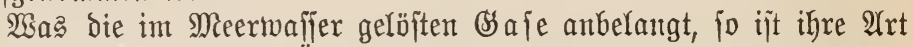
und Menge je nach ber D̈rtlichleit, der $\mathfrak{A}$ maghl ber Tiere ober pflanz= lichen Drganiamen fefr verjefieden, und wir find noch weit bavon ent=

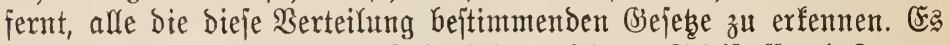

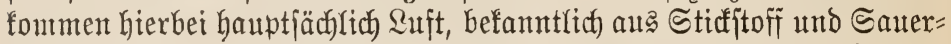
fton bejtehend, Sohlendioxys unt Schwejelwajieritoff in Betracht. Die Quft ift int Mieerwajier löslich, aber es wirb bort mehr Saueritoff auf

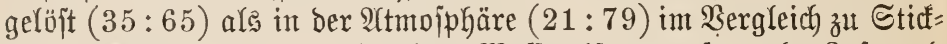

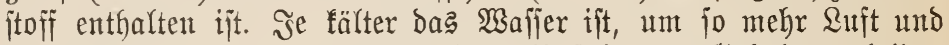
Sauteritoff fann es aufnefmen; Deahalb jteigt ber Behalt an beiden mit zunehmender Tiefe. Ter Şehalt an \&uft wird Durch die Beptim=

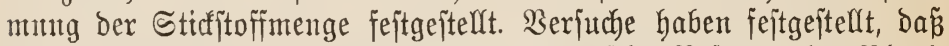

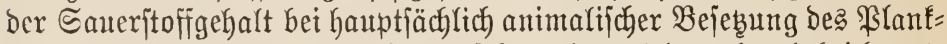
tons burch $\mathfrak{A}$ tmung? gerbrauth bald jehr gering twirb, während bei haupt=

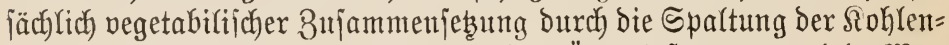

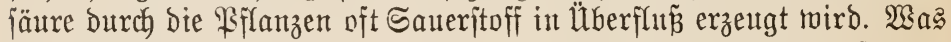
bie Siohlenfäure anbetrifift, Das Probuft ber tierijhen 2 tmung, fo war man noch vor wentigen Jahren ganz allgemein ber $\mathfrak{A}$ njicht, baz̃ in ben fal= ten Tieien Der Dzeane burch ben ungeheuren Drutf eine grope Menge Diejes (Sajes autigejpeidjert jein miifie, zuntal bie wärmeren Meere ärmer baran find als bie falten, und man erffärte auth daraus bie grop̃e Salfarmut ber Tiefen, bie fith in ben immer bünner merdenden $\Re$ alf $=$ panzern Der Tiere und in Dem Fehlen ber Foraminiferenfahalen in groß̈en Tiefen zu erfennen gibt. Zahlreiche 2tualyjen haben aber er=

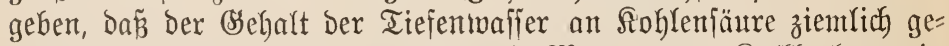
ring ift, jebenfalls nidyt geniigend, bie Mengen bon Salffurbonat in

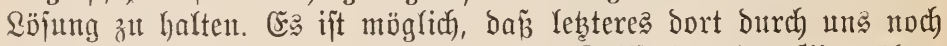

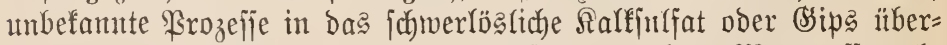
geführt ift, Den ftäntoigen Begleiter unjerer aus dem Mieerwafier $a \mathfrak{b}=$ geidhtebenten Eteinfaljlager. Bei Unterjudyungen ber Etiffïtofimengen

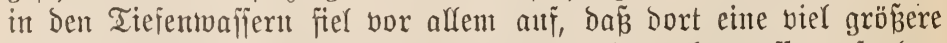
Mienge Eticfitoffis in Bergleid) mit ber ber Dherflächentwafier gefunden tourbe; bie Berteilutg beider (Saje ijt aljo aud im Tiefentwajier anders 
als in ber $2 u f t$, wo mur rutb fünfmal fo biel Sticfftoff wie Saueritoff vorhanden ift. Dieje auffallende Menge Sticfiftoff fann nicht allein den Sinffitoffen entítammen, bie bie Frlizffe dem Meere zuführen, anch nidft Den Sïrpern abgejtorbenter $D$ rganismen, jondern entfteht nach Benecfes uno Reutners 11nterfuchungen Durch bie Tätigfeit von Balterien, bie,

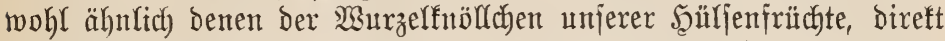

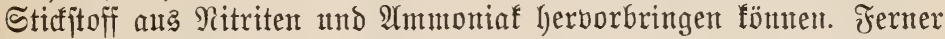

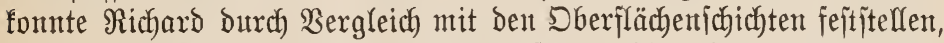

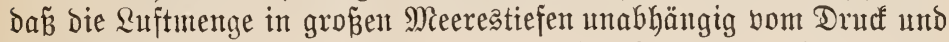

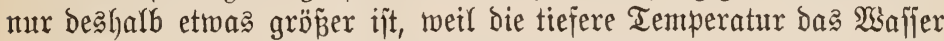

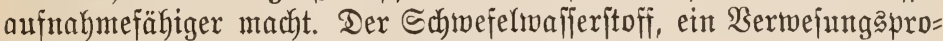

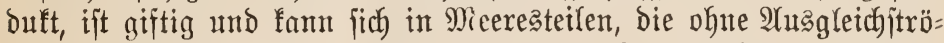
ntungen find, in ber Tiefe anjammeln, fo z. B. im Schmarzen Meere.

Bornebmlich bie Beimengungen ber oben genannten Ealze betwirfen,

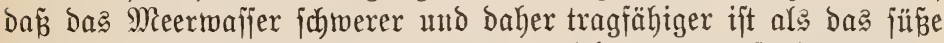
Waffer; $1000 \mathrm{ccm}$ von eriterent wiegen nicht $1000 \mathrm{~g}$, jondern 1024

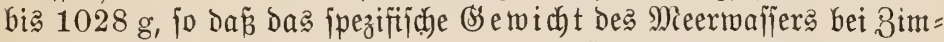
mertemperatur 1,024 bia 1,028 beträgt. (5) wiro bejtinumt mit Şilfe fein graduierter 2(räometer. Der Salzgehalt betwirft aber auth), bả ba Seewaffer mentiger leidft gefriert, in rufigem Zuitande, bei etwa -

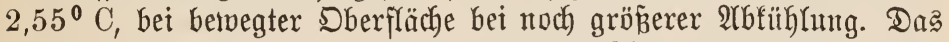
Salz wird beim Bsefrieren gröptenteila ausgefdhieben, vermehrt fo bas (Sewwicht ber nodh nicht feit getworbenten unteren Echichten und läpt jie noch jafwerer gefrierent. (Fin Teil bes Salzes bleibt jedoch ztwifhen ben

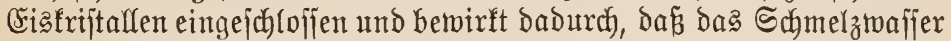

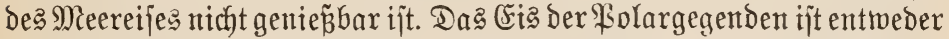

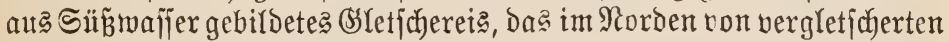
Landmajien in S̈rönland, franz= Jojeph=:and, Spib̧bergen u. a. itantmt

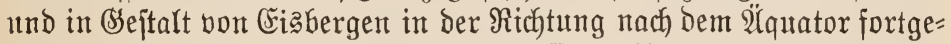
führt wirb, oder es ijt aus jalzigem

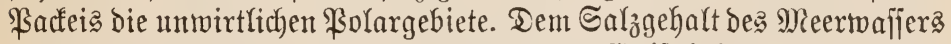
gegenüber verhalten jidh bie Tiere veridjieden. (Es ijt befannt, da manche

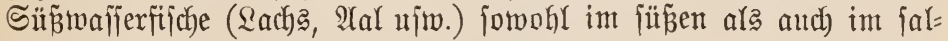
zigen Waffer zu Yeben vermögen un Sanderungen aus einem inz andere unternegmen, ambere (Şecht, Barja) fömnen leicht an Eeewajier getwöhnt merben; gewifije Seefijhe (Flundex, Scholle u[w.) mandern meit in bie Mïndungen Der Flïfje Ginein. Interefjant ift bie $\mathfrak{B e r}=$ breitung ber Tiere in Der Ditjee, bie, wie wir fahen, im Ditent fajt

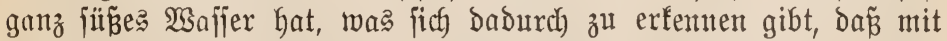
Dem Forjdyreiten nach Diten ber Artenreichtum und bie Bahl Der In= 
bividuen geringer wiro, wobei zugleid) bie einzelnen 2 (rten an Şröß̈e abnefmen und teilweife zmerghaft werden.

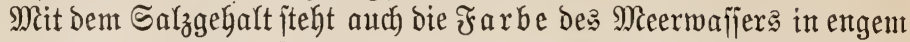
Bujammentyang. 2(uf jie mirfen aber anterdem nod manthe andere

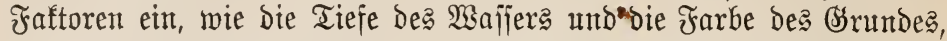

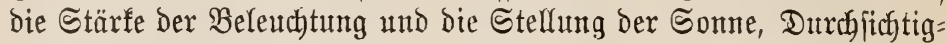
feit, Temperatur und Berwegung des $\mathfrak{B a f f e e s}$ unt in ifm jhrvebende

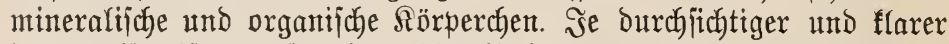
daz Wafjer ijt, um fo reiner blau ift jeine Farbe; je unburchjitchtiger, bejto mefr ift die Neigung zu grün vorhanden. Um die Farbe bes Meerwaifers feitzuftellen, hat man einen Qidhtitrahl burdh eine meter=

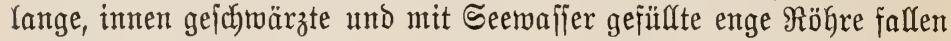
Yaffien, uno man beobachtete einte prachtoolle blaugrüne Färbung, bie aljo als jeine eigentfiche farbe zu betrachten ijt und wahricheinfich her= vorgerufen miro burch feine, in ihin johnebente Staubflitterchen, bie

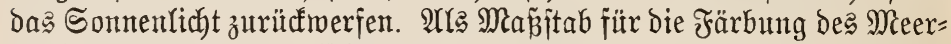
mafjers bient bie Foreliche Sfala, bejtehend aus einer Reife von $\Omega \ddot{0}=$ jungen eines blauen ภripferfalzes, benen genau nad Prozenten bejtimmte

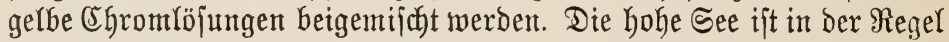
tiefbłau gefärbt. Dả reinjte Blau zeigt ber $\mathfrak{A}$ tlantijche und Stille $\mathfrak{D}_{z}$ eant,

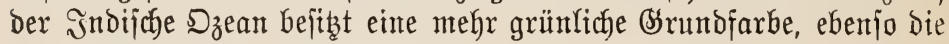
falten $\mathfrak{B o l a r w a j f e r . ~} \mathfrak{s}$ jalzreicheren $B$ intmenteeren, wie int Mittel=

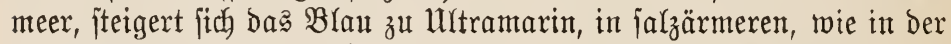
Diffee, neigt es mefrr zu Srrün. Doch ber Salzgehalt ijt nicht allein fïr

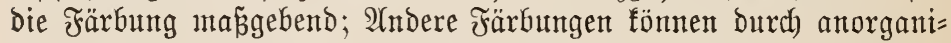
iche Beimengungen entitehen. Crrjteres findet öfters an Den Flümün=

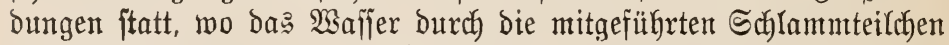
gelbbraun gefärbt wiro; bas đselbe Meer hat befanntlich von den $\Omega_{00} \tilde{\beta}=$

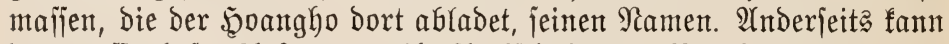

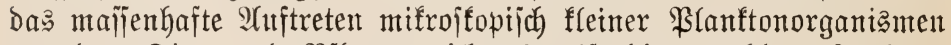
aus Dem Tier= und Pflanzenteich) zeitweije die grünblaue Färbung in purpurrote uno antere Farbentöne verändern; bas Rote Meer

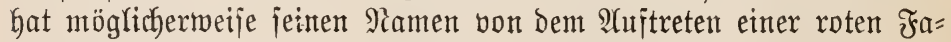
Denalge (Trichodesmium) erfaltent, während, nebenbei gejagt, bą Schmarze Meer ben über ifm jo häufig ichmebenden bunflen Sturm=

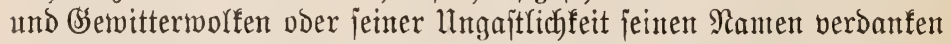

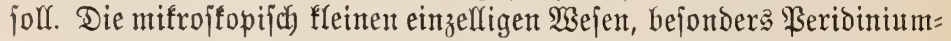
arten, färben burch ifhr mafienbaftes $\mathfrak{Z}$ (uftreten zeitreije ganze Meeres= teife rot, wie ichon Darmin befant mar. 2Uuf Deren Artwejentheit be=

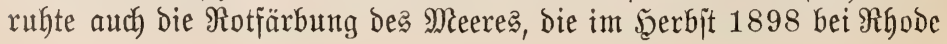




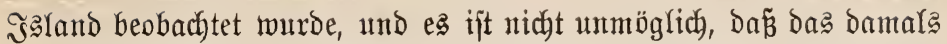
Dort exfolgte Arbjterben Der Fijache mit biejen Drganismen im Zujammen=

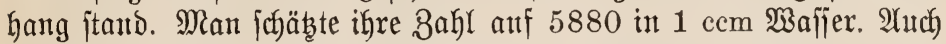
Carter hat als llrjache Der Rotfärbung des Meeres um Bombay ein ßertbinium (P. sanguineum) bejahrieben. Manddmal fönnen Bafterien

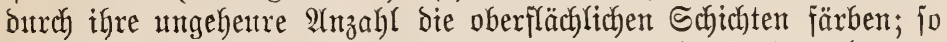

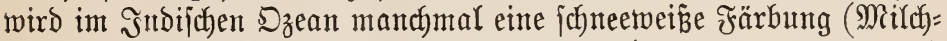
meer) beobachtet, die durch einen Reuchtbazillus (Bacillus phosphoreus) hervorgerufen wird.

\section{UGjuntitt.}

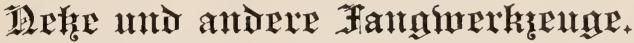

Menn wir bie Entwidflung Der inftematijchen Meeresforidyung ver=

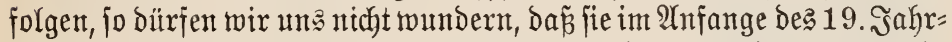
hunderts mur febr langiame Fortiduritte machte. Trobsem gerabe in

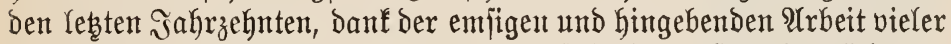

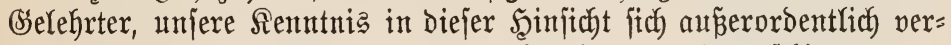
mehrt hat und ber Sd)leier von mand hen ber - wie eb jofien - gar nicht löß̧冖aren Bseheimnifje der Tieffee genommen worden ift, beher= bergt fie beren nodh eine unabjehbare Menge. Sm Bergleid mit ben

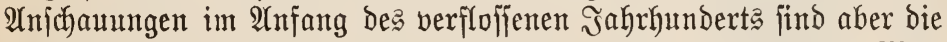
Fortfichritte auf unjerem Biebiete gerabezu bemunderungsmert. Man

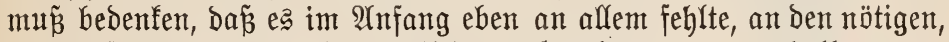
gerabe für biejen 3weef́ vorgebildeten (S̈elehrten tmb beshalb an der nötigen \&iteratur, an 2lpparaten und Majuinen, an Fangwerf́zengen imb Fangmethoden. Dagegen gab es eine Mienge faljcher vorgefajpter Meinungen, bie erft über den Şaufen geworfen werden mušten, bevor man an ben 2 (uffbau neuer Lehren ernjtlich benten fonnte. Das galt

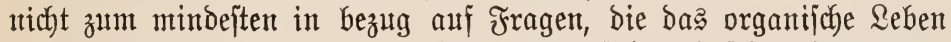
in ben Tiefen angeht; hatte boch Forbes ant Sirund jeiner bamaligen Senntniffe Den überall angenommenen Şrumbjak aufgejtellt, baz̃ unter $500 \mathrm{~m}$ jebes organifdye Qeben auffören müffie.

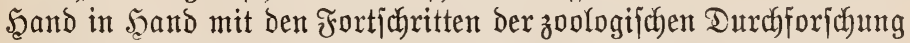
ber Meere ging naturgemäñ bie Entwicflung Der Fangmerfzeuge und

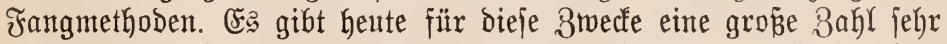

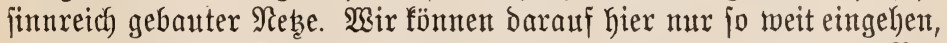

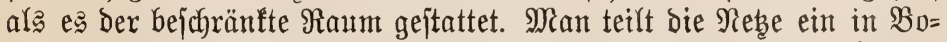
Den= oder Schleppnebe und in Schwebenebze. Eritere (2tbb. 16), aus ben einfachen Silfsmitteln ber âjtern= und Sdyammfither herbor= 
gegangen, werden über ben Meeresgrunt gezogen. Im 2 (njang eine

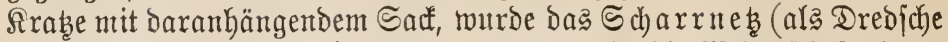

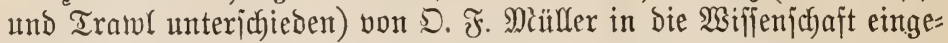

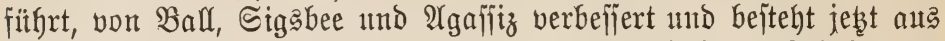
einem zipjelförmigen Neb mit Majhen von verfohiebener Feinheit, in

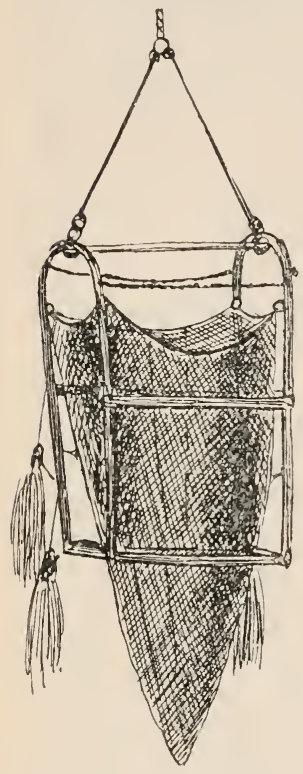

abb. 16. Ed)leppneg. bas auf ber gieije bes "Challenger" noch ein zwei= tes untert offente eingejenft wurbe, fo da

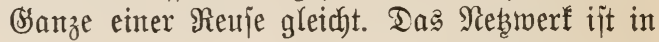
einem aus zwei $U=$ förmigen und miteinander ver= bunbenen Bügeln bejtehenden $\Re a h m e n$ aufge=

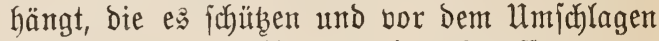

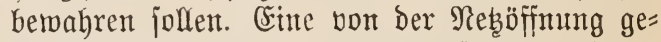
ipannte Sette ober eine Stange icharrt bei ber Dredjche den Bodenjab zufammen, wälyrend jïch in ben angehängten Sluajten manthe Eeetiere fan= gen. Se nach der zu ermartenden Tiefe werben

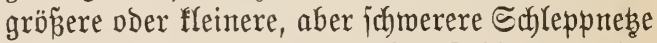
verwendet. Würbe nut aber Das Sdyleppnete ein= fach hinabgelajien, jo twitroe es bald ins Treiben geraten und gar nicht ober jefr ipät erjt ben (Šrund erreichent. Um Dem vorzubengen, werden in ge= wiffer Entfermung von bem Neb an bem Stahl $=$ braht, Der bą früher gebräuchliche ફ̧anffeil ganz

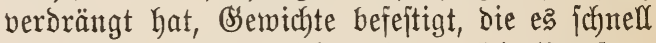
hinabzieben und es richtig legen. Die Dltaften=

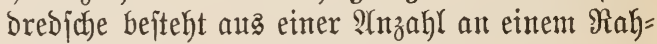
men befejtigter Şanfbiijcher.

Die ऽ(fwebenebe follen die Drganismen fangen, bie im Meere

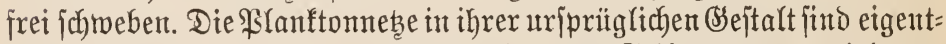
lich) feine Fantgwerf man ans einer bejtimmen Menge $\mathfrak{W a j j e r}$ bie fleinen organifjen $\mathrm{Lebe}=$

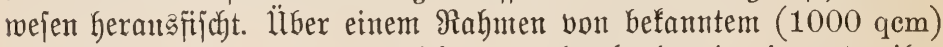
Flächenintyalt wirb ein Bengtridyter angebracht, ber in eit ututer ifm

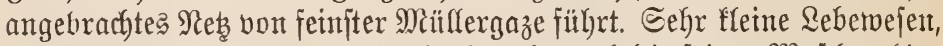

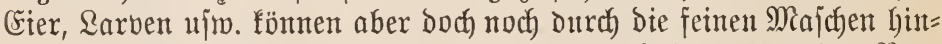
Durchichlïpfen, Deshalb befindet fich barunter noch ein eimerartiger Ben= tel aus bemjelben Iudhe. Diejer gauze 2(pparat wirb mut in bie ge= wünjhte Tiefe Ginabgelajien und dann jenfrecht heraufgezogen, fo Da int ifm ber ganze Jnthalt Der burchjifichten wafferiäule in einem unten

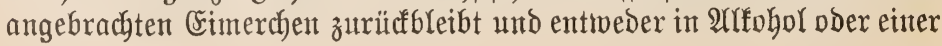


anderen flüfiligfeit fonjerviert ober gleich gezählt und bejtimmt wer= Den fant wofür jogar bejondere 2Ypparate fonftruiert jind, auf bie wir Gier nicht meiter eingehen twollent.

3urzeit, wo fich ein grofeses Sntereffe gerabe ben in ber=

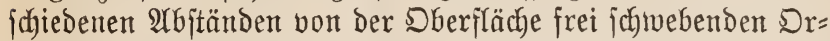

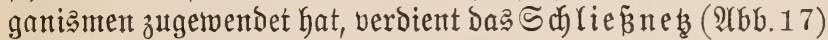
bejonderer Errwähnung, um bejien Sonftruftion fich vor allem

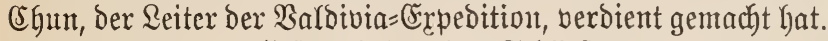

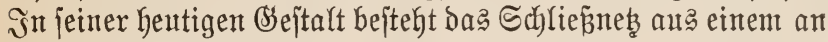

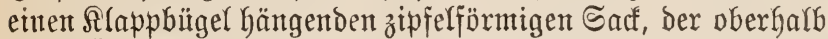
feiner ఏ̈finung einen jehr finnreichen Mechanißmus trägt. Sein Sauptbeitantoil ift einte fein gearbeitete Flïgelichraube oder ein Bropeller, eine Sdiff

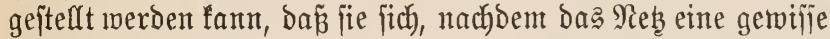
Wajjerjdicht, jagen wir von 2500 bis $2900 \mathrm{~m}$, Durchlaufen

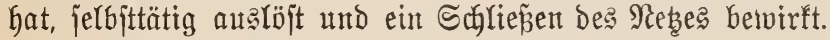

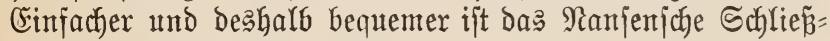

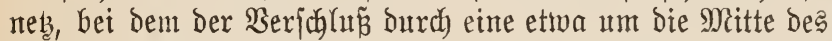
Beutels laufende Schlinge bemirlt wird, die man bou oben

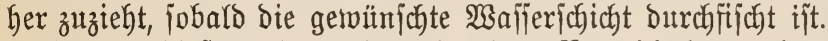

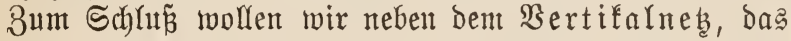

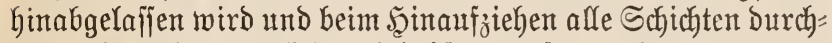
fiidgt, bie eigentümlichen Tieffeerenjen, bie ber unt bie Meeresforichung io veroiente Fitrit von Mionaco gebaut hat,

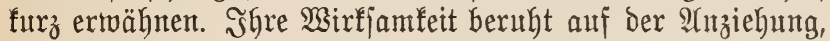
die das gicht auf alle Dunfelbemohner, aljo auth auf bie Tief= jeetiere, ausitbt. Diejer Fangapparat bejtegt aus einem Rajten aus Drahtgitter, in befien Sntneres fünf allmählich jich verengertide reufenartige D̈ffmutgen füfhren. Int ber Mitte ijt eine eleftrijche (silühlampe angebracht, für bie

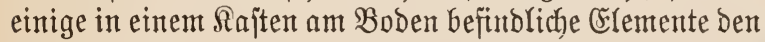
Strom erzengen. Damit fie aber nicht durch ben gropent Wafferbrud zeritört werbe, bejorgt ein an bem Rajten an=

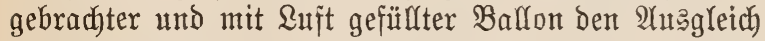
Des Druffes. Der ganze 2(pparat wird ints Meer hitab= gelafien, jeine $\mathfrak{a} a g e$ burch eine Boje bezeichuet, und nadh einiger Beit, oft erjt nach 24 Stumben, wieber an bie

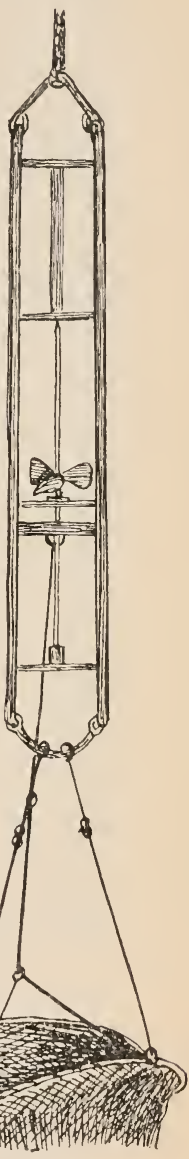

Ább. 17.

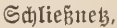
geöffitet. Dberfläche getounden, und man hat gute Erfolge mit ifm erzielt. $\mathfrak{A} n=$ dere Tieffeereufen enthalten nur $\Re$ öber für die zu fangenden Tiere.

Das Fifichen mit berartigen jutweren 2 (pparaten verlangt biel $\mathfrak{A} r=$ 
beit, Gietet aber Den Dabei Beteifigten oft eine Menge Danfbarer über= rajadungen, nicht jelten aber auch Enttäujchungen. $\mathfrak{u m} 1 / 27 \mathfrak{l b r}$ mor=

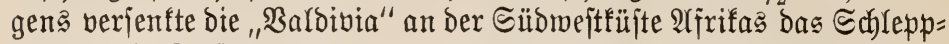
neb in bie Tiefe, um 12 Mhr erreidjte es bei $5500 \mathrm{~m}$ den Brunt, murbe bort eine Etunde lang gezogen und rar exit um 7 uhr abends wieder an Bord. Und was enthielt es? Saum ein einziges lebendes

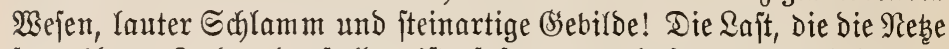

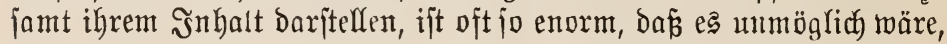
fie mit Mienjodentyand zu betwegen. Thomion berechnete fie für einen

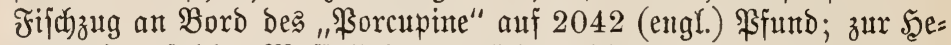
bung einer foldhen Maffe find natürlid) Majuinen nötig, und bie ", $\mathfrak{W a l}=$ Divia" hatte Deren cine eleftrifhe und eine Dampimajchinte an Borb.

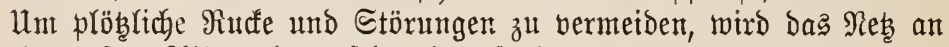
einem log. 2Uffumulator federno aufgehängt, ein Tynamometer zeigt

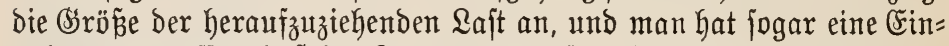

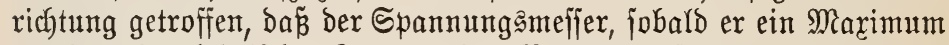

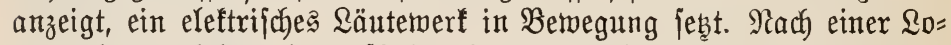
tung ober nach Dem Şerauffolen eines Dredjdyzuges herridgt natürlich bas regite $2 e b e n$ an $\mathfrak{B}$ orb. Da gibt es gar biel za tun für einen je= Den; Stunden, ja Tage gehen barüber hin, bis alles Notmendige be= jorgt ijt! Uno bod, jo wollen wir mit Marihall ichliȩ́en, "föjtliche

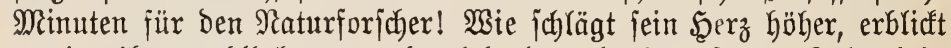
er eine ifm wohlbefannte, aber lebend noch nie gejebene Seltenheit, ober eine neute, frembartige Form, ber er auf ben erjten Bliff anfieht,

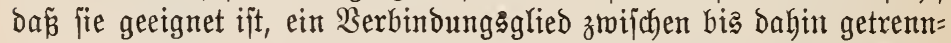
ten und ijoliert jtehendent Sejejöpfen zu bilden! Dieje Bejühle fennt nur Der Fachmant, ę find bie Gerrlichjten $\mathfrak{B}$ (üten, welche auf bem nicht eben Dornenlojen $\mathfrak{B f a b e}$ unjerer Wiffenjabaft blühen!"

\section{A(bjunitt.}

\section{Die Pflangen Des 4lexes.}

$\mathfrak{B i s}$ in bie Mitte des vorigen Jahrhunderts war allgemein die $\mathfrak{A} \mathfrak{n}=$

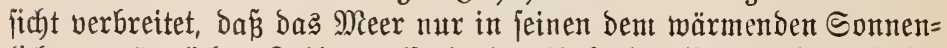

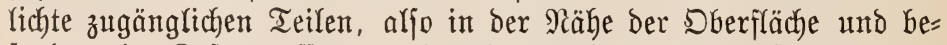
jonders im Rüftentraffer von Yebenden Wejen bebölfert jei. Der mit ber Tiefe zunefmento ungeheure Drucf, bas Fehlen bes Qidhts in grö=

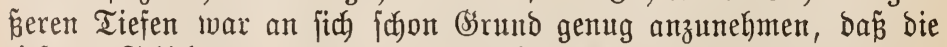

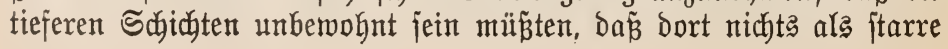




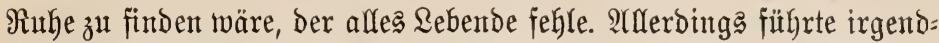
ein $\mathfrak{u m}$ itand bier und ba einmal einen jeltjam ausfehenden ofifh ober einen abjonderfich geformten Srebs an bie Dberfläche, Der von Schif=

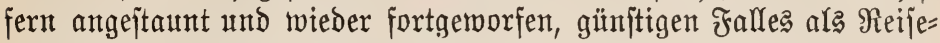
erinnerung heimgebracht und als Sehenswüroigfeit einem Miueum über= geben wurbe. Erit als jpäter die erjten $\mathfrak{A}$ nfänge mit einer injtemati= ichen Erforichung der Meere gemacht wurben und bie Rebe zugleich mit größ̈eren Meereß̧bewohnern eine ungeahnte Lebewelt tleiner und fleinjter $\mathfrak{W e j e n , ~ b e r e n ~ F o r m e n ~ u n d ~ M e n g e n ~ m u r ~ d a s ~ m i t ~ b e m ~ M i f r o = ~}$ ffop bewaffinete Menfichenauge zu erfenten vermag, an bas Tagezlidft

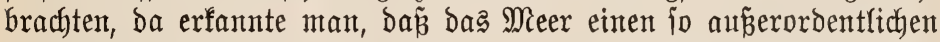

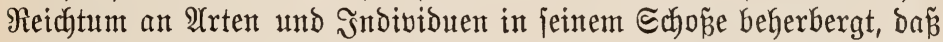

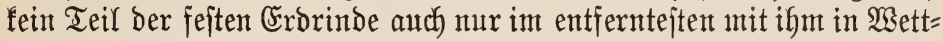

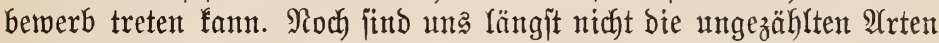
audch mur antäherno alle befannt; zäblte boch Scaecfel allein von ber einen 2loteilung ber Foraminiferen nidyt weniger ala 4318 veridjie bene 2 rrten auf. Sebe Expedition bringt newe und bis dahin unbe= fante Formen mit nach Şats, und bis auf Jahrzefnte Ginaus wer=

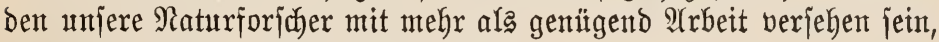
die das unendlidbe Meer ifnen bietet.

Eine fehr nahe liegende Frage ift nun bie: wie ernähren fich alle bieje Seerjcharen ber Meerbewohner? $D b$ viele Tiere, wie vermutet wurbe, bas Meerwafjer mirflich als Mährlöjung benuben unb bie bort vorbandenen Stoffe einfach in fich aufnehmen fömen, erjotheint body z'weifelhaft. Alber wir wifjen, unjere Frejtlandatiere, felbit jolche, bie von Dem freijd) anderer leben, fint in lester Scinjidyt auf biejenige or=

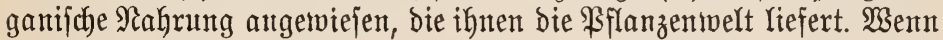

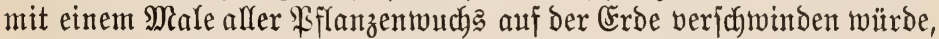

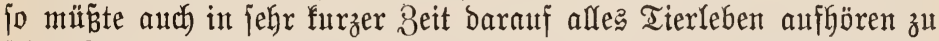
fein. Denn mur bie Bflanze ijt imitanbe, aus ben anorganifhen $\mathfrak{B} e=$ itandteifen, bie jïn auf unjerer (Erbe finden, organifde herzuftellen, nur fie vermag ans biejen Stoffent dutrch den unt noch fo rätjelhaften Qebenz=

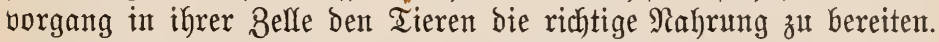

Site verbält es fich mutn in biejer Beziefung mit ben Milliarden

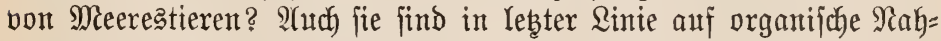
rutng angewiejen. Zwar bringen bie grofenen Flüfife beren eine bebeu= tende Mienge int Meer; aber bieje Sinfitoffe fomment mur eittem febr fleinen Teile ber riefigen $D_{z}$ eambecten zugute und liefern mur einten

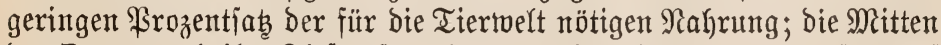
ber $D_{z e a n e}$ und ifre Tiefen famt den bort lebenden Tieren müffen anf 


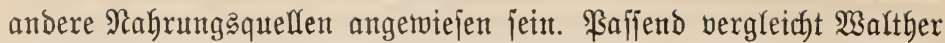
bieje Ssebiete mit einem Sndujtrieland; wie ein joldhes jinto jie burd = aus auf eine Cinfuhr von ?ahrungajtoffen angewiejen.

Nun bat auth das Meer jeine Pflanzen, bie fich alleroings meift in

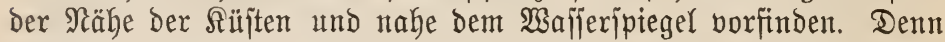

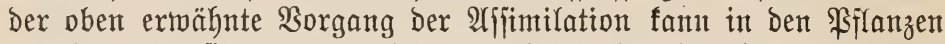
nur bann jtattfinden, went bie alles belebenden Strahlen ber Sonne

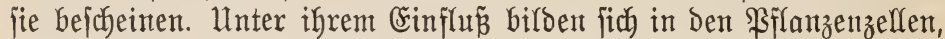
bie mit eitem meijt grïnen, oft audch gelblichen ober rotbraunen $\mathfrak{I}=$

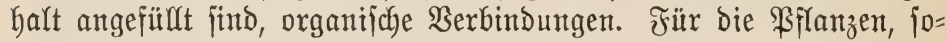
weit fie nidht Schmaroteer ober Fäulnishewohner finto, ijt das Qidht viel mehr Lebenshebürfnis als für bie Tiere; es liejert ifnen bie Energie für bie Stoffim jebung. Die Qidytjtrahlen verlieren aber, wie wir jahen, beim Cindringen in bas $\mathfrak{S a f j e r}$ gar bald ifre Sraft, und ztwar find e马 gerabe bie rotent und gelben Lidhtitrahlen, bie zuerjt verichludt mer= Den, währent bie für biejen $\mathfrak{B}$ organg ber 2 (fjimilation jo nötigen grü=

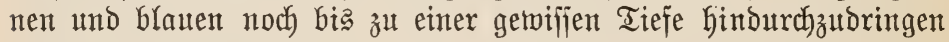
vermögen. Die rote und brantne Farbe ift als eine 2 Tnpaffung an bie Ridhtverhältniffe bes Meerea; bie roten uto braunen $\mathfrak{A}$ (Igen legen ge=

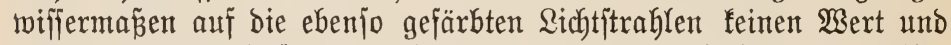
itrahlen fie zuriud, für fie finto nur bie grïnen und blauen von $\mathfrak{B e}=$

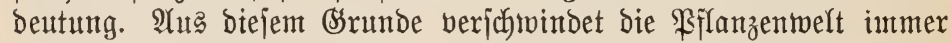
mehr, je weiter bas Schliep̃nes ins Meer Ginabjteigt. Die Durchjich = tigfeit bes $\mathfrak{B a f f e r}$ fpielt babet natürlidf eine widftige Rolle; oft ift

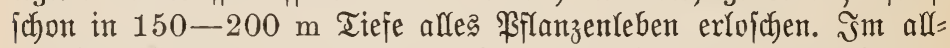
gemeinen fant man bon oben nach unten brei 80 nen untericheiden. Die oberite reidft bis etroa $80 \mathrm{~m}$; in ing findet fich unter bem (Fin=

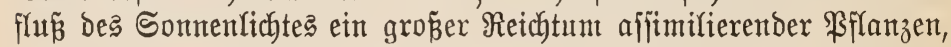
anfang? folche mit grïnem Farbittoff, weiter unten übergebeno in braune

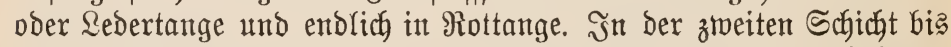
$150 \mathrm{~m}$ hat bie $\mathfrak{P f l a n z e n w e l t ~ g a n z ~ e r h e b l i d , ~ a b g e n o m m e n , ~ b o c h ~ h a b e n ~}$ fich bem hier herridhenden Dämmerridyte, bas in ber unteriten Stufe unjeren $\mathfrak{A}$ ugent faum wahrnehmbar fein bürfte, einige wentge 2rlgent (Halosphaera) und Diatomeen noch anpafien f̈nnen. In Der unteriten 3one ift bas \$flanzenleben jo gut wie erlojichen. Nur bie zu ben $\mathfrak{\Re u}=$ gelalgen gehörenden, obengenanten Šalojphaeren jind noch in Tiefent bon 1000 bis $2000 \mathrm{~m}$ angetroffen toorben; vont einer alfifimilation

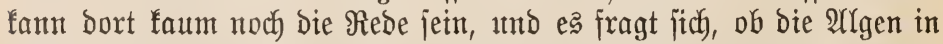

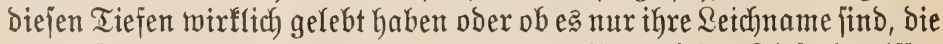

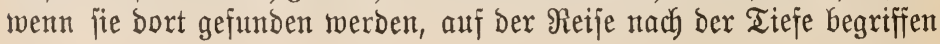




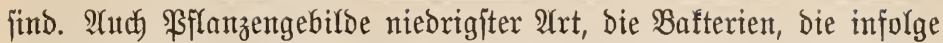
Mangels einer foldhen affimilierenden Farbjubjtanz vom Qicht unab= Gängig finto, gewifijermaz̃en als Schmarober im Meerwafjer leben uno jid von ben herabfinfenden organifhen Stoffen ernähren, föment in gropen Tiefen nod exiftieren, und bie Deutfhe Tiefiee=Expedition ftellte igr $\mathfrak{B o r g a n d e n j e i n ~ n o d y ~ i n ~} 1758 \mathrm{~m}$ Tiefe fejt. Sar bie allergrö̈ten Tiefen jheinen frei bon ifnen zu jein. Sie fpielen jedenfalls aud im Meere

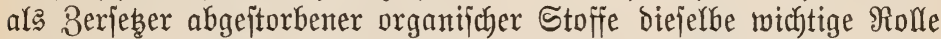
twie auf Dent Rande. Athe Meerespflanzen - abgeiehen von ben bei= ben Seegragarten (Zostera marina und Z. nana) - gebören zu ben Sryptogamen, ס. h. fie erzeugen feine mit blozem $\mathfrak{A}$ utge fichtbaren $\mathfrak{B l i}=$ ten, Frübchte voer Samen. Wir fömten fie in feptfithende und freitrei=

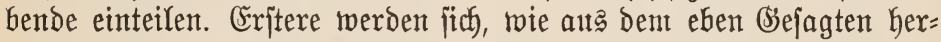

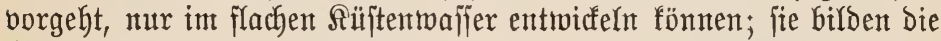
Süftenflora, bie in einem idymäleren ober breiterent Ssürtel fich bis zur Tiefe von etwa $30 \mathrm{~m}$ ints Meer hinein erjtrecft. Die $\mathfrak{B f l a n z e n =}$ geographen untericheiden hier einen Ssitrtel von zeitweife auftauchen=

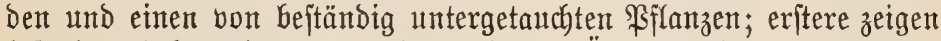

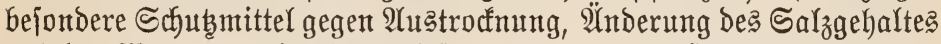

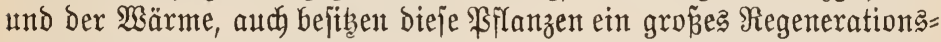

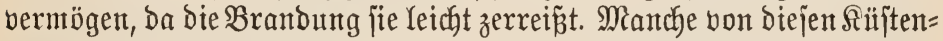
pflanzent fönnen allerbings ben $\mathfrak{A}$ njchein erwecfen, als bb fie aus grö= Ëeren Tiefen emporjteigen, renn man fie an jteil abfallenden $\Re$ ïjiten mebrere Gundert Meter vom Strambe entfernt findet. Dazu gehört bet=

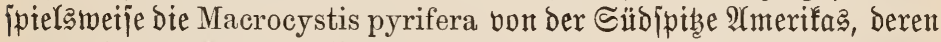
flatternde, bunfelgrüne Blätter, bie eine \&änge von 200 bis $300 \mathrm{~m}$ erreichen follen, 100 bis $200 \mathrm{~m}$ jahräg vom Boden auffiteigen und flach im Meere an ber Dberfläche fábeben. Zahlreiche andere Tang= arten gefören hierfin, jo bie ßiementange (Laminaria), beren gejtielte, jămale bantoförmige Blätter bis zu $3 \mathrm{~m}$ lang werben, und bie Riejen= tange (Nereocystis), bie eine Qänge von $90 \mathrm{~m}$ erreichent fönnen. Der

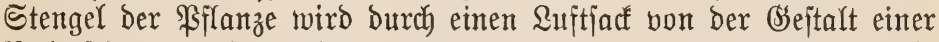

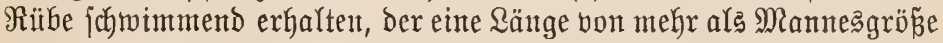
erreichen fann. Diejem \&uftballon entjpringt ein $B \ddot{u} j$ jhel biffer jchmaler

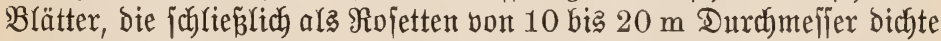

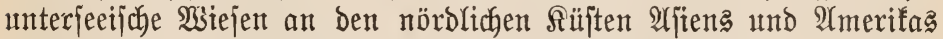

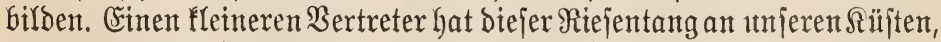
Den Blafentang (Fucus vesiculosus, 2HbG. 18), Defien Blattorgante Durch) zwei einander gegenüberjtehende Blajen idjwimmend exhalten werden.

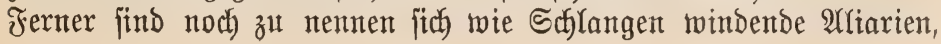


baumförmig verzroeigte Sefijonien, zahlreiche zierliche Florideen mit ro=

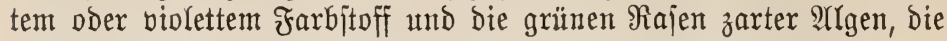
Steine, Feljen und Majdeln an Der Säfte überzieben. Şöchjt inter= efjant find mandse ber meerbetwohnenden Tange und Floribeen (Phyllocladia, Wrangelia u. a.) Deshalb, weil jie unter $\mathfrak{W a f j e r}$ ein gemiffes Seuchten zeigen und ein mattes হidyt auszuftrablen idjeinen, Das aber

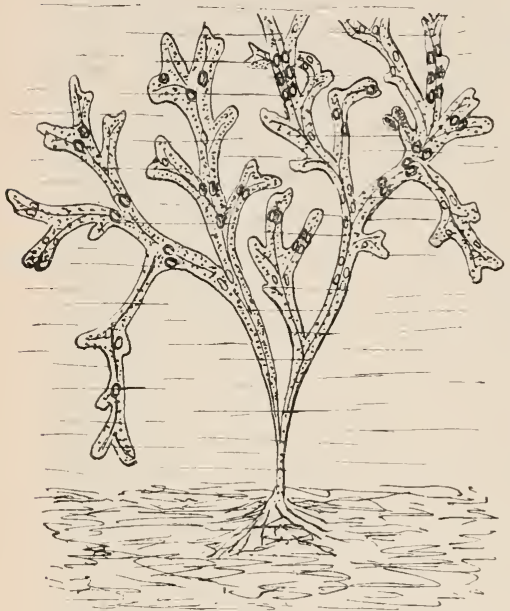

YGb. 18. Blajentang (Fucus vesiculosus). nicht von ben Pflanzen jelbjt aus= gebt, jondern burch das refleftierte Tageshidst bewirft wird, Deflent we= nige in die Tiefen oringenden Strablen bon linjenartigen $\Re 0 ̈ r=$ perchen in ben 'Sflanzen eifrig ge= jammelt werben. Demjelben Zwed Der Sidbtanjammlung ichetnen aud die zierlichen, gegitterten Schalen vieler Diatomeen zu dienen, die wix unter bem Mifroffop bewun= Dern und die als Bewohner des Meeres in zahlreichen Formen an= zutreffen finto.

Einen übergang zu Den frei im Meere treibenden Pfflanzen madyt der Beerentang (Sargassum bacciferum) injofern, al: grof́e Măfien von ihm im Artantifich Sozean zwijchen $20^{\circ}$ und $30^{\circ}$ nörolicher Breite treiben und das befante Sar= gaj jo bilden, von bemjener Meeresteil jeinen Namen hat. Da diefe Tang= twiefen aber uriprünglich von Süftentplanzen an Den Weftindifchen すn= feln jtammen, bon to bie berrichenden Winde fie auf Das hohe Meer Ginaus entführt haben, gebören jie rechtmäpig nicht zur ß̧anftonflora. Befannt ijt, Daf́p Columbus, als ex dieje treibenden \$Flanzenmafien in Sidyt befam, fie für das er jebnte Fejtland bielt. Die Planfton=Erpe= Dition bat fich auch mit Dem Sargaffomeer beidäftigt. Sie fonnte feft=

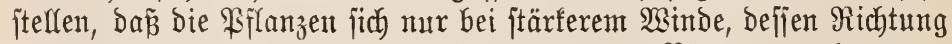

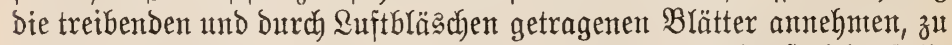

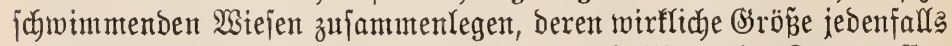
nicht Den früheren Borjtellungen entipricht. Die Menge Der Tangmafjen ändert jich aber jährlidb. Die ßlanttonforjcher fanden im Sargaffomeer eine auffallende Armut an Tieren; lyauptfächlich jüto es Seenadeln und Seepferdchen, die fich mit ihrem Sdyrwanz an Den $\mathfrak{P} f$ lanzen fefthalten, $\Omega_{0}=$ 


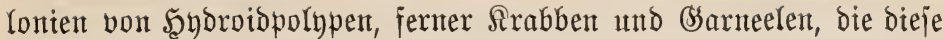

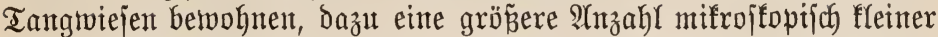

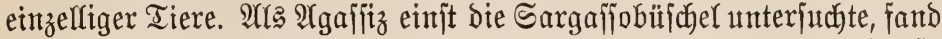

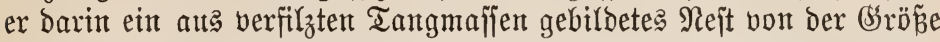

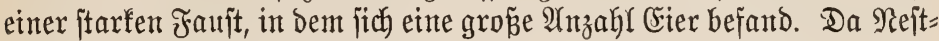

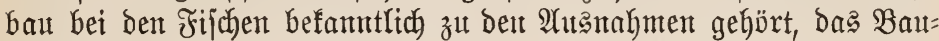
twerf aber wohl mur bon eintem folchen herrithren fonnte, wurbe er neu=

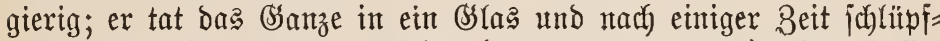
ten alt ben Eiern fleine Fijhdhen (Chironectus pictus), bie, wie fith herausjtellte, den Meerteufeln unjerer Morbjee nahe verwants waren.

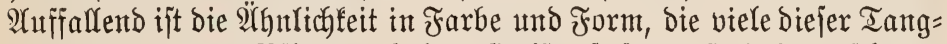

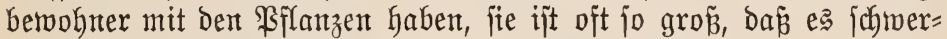
hält, Titere und $\mathfrak{B f l a n z e n ~ v o n e i n a n d e r ~ z u ~ u n t e r j h e i b e n . ~}$

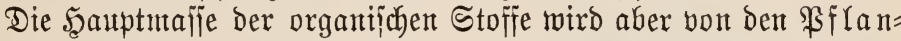

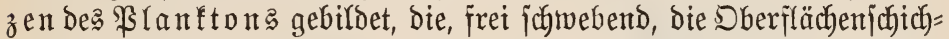

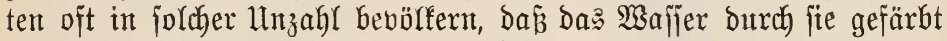
ericheint. Sie gefören faft alle ber Bsruppe der einzelligen 2 (Tgen an,

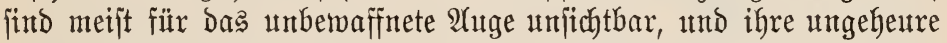

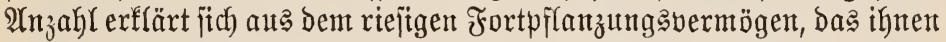

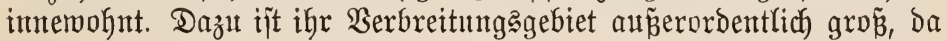

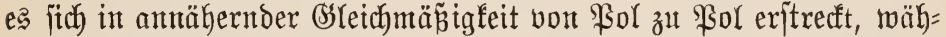

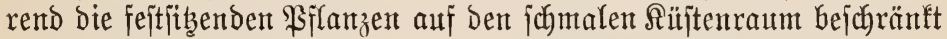

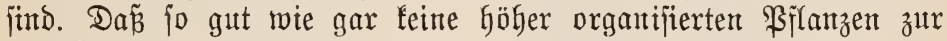
Planftonflora gebören, ift auf ben eriten $\mathfrak{B l i d f}$ auffalfend, erffeärt jich

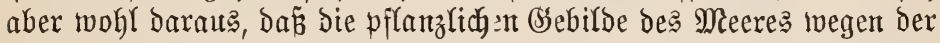

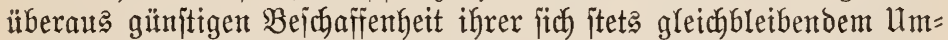

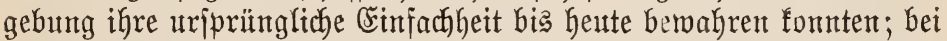
Den Randpflanzen bagegen, wo Rlima, Bodenteidaffenheit tijw. ganz

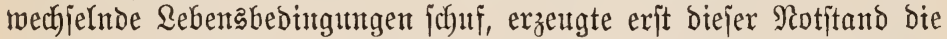
höher umb am hödyjten organtijiertent Formen. STuth fömen in ben durch Strömungen und Temperaturtwechjel jtetig fich verändernden $D$ ber= flädentwajlern mur furzłlebige Formen Bejtant haben, bie fich Durch

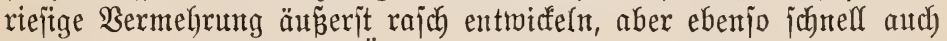

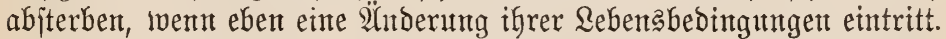

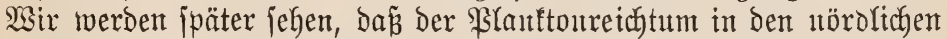

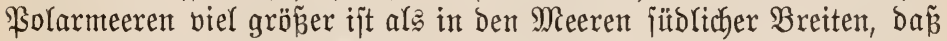
ber Frühling mefre $\mathfrak{B l a n t t o n p f l a n z e n ~ m b ~ = t i e r e ~ h e r v o r b r i n g t ~ a l s ~ b e r ~}$ Şodjommer.

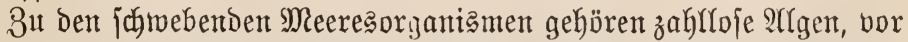
allem bie zierlichen Diatomeen, von beren zu Boden finfenten Schalen 
wir jayon früher gejproden haben; dann bie ebenfalls mit einem Siejel= panzer umgebenen Dinnflagellaten und bejonders bie ßeribineen (Cera-

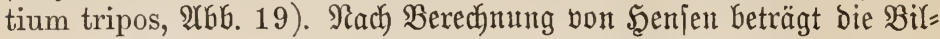
Dung organijajer Subjtanz Durch bieje mifroffopijdy fleinen, auf ber

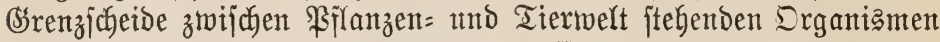
jährlich in einem Duadratmeter Meerwaffere etrwa $150 \mathrm{~g}$, von benten

26৮. 19.

$130 \mathrm{~g}$ allein anf bie oft $\mathfrak{a b}=$ jonderlich geformtent Cera= Drei Formen von Ceratium, oben C. tripos. tien fommen. Die 3 ahl bie $=$

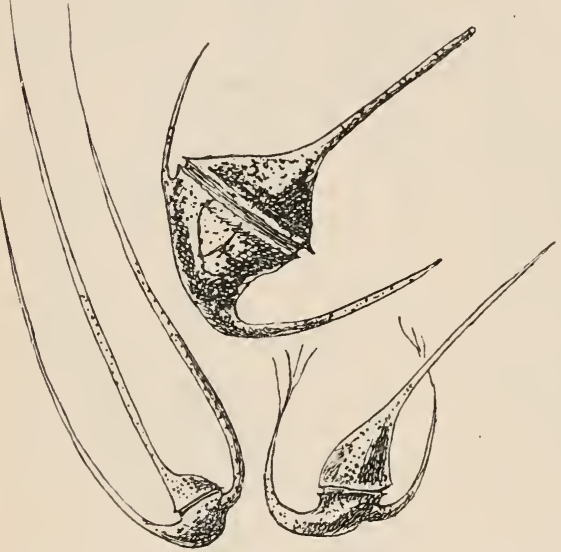

jer $\mathfrak{B f l a n z e n o r g a n i s m e n ~ d e s ~}$ Dberflächentwajiers ift $b a=$ nach ungeheuer grố. Bei einem Sebzug Durch eine $20 \mathrm{~m}$ bicte $\lesssim$ berflächemichicht wurben 5700000 Drga= nismen gezähylt; fünt $\mathfrak{M}$ illli= onen itellten bavon allein bie 2rgent. Fine idfarladdrote fiugelalge (Protococcus at-

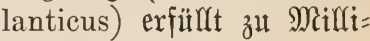
arden oft bas Meer an ben Süften $\mathfrak{P o r t u g a l s , ~ a ̈ h n l i c h ) ~}$ wie bie roten Bündel einer Fabenalge (Trichodesmium erythraeum) in gewiilien

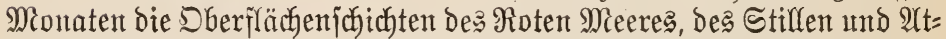

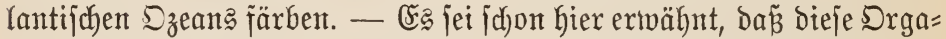

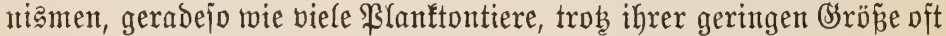
überrajchende (Einrichtungen befiben, Durch bie ifnen bas Schmeben im

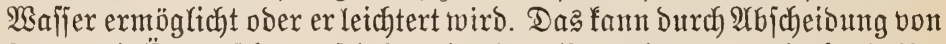

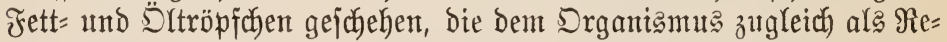
jervejtoffe bienen, ferner Durch Dberfläd)entuergröß̈erung burch Strectung und $2(6 f l a c h u t g$ oder burch Bildungen, bie man gerabezu als Schwebe= apparate bezeichnen fann, wie Şörner, Stacheln, Flügel und andere Mem=

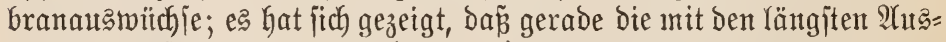
wüchjen verjełenen Ceratien (26b6.19) bejonders in Den wärmeren und \{ałzärmeren und baher wentiger tragfähigen 5 berflächenjtrömungen zu

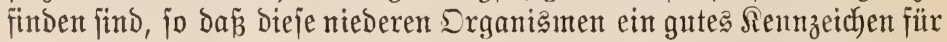
bie verjdjiedene Temperatır, den Salzgelalt bez Dberflädhenwaffers und die baraus rejultierenton Strömungen find. Dieje pilanzlichen $\mathfrak{u} r=$ 
gebilde find nun in ifyrer Sejamtheit für bas Tierleben im Meere von ber alfergröp̧ten Bedentung. Sie bilden, wie wir fahen, die "Ilnnah)=

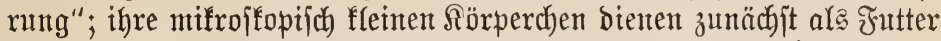

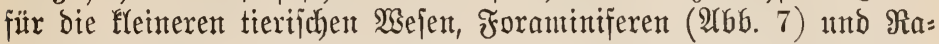

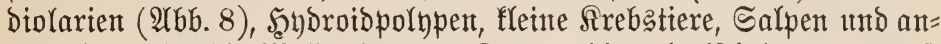
bere, jotvie für bie Milliarben vott Qarven, bie pelagifo leben, um exjt ipäter eitte andere Lebengtweife anzunehmen; fie erjeben im Meere bie Wiejen und Weiben, die Wälder und Felder des Fejtlandes. Diejer Urnahrung wandte Senjen und jeine Siachfolger ganz bejonderes Int=

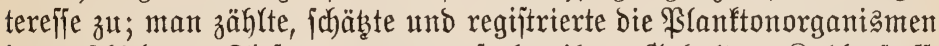
in verjaciedenen Tiefen, man unterjuchte ihren Bebalt an Siohlenjtoff, Sticfitoff und anderen Bejtandteilen, und biejer 3weig Der Meeresbio= logie brohte eine Beitlang alle anderen Unterjudyungen zu exfticfen.

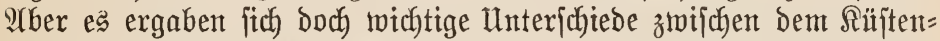

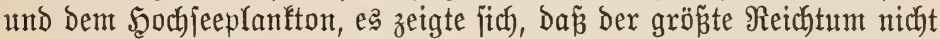

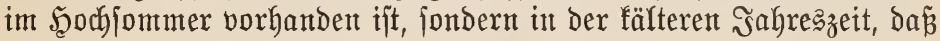

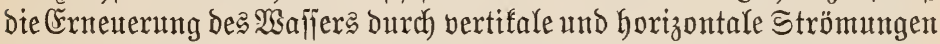
fïr bie qualitative und quantitative Berbreitung biefer Sabebeorga= nismen von größ̈ter Bebeutung ift. Die \$Filanzen bringen aljo orga= nifche Subjtanz hervor, bie Tiere verzehren fie twieder. Die fleinerent Tiere bilben wieder die Nahrung Der größ̈eren, und dieje endich mitfien ben Magen Der zahltreidben Meerriejen f̈̈̈llen. Dabei ijt wob) zu beben=

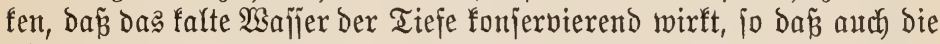
abgejtorbenen 乏eiber der Dberflähenorganismen während des Scerab= finfens noch einte gute Nahrung für bie Tieffeetiere bilden. Auch ibre

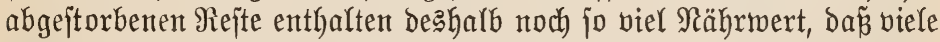
Bodentiere bavon leben fönnen. Sebt beritehen wir audh, wie widh=

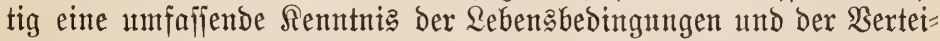

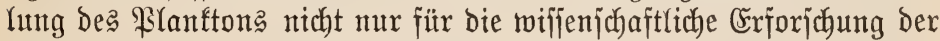
Meere, bejonders auch ber Meeresitrömungen ijt, fondern auch wel= dyen praftifhen Wert fie fïr Fifduzucht und Fifdyfang hat. Deshalb

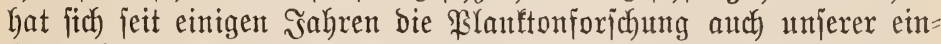

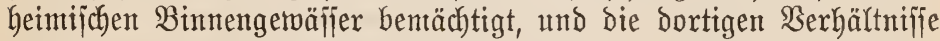
teilweije ganz ähnlich Den im offenen Meere herrjobenden gefunden.

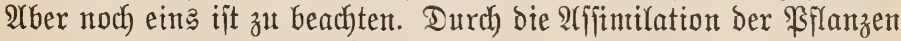
wirb die im $\mathfrak{W a j f e r ~ g e l o ̈ f t e ~ R o b l e n j a ̈ u r e ~ z e r l e g t ~ u n d ~ f r e i e r ~ S a u e r i t o f f ~}$ abgegeben. Diejer ijt aber für Die Exijtenz jeglichen organijuch \&eben: unbedingt nötig. Unterjudyungen des "Challenger", Der "łola", Des

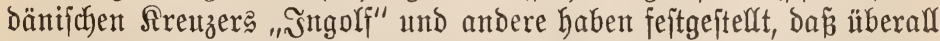
da, too vorwiegend pflanzliche Sebilde das ßlanfton ausmachen, bas 
Baffer einen reichen Behalt an Sauerftoff bejtz̧t. Wo ferner ein feiner

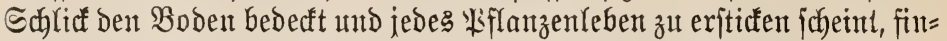
ben fich häufig noch bie હdywefelalgen ober Beggiatoren; fie find injofern von groß̈er Bebeutung, als fie bent dort fich entwidfelnden giftigen @edwefel= mafjeritofi zerftören und zu Schwefelfäure orybieren. So bilden bie Pflanzen Des Meeres nicht nur bie Unnahrung aller Betwohner, fondern

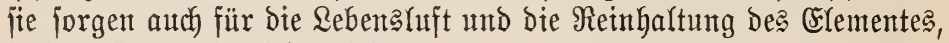
in bem fie unt bie Tiere leben.

\section{IX. $\mathfrak{U}$ bjuntitt.

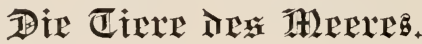

Der 1854 veritorbene Edinturger 30 loge Estward Forbes hatte bie Bebauptung aufgeftellt, bå unter ber Tiefenlinie von $550 \mathrm{~m}$ organijuches

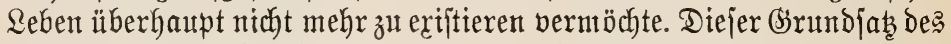
Gerühmten englifact Sielebrtent twurbe bald alfgemein angentommen unto

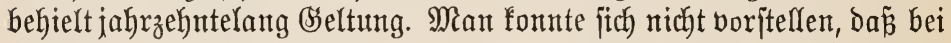

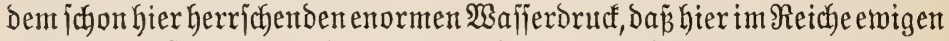
Dunfele, dás bei ber, wie man antahm, enorm falten Temperatur Des Wajfers irgendweldhes lebende Wejen fein Dafein friften fönne. Zwar

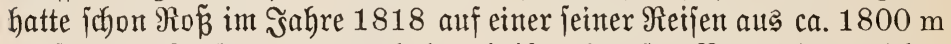
Tiefe einen Seejtern emporgefolt und ifn als eriten $B$ pten eines reichen

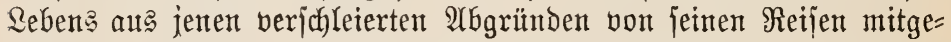

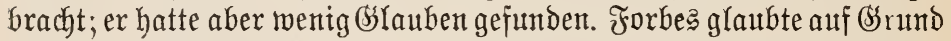
jeiner bamaligen Senntnis in bezug auf bie Berbreitung ber Meeres=

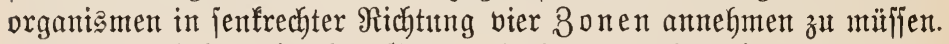
Die Schmierigfeit, bie ohne GSrenzen ineinander übergehenden Meeres= jubichten einzuteifen, ijt nicht gering; man war gezwitngen, bem Bei= jpiele bes Bseologen zu folgen, der feite Schichten nach ber ḩäufigfeit ber in iłnen vorfommenden Beriteinerungen, nad) Leitfofijifien, unter=

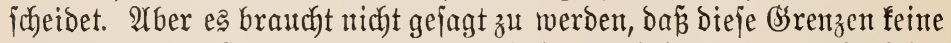

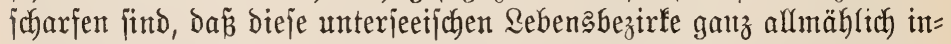

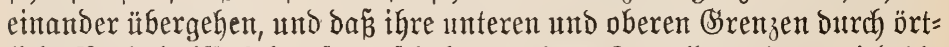
liche Berbältniffe fehr oft verfdgben iverbent. Sm allgemeinen wiro bie Tieffeefauna ba beginnen, wo bas pflanzlidbe Rebent infolge von Lidft= mantgel auffört und bie niedrige Temperatur einjest. Da Yeghteres in Den äqutatorialen Ssebieten erjt in größęerer Tiefe erfolgt ale in ben po=

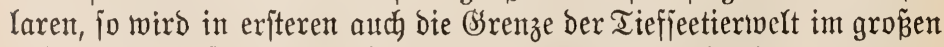
und ganzent tiefer Yiegen als in ben $\mathfrak{P}$ olarmeeren. Sn bent wärmeren 
Meeren liegt bie Sirenze nach Chun etwa in $400 \mathrm{~m}$ Tiefe. Wir wollen uns Gier einer allgemeineren Einteilung anjchließen und bie Meeres= tiere entiprechend inrem hauptjächlichen $\mathfrak{B}$ orfommen unter ber 3 ujam= menfaffung als Süjten=, Tieffee= uno Dberflächenfauna betrachten.

Die 2 itorial = oder Süjtenzone der Mieere zeidnet fich vor ben oberflächlichen Schidhten ber מ̧odhjee und ben tieferen Senfen vor allem burch ifre Berwegtheit aus. Ebbe und oflut, Binde und Stürme lajien

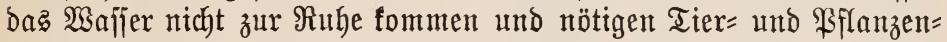
welt, fict) fejt vor $\mathfrak{2}$ (tuter zu legen oder fich auf andere 2 rt gegen bie $\mathfrak{B} e=$

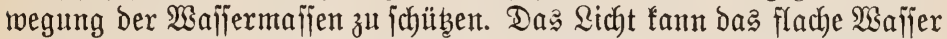

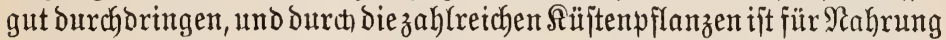
und Saueritoff reichlich gejorgt. Wo Flüffe in ben §üjtenjaum einmiün=

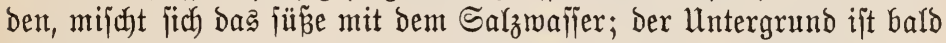
fandig, bald jelfig; furz, für bie Rebetwelt der Rüptenzone find jo wech=

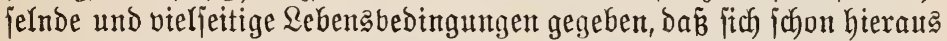
bie groß̌e Mannigfaltigfeit ber bort borfommenden Tieı formen zur B̧e= nüge erflärt. Die Betwohner ber Qitoralzone zeigell nod) vielfach grof́e

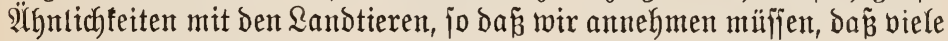
von ifnen erit bon bort her in ifr jebiges Element eingetwandert finto. Es?

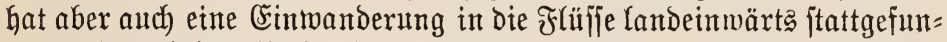
Den, und an einigen Beifpielen aus der Tierwelt fönnen wir heute Den $\mathfrak{B e r}=$

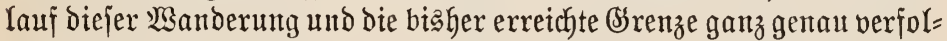

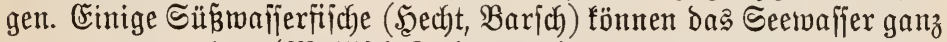
gut ertragen, andere (Maifilich, \&achs, Stör) ziehen regelmä̈ỉg von einem

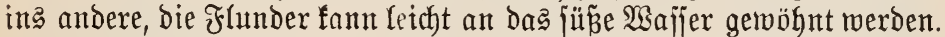
Teils auf jolcher Eintwanterung ins \&and, teil's auf ben folgen groperer geologifcher Beränderungen unjerer Erobberfläd)e beruht bie auffallende Ericheimung, baz wir in manchen Binnenjeen Titriormen finden, bie echte Seefiiche find, fo in ben ffandinavijhen Seen einten zur Siruppe Der $\mathfrak{P a n z}$ erwangen gehörigen $\Im$ Fif (Cottus quadricornis), einen echtent Seefijid uno Berwandten umjeries Saulfopfes, in ben oberitalijhen Seen Yrten der Brrundel (Gobius), de? Shleimfitiches (Blennius) und andere.

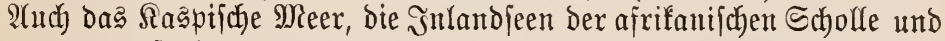
andere groß̉e heute abgejhlojiene Bimnenjeen, der Labugajee, Der eine

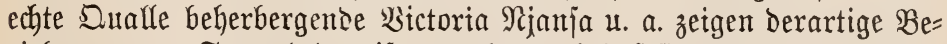
ziefungen zatr See und beweifen uns dadurch, Dẩ fie eimitmals zu Beiten groperer Erorevolutiunen vom Seltmeere abgealiebert wurben. - Je nadh= bem twir eine rafd abfallende, von ber Brandung jtetig umipülte @teil= füjte vor uts haben ober einen fandigen, langjam abjteigenden Strand, ändert jich bas Bild der Qitoralfauna. Dort jehent wir ein Seeer poffiter= 
(id) ausjebender Srabben eifrig bejdäftigt, einen gejtrandeten Seefifd,

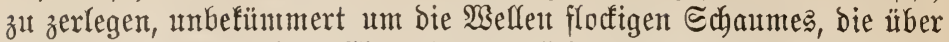
ignen zujammenbrechen. (Fine eigentümliche $\mathfrak{A}$ rt ber $\mathfrak{B}$ erteibigung hat die Ratur biejen Bsejäjpfen mit auf ben Rebensmeg gegeben; jobald irgendein Feind eine ifrer ভcheren fräftig pact, find fie imjtande, durch,

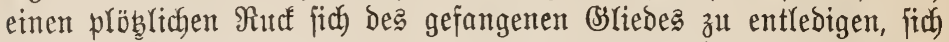
jelbit zu "amputieren", und bebor fich der berblïffte (s)egner von feinem Eritaumen erbolt hat, find fie längit feinem Befichte entichtounden. Das

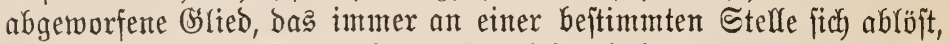

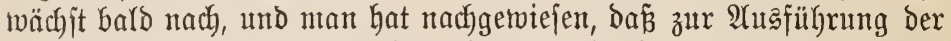
Dperation ben Tieren jogar eine befondere Mußfel zur Berfitgung jteht, Den unan Den Brechmutel genannt hat.

Şier, auf bem Meeresboden, fpielt ber Sampf ums Dajein eine viel=

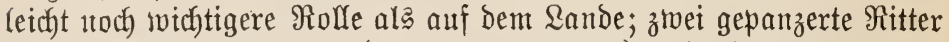

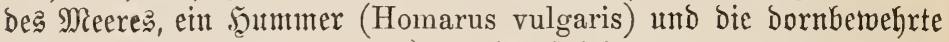
\&antgufte (Palinurus vulgaris), machen fith dort gegenjeitig bie Beute

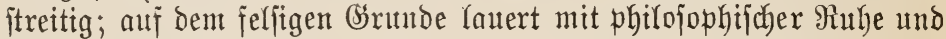

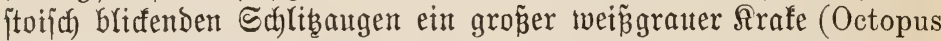
vulgaris) altf Beute. Sobald er aber erregt wird, ändert fitd) fein $2 \mathfrak{A}$ ta:

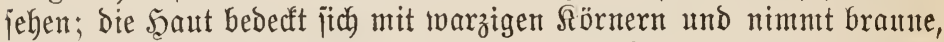
rötliche, gelbe Färbungen an. Trümmer von Rorallenitöcłen, Schalen von Mlufdeln und Schnedfen bedecfen int bunten Durd)einander ben

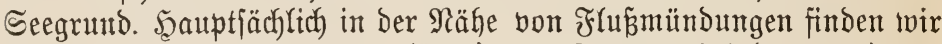

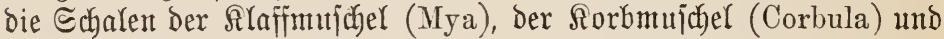
zahlreidye andere; im tweidfen Meeresjichlanm ruhen verborgen Sand= muj jeln (Psammobia) uno Sonnemmujheln (Tellina), ausgezeidnet

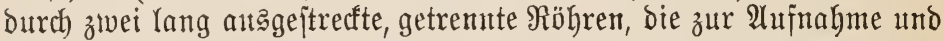
Arggabe des Attemwaffers bienten. In den wärmeren Meeren finden wir ant Şrunde, in ber Tiefe von 12 bis $30 \mathrm{~m}$ bie echte Pertmuichel (Meleagrina margaritifera), Deren ßerfen -- nach netterent, aber noch

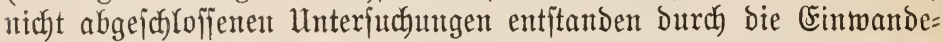
rutg won Saugmitrmern - po begehrt find. Taucher holen an ifyren

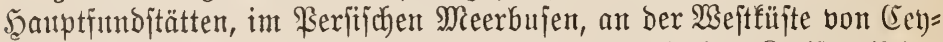
lon, bei Japan, im Meerbutien von Merifo und in ber אalifornijchen

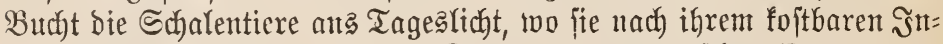

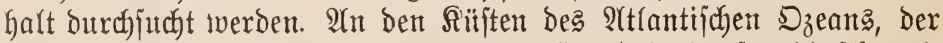
Sordjee und Des Mittelmeeres lebt in gropen (Sejellichaften sie idgmadt=

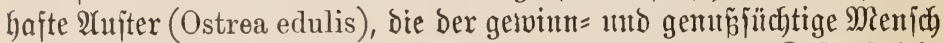

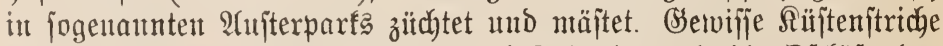
Des Mitteluteeres, fo bie Beftabe bei Tripolis uno bie Ditfiifte der 
Adria, bewohnt ill geringer Tiefe unjer Babefdwamn (Euspongia officinalis). Mit vierzinfigen langen (Sabeln ppieśt man bie Sdyvamm=

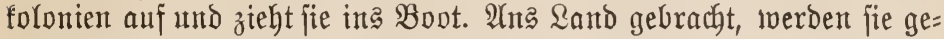
fuetet und getreten, bantit fich bie weiche Sïrpermaffe von bem \$̧orn= gerüjt löje, barauf gerei= nigt und gebleicht. Dex Sand, Der fid beim cin= fauf mandfyal noch in den Schrömmen findet, wirb von fad)lauen Şänd = lern abjichtlich zugejebst, bantit ex bas (Setwidst ihrer Ware erhöhe. Der bejte ift Der becherförmige,

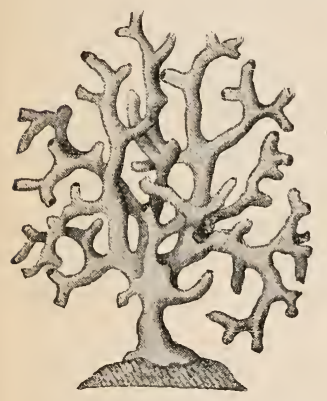

2Cbb. 20.

Storf eines Ralfichivammes (Ascyssa acufera).

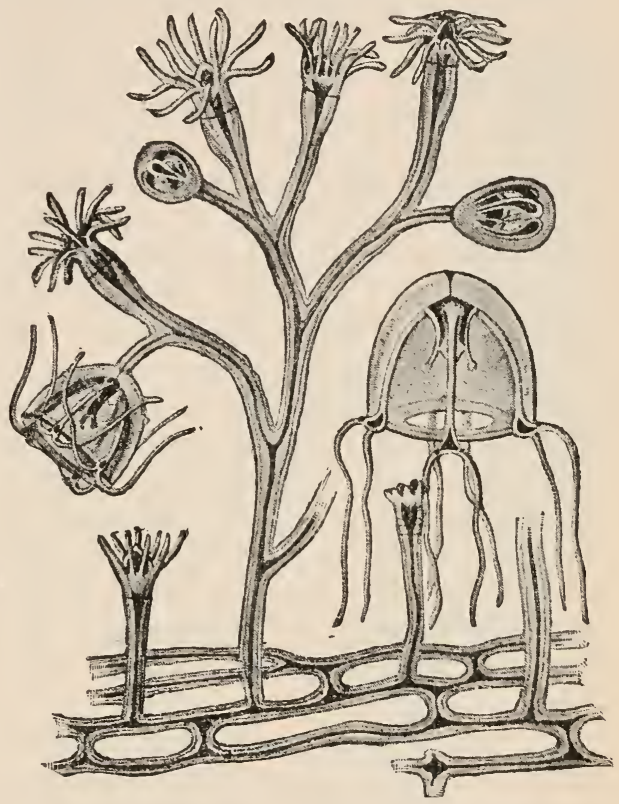

2Gb6. 21. Folt)penftorf (Bougainvillea ramosa) mit fuvpenden und fich ablöjenden Mebujen.

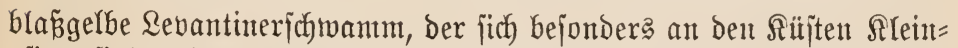
ajiens futbet; Die id)(ed)tejte Sorte Des Scandels bildet ber grobe Pferbe= jatwamm. Stachelige Seeigel, Seeiterne in mannigialtigen Formen un oft prachtooll roten Farben finden wir dort ziwifhen den Seepflanzen

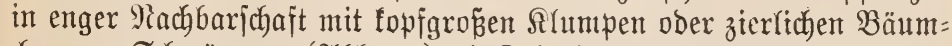

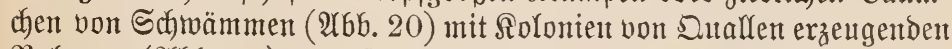
Folypen (2lbb. 21), mit farbenprächtigen Seeanemonen, Den Silien,

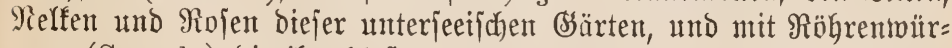
mern (Serpula), die ifre blä́roten Fieberfronen entfaltet baben. Finten

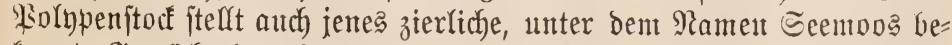
fannte (Setwächs bar, bas man fo oft in fleinen $\mathfrak{A}$ mpeln als Bimnter

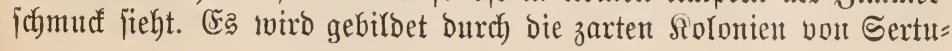


larten, bie jeşt aud an ben beutjchen @iijten gejammelt und bann fünjt= (ich) grün gefärbt werben.

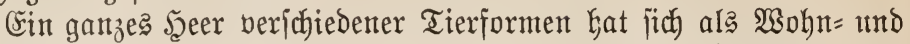
Jagdgebiet bie vielgeitaltigen, zierfichen voer mafitgen falfbauten ber Rorallentiere außerwählt. Dazu gehören nicht mur bie Meerdatteln,

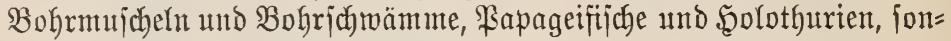
Dern audb Der rätjelhafte \$alolowurm, Defien toahre Slatur exft vor fur= zent von Sirämer und Friedländer zut gleicher Zeit erfannt worben ijt.

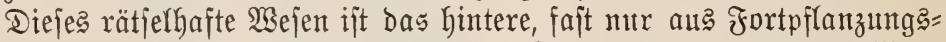
produften bejtebende (Ende eines zu Den Sieferwïrmern gehörigen $\mathfrak{W u r}=$ mes (Eunice viridis), ber im Sorallenfalf wohnt. Er erjejeint ganz

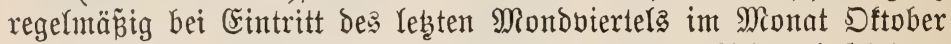

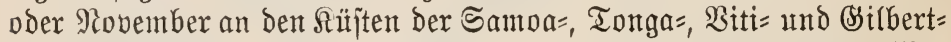
injeln und wirb banu von ben Cingeborenen majjenfaft veripeift. $\mathfrak{W}_{\mathrm{D}}=$ her biejer rätjelhajte Bujammentang mit ben Mondophajen fommt, ijt

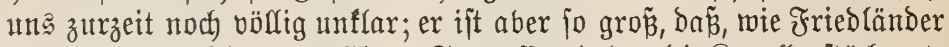

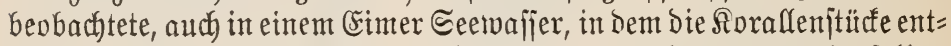

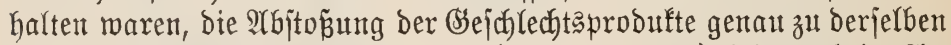
3eit jtattfando. Cinte vertwande $2(r t$ (Eunice fucata) Yebt aud im $\mathfrak{A} t=$

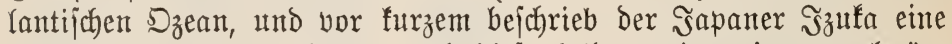
andere aus feiner Sceimat; audh bieje beiden zeigen jene merfmür= bigen Beziehungen zum Menowedjel, mur ijt ez bei ber japanijdent 2(rt das Borberentoe, bas mit Criern vollgeitopft ijt und abgemorfen wird.

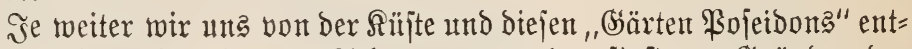
fernen, je megr wir vom Lidfte meg uta ben finfteren Gründen ber Tieffee nähern, bejto mehr äntert fich daz Bitlo. Dort ewiger Wedjjel,

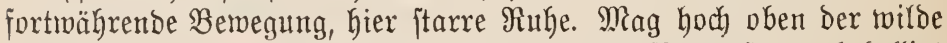

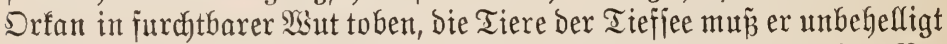
Iaffert. Seerrichte an ber Sïjte bei allen Tierformen vor allent bas $\mathfrak{B e}=$ itreben nad) Feftigfeit ber $\Re$ örperbecfe, nach einer gemifien Stabilität

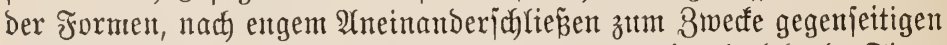
Schubes vor, fo finden wir in ber Tiefjee mehr einzeln lebende Tiere,

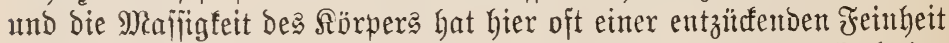
Der (Bejtaltung \$lats gemadt. Dabei zeigen bie Tieffeetiere vielfach eine Farbenpradht, ste man früher Dort nidyt geahnt hatte, und bie nur Daburdy

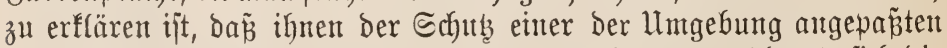
Färbung bei Dem Mangel Des \&idbtes unnötig war, währeno ïch bie Bewohner ber Fladjee am bejten jtehen, wenn jie ifhrer 1 mgebung mög= lidjft ähutich find ober als grau im Srauten verjduminden. Wir werben 


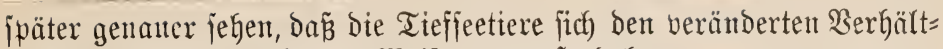

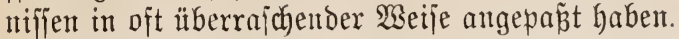

Biele Tiefieeberwohner Yeben am Boben bes Mieeres oder halten fich

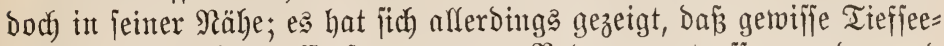
tiere aud in weiterer (Entfermung vom Boben angetroffen tverden und beshalb mehr als pelagijach lebend anzufehen pint. Das eigentlidge Ǵebiet Der Tiefieefatma begintt in etiva $400 \mathrm{~m}$ Tieje, in wärmeren und jalzreicheren Bimten=

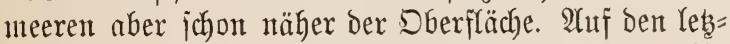
ten Expeditionten find nun aus Tiefen von 4000 bis $5000 \mathrm{~m}$ Tiere heraufbeförbert worben, bie man bor $=$ her nux als şberflädyenformen gefaunt hatte. Einte, interntediäre" unbelebte Schicht zmi=

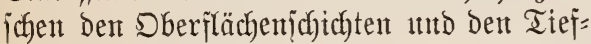
jegrïnden jocheint überbaut ganz zu jeblen, jedenfalls aber burdfaus nidjt jo tierarut zu fein toie utan früber anzunehnten genteigt toar.

(Ed)te Tieffeetiere fint in erfter Rinie die

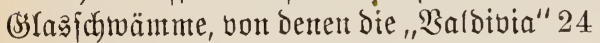
nene Arten heimbrachte, Sebilde von oft ganz

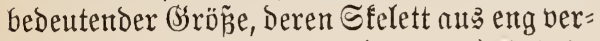
filiten feinen Siejelnabeln ( $\mathfrak{A b b} .22$ ) bejteht. Wie ungeheuer zahlreich dieje meijt regel=

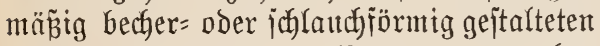
Wejen den Boden des Meeres an mandben Stellen bedecfen miifĩen, geht idjon darats

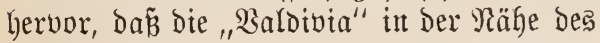

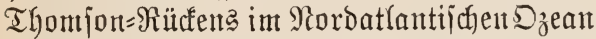

ฯ๖६. 22. Riejrifelett Dez

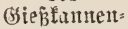
ifhroammes (Euplectella aspergillum).

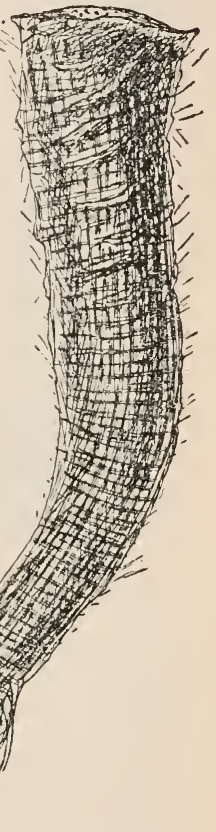
mit einem 8 uge mehr als 500 Stüde eites und desfelben Tieffeefdyan= mes (Tenea muricata) ans Tageslicht bradjte. Finer ber ichönjten bie=

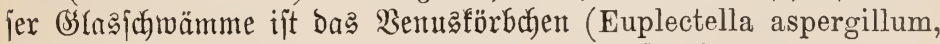
Ubb.22). Der röhrenförmige, ca. $30 \mathrm{~cm}$ lange, janft gebogene und in eiten Wurzerfahopf auggehende Sïrper ijt oben mit einer fiebartig Dutrchlöcher=

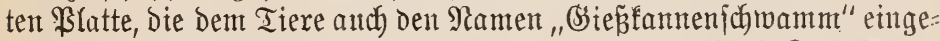
tragen hat, verichlofien. Das prachtod la zarte und zerbrechliche Si iejelifelett, das allein von biejem Tier nach (Furopa gebracht wirb, ift aus vielen an=

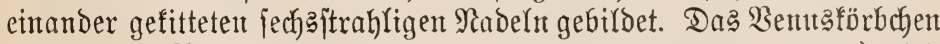
wirb bei ben \$hilippinen gefunden; ein Berwandter (Hyalonema) tvirb

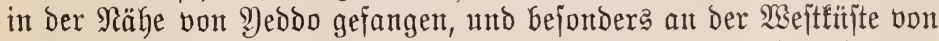
Sumatra und bei ben Nifobaren fand die "Baldivia" zahlreiche, zum 
Teil neue Bertreter biejer @dyrämme, unter Denen eine $70 \mathrm{~cm}$ lange

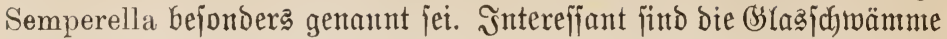
auch aus beut Srumbe, weil fie jegr oft anderen Tieren als ßohnung

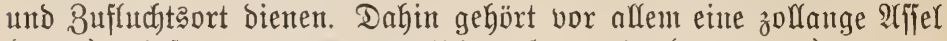
(Aega) unt ferner eine 2(rt von fleinen Sarneelen (Palaemon); Yebere,

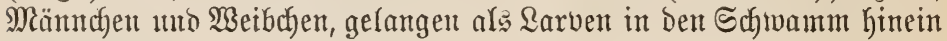

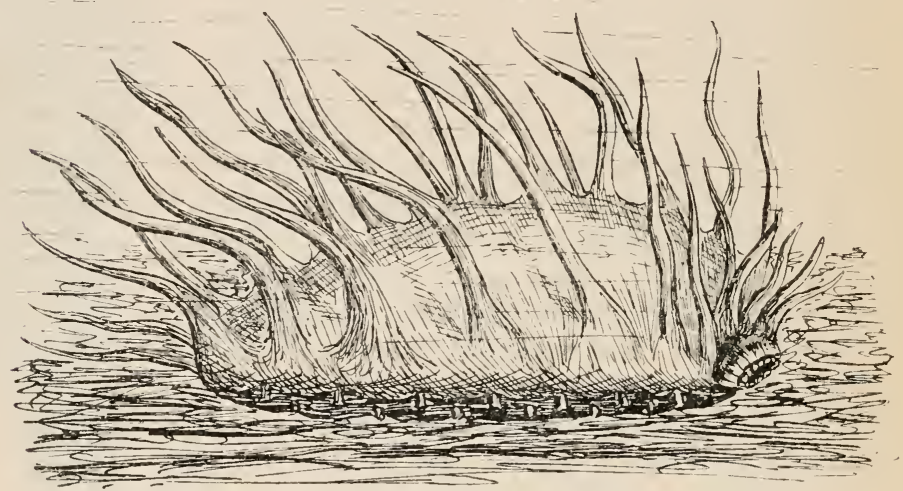

26b. 23. Eite Scewarze aus Der Tiefe (Oneirophantes mutabilis)

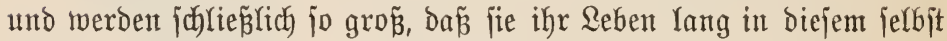
gewoählten Bsefängnis zu bleiben gezwungen jind, bas auch aljo ibre (Siruft wird.

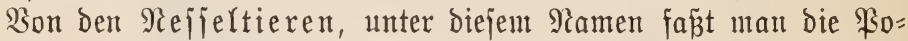

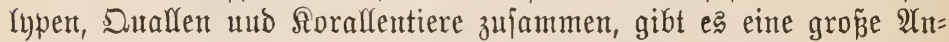

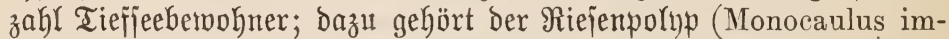

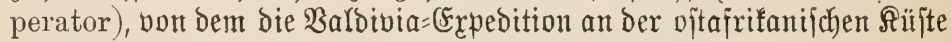
ein Eremplar von $1,5 \mathrm{~m}$ \&änge herborbrachte, beffen zart roter Samm oben zivei hochrot gefärbte Tentafelfränze trägt, während bas untere Ende auf bent Boben befejtigt ift. Bu nenten find weiter die See= anemonen, bon Denen nandje einen llbergang aus Dem itrahligen Bau in Den zweifeitigen zeigen, Der bereits eine rechte und einte linte Seite

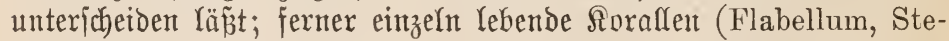
phanotrochus) und Rolonien von joldhen, von benen Lophohelia pro-

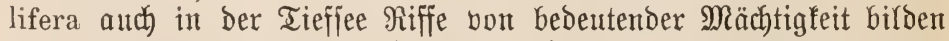
fann, joldbe mit Şornffelett (Antipathes) nnd enblich bie achtarmigen Sorallen, zu benen auch unfere Edelforalle ( $(\mathfrak{b b}, 4)$, bie aber unter $200 \mathrm{~m}$ nidgt mehr vorfommt, forwie die leudytenden Seefedern (Penna- 
tula) und andere fob̈ne Formen gebören. Selbit bon den zarten und ätherifden Suallen nno @drmimmtpolypen find heute zablreiche Ber= treter in gröferen Tiefen befannt; von erfteren nenne ich die (Şattungen Atolla ınd Periphylla, von Yebteren die $\Re \mathfrak{i} ;$ ophyjen, von Denen bie "Yaldivia" einen $4 \mathrm{~m}$ langen Storf exbentete.

Echte Tieffeebetwohner find vor allen bie Stadyerhä ter, bie in ihrer ganzen Qebentweife, twäbrend ibres Puters twentigitens, anf den Meeres= grund angewiejen find. Dahin geljören gewiffe Sectwalzen ober Şolo= thurien (Oneirophantes, $\mathfrak{2} \mathfrak{b b} .23$, Psychropotes u. a.) von raupenähn= licher Sseftalt mit langen, tentafelähnlichen Fortiäzen, bie merfwüroigen, mit Schrommianeibe frei flottierenden Pelagothtrien ber Baldivia= Ex pebition, Seeigel (Salenia) mit oft riejigen Stacheln ober foldye von

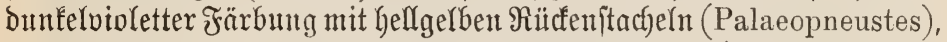
bewegliche, rot ober orange gefärbte Srblangenfterne (Ophiomusium), ıunberbar Yeuthtende Seejterne (Brisinga) und ?hgebörige der uralten

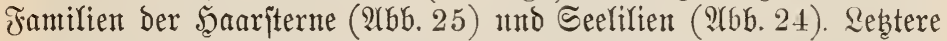
treten jờn in ben ältejten Schichten ber cambrijuen Formation, erjere

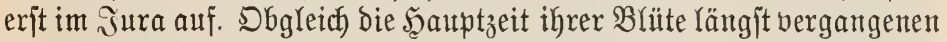
sahrtaujenden angehört, fobeinen jie jtellentweije mit ihren auf johlanfem, gegliebertem Stiele getragenen tentafelreichen förper Den Mieeresboden geradezu zu bedecten. fap $\mathfrak{B i n c e n t}$ in bie Tiefe von fajt $2000 \mathrm{~m}$ hitablies, brachte eS ztwanzig Stüaf einer und derjelben Seelilie (Pentacrinus Thomsoni, 2lb6. 24,1) Gerauf, und der "Ehallenger" erbeutete in ber Sïbjee Deren jogar fümf= zig mit einem Male. Sn bezug auf die Crbentung neuer und inter= efianter frinoiden war befonbers die Dentiche Tiefiee=(Expedition vom

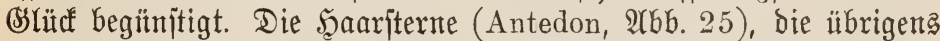
meijtens feichteres $\mathfrak{W a j j e r ~ v o r z i e b e n , ~ g l e i d g e n ~ a u f ~ D e n ~ e r j t e n ~ B r i d ~ b e n ~}$ Sallangenjternen; fie fönnen fich nit Şilfe ifrer Ârme frei belvegen,

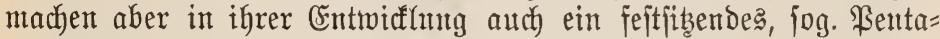

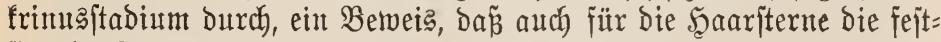
jibende হebensweije der nriprünglichere Bujtand war.

Un $\mathfrak{W}$ ürmern find die Tieffeegründe fehr arm; zu erwähnen find

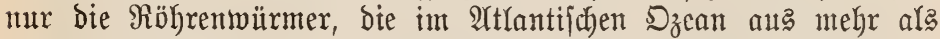
$5300 \mathrm{~m}$ Tiefe, bei den Biti= Jnjeln in $5200 \mathrm{~m}$, zwijenen Japan und

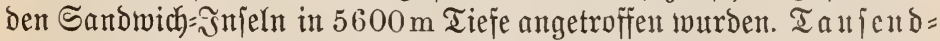

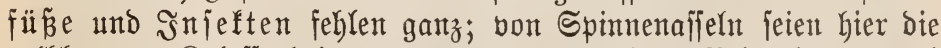
gelbbraunen Soloffendeisarten genannt, Deren lange Beine bis zu zwei

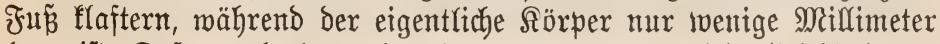
lang ijt. Dejto verbreiteter ijt aber Dort bas artenreiche (sejchlecht ber 


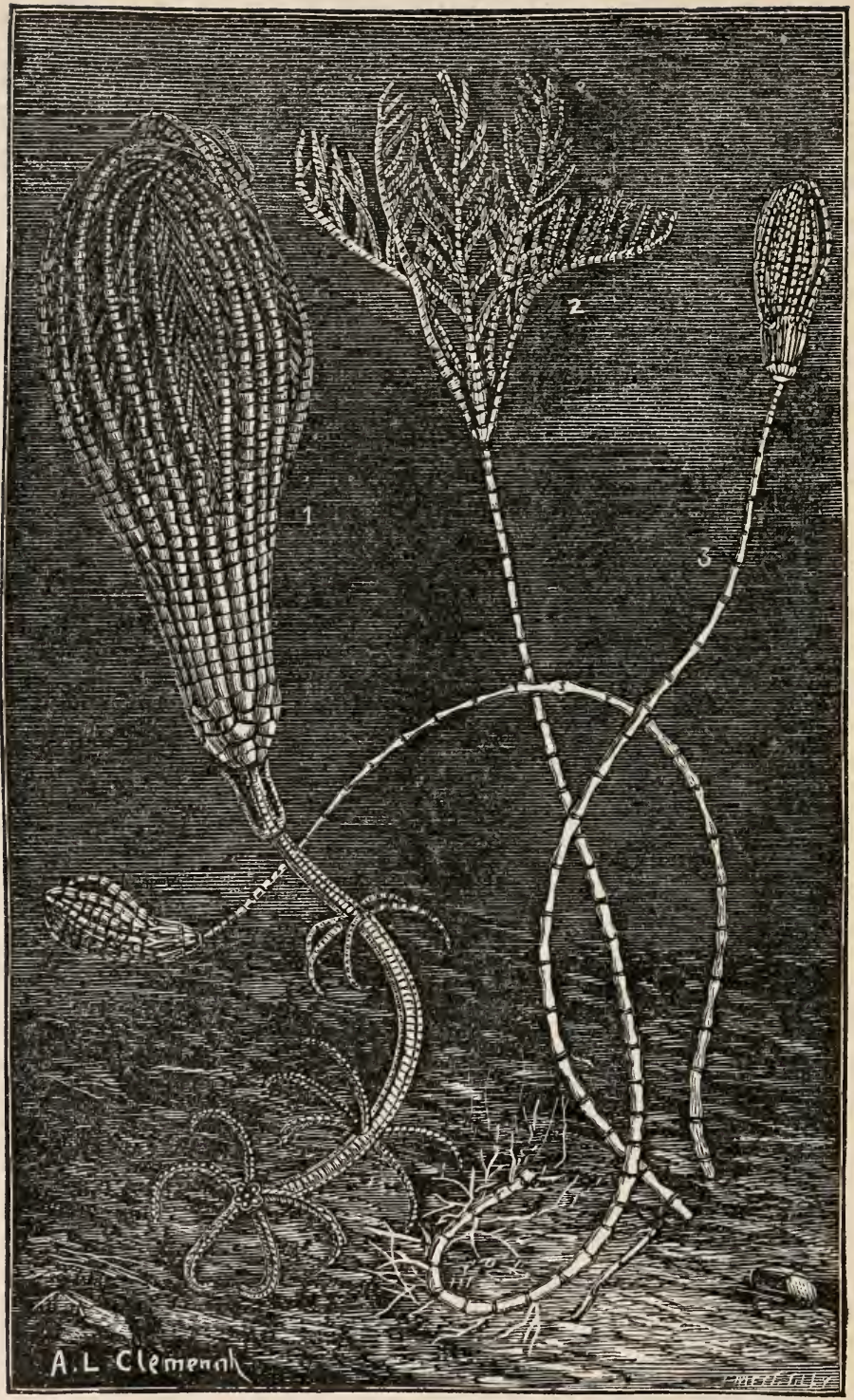

IGb. 24. 1. Pentacrinus Wyville Thomsoni. 2. Rhizocrinus lofotensis. 3. Bathyerinus gracilis. 
Srebje. Sie madhten in antarftifden Breiten mand mal etwa ein Finnfel ber ganzen Beute aus grö̈peren Tiefen auts. Mnter biejen ift bie Riejen= ajfel (Bathynomus giganteus) zut nenten, die die für dieje Brruppe

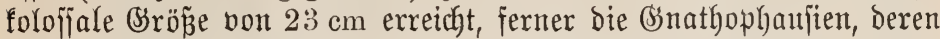

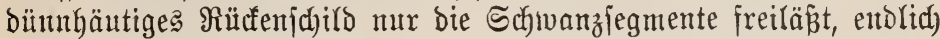
Glinde (Thaumastocheles, 2(bb. 26), zum Teil aber auth mit guten

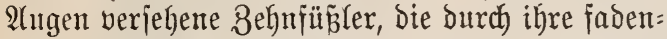
bümnen Füthler und riejenlangen Beine ebenjo auf= falfen (Nematocarcinus, Hapalopoda), mie Durch) ifre oft hochroten, violetten oder bratmen Fär= bungen.

Die Fifdue ber Tiefiee, bie ung Gier bejonders

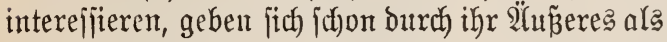

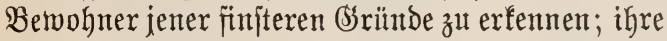
Srrundarbe ift meijt ein tiejes Sammetjumarz, Flecten ober bejondere Beidhungen fehlen ihnen.

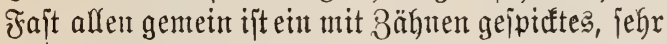
groées Maul, defifen Unergründfichfeit bei bem im Schlamme haujenden Melanocetus Johnstoni (26b6. 27, 3) Durch eimen riejigen Magenfact, ber brei Bierter bes Tieres aummadht, gefenmzeichnet miro; beim ßelifanfifich) (Saccopharynx peleca- \$ibe. 25. Antedon rosacea. noides, $\mathfrak{A}(\mathfrak{b}$. 27, 1), einem im übrigen aalartig

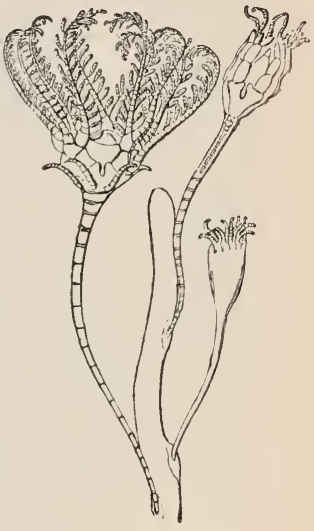
idjiebenter Entroidtung. ausjefenden Fifh, findet bas riefige Maul eine Fortjebung in einem

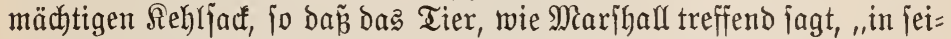
ner BSeftalt Qöffel und Irichter vereinigt". WSie ber unterfättliche Meloch, einer lebenden Fifdhreuje vergleidbar, werbent bie Tieffeefifdye mit weit geöffinetem Maule bie meite $\mathfrak{B a f f e r w i i f t e ~ b u r c t z i t e h e n , ~ r u h e l o s ~ u n d ~ o h n e ~}$

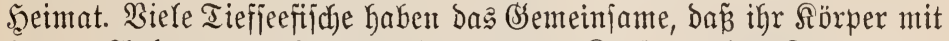

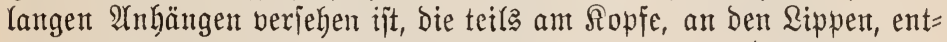
ipringen, teifs mächtig verlängerte Frluffenftrahlen find (Stomias, Eustomias, Nelanocetus, Malacosteus); bie Baudfflofifen find im allge

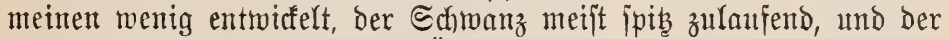

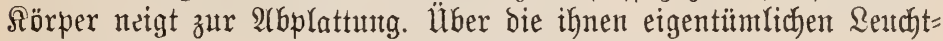
organe werben wir an anderer Etelle zu iprechen haben.

Wie jchon vorker geiagt, haben neutere Beobachtungen, namentlich

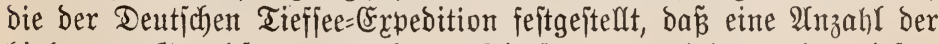
bisher zur (šrunbfauna gerechneten Tierformen aud in weniger tiefen, in ben jog. intermediären ๔chichten angetroffen werben Sie gehören Danach mehr zu jenten Tieren, bie man als pelagijde bezeichnet, ๖. h. 


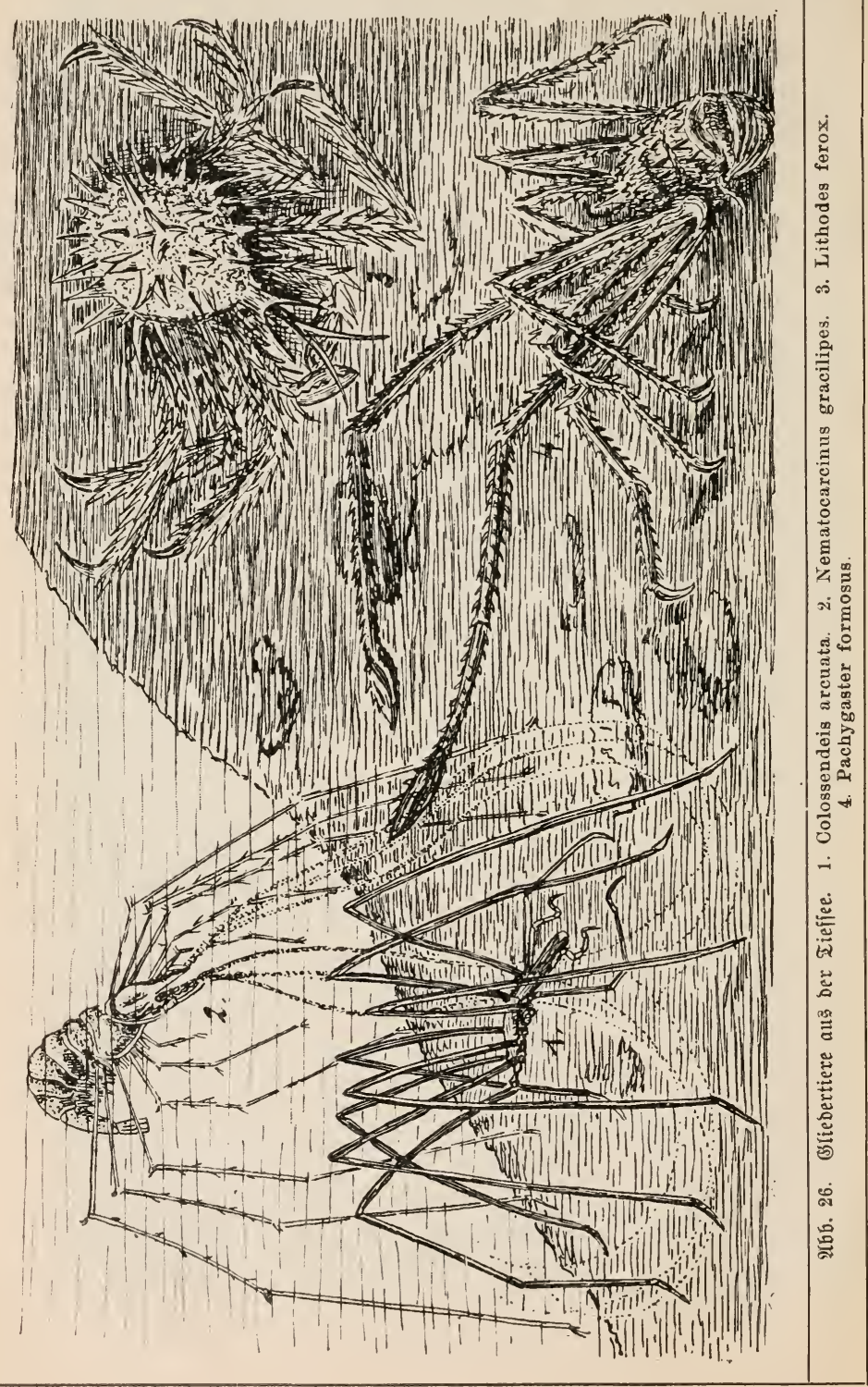




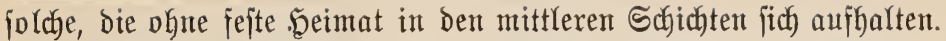

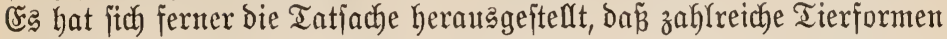
fowohl im sörblichen als aud in Sïblichen (Fismeer angetroffen wer= ben, in ben zwijhen beiben liegenden Sebieten aber fehlen. Man be=

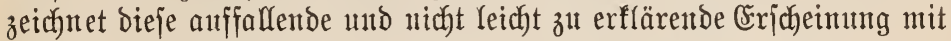
bem গamen Der "Bipolarität" Der Tierwelt. Sie ijt weniger autgge=

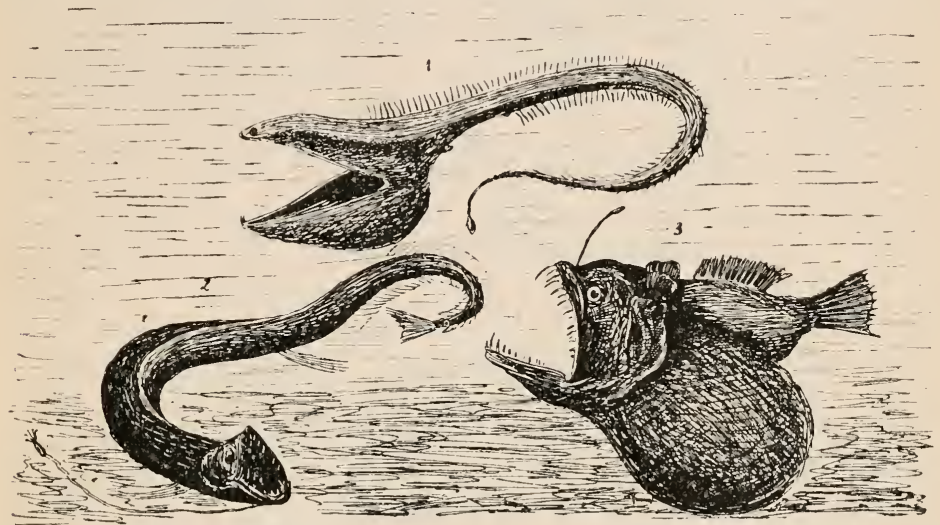

\{bb. 27. Tieffeefifife. 1. Saccopharynx pelecanoides. 2. Eustomias obscurus. 3. Melanocetus Johnstoni.

prägt in Der Tierwelt Der Flachjee und ber Süftenregionen, Deutlich

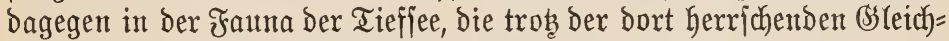
förmigfeit ber $2 e b e n$ bebingungen nidht ïberall gleich, fondern in ex= iter Sinie von ben in ben oberen Schichten Yebenben Sä̈rorganismen

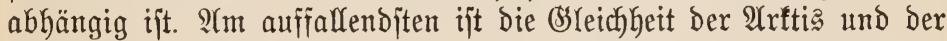
Antarftis in bezug auf bie noch zu erwähnenden ßlanftonorganismen. ¿s jind Gauptjächlich zwei Iheorien, die dieje Bipolarität erflären

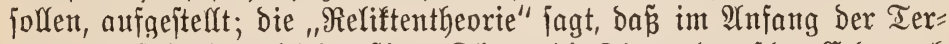
tiärzeit infolge bes gleichmäp̃igen Srimas bie Tierwelt auf Der (rrbe aud

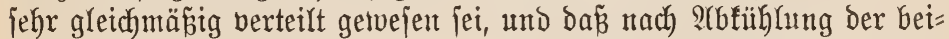

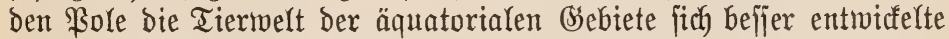

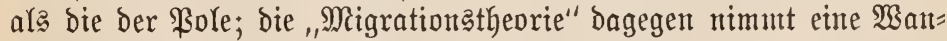
berung ber Tiefieetiere auf dem Meeresboden von $\mathfrak{P o l}$ zu Pol an. Da

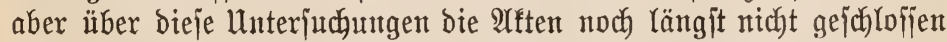
find, wollen wix uns wieder Ginaufwenden zu হidht und Sonne, zu

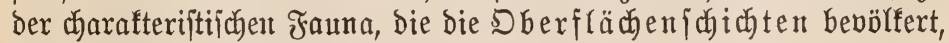
ber Tierwelt des Prantton. 
Weld ein (Segenją̧ zu Der ftiflen Finfternis der Tiefe! Şier ift doch

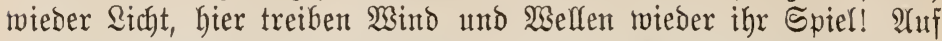
ber ambern Seite aber audf wieder ein bemerfenztwerter Unterfachied von ber Flachjee. Dort fanton wir bie Tiere an ihren @ieblingąpläbent, bie einen verjteçt in ben üppigen Tangtwäldern, andere im Shlamm auf ihre Bente lauterto; bieje zogent jteile, Feljige, jene jandige Süjten vor; ie nach ihrer $2 o r l i e b e$ fandent wir bie einen nahe ben Mündungen von flitffen, bie anderent burch bie zurï̈ftretende frlut auf bem jchlant= migen (Sirund gebettet, furz, jeber biejer Sïftenjtriche hatte getvifjer =

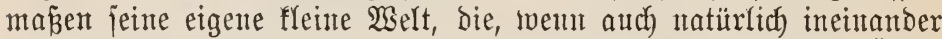
übergefjend, boch burch bejondere Tierfornten gefennzeichnet twird. Über=

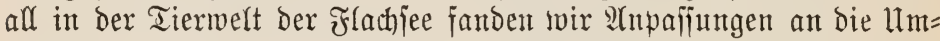
gebung, in bezug auf Dic Farbe an ben bald fteinigen, bald jantigen

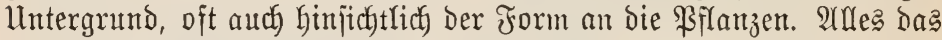
fällt fort, je tweiter trir ung von ber Sï̈̈te entfernen. Şier emiger Wechjel, Dort die meite Fläche des Meeres, getragen non Den Yidytlojent 2lbgründen, mit ziemlich gleichem Salzgehalt, gleichen \&ichtverhältmiffent,

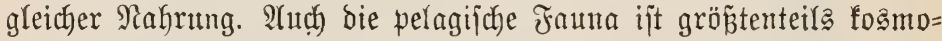
politija); nur für viele nalge ber Dberfläche Yebende Tiere gibt es eine Grenze nach den Bolen hin; two aljo andere tremmende llnterichiede

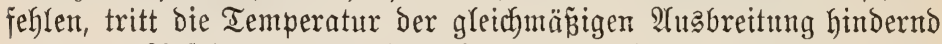

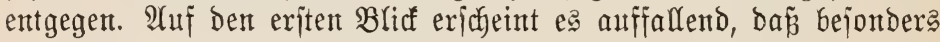
bie nördfichen Mieere planttonreicher finto als die jüblicheren, daz nicht

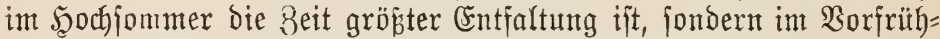
ring. Dodh bieje Erricheinung hängt mit ben horizontalen und verti= falen $\mathfrak{W a f j e r j t r o ̈ m u n g e n ~ z n j a m m e n ; ~ e i n ~ r e i c h e s ~ \$ l a n f t o n l e b e n ~ e n t w i f f e l t ~}$

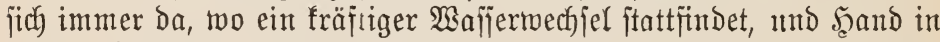

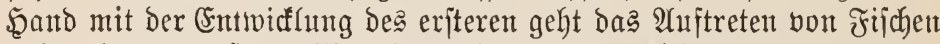
und anderen grözeren Meertieren, bie von den fleinen Planftontwejen

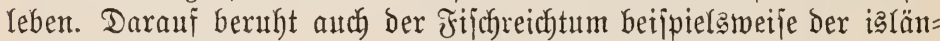
bijacen Gerwäffier.

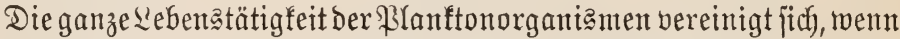
mant jo jagen barf, in bem $\mathfrak{B}^{2}$ freben, in Dem flüjfitgen Nährelemente zu

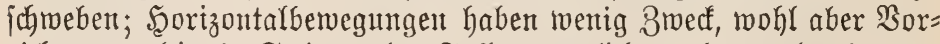
richtungen, bie ein Eteigen Dder Fallen möglich machen, und wir wer=

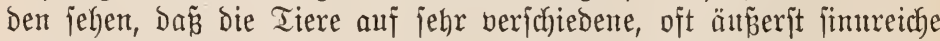

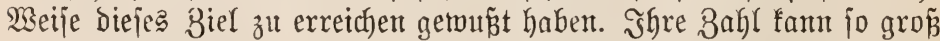

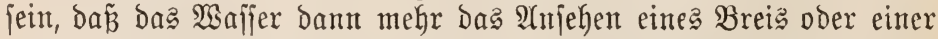
Suppe erhält. Sie geben das Fntter für bie fleinften tierijhen $2 e b e=$ wejen $a b$, zunächjt für die Miđlararden von Foraminiferen und $\mathfrak{R} a=$ 

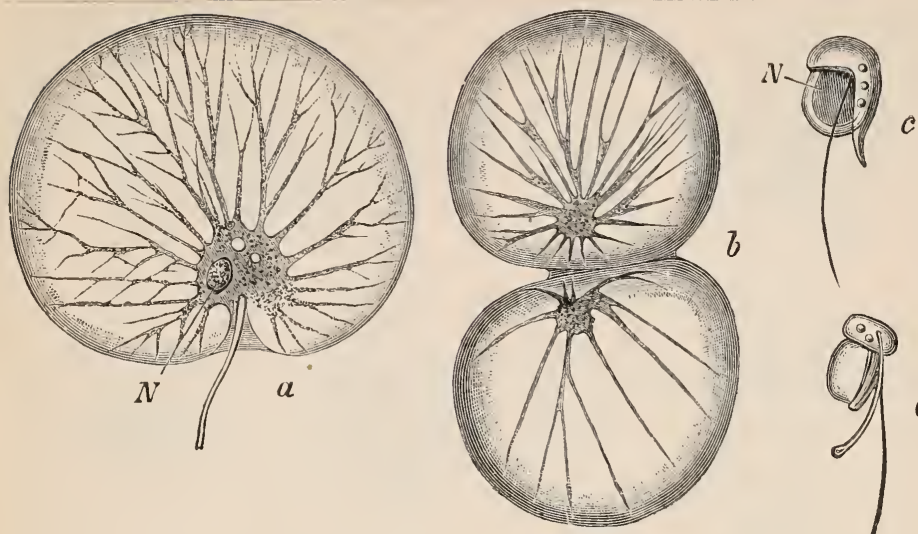

216b. 28.

Noctiluca miliaris.

$N^{\prime}=$ Rexı; $a=$ Finzeltiex; $b=$ zwei Einzeltiere in

Ronjugation begrifien; $c$ tno $d=$ Sdfwärmiporen.

Diolarien. Beide Dronungen gehören zu ben Planftontieren und unter=

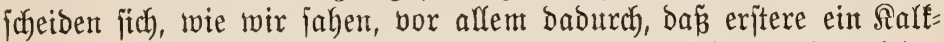

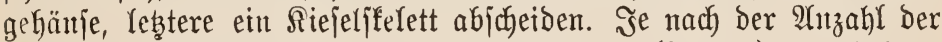
Rammern untericheibet man bie Foraminiferen ( $\mathfrak{A b b}$. 7) ars einfam= merige (Monothalamien) mit mur einer meijt gröperen, manḑmal jieb= artigen Б̈ffnung, und vielfammerige mit zablreidben fletuen \$oren (Rolythalamien), bei benten die Ramment nadh bejtimmten Sejeszen aneinander gereiht find uto mutereinander in Berbindung jtehen. Be=

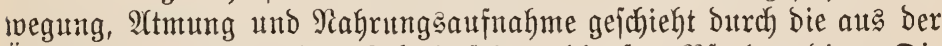

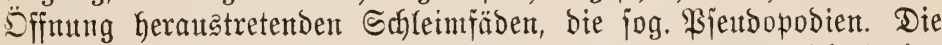

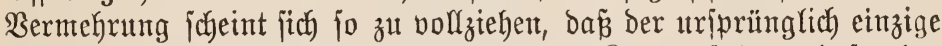
Sern in Teilftüfe zerfällt, Denten Der ganze fiörper folgt un fo eine Alnzahl junger einferniger Tiere liefert. Fine ähnliche 2 rt ber Fort= pflanzung fennt man aud von Den Rabiolarien (Abb. 8), Deren For =

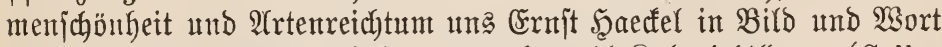
gezeid)net hat; gelegentlich fommt aud tobyl Soloniebildung (Collozoum) vor. Bmeitens finbet fich bei ifnen nod) eine Bermebrung Durd) Sdymärnier vor.

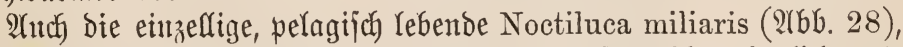
Deren äußerem Rörperranbe gelegentlich ein janftes ßhosphorlicht ent= ftrömt, gehört zu den ßlanftontieren. Die fleinen Wejen erjobeinent oft

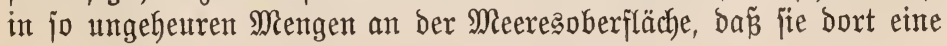



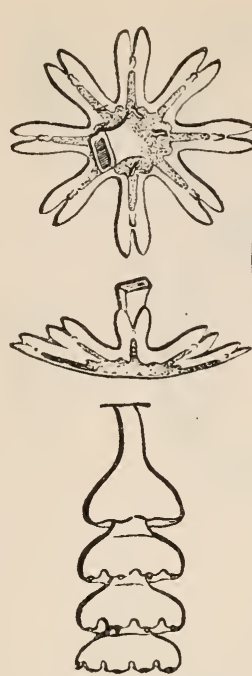
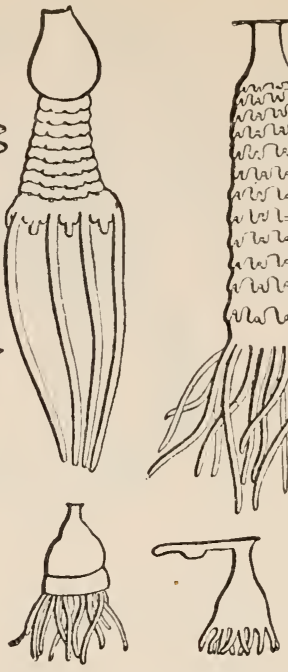
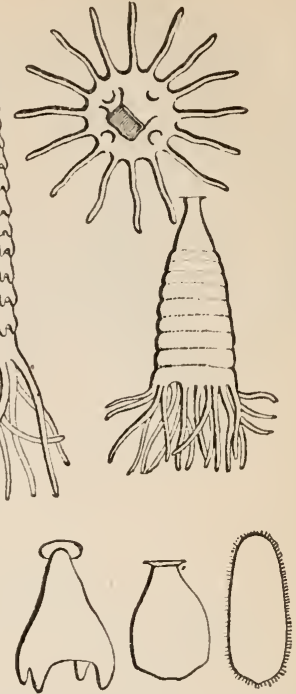

2̧b̧. 29. (Entwicflung ber Dhrenqualle (Aurelia aurita).

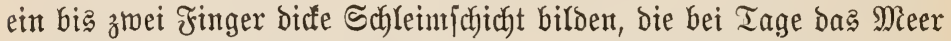

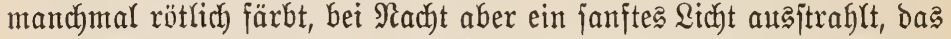

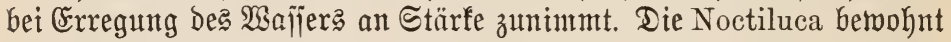

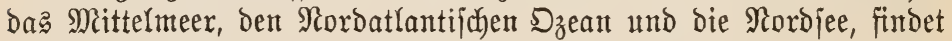
fich aber jeltener in Der jalzärmeren Ditjee.

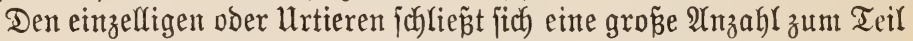
anfantg sinfach gebauter \&a r ven höherer Tiere an, bie bie Dberflächent=

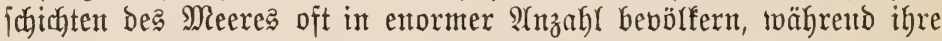
(5)tern in ber Tiefe Yeben, wohin auth) bie jungen Tiere nach vollzogener Berwand hung fich jenfen. Die ₹rortpflanzungsfähigfeit ber meiłten See= tiere ijt eine ganz auzerorbentliche; man braudyt mur einmal bie trau= benförmigen Eierftöcfe eines Seejternes gejehen zu haben, um bas be= greifen zut fönten. Daju lommt nod, da Seriobe ber Fortpflanzung zeigent, fondern daz man in ifren Ěier= ftöffen jederzeit reife B̌ejulechtaprodufte findet. Die meiften Tiefiee=

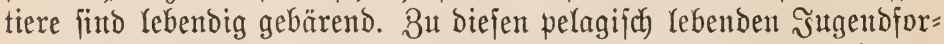

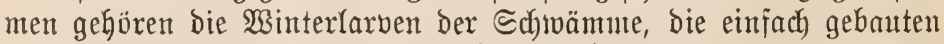

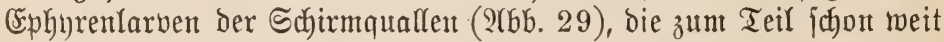
vorgebildeten, ebenfalls bemimperten Iugendzuftände ber fpäter feft= 

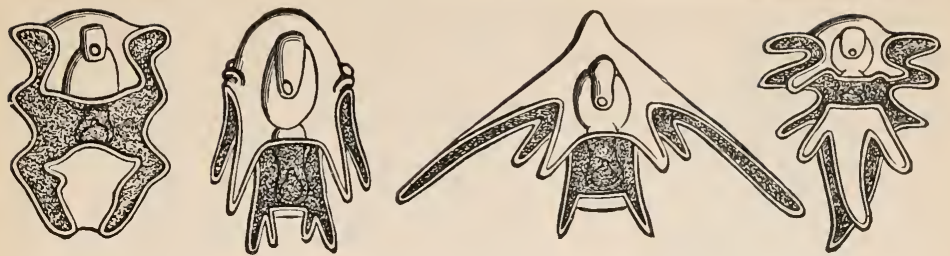

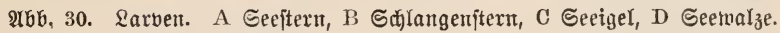

fibenden Aftinien und anderer Rorallentiere, fowie die mexftwïroigen, im Segenjab zu ben erwadjenen Tieren ztweijeitig gebauten Larven ber Stachelfäuter (âbb. 30). Sie erhalten ferner Durch Bildung bon

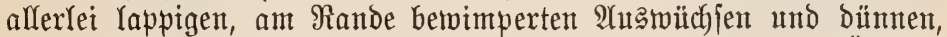

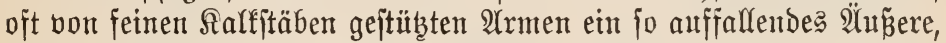

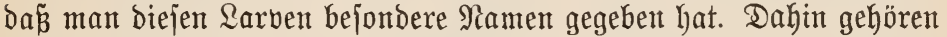
ferner die verichiedenten $\mathfrak{B}$ imperlarben der $\mathfrak{B u ̈ r m e r}$, der einäugige

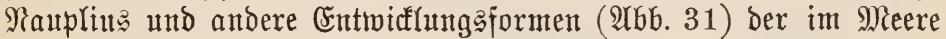
jo überaus zahlreichen Rrebje, dann die betwimperten Zarben vieler

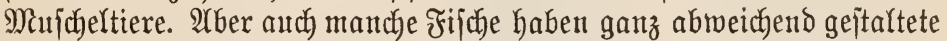

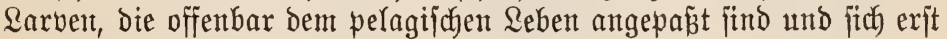
ipäter tvieder ber fiüfte ober ber Tiefe zumenden, wo ihre Grtern wohn=

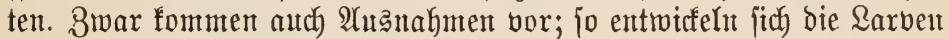
der Segelqualle (Velella) in einer Tiefe von mehr als $1000 \mathrm{~m}$, $1 \mathrm{~m}$ erjt fpäter an die sberfläd)e hinaufatiteigen.

Fine grof̉e Menge Tiere hat jich auch in fertigem $3 u$ tande bem pelagijüen Leben angepañt. Dazu gebören bie sutwelen des Meeres, bie mannigiach geitalteten, glocfenförmigen Duallen ( $\mathfrak{A b b} .32$ ) von mi= froffopijcher Rleiubeit bis zు $1 \mathrm{~m}$ Durchmeffer (Chrysaora, Rhizostoma, Aurelia), die fanimmenten, glashellen, vorneymlich den tro= pifden Meeren angehörenden ๔abrimmpolypen ober Siphonophoren (Physalia, Physophora $\mathfrak{A b b}$. 33, Velella) und die zarten, eleganten Rippenqualfen (Beroe, Pleurobrachia, Cestus Veneris). Zahllos ift das Seer der pelagifuen Srebje, meijt Tierchen bon wenigen Millimetern Sänge.

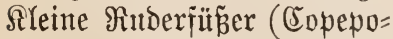
Den), die Şauptnafrung des jeering und jeiner $\mathfrak{B e r w a n d}=$ ten, Darunter die leudytend iri= fierende Sapphirina, färben

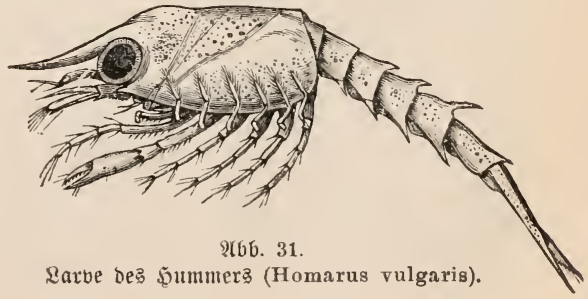


bas Meer oft rotgelb; Durchjichtige @dyalenfrebje (Ditracoden) und

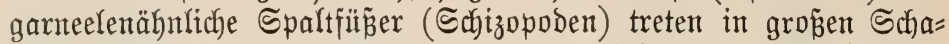
ren auf. Bon Molltaken find zu nennen viele Tintenfijache (Cepha= lopoden), bejonders das Papierboot (Argonauta argo), beffen $\mathfrak{W e i b}=$

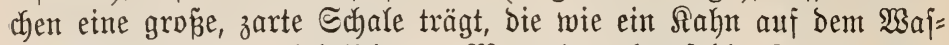

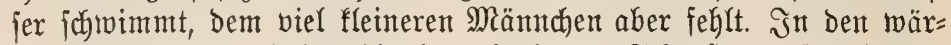
meren Meeren entfalten die Geraufgebolten Schlię̧nebze fajt immer

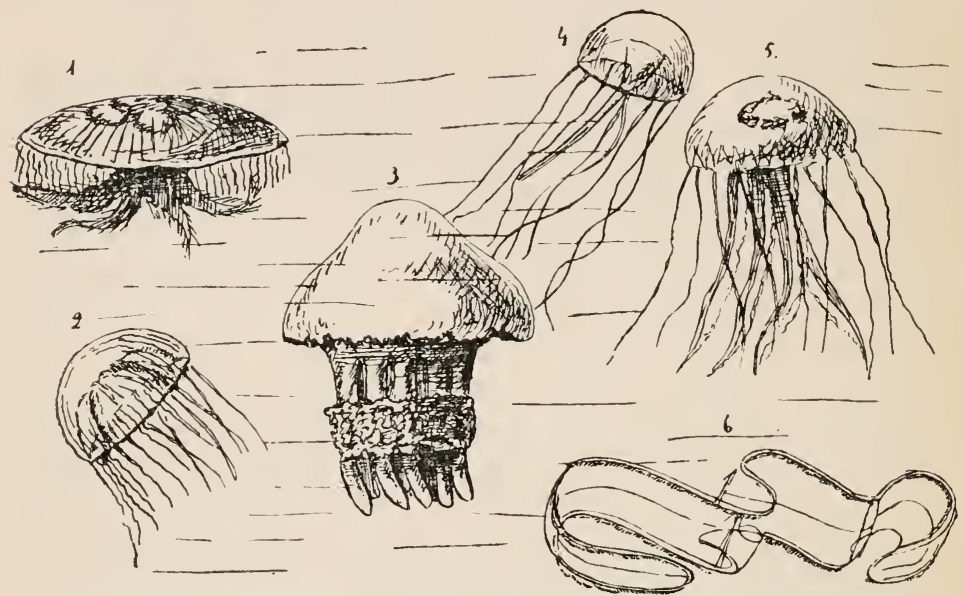

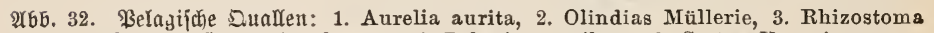
pulmo, 4. Carmarina hastata, 5. Pelagia noctiluca, 6. Cestus Veneris.

größ̄ere ober geringere Mengen von eigenartigen Sdyneden bou gallert= artiger ßörperbejchaffenheit, Şeteropoden und Pteropoden. Eritere, bie

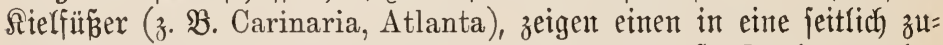

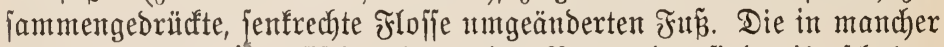

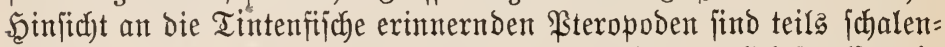
tragente, teils nadte, augenloje Schnedfen mit eigentitmlich) iegelförmig gebildetent Rappen, bie bent Frú barjtellen (Clio, Creseïs u. a.); fie finto echt pelagijhe Tiere, bie in ungeheutren Schmärmen bejonders in wär= meren Meeren fich finden, tagë̈̈ber fich in mäpiger Tiefe halten und mur nachts bei rutbigem Wetter an bie Dberflädbe jteigen. Mauthe von

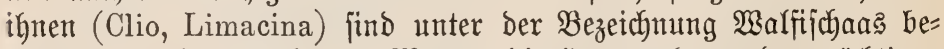
famt, weil ihre ungeheuren Mengen bie Şauptnahrung ber mächtigen Waltiere bilden. (5idht pelagithe Forment jind eltolich bie aus leuth= tenden Manteltieren (Tunifaten) gebildeten Solonien Der Fenerwalzen

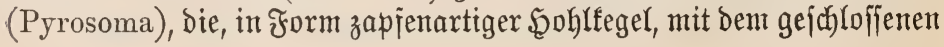


(snde nach vorn eine Rüctwärtsbetvegung burch den Stö́ Des aus bem anderen Ende getriebenen Wafjers ausfülyren fön= nen, fowie die Retten ber Salpen und an= bere Tunifaten. Es ijt beobachtet worben,

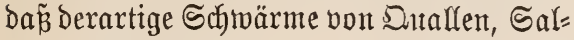
pen, Flïgelichnedfen $\mathfrak{a}$. a. fich fehr off in Der Nähe von Meeresftrömungen vorïuben, und vor allent bort, too joldye fich treffen.

Bon Fif lebent die Şate (Squalidae) mit Dem Rot= jenfijch (Naucrates), die auf ibren Raub= zügen weite Meeresgebiete Durcheilen, bie Flugfiche (Dactylopterus, Exocoetus), jo= Ivie ihre Berfolger, die farbentprädtigen Soldmafrelen (Coryphaena) und mandye andere. Viele Jૅodjieefijche pflegen übrigent? taģüber in gröseren Tiefen fich aujzuhal= ten und nux nachts bei gutem Wetter an bie Dberflähe zu fommen. Wale, die oft roie die Mïmen Den Seringszügen folgen, juhei= uen nad) Banboeffens Beobachtung elyer Sïften= als Şodjejetiere zu jein.

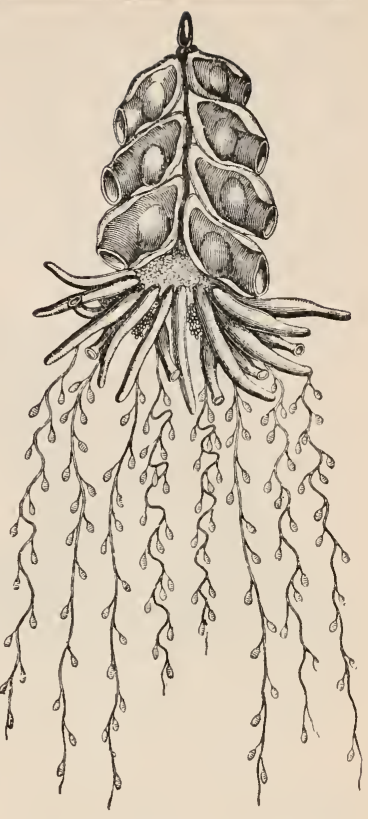

2(bש. 33 .

Physophora hydrostatica.

\section{X. $\mathfrak{U} \mathfrak{b} j \mathfrak{d}$ nitt.}

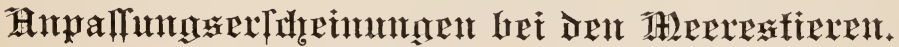

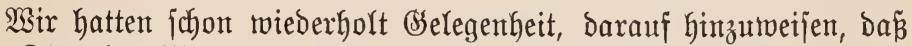
bie Tiere des Meeres in ihren jo vierjeitigen (Exjd)einungsformen eine großze Reihe oft jebr auffallender Finrichtungen zeigen, bie ifnen Den

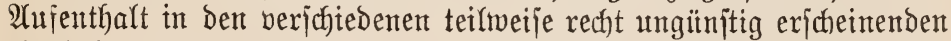
Berhältniffen erleichtern oder überhaupt erit möglich madhen. Die Flach =

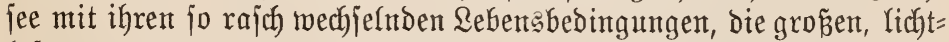
lojen, unter enormem Druf jtehenden und fajt unbetwegten Tiefen, die

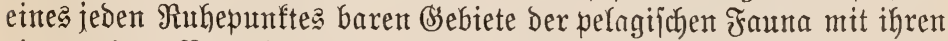
eigenartigen Berbältniffen zwangen die Bewohner, jich irgentotwie anzu= paffen, Ginridytungen zu treffen, bie ihnen bas Qeben in ibrem berweglichen

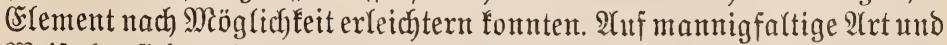

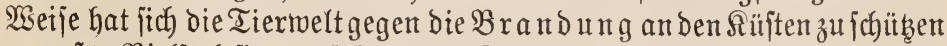

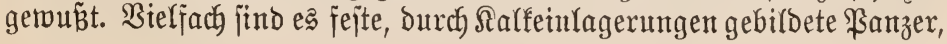


Durb) bie bie Tiere zugleich auth bor feind lichen 2 (ngriffen gefichert find, wie twir bas bei zahlreichen höheren firebstieren, ben ভtachelfäutern, Mu=

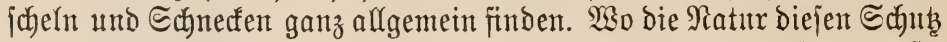

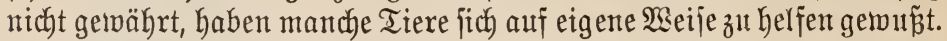
Sleine Irebje (Pontonia, Pinnotheres) verfriechen fich in bie Echalen von Mujcheln, bejonders ber Stedfmufdyel (Pinna) und juchen bont

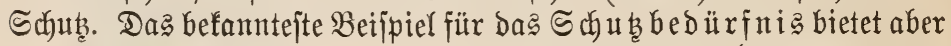

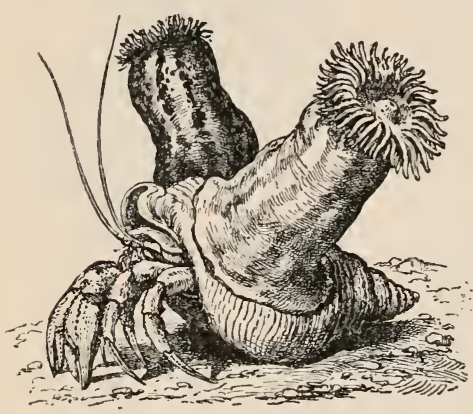

IYb6. 34. Cinfieblerfrebs (Pagurus) in ber Edjale eines Belfforns (Buccinum) mit ztwei Aftinien (Sagartia). Der Cinfiedlerfrebs (Pagurus bernhardus, $\mathfrak{2}(\mathfrak{b b} .34)$, ber jeinen weichen Şinteríetb mit Den z̆ Şaftorganen

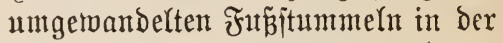
leeren Echale des Wellforns (Buccinum) birgt, aus welcher ber gepan=

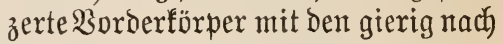
Brute ausfochauenden $\mathfrak{A}$ hgen herbor= ragt. Man fennt von diejen Eremiten mefra als Gumbert 2 rten, bon benen etra ein Biertel den entropäijchen Meeren angehören, und bie bie ভcha= len verjubiedenter Schnecten alమ $\mathfrak{B}$ oh= nung benuben. So fand bie Baldivia= Expebition einige 2 rten, bie in ben zahnartigen Schalen von Denta= lium wohnen. Snterefiant jinto uns fermer bieje Cinfieblerfrebje, weil

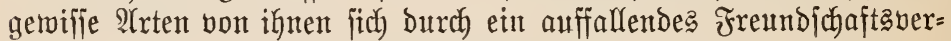
hältnis zu ganz anders gearteten $\mathfrak{B e j e n , ~ D e n ~ S e e r o j e n , ~ a u s z e i c h n e n , ~}$

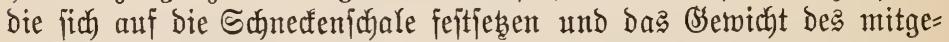

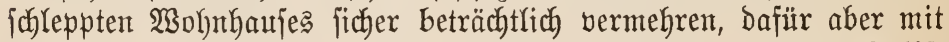

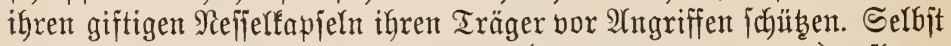
Einfieblerfrebje aus $5400 \mathrm{~m}$ Tiefe (Pagurus abyssorum) pflegen

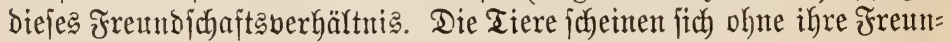
bin nicht recht wohl zu fühlen, ja, mandbe von ihnen wohnen in aus= getwachjentem 3uftande gerabezu in einer folonie folcher Tiere, mohlge=

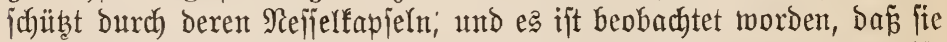

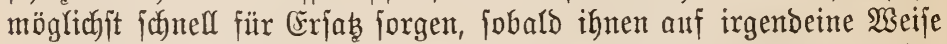

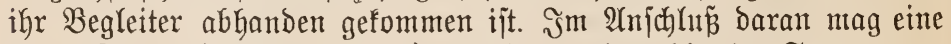
fleine §irabbe (Melia tesselata) erwähnt merden, bie eine Seeanemone beftändig in ihren beiden Echeren trägt.

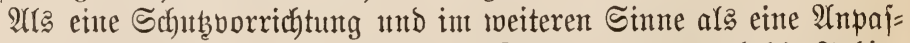
fung an bas \&eben in Der betweglichen Süftenjee mag auch bie Fä̆ig=

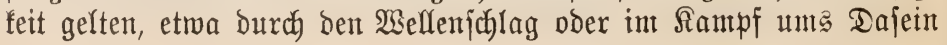


verloren gegangene Teile des Sörpers wieder zu erjeben, z" regente= rieren. Bon den die Sdjeren abwerfenden Irabben haben wix vorbin bereits geiprodben, ganz $\ddot{U}$ hnlidyes ijt von zahlreichen anderen Srebs= tieren befannt (Alpheus, Dorippe u.a.). Dieje Regenerationg fäbig= fe it bejizen bejonders die Stadyelfäuter in hobem Srabe; ber Schlangen= jtern Ophioderma longicauda wirft bei 2lugriffen oft jämtliche $\mathfrak{A}$ (rme $\mathfrak{a b}, \mathfrak{n} \mathfrak{d}$ von manchen Seejternen (z. B. Asteracanthion tenuispinum) findet man jo jelten vollfommme, mit lauter normalen $\mathfrak{A}$ rmen verjebene

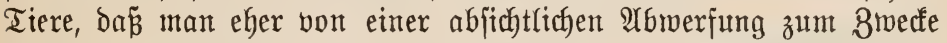
einer ungejd)ledytlichen Bermelyrung fprechen möd)te als lebiglid von einem Erjas verloren gegangener Sïrperteile. Bei mandyen Pljteroiben

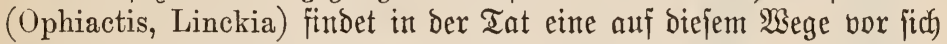
gehende ungeidyledytliche Fortpflanzung burch Teilung jtatt. Fin böbjit

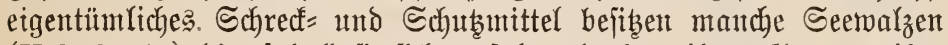
(Holothuria), die, jobalo fie fich verfolgt glauben, ihren Siegnern ifre

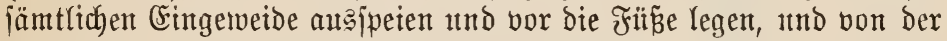
Seelilie Antedon rosacea hat $\Re$ iggenbad beobachtet, Daf fie ruhig tweiter= lebt, jelbjt wenn jie ihres ganzen Seldinhaltes beraubt wurbe. Für alle bieje Tiere ijt die Fähigfeit, Durch Selbitberitümmluntg und Regene= ration ber im Sampf ums Dajein gefähroeten oder verloren gegangenen Sörperteile weiterzuleben, jebenfalls von ber gröpiten Bedeutung. Die in Bereich Dex (Srenzen zwifden Ebbe und Flut wohnendent Tiere

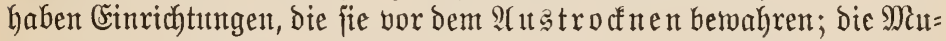
jabeln und andere Schalentiere flappen ihre Wohnung jeft zu; mandue andere jüüben fich burch Bildung von Decteln, burch die Miöglichfeit jid einzuftülpen, während die fitgelafjel (Sphaeroma) ifren Я̈̈rper wie ein Э̧gd einzurollen vormag. Biele Bewohner ber Sïften Gaben die Fähigfeit jidh fejtzuheiten. Bei den Schnecten gejdieht dieje $\mathfrak{B e}=$ feftigung mittels bes als Saugnapf dientenden Funes, bei ben See=

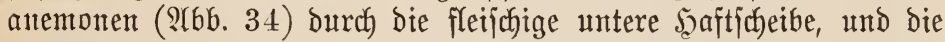

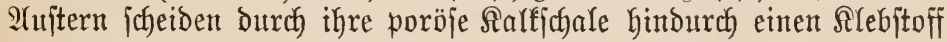
aus, mit bem fie fith an bie Interlage anleimen und fo zu Taujen= ben neben= und aufeinander angeheftet find. Andere Mrujcheln enthehren joldyer Scaftmittel; dafür haben viele aber bejonbers in ber șugend eine andere Sinnichtung, fie fönnen fich Durch feine Spinnfäben fejt vor 9 Anfer legen. Dieje werben Durch die im Fuñe liegende Bnflüsoüje geliefert, aus der ein im $\mathfrak{W a j j e r ~ e r h a ̈ r t e n d e s ~ S e f r e t ~ h e r a u s t r i t t . ~ D a s ~ b e f a n n t e j t e ~}$

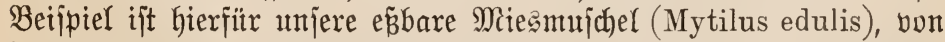

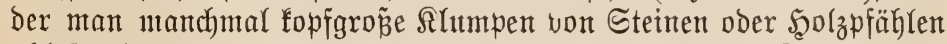
ablöjen fann. $\mathfrak{B}_{\mathrm{D}}$ jolche natürliche Befejtigungantittel im fampf gegen 
Strömung und Wellenjalag feblen, vergraben fich die Tiere in den

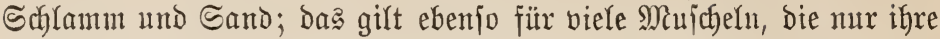

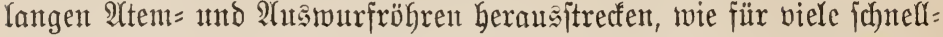

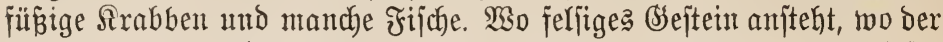
Boben mit Den Sierölle Der Brandungatwelle bebecft ift, wird diejes angebohrt. Derartige bohrende Tiere find aus zahlreichen Dronungen

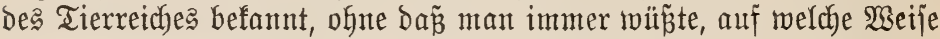

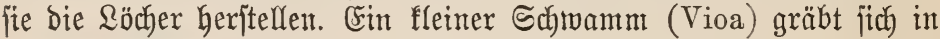

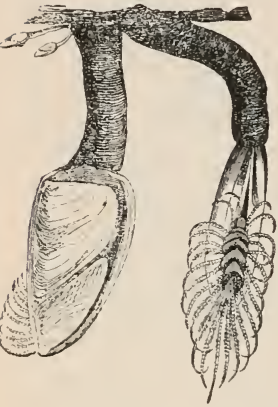

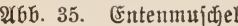
(Lepas anatifera). Den Salf der Rorallen und Mufdueln ein, gemifje Seeigel (Strongylocentrotus) bohren burd) fort= mährendes llmorehen ihres ftadyelbewehrten Reibes tiefe Södjer in die Feljen, unter Den Srebstierent ift eine $\mathfrak{A}$ ffelart (Limnoria) zu ermähnen, unter ben Mollugfen find es die ihre Sdale als Jeile be= nubenden $\mathfrak{P h o l a s = 2 ( r t e n , ~ d i e ~ M e e r d a t t e l ~ ( L i t h o d o - ~}$ mus) und ber ๔dyiffgbohrtwurm (Teredo navalis),

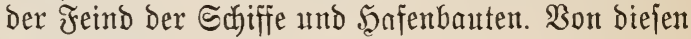
in felbjtgemählten Ssefängniffen lebenden Tieren bis zu Den Dauernd oder Dod wäfrend des grö̈ten Teils

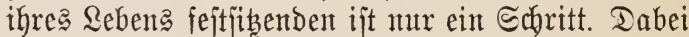

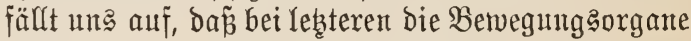
zurüafgebildet werben; an ifre Stelle treten lange, oft freiḡörmig geitellte Fangarme (Bryozoen, Serpula, Lepas $\mathfrak{U b b} .35$,

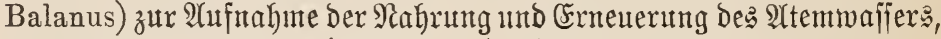

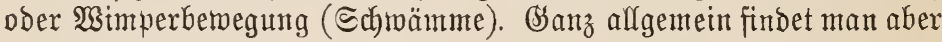
bei ben feitfibenden Tieren, Daş ihre Rarben fïr fürzere oder längers

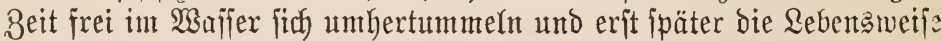

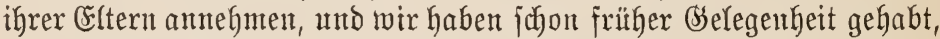
auf die \$id)tigleit diejer Sinridytung hinzumeijen. Sm engen 3ujan=

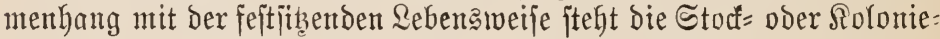
billung, bie bei zahlreicheu nieberen Tieren (Sorallen, Movatieren,

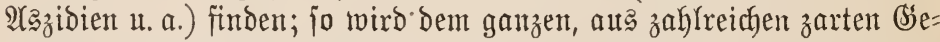
jajöpfen aufgebauten Stamme exjt ber fejte Scalt, ben bas Einzeltier allein fich nidyt würbe veridyaffen fönnen, zuteil.

Yuch Die Yrnaffung in ber Farbe fpielt bei Der Säftenfanna eine Rolle; bie zahlreichen bichten $\mathfrak{W a ̈ l d e r ~ b e r ~ S a m i n a r i e n ~ u n d ~ F u c o i b e n , ~}$ die verjajiedene Färbung des Stranbes doer der forallenbänfe Iaffen

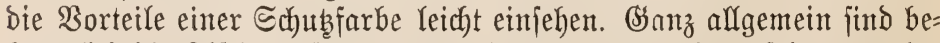

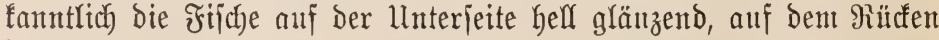
bagegen Dunfel gefärbt; fo futb fie vor Entbeding Durch einen über 
ober unter ifnen befindrichen Feind nach Mëglichleit gejchüht. Tief= jeefijuche zeigen bieje ltnterichiede meijt nicht. Bejonbers auffallent ijt bie Färbigteit, fich ber Farbe ifrer Ulmgebung anzupafien, bei manchelt Blattfifden, jo bei umieren Echollen (Pleuronectae), bie ihre fomijch verbrehten 2lugen gierig aus Dem Sanbe Keraukheben, in bent ifr übri= ger Sïrper zum Teil vergraben ijt. Die 2lugenjeite ijt bunfel gefürbt, bie andere Keller; bie erjtere vermag fith ber jemeiligen Farbe bes $\mathfrak{l l}_{\mathfrak{n}}=$ tergrumbes jo jegr anzupafjen, báz es oft jhtwerbält, bie Tiere zu er=

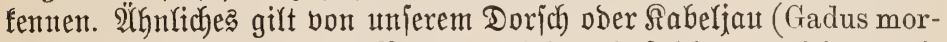
rhua); bie graute und rote Barietät fheint als folche gar nicht zu exi= jtieren, jondern bie verjchiedene Färbunt ift mur eine Folge ber $\mathbb{1 1 n t =}$ gebung, wie Şjorth, Der Reiter ber norwegifhen Fijhercierpebition, experimentell nachweifen fonnte. Erit bei näberem Bujehen entbect' man ferner bie Durch bie eigentïmliche Brutpflege ber Mämnthen befannten Seepjerbchen (Hippocampus), bie zwijhen den Tantgbüfcheln mit Şilfe ihres Sitfelidwanzes flettern, bic fihlanfent See: unt Schlangennabeln,

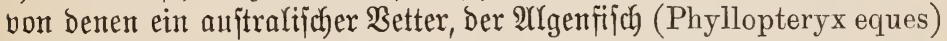
Durch Biloung von Dornigen unb lappigen 2 tnfängen und burch feine

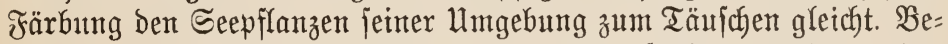
jonders auffällig ift toas auth bei bem bereits früher ertuähnten Antennarius, Der zwifhen ben Sargajiobündeln mit ફ̧ilfe feiner finger= artigen Frortiäke flettert, bein Seeteufel (Lophius piscatorius) mit jei=

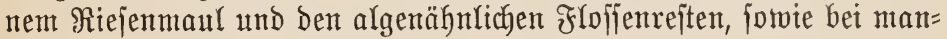
when Fijhen ber Siorallenfee, währent gewifife Seeigel (Toxopneustes, Strongylocentrotus) fich Daburch Den Blicfen ihrer (šegnter zut entziehen

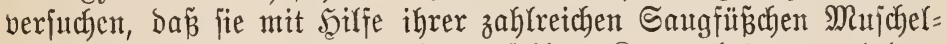
jejalen, Steinthen und Dergleichen auf ifren Sörper bringen und bort

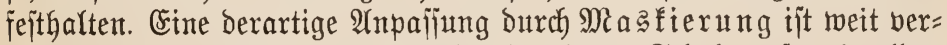
breitet bei Den Mafucheln ober Schnedfen, Deren Schalen oft mit aller= let tierifden ober pflanzlichen Drganismen bebectt und betwachjen find und jo einen ganz andern Eindruct abgeben als bie Exemplare un= jerer Sammluntgen. $\mathfrak{S a s}$ bei biejen Tieren wohl mehr ein Werf bes 3ufalls ift, ift bei manchen Srabben zum Bebitrints geworden; jo fieht

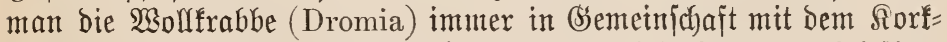
fchmamm (Suberites domuncula), tno es ift bei ifnen unb bei ffan= binavijchen Dreiefferabben beobachtet worben, baz bie Tiere jich offen=

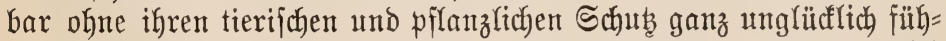

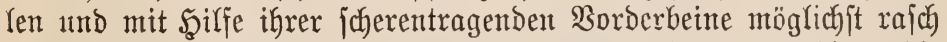
für eine neue Bedectutng ihres Sörpers jorgen, falls man ifnen bic alte genommen hat. 
Wenden wir un jest den Tieren ber Tiefiee zu, fo finden wir

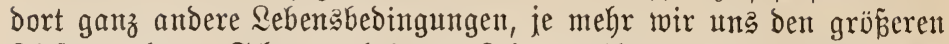
Tiejent nähern. Sdyon nach furzer Zeit umgibt uns finftere Siadyt, bie Temperatur nimmt erift jodnelf, bann langiam ab, um joblieşlich über= all ziemlidy fonjtant zu bleiben, und an Etelle des betwegten $\mathfrak{B a j f e r s , ~}$ bas bie vielen $\mathfrak{A}$ tupafiungserjcheinungen bei ben Fladjeeberwohnern er=

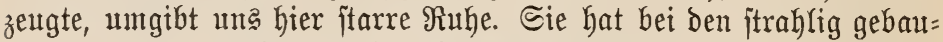
ten Tieren, vor allem bei ben Shtwämmen, biel bollere, rumblichere Formen erzeugt; an Stelle ber ben (sinzeltieren Schub und Şalt ge= währenden Solonien jehen wir hier öfters Eingelmejen. Die Tief= jeebemohner leben wie Bäıme in einem gejühüten Ial; alle Stürme bes Meeres ziehen hod) ïber ifren Scäuptern bahin, und nur Iangjam

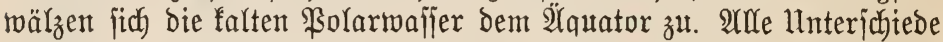
gleichen jich bort bis auf geringe 2(bmeichungen aus; bie Berfältniffe

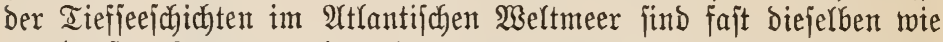

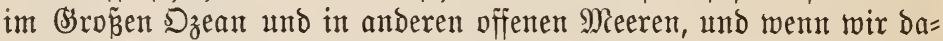

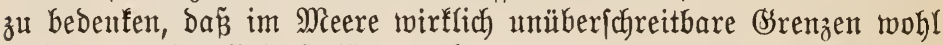

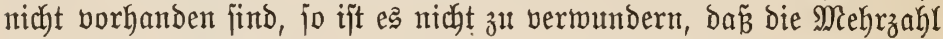

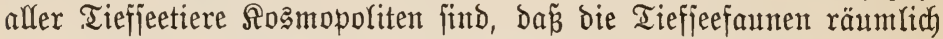
weit getrennter BSebiete jich in feiner bejonderen (Eigenjichaft vonein= ander intericheiden. Dả haben bie Yebzten Forichungareifen wieber be= wiejen. Freilich jint uns bieje Berbältniffie bei weitem noch nicht voll =

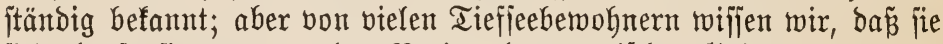
jich ebenjo finden unter ben Breiten ber tropijchen Bsebiete wie unter Der eisftarrenden Fläche Der $\mathfrak{B}$ olarmeere. Bon jeher hatte man als

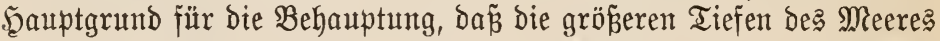
ohne organijches Leben fein müß̈ten, Den tolofijalen Dru af angeführt, ber bort herridgt. Er mag in ben grö̈zten rumb 900 Âtmojphären be= tragen. Arber gerabejo, wie jith bie Tiere hoher Bsebirgaregionen an ben verminderten Druff angepañt haben, befinden fich aud bie Tief= jeetiere unter biejem jo auperorbentlich verftärften Drud ganz wohl,

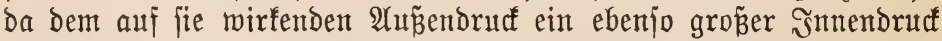
in ihren Betweben gegenüberjteht. 2 Un viele Tiefieetiere ganz bedeutende vertifale Unterichiede ohne Schaden ertragen fönnen. Sserabe bie Yekten Tiefjee=Expebitionen haben ja, wie

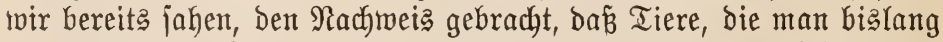
nur als Dberflächenformen fante, anth in bebeutenderen Tiefen ange= troffen werden, und umgefefrt.

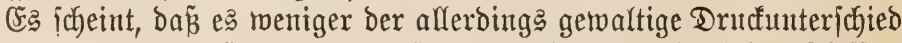

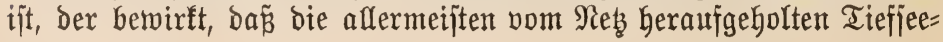


tiere tot an die Sberfläche fommen, fondern vielmebr bie Temperatur= veränberung. Sedenfalls ift bie Fähigfeit, fich einem geänderten Waffer = brutf anzupaffen, bei ben einzelnen Rebetwejen der Tiefiee jelyr berjate= Den itark auggebiloet.

Bei vielen Tiefieefijchen, die die Fähigfeit nicht haben, breitere Tie= fenzonen zu Durdymefien, zeigen die Sinochen fich fehr arm an Sialf; fie find weich und fajerig und zerfallen bein \$̧eraufgolen. Zugleidy zer=

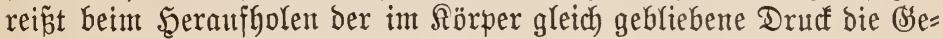
webe, die Argen und Cingetweide quellen heraus und bie Schuppen \o= dern jich; die Tiere jterben an der "Trommeljucht", wie die Seeleute jagen, fie gehen an Derjelben Sranfheit zugrunde, bie Den allzu hod)

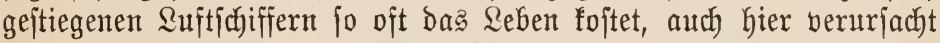
Durdh Den fehr verminderten Drud. Die \$coffnung, Dẩ die Tiefiee=

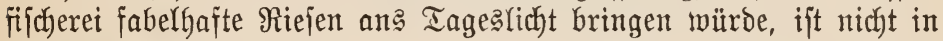
Srfüllung gegangen, felbjt über bie viel befabelte Seejalange nifjen

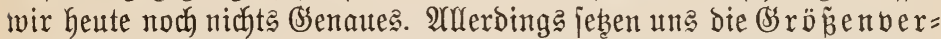
bärtnifje mancher Tiefieebewohner im Bergleich zu ihren in jonnigeren Šegenden lebenden Berwandten zuweilen in Eritaunen. Die Tubu= larien, meijt fleine, nux wenige Bentimeter hohe Bolypen, Gaben in ca. $5000 \mathrm{~m}$ Tiefe einen Bertreter (Monocaulus imperator), ber bie foloffale Ränge von mebr als $2 \mathrm{~m}$ hat. Die $23 \mathrm{~cm}$ lange Riejentaffel (Bathynomus) aus $1700 \mathrm{~m}$ Tiefe und die groß̉en Srabbenjpinnen (Colossendeis) mit ifren $70 \mathrm{~cm}$ flafternden Beinen haben wir bereit? erwähnt. Auch unter ben höheren Srebjen gibt es joldbe Riefen; ein jolcher ijt bie Gnathophausia goliath $(2270 \mathrm{~m})$ unter Den Schizo=

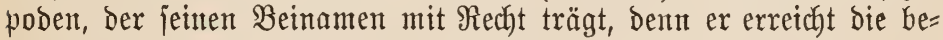

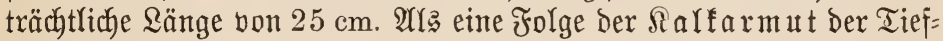

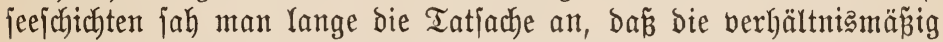
in geringer $\mathfrak{A n z a h l}$ bort anzutreffenden Schalen ber Weidhtiere immer bünner werben, in je tiefere Schichtent wir hinabfteigen. Arud bie fialf= ffelette ber forallen werden immer feiner, und bie Srebje erhalten dort einen dünnen burchfichtigen ßanzer. Da tatjächlich, wie wir fahen, dieje falfarmut in ben Tiejen nidyt bejteht, müfien andere Urjachen zur (Fr= flärung biejer Erjoheinung gefucht werden, vielleicht das Fehlen von Feinden ober Das Bejtreben nach einer größ̈eren Bemeglichfeit. Dabei

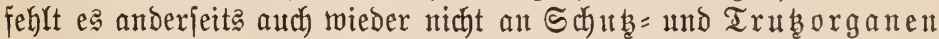

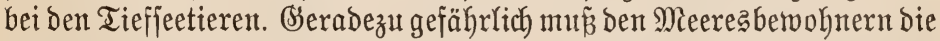
itachelbemehrte Srabbe Lithodes ferox exjcheinen. Da iłr mächtige Waffen in Sejtalt von Scheren fehlen, hat bie Natur diejem Sefdöpfe

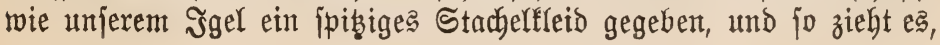


ein gepanzerter Ritter des Meeres, auf Raub aus. Denn auf Dem Meeres= grunde gilt ber Sampf ums Dajein wohl mehr als irgendwo anders; alle Tiere find Fleijhfrefjer, die fich entweder im weid)en Gd)lamm verfriechen und bort auf Raub laueru (Melanocetus), ober wie lebende Tieffeereujen mit weit geöffnetem, zähneftarrendem Maule die dunflen Tiefen Durchjichen (Eustomias, Stomias, Malacosteus, Saccopharynx, $\mathfrak{U G b}$. 36) und teilweife für bieje Räuberfahrten, wie wix jehen werben, noch mit ganz bejonderen Mitteln auggerïftet find.

Bejonders mú uns hier Die Frage intereffieren: wie jtellent jich Denn die Meeresbewohner zu Den হichtverhältnifien Der Tieffee? Berjuche

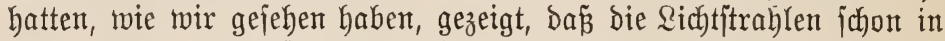

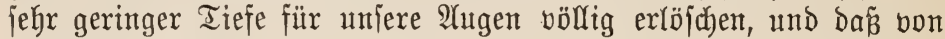
geringer Tiefe an für immer formarze Nacht jein muś. Und doch fin = ben wir in viel bebentenderen Tiejen nod) hod entwicfelte Tiere, ja fogar jolche mit auferorbentlich gropenen und abnorm gebauten Stiel= und jog. Teleffopangen (Fijhe, Tintenfijdye und frebstiere), aller=

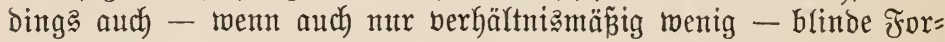
men. Dieje mächtig entwicfelten Sebwerfzeage der Tieffeetiere, bon Denen

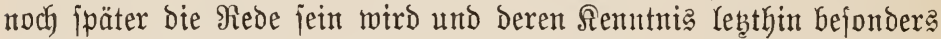
(Shun, v. Qendenfeld, Brauer u. a. gefördert haben, weijen, ausgezeichnet

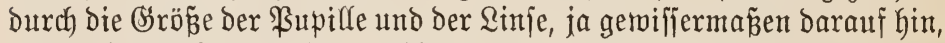

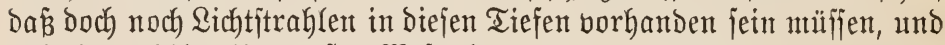

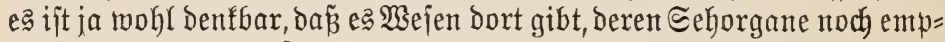
find licher jind als unjere empfind lichjten photographijchen ßlatten. 2Uber Die dunflen 2 bgrünbe haben einen gewifjen Erjab̧ für bas ihnen entzogene Sonnenlicht barin, dấ inge Bemohner teilmeife ihr eigenes Sicht mit fich

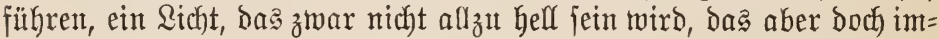
jtande jein bürfte, Der llmgebung einen grïnlich Yeuchtenden Dämme= rungsichein ntitzuteilen, bejonders ba bie leudjtenden Tiere oft zu Milli= arben vereint find, wenn fie ihre Sidhtjtrahlen ausfenden. Tiere, bie ein

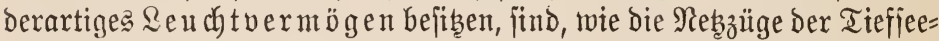
Expeditionen gezeigt haben, berbreiteter als man früher annebmen fonn= te; jie fommen überalf im Meere bor, nicht nur in ben Tropen, fondern auch in ben \$olarmeeren, an ber Dberfläche und ebenjo in Den grö $\bar{\beta}=$ ten Tiefen. (5) gibt feine ber grofen Tierfla fien, bie nicht bei biejer magijach summination ibre Bertreter jtellte; felbjt leudytento Iinten=

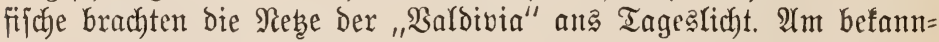
tejten ijt bie jdyon erwägnte Noctiluca miliaris, bie J̨obltiere jün mit einigen $\mathfrak{P o l y p e n , ~ \Re o r a l l e n , ~ A f t i n i e n ~ u n d ~ \Re i p p e n q u a l l e n ~ v e r t r e t e n , ~ D i e ~}$ Stachelbäuter u. a. mit ber pradjtvoll leutbtenden Brisinga, eintem 


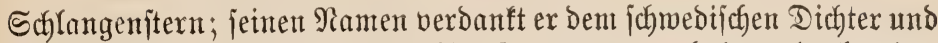

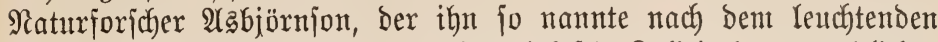

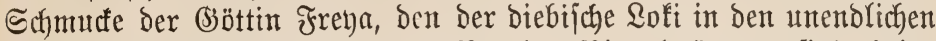
Orbgründen bes Meeres verbarg. \$on ben Ringelwürmern find einige Arten ber F゙antilien Nereis, Syllis und Polynoë, fotwie die Iomopte= riben zu erwähnen; eigentümliche augenartige Flecfe auf Den ruberar= tigen Floijen Diejer Würnter find als হeuchtorgane erfant toorden.

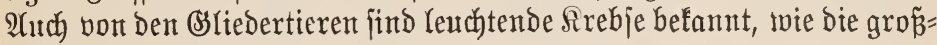
äugigen Euphaufiben, die am Scinterletbe zroei in tiefem Blau leuch)= tende aaternen bejigen, und von ben Manter= tieren gehören die ธal= pen und Femermalzen zul ben wohl an mei= iten lichtipendenden Formen. Ebenjo gibt es eine ganze $\mathfrak{A n z a b l}$ Tieffeefiiche, bie eigen= tünliche Seuchtorgane

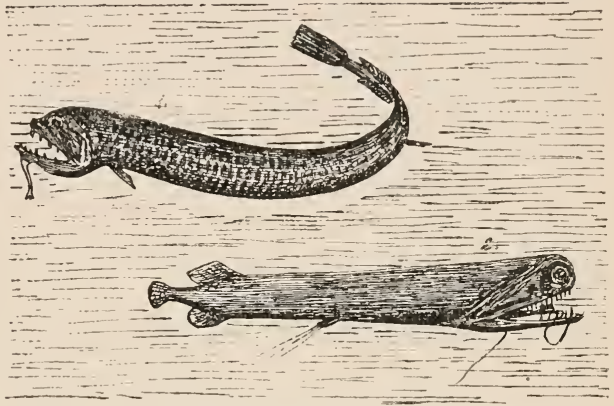

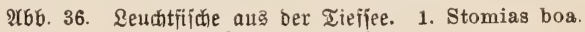
2. Malacosteus niger.

tragen und uns deshalb bejonders interelfant jind, weil der Bau die= jer jeltjamen Serf́zeuge uns burch neue Interjuchungen etmas näher befannt ijt. Woher fonmt aber diejes হidt? Sein grïnlich forim= mernder Slanz, den wir ja von unjeren sohannibfäferchen fennen, erintert an bas \&eudften Des \$hosphors, Gervorgebracht Durch deffen Bereinigung mit bem Sauerftoff ber Suft. So nimmt man aud an,

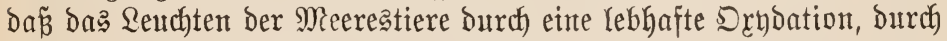
eine infolge Der energif hen Sebenstätigfeit hervorgerufene Berbrennung

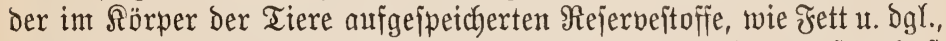

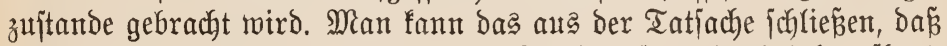
bei eintgen leudbtenden Bafterien die Reudbtfraft nachweislich aufhört, jobalo man ibrex Ilmgebung den Saueritoff entzieht. Bon ben Fijchen fennen wir eitte ganze $\mathfrak{A n z a h y ~}$ leudftender Urten; jo trägt ber Mala-

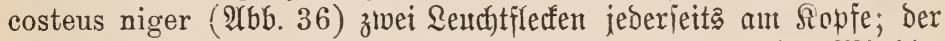
eine ftrahlt in gologelbem, der andere in grünlidbem @ichte. Mit die= jen Saternen auggerijitet, exjocint ex twie bas abenteuerliche Unterjee=

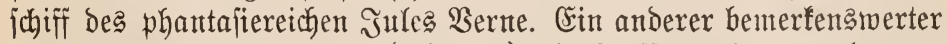
Seuchtfiich ijt Stomias boa (2Ubb. 36), ein Tiefieeräuber von langge= itredter Sieftalt; auf ber Unterjeite von Ropf, Rumpf und Shwanz 
befinden fich Reifen von phoßphorefaierenden \$utten. Es gift nodh eine ganze $\mathfrak{A}$ nzahl von Tieffeefifichen, bic berartige Reuchtorgane tra=

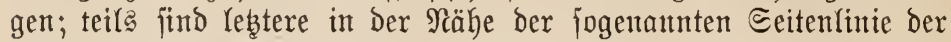
Fitiche befindlidy und beshalb audh mit ben in biejer aufgefundenen eigentitmlichen Drganten in Bujanmenbantg gebradht worden, teifs fin=

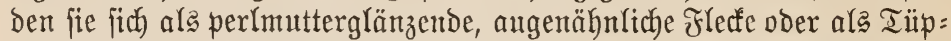
fel, Tridgter und Şödfer an ben Seiten, auf und unter bem Sopfe, auf Den Riementoecfelnt uto am Maule der Fijche. Erhon v. Lendenfeld, ber bieje merfmürdigen Drgane näher unterfucht hat, fonnte z'wei Scaupt=

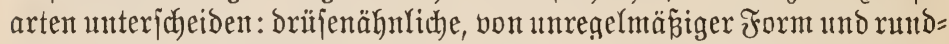
liche, mehr augenähnliche. Beide fönten an Demjelben Tiere auftreten. Nach den eingehenden lluterfuthungen zweier italienijher Zoologen, (Shia= rint und BSotti, merben bie brüfenartigen Seud)twerfzeuge zumeilen von

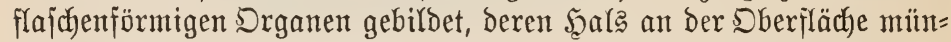
bet; fie fommen bei bent Sternoptyxarten und bei bent Efopeliben vor.

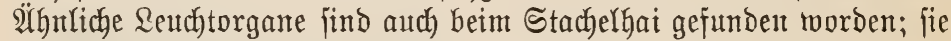

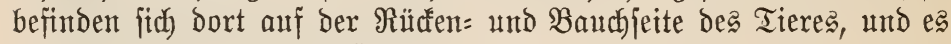

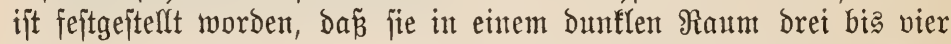
Meter weit fichtbar waren. (Finfacher gebaut jind bie Yeutchtenden $\mathfrak{P e r}=$ len an ber Seite, bie Fłleffen am Schrwanze mb bie gröperen \&aternen am $\Omega$ opje; es find napfförmige Drgane, bie mit eintem burch) eine (injen= artige Schuppe gebilbeten Deffer verjehen jint. Şhr inmerer $\mathfrak{B a u}$, auf ben wir hier nidht näber eingehen wollen, zeigt eine fo groß̧e ähn= (ich)feit mit dem Baut ber eleftrifden Drgane bes Zitteraals und an=

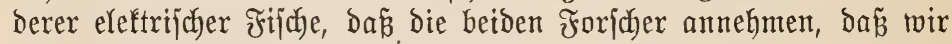

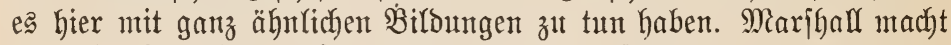

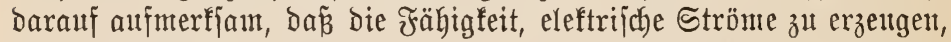
bei ben Fifchen fitd öfter finden bürfte ala bis jebt befannt wäre. $\mathfrak{B i r}$

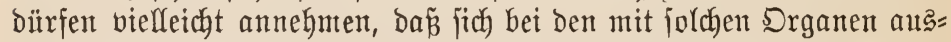
gejtatteten Fifichen bie burdh einten lebhaften Stoffmedhel erzengte elet:

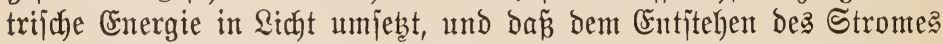
eine Drybation, eine langjame Berbrentung von Stoffiwedfielprodul= ten zugrunde Yiegt; befauntlich fïhrt man ja audb bie eleftrifde Siraft bes Bitteraals auf einen mit bem Stoffined) fer verbundenen Dxydations= prozes zurïct. 2(utch bei ben ein Sefret abjondernden brïfenförmigen

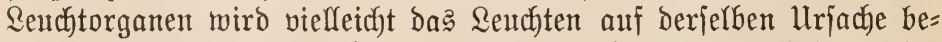

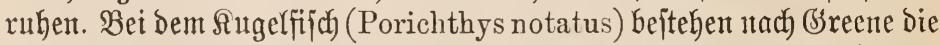

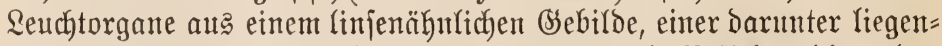

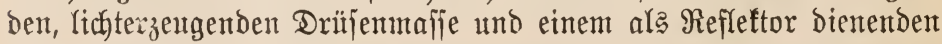
Belfentomplex. Denfelben (Srundbau zeigen aud die Reutbtorgane der 
Tintenfifache, bie bie "Baldivia" ans Tageslidyt brachte unb bei benen

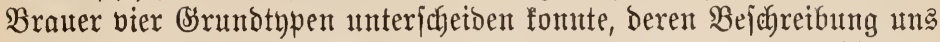

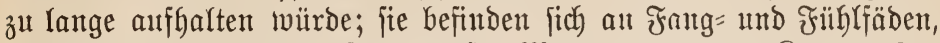

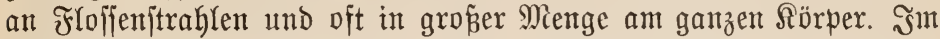
einzelnent ijt ber Bau biejer Drgane natürfich gropen unterworfen; ja, bei mtanchen Tieffeetintenfijichen finden jich an bem=

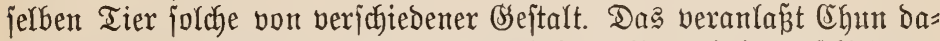

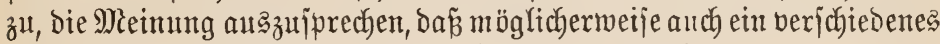
Qicht bon ben verichieden gebauten Drganen ausgehe.

Bie ver halten jich mut bie nidbt mit joldyen \&idgtquellen ausgerïfteten

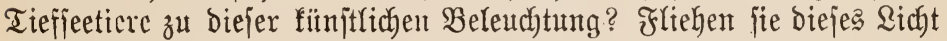

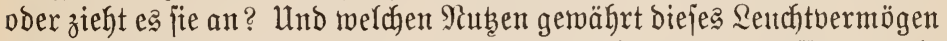

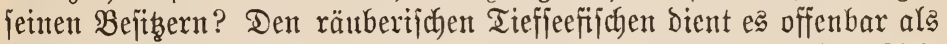
Socfmittel für ifre Beute. Siele Meerestiere werden burch das \&icht angezogen, wie bie Miüfen und Miotten in ber Sommerntacht von ber brennenden Rampe. Sie werben getwiffermažen von bem blendenten Lidjtichein hypnotifiert und rennen in ihr $\mathfrak{B}$ erberben. 2An ber englijhyen Riujte hat man ben Serjuch gemadht, bie Fijche mit Şiffe von Echein=

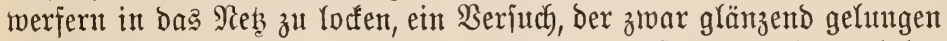
ift, aber Gald ben Fifichreichtum unjerer Meere zerftören würde; und bie eleftriich beleuchtete Tiefieereufe bez Finriten von Monaco berubt eben= falls auf ber 2 ntziehungatraft, bie bas Sicht auf bie Meereätiere aus= übt. Den Tieffeefijichen bienen ihre Raternen aljo vielleicht als Mittel zur Füllunt ifyes uneriättlichen Magenz, und bei manchen anderen, wie bei den Rorallen, bient bas Licht wohl dem felben 3wect. Merfwüroig ift,

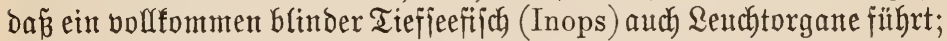

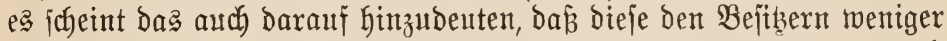

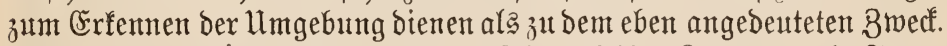
Mandhe Reutdftifiche verlafijen fich jo jebr auf ihre Raterten als Fang=

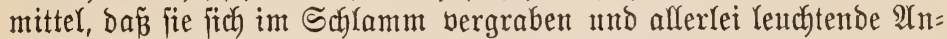
hängjel und Fäben heraug̈trecfent und hin und her betwegen 2(Ger wie ift's ntit ben Tieren, bie offenbar nicht auf bas 2Anloffen von Beutetieren angemiejen find; wie z. B. Die oben ertwähnte Brisinga, bie mit ifrer

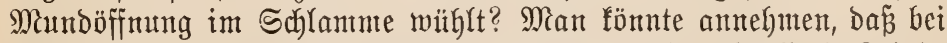
ifnen bie Qeudtorgane als Echredmittel bienen und nadjitellende Feinde

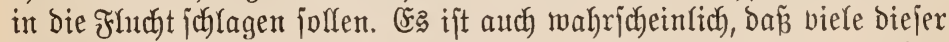
Qeudttiere imftande find, je nach Belieben igr Sicht leudbten zu lajīen ober nicht; zumal bei ben höher organifierten ifł ein Bujanmenthang

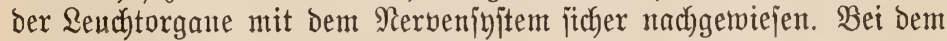

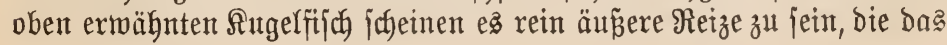


Seuchten herborbringen, wie erperimentelf nachgetwiejen merben fonnte. Bei twieber anderen ift es möglich, ba auftritt, wenn ber Fortpflanzungstricb fich regt, und ba j fie baher zur

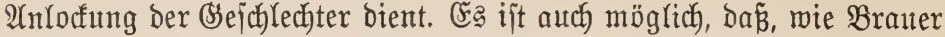
meint, bie über den ganzen $\Re$ örper verteilten und in verichiedentem Lidfte erglänzenden Leuthtorgane dort in Der Tiefe bas Farbentfeio ber am Sichte rebenden Tiere erjeben jollen. Wir jehen, ba ja hier ber biolo=

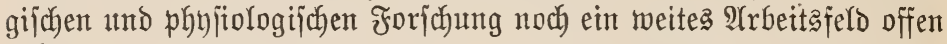
fteht.

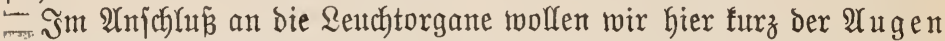
Der Meereß̧betwohner Crrwähnung tun. Wir finden hier höchit über= rajchende Tatjachen, bie zum gropenen Teile auch noch weiterer 2 Hufflärung harren. Bei nen niebrigiten Tieren, Den einzelligen Protozoen, fehlent meijtens bie $\mathfrak{A}$ ugen oder es jind bei ifnen einfache \$igmentflesfent vor= handen, mit benen bie Tiere möglichermeife einen gewifjen Srad von

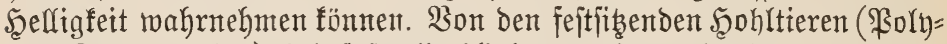

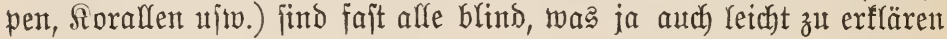
ijt; erjt bei den in ausgebildeten Bujtand freifonwimmenden Medujen

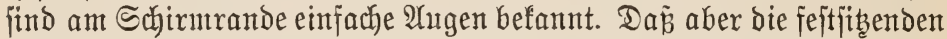
Formen audh auf Qichtreize reagieren, ift genügend nachgetwiejen und von Loeb burch Beriuche mit Eudendrium feitgejtellt tworben. Je Göher wir in Der Entwidflungsreihe ber Tiere fteigen, Defto mehr berbollfommment

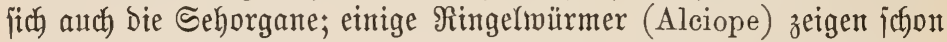
jehr gut entwicfelte 2 Hugen; bei ben 2 Seichtieren finden wir bei mandhen Murcheln einfach gebaute Eehorgane am Mantelrande, während die am Göchjten jtehenden Tintenfifice jchon 2lugen befizen, bie in ihrem Bau Denen ber $\mathfrak{B i r b e l t i e r e ~ a ̈ h n e l n . ~} 2 \mathfrak{d}$ auffallembiten ijt aber bie Cntwidf= lung biejer Sintesorgante bei ben Rrebfen und Fijichen ber Tieffee. Bei betben finden wir abnornt vergröf̈erte neben berfïmmerten Alugen und

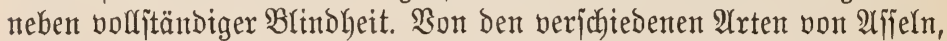
bie bie Neke Des "Challenger" aus verjhiedenen Tiefen heraufholten, waren 34 volfitändig Glind, vier hatten ganz berfïmmerte und 18 gut

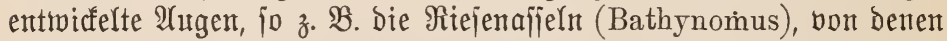

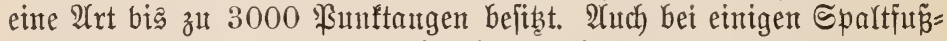
frebjen find bie Seborgane mefr oder weniger berfümmert (Bentheuphasia, Eucope, Amblyops u. a.). Sogar bei den am höchiten jétendoen

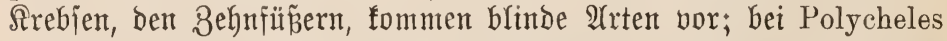
unt Pentacheles feglt jede Sputr eines 2luges, bei Astacus zaleuca uto bei Nephropsis, zwei unjerem F⿱⺈

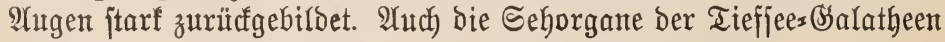


find faft imnter pignentlos und baher unbraudbar, und Mariball teilt

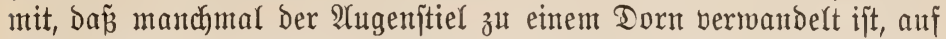

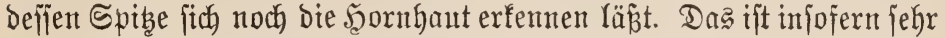
interefiant, als Serbit burch Berjuche an Sarneelen betwiefen Gat, wie leicht Die Ägen Der Srebstiere verforwinden und anderen Billungen Plab machen. Er hat Den Tieren eines ifrer geftielten Âtgen fortge= nommen, und, fiehe da, an Stelle ber amputierten Sebmerfzeuge ent= ftand eine geglieberte Sieižel, die mit den gemöhnlichen Untennen eine groß̉e थ̈hnlichfeit hatte. Cin anderes Beijpiel liefert eine Ŝrabbe (Ethusa granulata); diejenigen Tiere, die im flachen $\mathfrak{W a f f e r ~}$ leben, haben noch gut entwidfelte Uugen, aber je tiefer bie Tiere ing Meer hinabgeitiegen find, Defto mehr verfümmerten ihre Seborgane, und bei ben in 900 bis $1260 \mathrm{~m}$ Tiefe lebenden find die Âtgentiele zu einem Stimitachel ver=

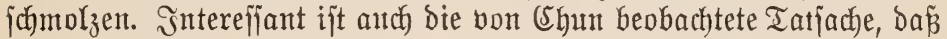

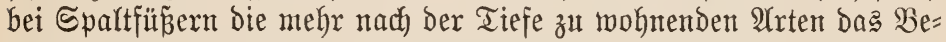
ftreben zeigen, ifr $\mathfrak{A}$ uge in zwei $\mathfrak{X}$ bidnitte zu trennen, in einen Stirn= teil und einen jeitlichen Teil. Sbenjo anffallento find die Berhältnifie

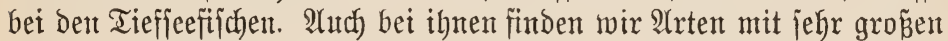
und gut entwicfelten $\mathfrak{A}$ ugen neben joldhen mit berfümmerten Sebrwerf: zeugen (Inops, Typhlonus). Ein ebenfalls blinder Fifd (Amphionus

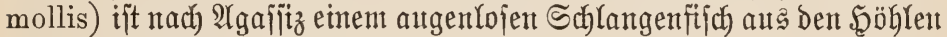
ภttbas (Lucifuga) nahe vertwandt.

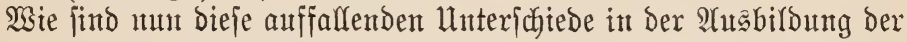
Augen bet Tieren, bie oft eintander nabe verwand find und oft autd in annähernd gleichen Tiefen gefunden wurben, zı exflären? Bon ben $a b=$ norm entwidfelten und auf langen Stielen jibenden Telejtopaugen man=

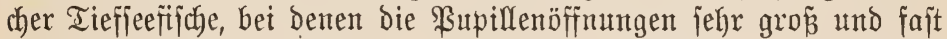
ganz von ber Qinje auggefülllt find, haben wir bereits furz geiprochen. Dá̉ die Sehtwerfzeuge diejer Tiere fich vergrö̈ern und vervollfommnen, Damit in Den Meeresgründen von Der geringen Dort vorhatbenen Qidht= menge möglichft viel aufgenomnten werben fönne, vermögen wir ebent= falls zu veritehen; auch ungefehrt wifjen wix, baj̃ Tiere, bie in bunflen Şöblen leben, allmählich ihre 2lugen zuxüdfbilden, da jie ihrex zum Sehen nicht mebr beditrfen. Man jollte aljo annehmen, oa ź wir bei Den Meeres= tieren, je tiejer wir bie Nebe verjenfen, entweder eine Berbolfommmng

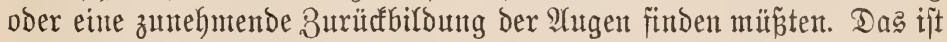
aber Durchaus nicht der Fall, wie mix faben. Bweifellos hat bas ab= nehmente Ridyt aif Dieje Sorgane in ber eben bejdyriebenen Weije cinge= wirft; fanon bie Borfahren in Der Entwidflng haben fich eben Den ver=

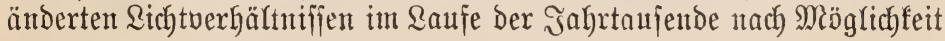




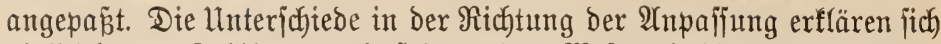

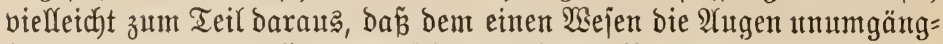
lich nötig waren zur Crlegung feiner flüdytigen Beutetiere, während Dem anderen Tiere andere Sagdmittel zu Bebote ftanden in Sejtalt von Fangfäden, mächtigen Sđjeren ujw. Uber bas erłlärt immer noch nicht Das gleidjzeitige Bortommen nahe verwandter blinder und gut jeben= ber Formen, denn die Berbältniffe der Tiefiee, in der fie heute Yeben, jund für beibe ja ganz gleicf. Nun fönnen wir mit Beftimmtheit an=

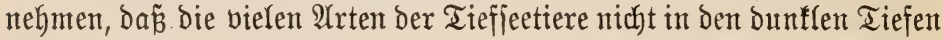

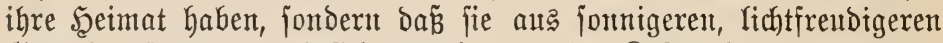
Segenden jtammen und fich entweder von ben fï̈ten her oder aus den

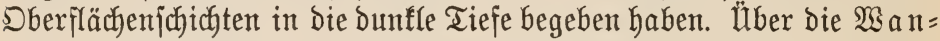
berungen ber Seetiere wuphten wix bis vor wenigen Sabren herzlich wentg; erit in den lesten Jahren hat man Durch Marfierung bie Wan= derungen der Fifche, z. B. Der Flundern, zu verjolgen gejucht; an Der englifhen Siujte hat man gleiche Berjuche mit Sirabben gemacht. Die Wanderungen geben jowo gl in horizontaler und aud in vertifaler fichtung vor fich; die Cinwanderung ber Tierwelt in bie Tiefen hat aber natü: lich nicht für alle Tiere gleichzeitig begounen und geendet, fondern fie ift ganz allmählich von jeder Form füx jich im Laufe der Sabrtaujende unternommen worden und bautert noch Geute fort. So jobeint es uns

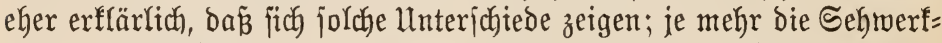
zeuge ber Tieffeetiere bom normalen Bau abreidyen, Defto ferner liegt die Beit, wo jie die $\mathfrak{B a n d e r u n g}$ in bie Tiefe antraten.

Wą die Färbung der Tieffeetiere anbelangt, jo hängt fie innig nit

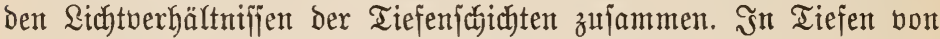

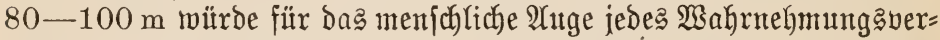
mögen für Qidhtitrahlen aufhören. Wenn beshalb aud bet zunehmender Tiefe bie Farben ber fie betwohnenden Tiere im allgemeinen bunfler werben, jo finden fich bod zahlreiche $\mathfrak{A}$ rten mit tiefroten und gelben Färbungen vor. Fine Erflärung Diejer Tatjachen gibt ung wenigjtens

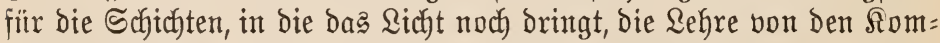
plementärfarben. Soldje jind grün und rot, orange und blau. Sn bie größjren Tiefen gelangen, wie toir jaben, aber nur die grünen und blauen Strablen, und in ifnen find bie roten und gelben Farben ebenjo jobtwer fichtbar, wie rote und gelbe (5iegenjtände unter grïnen und blauem

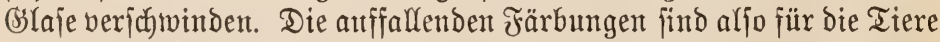
als Schubfarben anzujeben. Smmerbin herrichen aber in ben tiefiten Schichten jabrwarze, violette nno braune Farbentöne vor.

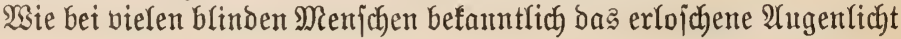




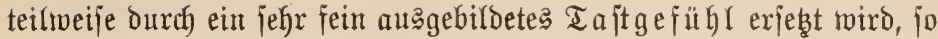
ift bas aud bei vielen Tieffeeformen ber Fall. So finden wix bei vielen

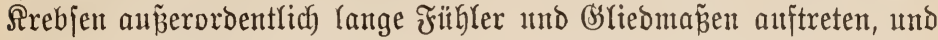

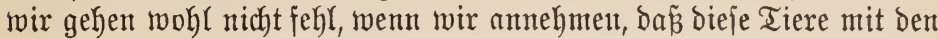
langen Fortjäben igre dunfle Ungebung prïfend unterjucheu. Derartige

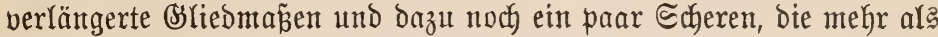

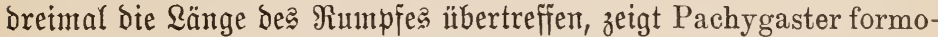
sus. Die Srabbenfpinnen der Tieffee befteben, wie ihr Siattunggname (Pantopoden) jagt, tatiädylich fajt mur aus Beinen. Bet Colossendeis arcuata ณus $1470 \mathrm{~m}$ Tiefe jind die Santwerfzeuge, auf denent bas wumberbare Tier auf Dem Meeresgrunde einherjtelzt, fanon fajt oreimal jo lang wie Der Sörper; bei jeinen Berwandten von der wejtamerifanifden アüjte aus $900-2700 \mathrm{~m}$ Tiefe aber trägt Der mur menige Millimeter

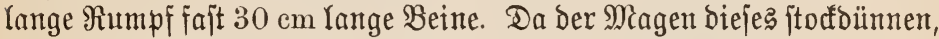

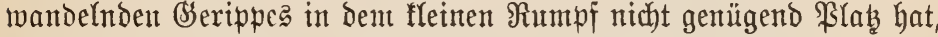
jeben jich feine Fortjäb̧e als Blindärme in jedes ber acht Beine fort, jo

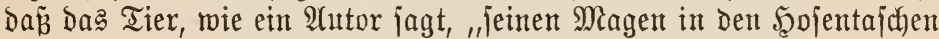
trägt". Aluch manche Tiefieefijche bejiben feinempfindliche Tajtuerf: zeltge in Sejtalt von Fühlfäden; bei Eustomias obscurus ( $\mathfrak{A b b} .27$ ) betragen jie ein Drittel Der Sörperlänge und endigen in quaftenförmig angeoroneten Jüblwärzchen, bei Stomias boa (2(bb. 27) find fie ähnlich gebaut, nur lleiner, bei Bathypterois longipes Dagegen fajt von Rörper= länge utb ant Ende gegabelt. Bei Dent im Eablamm fich vergrabenden

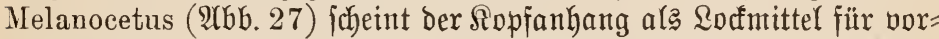
̈̈berziebende Beutetiere zu dienen. Derartige lange Sörperfortjäbze lonn= ten naturgemän mux joldyen Tieren von Nuben jein, bie in einter jo rubigen IImgebung leben, wie jie die Tiefjee bietet; in bewegtem Wajjer wïrden joldye Fühlfäden fich bald verwideln und ifren Bejitzern eber Srbadent als Borteil bringen.

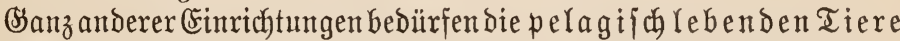
Des Meeres. Drgane, bie eine Betwegung in wagerechter. Richtung ex=

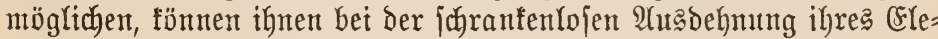
mentes nicht von bejouberem Nuben jein; fie fehlen beshalb jegr oft Doer ifre Mugfulatur ift zuritffgegangen. Nur bei den nahe ber Dber= fläche lebenden funben fich bismeilen fegelartige (Finridytungen, Die eine paffive Fortbelveging Durch Den $\mathfrak{W}$ ind ermöglicben. Dagegen find oft Mittel zu einer jenfrechten Bewegung, zum $\mathfrak{2} u \tilde{f}=$ und Siteder jteigen, vor $=$ Ganden, und bei vielen Tieren, die mur nadyts an bie Sberfläche fonmen, jind die Augen berfümmert oder fehlen ganz. Urle Sräfte find in erjter Rinie auf Den Nabrungserwerb fonzentriert, und bieier Broef wirb um 
jo Yeidter erreicht werben, je weniger Sraftaufwand ber Âfenthalt in bem flüfifigen und leicht bemeglichen EYTement erforoert, je befifer bie

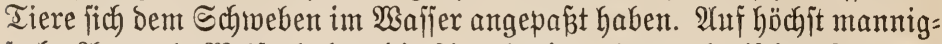
fache $\mathfrak{A}$ rt und Seije haben bie $\mathfrak{A}$ ngehörigen Der pelagijaben Tierwelt

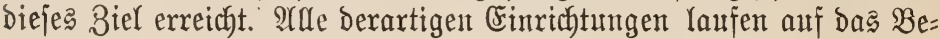

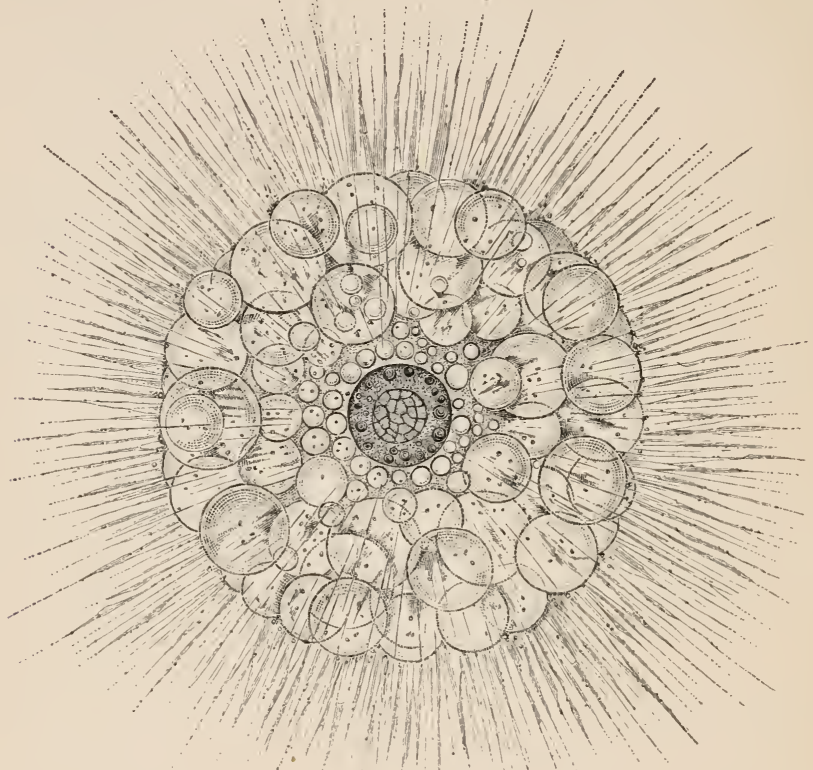

\{6́b. 37. Thalassicolla pelagica

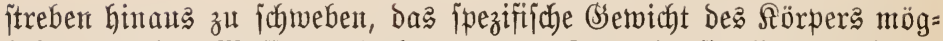
licbjt Dem des Wafjers gleichzumachen. Sehr härfig fintoet fich bie

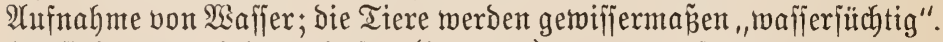
So find z. $\mathfrak{B}$. viele Medufen (2Hbb. 32) von einer fo breiartigen $\mathfrak{B} e=$

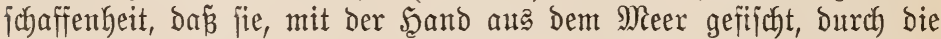
Finger lanfen und, an der \&uf̣t getrodfnet, nur ein jitberglänzendes Scäut=

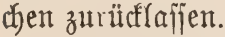

Eine Derartige gallertartige Sïrperfubitant findet man ganz allge=

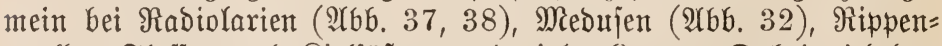

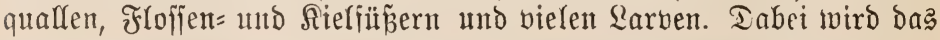

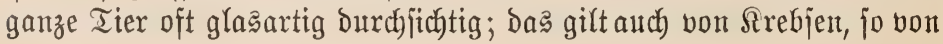




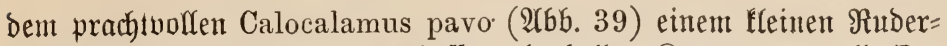

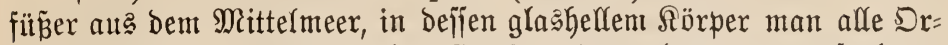
gane fehen Lam, jowie von ber Copilia vitrea, beren orangefarbener

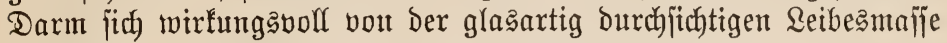
abjebt.

Die Fähigfeit zu jteigen und zu fallen wirb bei niederen Tieren burch

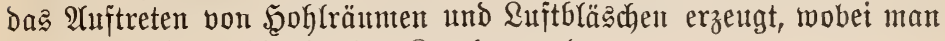
unwillfürlich an bie hohlest Snochen tmo

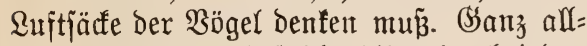
gemein findent fidh foldye allveolen bei bent

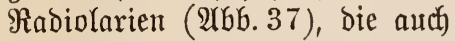
bezhalb bejonders intereijant jind, weil jith in igrem snmern oftmals grünlich=gelbe âlgenzellen $\left(3^{0}=\right.$ oranthellen) finden. Diejes $3 \mathfrak{u}=$ jammenleben (Symbioje) zmeier jo veridiedenartiger Drganismen ijt beiben Teilen offenbar von Borteil; ber tieriface Rörper lie fert ben mineralijhen Stoff und vor allem Sohlemiäure, twähren lebztere ifrem Wirte organijode Subjtanz uto Saueritoff im 2 (ustauich abgeben.

Beit verbreitet find aud (Finritgtungen

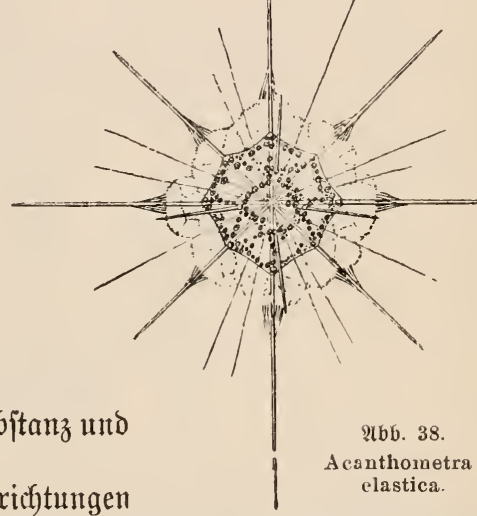
zur Berwegung in fenfrechter Ridhtung. (Figentümlid) ift bie Fähigfeit

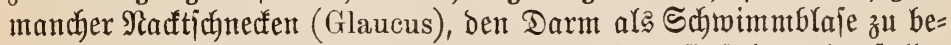

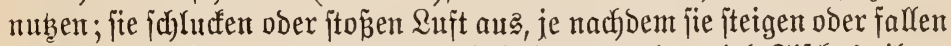

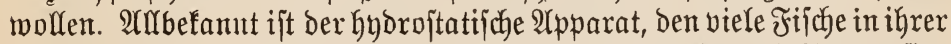
Quftblaje bejiben. 2⿰亻弋 ben fich aud bei bielen anderen Tieren, fo bei ben Solonien ber Fiöhren= quallen ober Sdywinmpolypen (Siphonophoren, 2lbb. 33), ienen mert $=$

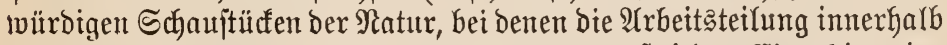
des ganzen Stocfes jo weit Durchgeführt ijt, oa ź jedes Einzeltier eine ganz bejtimmte 2 affgabe zu verrichten hat. Bei ben baumförmigen Stödfen ber \$gyjophoren befindet jid zu oberjt ein zu einer \&uftblaje

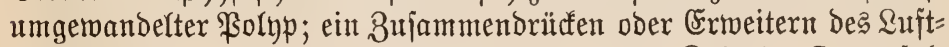
jacfe马 Gemirft ein Fađfen ober Steigen ber ganzen Rolonie. Dann fol=

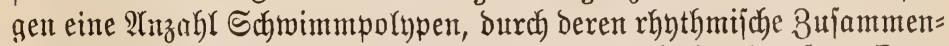

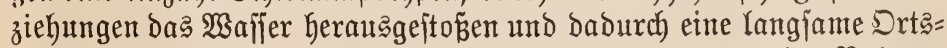
veränderung erzielt wirb. Damit nod nicht gemı; eimzelne Folnpen

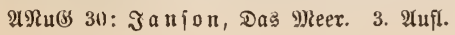


ohne Mundöffinung find z̆ bloḱen Taftern getworden, von Denen lange

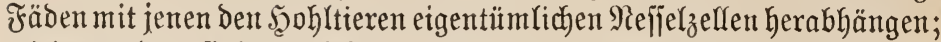
wieber andere find zu blozen Decfitücfen verfümmert, unter benen fich zu fruchtbaren Medufen umgemandelte Polypen befinden, und endich fin = Den wir foldbe, bie eine Mundöfifnung befitzen und für bie Ernährung bes ganzen Stammes jorgen. - Sehr gró̃ einem Ballon aus feinjter Seibe vergleichbar, wirb ber @uftjaff bei Physalia caravella u. a.; bei

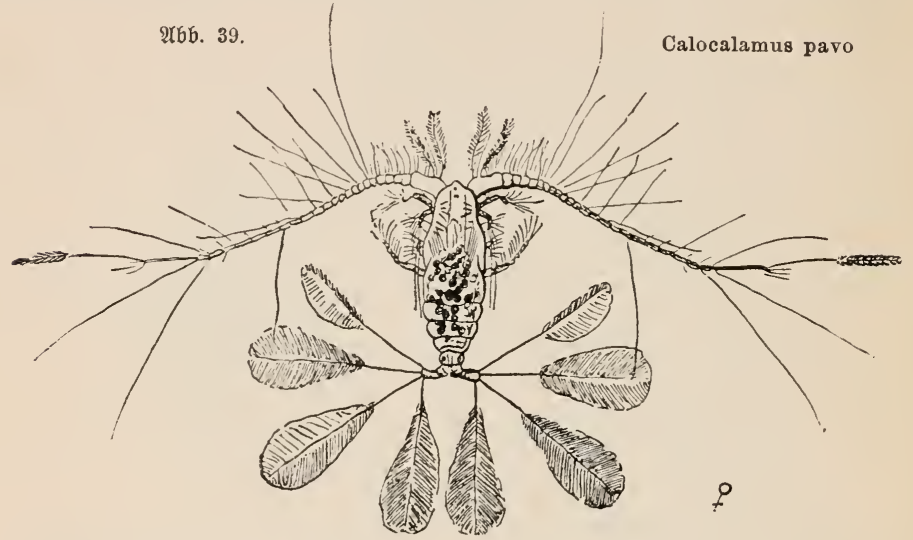

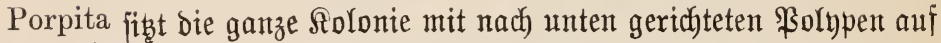
einer fre

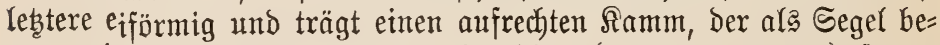

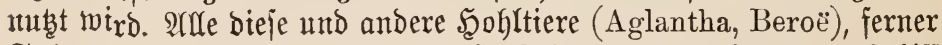
Salpen u. a. bilden manchmal groß̉e Schmärme, burch bie bas ভchiff

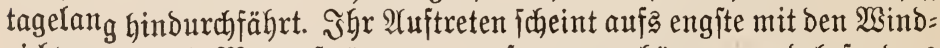
richtungen und Meereştrömungen zufammenzuhängen, und bejonders

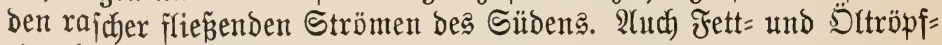

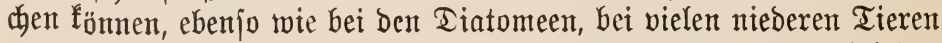
zur Errleichterung bes Schwebens bienen, hauptiächlich zmar bei ben

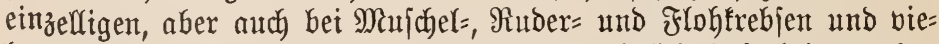
Yen Larven. Es ijt, wie wir jahen, wahricheinlich, ba Phosphorejzenzericheimungen ber Meerestiere bieje Stoffe eine Rolle ipielen.

ङ゙anz alfgemein verbreitet ijt als Schmebemittel bie Dberfläd)en=

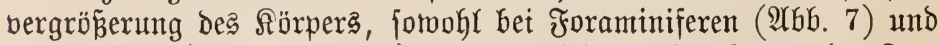

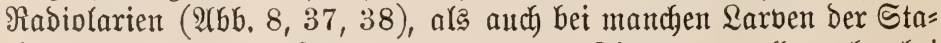
chelbäuter, ben Frlügerfobnecfen und anderen Tieren, vor allem aber bei 
Den Srebjen. Die zu papierbünnen \$latten umgemanbelten Sïrper ber

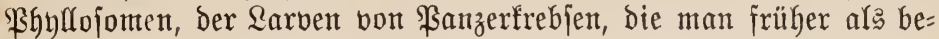
jonbere Arten bejarieb, die blattförmigen @ibeiben ber Sapphirinen,

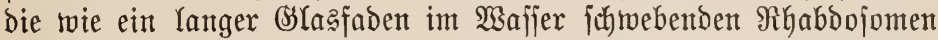
gehören ebenjo hierbin, wie die früber erwähnte flof́bauende Beildsen= iđnecfe (Janthina). überalf zeigt fich das Bejtreben, die Dberfläche des

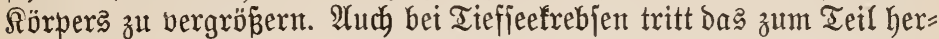

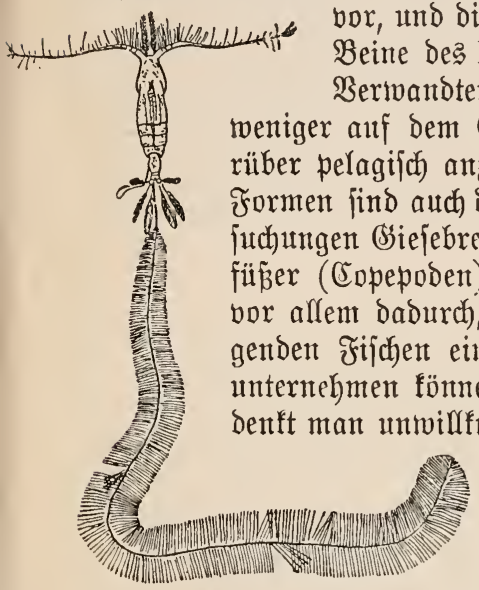

$\mathfrak{6}$ b. 40. Calocalamus plumulosus.

Beine des Nematocarcinus gracilipes und jeiner Berwandten beuten Darauf hin, Daj̃ das Tier wohl wentiger anf dem Srumbe als in Den Wajferjobichten ba= rüber pelagifoc anzutreffen ift. Sntereffante und reizende Formen find auch die vor einigen Jahren burdy bie Unter= juchungen (Siejebred)t näher befannt getwordenen Ruber= fü̈̈er (Copepodent) aus dem Mittelmeer, bemerfenswert vor allem dadurch, baj einige von ihnen gleich ben flie = genden Fijhen eine freilich nux jeftudenlange Suftreife unternebmen fönnen. Bei Der Betrachtıng ber Tierchen benft man unwillfürlich an die zahlreichen Sdyebe Flugeinridytungen bei ben Pflanzen= jament. So hat Calocalamus pavo (26b. 39) Fühler an fopfe, die dop= pelt fo lang find wie bas ganze Tier und ifm als (s)leichgemidhtsptangen im Wajןer dienen; am Ende des ̊̈̈rpers befinden fich aber fächerför=

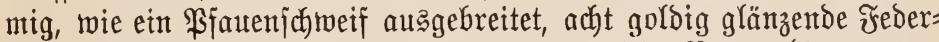
den, denen es jetnen Betnamen berbanft; jein Better (C. plumulosus, 2 bb. 40) trägt ähnliche Schtwebeapparate vorn mo am Snde

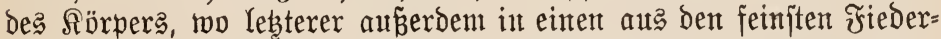
d)ent gebildeten $\mathfrak{A}$ hbang ausläuft, Der jechsmal jo lang ijt wie ber Rör per. Bei ber glaßhellen Copilia vitrea endigen die vier Beinpare in feine Federbiurfitchen, bei der lidbtblauen Pontellina plumata erleidytern

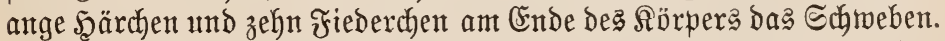

Die Farbe ber pelagija lebenden Tiere hängt aufz engite mit ben

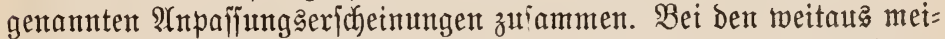

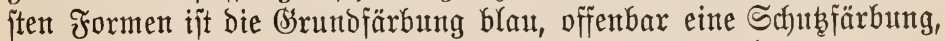
bie bejonbers bie der Dberfläche nahe Yebenden Formen (Velella, Physalia, Sapphirina) zeigen; farblog find aud einige Fijuche und Fifd larven. Bu Yebsteren gebört aud ber durchjuttige Leptocephalus; (Srafifi

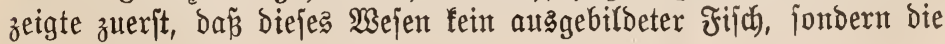


Sarbe unjeres Fluzanales ift, befien Crier unlängit in Tiefen von mebr als $1800 \mathrm{~m}$ jhyebend gefunden worben find. Die Flupaale find arjo uriprünglich Tiefieetiere. Tiefer Yebende アrebfe find oft hodhrot gefärbt. Fine Schnecfe (Glaucus) zeigt eine blaue fäarbung mit firberweip̌en Flecten, fo bå fie bom ভchaum ber Wellen faum zu unteridheiden ift. 3wifhen ben einzelnen Farben finden fich, oft an bemfelben Tiere, zahl $=$ reiche übergänge. Bejonders zeigen biejes Schaujpiel bie Sutwelen bes Meeres, die zarten Duallen. Den Einorud, Den Refijon von ber Physalia caravella hatte, bejdreibt er mit folgenden $\mathfrak{B o r t e n t}$, "Die Blaje

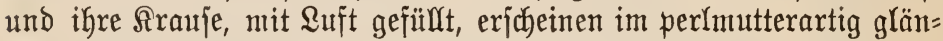
zenden Silber, bem fich harmonifd bie Farbentöne Blau, Biolett und

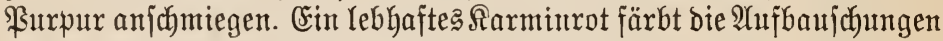

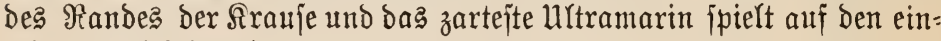
zelnen Fühlfäben."

\section{牙 $x$}

Werfen wix nodh einen furzen Blict auf ben zurïtfelegten Weg. Saum jects Jahrzehnte Yiegen zwijhen heute und den Zeiten, als bie Wifienjuaft zum eriten Male mit Ernit baranging, bie unbefannten

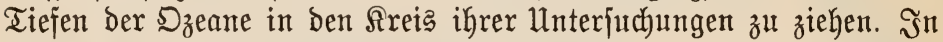
Inbetracht biefer furzen Spanne Beit barf fie mit berechtigtem Stolz auf bas Grrungene zurüׁfjehen. Wie vieles ijt jeit jenem Tage, ba bas erjte Wort, geleitet vom Telegraphenfaber, blikgidnell bie Tiefen bes 2lthantif burcheilte, erreidyt worden; wie vieles aber bleitht nod) zu tun übrig! Trobe der Taujente von Lotungen und Negzägen, bie in ben

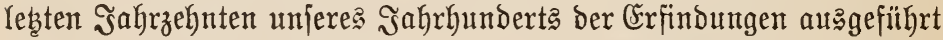
tourben, ift unjer heutiges Sifjen in vieler Beziehung nodh äuñerit lüufentaft. Sioch redgt weit find wir bon einer volftändigen Erfenntnis Der Natur ber verjojiedenen Strömungen im Meere entfernt, bejon= Ders der falten Bobenftröme, von ihren Wechfelbeziefungen zueinander, ihrer fenfredten und horizontalen $\mathfrak{Y}$ (1) bodens unter dem Broßzen Dzean ift uns nod fajt ganz unbefannt, und in Beziehung auf bie Sinfĩtoffe der Tieffee fönnent mir ung nur von benen

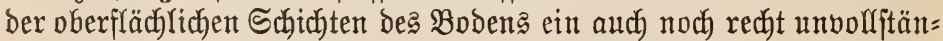
biges Bild machen. Ebenjo unvolffonmen ift unjere Senntnis von ben mannigfaltigen und ineinander greifenden (Sejeken, nad) denen bie (Fr: fcheinung Der B̈ezeiten verläuft, forie von Den Scebungen und Sen= fungen bes Meeresfpiegels und vielen anderen wichtigen \$unften. Was die Drganismen der Dzeane anbelangt, fo harren eine ganze Reihe idjwerwiegender biologifcher \$robleme hente nod) ber Qöfung. Lautete früher bie Frage: too in ber Tiefe liegt bie Srrenze organijđen Rebens? 


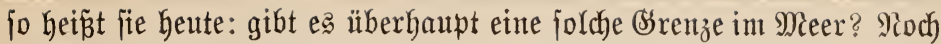

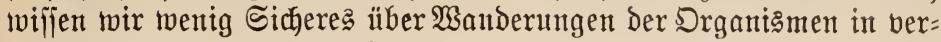

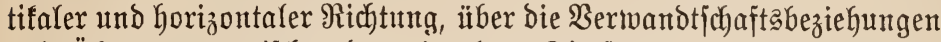

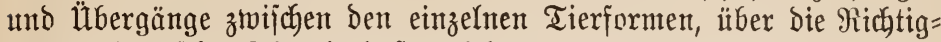

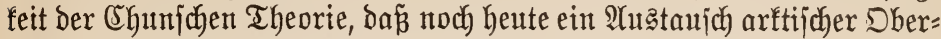
flädhenformen mit antarftifichen Tieffeebewohnern ftattfindet, und zahl = reiche andere Puntte. $\mathfrak{2} \mathfrak{n}$ bieje Frage reihen fich viele, viełe antore, bie

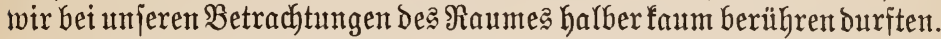

Wir bürfen nicht vergefien, da gierbe burch bie Meeresforjhung ifre gewiz berechtigte Befriedigung

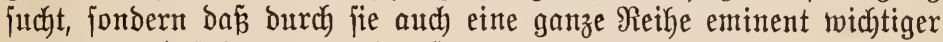
praftijher Ssefichtapunfte eine früher ungeahnte Föroerung erhalten hat. Sn erjter Sinie hat natürlich die Seejhiffahrt aus biejen $\mathfrak{A} r b e i=$ ten ifren Nutben gezogen, und unjere gropenen Schnelloampf̣er ourch= eifen Geute bie weiten $\mathfrak{S a j j e r w i ̈ j t e n ~ m i t ~ e i n e r ~ S i c h e r h e i t ~ u n d ~} \mathfrak{B u ̈ n f t =}$ lichleit, bie ans Wumberbare grenzt. Weiterhin ift bie Seefijherei zu nenten, bie erit nach einem genauten Studium ber gropent Wanderzinge ber Fifiche und ihrer Qebensgewohnheiten ihre heutige Şöhe gewinnen

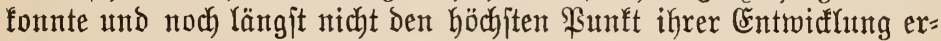
reicht hat; erft went wir eine eingehende Sentntis von ben Rebens= gewohnheiten ber Fifiche, ihrer Nahrung, ihrer Laichzeit, ifrer Wan= berungen und anderer widftiger biologifher, heute noch rubender $\mathfrak{F r a}=$ gen erlangt haben werben, wirb es möglich fein, eine inftematifche 2 (tus $=$

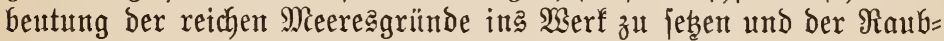
fiicherei, bie Geute fichon zu mancher ernjten Beforgnis $\mathfrak{2} \mathfrak{n} l a \tilde{\beta}$ gibt, ein Ende zu machen. 2lber wir alle jtehen audy auf bem Fejtlande im Banne bes Meeres; beruht doch bie widhtige $\mathfrak{B}$ orherjage des retters meijt auf Sorgängen, bie fich fern bon uns braufen auf bet tweiten Flächen

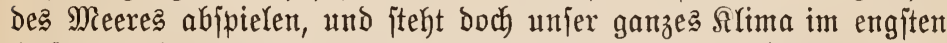
3ujammenthang mit bem toärmenten Mantel, Den ber Şolfitrom um

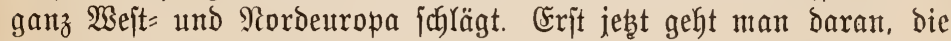
gewaltige Sraft bes Meeres, bie in Der Ericheimung Der Siezeiten Yiegt,

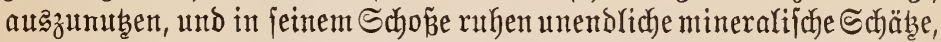
an beren Şebung Der Menjch eben erjt überhaupt zu benfen beginnt.

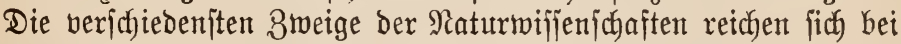
Der Erforichung Der Meere die Şände; jeber fleine Erriolg bedentet eine Stufe weiter auf Der langen Leiter ber Maturerfenntniz, jeder jchneibet zugleich neute Fragen an. Möge unjer beutfches Bolf auth n 3ufunft fein redfich Scherflein zu biejer gemeinfamen 2 trbeit ber Bölfer beitragen. 
Druff ton $\mathfrak{B}$. $\mathfrak{~}$. Teubner in Reipzig. 


\section{Aus Katur und бeipteswelt}

Jeder Band geheftet m. 1.-, in Eeinw. gebunden m. 1.25

AlIgemeine Geologie. Don prof. Dr. frib freç. In 6 Bänden. 2. Gufl. Mit zahlreichen $\mathrm{Abb}$. Bo. 207-211, 61.

Band 1: Dulfane einft uð jebt. Mit 1 Titelbilo und 80 АББ. Вठ. 207.

Band II: Ђеbirgsbau und Erobeber. Mit 1 Titelbils und 57 Аbb. Bठ. 208.

BandIII: Die Arbeit des fliebenden wafjers. Eine Einleitung in die phnjitalifáe Geologie. Mit 51 Abb. Bo. 209.

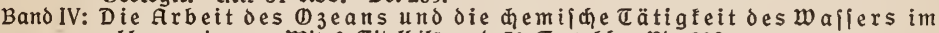
allgemeinen. Mit 1 Titelbilo und 51 - Tertabb. Bo. 210.

Bard V: SteinfohIe, wüiten und KItma oer Dorzeit. Mit 1 đitelbilo und $6596=$ bilourgen. Bo. 211 .

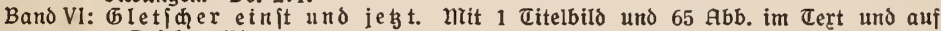
2 Cafeln. Bo. 61.

".... Daß das Werk in turzer 3eit eine 2. Auflage erlebt hat, beweift die Dortrefflid $=$ teit der Daritellung des Derfajiers. Stets geht er vom שatiächlichen aus und zeigt das, was ift und gejaieht an typifäen Beipielen, die den Eejer in den Stano fezen, das Ge=

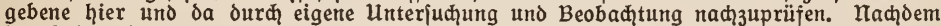
Jas Anjwaubare, das Kontrete nađ̆ allen Erjdeinungsformen hin erörtert worben i|t, folgt

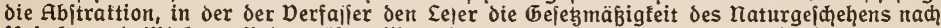
Uriache und Wirfung finden läkt. Wer die 6 mtt vielen und guten Driginalabbilourgen

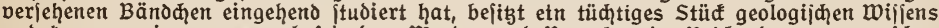

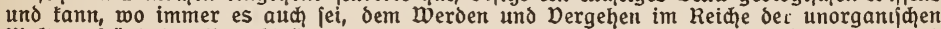
Welt veritänontsvoll nađipüren."

(Itatur und Unterricht.)

Das Oitieegebiet. Don Dr. (Gujtav Braun, Abteilungsvorjtand am Injtitut für Meeresfunde in Berlin. Mit $21 \mathrm{Abb}$. und 1 Karte. Bo. 367.

Betrachtet vom modernen geographifinen Standpuntt das vielbereijte Ditfeegebiet als

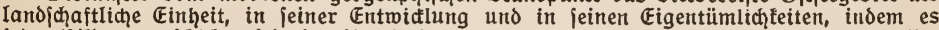
feine Biloungsgejąidhte feit der Urzeit bis 3u den reuejten Deranderungen und deren Be= ziehungen zur Dorgejhichte des Menjhen darjtellt und oaraus feine heutige Gejtaltung ver=

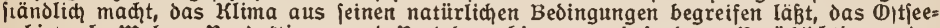
gebiet als Wohn=, produttions = und Dertehrsgebiet unter bejonderer Berücjichtigung der

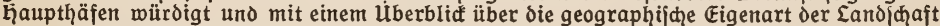

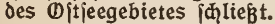

Das wajier. Don Privatdo3. Dr. D. AnjeImin o. Nit 44 Abb. Bठ. 291.

Auber der bejđiđhte und der engeren Chemie des wajfers, feiner AnaInje und Snntheje

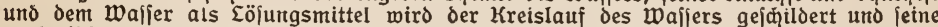
geologif̧̧en Wirfungen. Der zweite Gauptteil enthält oie Reinigung oes waliers zu ge=

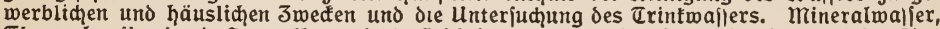
Chermalwaffer jowie Solquellen und die Erjąeinungen der Diffujion bilden den Sđlub. Eine Reihe vor Abbiloungen und đabellen ergänzen den đert.

Korallen und andere geiteinbildende ciere. Don Prof. Dr. walther Man. Mit 45 abb. Bo. 231.

Sđilidert die geiteinbildenden Tiere nađ Bau, Eebensweife und Dorfommen, bejonders ausführlich die für den Erobau fo wiđhtigen Korallentiere, und führt in das von Joologen und Geologen vielbeḩandelte problem der Entfteḩung der durḑ fie aufgebauten Riffe und Injeln ein.

Ebbe und flut fowie verwandte Exjcheinungen im Sonnen= initem. Don (5. G. Darmin= Cambrioge. Deutid von A. Podels. 2. Aufl. 52 Illuftrationen. Ђеb. M. 8.-

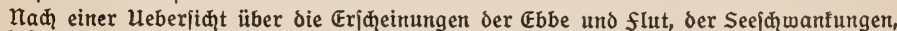
der bejonderen flutphänomene jowie der Beobachtungsmethoden werden in jehr artjąaulidier, ourch figuren erläut.rter Weife die fluterzeugenden Kräfte, die đheorien der (bezeiten jowie die Geritellung von Gezeitentafeln erłlärt. 


\section{Verlag von B. G. Teubner in Leipzig und Berlin}

Das Mittelmeergebiet, seine geographische und kulturelle EigenUniversität Halle a. S. 3., verbesserte Anflage. Mit 9 Figuren, 13 Ansichten und 10 Karten auf 15 Tafeln. gr. 8. 1914. In Leinwand geb. M. 7.-

„....Es ist in jeder Hinsicht eine des Meisters der Länderkunde, Ferd. v. Richthofens, dem es gewidmet ist, würdige Gabe. Die Aufgabe, die sich der Verfasser gesetzt hatte, das Mittelmeergebiet als ein nach seiner Entstehung und seinen Charakterzügen einheitliches darzustellen, den ursächlichen Zusammenhang der Erscheinungen, soweit sie geographisch bedingt sind, herauszuarbeiten und überall auf dem festen Boden exakter Beobachtung, nicht der geistreichen Spekulation, nachzuweisen, ist glãnzend gelöst. Philippson enthüllt hier ganz neue Seiten seines Wissens und Könnens. Methodisch bedeutsam ist auch die überall scharf durchgeführte Scheidung von Cieologie und Geographie."

(Petermanns Mitteilungen.)

Mittelmeerbilder Neue Folge. Von Dr. Theobald Fischer, weiland 1908. Geb. M. 6.-, in Leinwand geb. M. 7.-

Diese Neue Folge beabsichtigt das Verständnis für das immer mehr von deutschen Reisenden besuchte, nicht nur ästhetischen Genuß bietende, sondern auch im Wirtschafisleben und in der Weltpolitik eine immer größere Rolle spielende Mittelmeergebiet $\mathrm{zu}$ vertiefen. In dieser Sammlung allerdings mehr nach der physischgeographischen Seite hin, das Mittelmeer selbst nach seiner Entstehung und vor allem nach der Eigenart seiner Küsten. Nicht weniger als neun dieser Abhandtungen sind Küstenstudien gewidmet, fast durchaus nach Selbstsehen des Verfassers.

Von demselben Verfasser liegt vor:

Mittelmeerbilder. 2. Auflage, bearbeitet von Dr. A. Rüh1. 8. 1913. Geh. M. 7.-, in Leinwand geb. M. 8.-

„Wăhrend Philippsons ,Mittelmeergebiet" eine systematische Darstellung dieser ganzen Region versuchte, bieten uns die ,Mittelmeerbilder' des Vaters der Mittelmeerkunde eine Reihe prắchtiger Einzeldarstellungen, zum größten Teil auf eigener Anschauung begründet, daher nicht allein von echt geographischen Geiste getragen, sondern auch lebensvoll und farbenreich."

(Petermanns Mitteilungen.)

\section{Die Polarwelt und ihre Nachbarländer. Von Dr. 0tto}

Professor an der Universitât Gothenburg. Mit 77 Abbildungen und 1 Nordenskjöd.

bild. gr. 8. 1909. In Leinwand geb. M. 8.-

"Nordenskjöld zieht die ganze Polarwelt in den Kreis seiner Betrachtungen und betont sowohl das Gemeinsame des polaren Wesens wie das Besondere der einzelnen Polarregionen. Er führt uns nach Grōnland, Island, Spitzbergen, in die Südpolarländer, nach Nordamerika, Alaska, Sibirien und in die nordosteuropäischen Gebiele. Wir lernen die Bevőlkerung in ihren Sitten, Gebräuchen, Erwerbsquellen kennen; die Tier- und Pftanzenwelt, das Klima, die geologischen und typographischen Formationen und sonstige geographische Momente finden sachkundige Würdigung. Bei dem großen Interesse für die Polarwelt wird das Buch auch über Fachkreise hinaus großen Anklang finden."

(Literar. Handweiser.)

\section{Schichtenfolge Mitteldeutschlands, Zu Tabellen zusam-}

Gebrauch auf geologischen Wanderungen v. Dr. Th. Brandes. 8. 1913. Kart. M. -.50 .

Die Tabellen sind der geographische Ausdruck des heutigen Standes der statigraphischen Erforschung Mitteldeutschlands. Sie sind in erster Linie für Studenten und Freunde der Geologie als Vademekum auf Exkursionen bestimmt, um sich im Felde sofort Rechenschaft geben zu können über die Stellung kleinerer Zonen im großen Schichtenverbande, sowie über die ungefähre Sprunghöhe von Verwerfungen und den Umfang von Schichtlücken. Sie sollen für Lehrer und Lernende eine Erleichterung sein. 


\section{fleine Jaあwörterbüあer}

geben rafめ) und zuverläfíig Puskunft auf jedem Spezialgebiete und laffen (iid je nad den Jntereffen und den Mitteln des Einzelnen nad und nad) $3 u$ einer Enzïklopäbie aller Willenszweige erweitern.

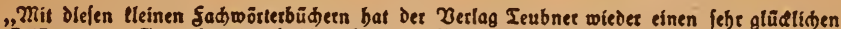

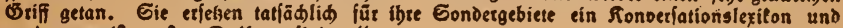
werben gewiß großen Pnilang finden."

(Deutfळе బarte.)

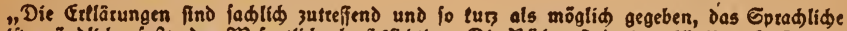

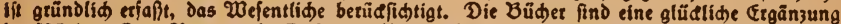

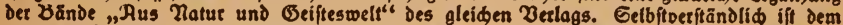

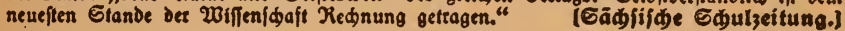

\section{Bisber erfdilenen:}

Bbilofophifdes 20beterbud von Studientat Dr. B. Ibormeger.

3. Rufl. (BD. 4.) (Jeb. M. 4.-

Bindologijळes wzrterbud von Brivatoozent Dr. f. Biefe. Mit 60 fig. (Bo. 7.) (उeb. M. 3.20

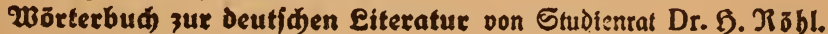
(BD. 14.) (Jeb. 2M. 3.60

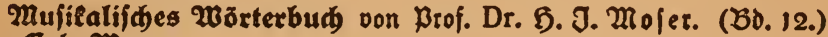
B.b. 2M. 3.20

*Runftgejめiळtlides wortexbud von Dr. G. Bollmer. (Bo. 16.)

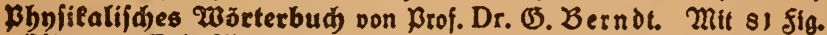
(BD. 5.) (3eb. M. 3.60

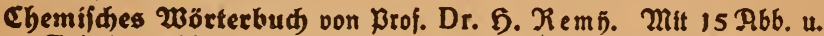

5 Tabellen. (BD. 10/11.) (5eb. 2M. 8.60, in Galbleinen $\mathfrak{M} .10 .60$

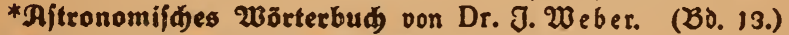

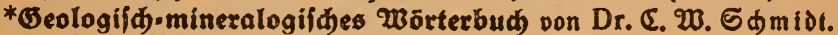

2. Rufl. Mit zablr. $\mathcal{H} b 6$. (BDo. 6.)

Seographifdes 20orterbud von Brof. Dr. O. Sende. Rllgem. Erdeunde. Wit 81 Rbb. (BD. 8.) (3eb. M. 4.60

8oologifdes 20 rterbud von Direttor Dr. Ib. Rnottnerus. Me jet. (BD. 2.) (Jeb. M. 4.-

Botanifdes wrrterbud von Brof. Dr. O. Gerte. Mit 103 Abb. (BD. 1.) (5eb. 2M. 4.-

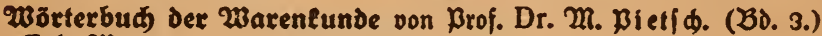
Jeb. M. 4.60

Gandelsworterbud von Gandelsiduldireftor Dr. $\mathfrak{B}$. Sittel und Juftiztat Dr. M. Stra uî. 3ugleid fünffipradiges Wötterbuक, zufammen: gefielit von 23. A rmbaus, verpfl. Dolmetider. (BD. 9.) (Beb. M. 4.60

* Eportwörterbua. Unter Mitwirlung zablteider Sportsleute beraus= gegeben von Dr. G. B. Müller, Borfikender des Eeipziger Sportclubs.

* (In 2orbereitung b3w. unter der Bteffe 1925) 


\section{(ธ) น}

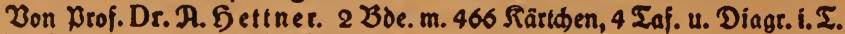

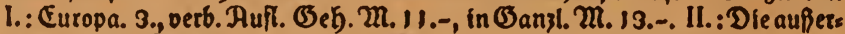
curopäijфen Erotelle. 1.u.2. Hufl. Beb. W. 14.20, in Banzleinen 21. 16.-

"Gier baben wic Jas, was uns gefeblt bas, ein Bud von Mteifterband getdrieben,

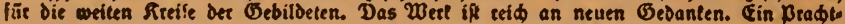

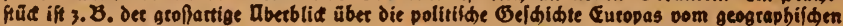
Gtandpuntt geleber."

(2nünden:Angsburger $\mathfrak{A b e n o z e i t u n g . ) ~}$

\section{Arlgemeine Wirtiðafts= $\mathfrak{u}$. Werkebrsgeographie}

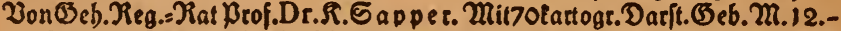

Zn diefem Gandbud, das die weltwirtibaft und den weltwerfebt in ibrer beutigen Auss Dehnung auf der tbren von der Natur gegebenen Escundlage und in ibrem geldictifiden und tuiturellen 3 ufammenbange sur Darfillung bringt, werben Brobuttion, Sandel und Bertebe übet dic ganse Eede bin oerfolgt.

\section{$\mathcal{A} \mathfrak{n}$ tb ropologie}

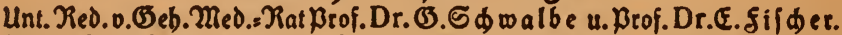

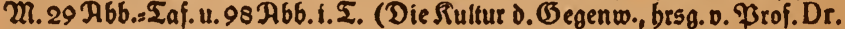
B.Ginneberg. TeillII, Mbt.V.) M.26.-, geb. M. 29.-, in GalbI. M. 34.-

Puf ibsem Eebiete fübrende Soridec baben fí in dem großangelegten, mit zablreiden Originalabbildungen ausgeftatteten werte 34 einet Belamidarfeliung dec Anthropologie, Döitertunde und Utrgef thret Bedeutung füe die Aligemeinbeit nldits Oleides an die Geite geftelft werden tann.

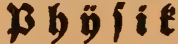

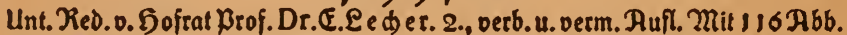
(Die Rultur D. (Begenw., brsg. o. Brof. Dr. B. Ginneberg. Teil III, Rbt. III, Bo. 1.) (Beb. M. 34.-, geb. M. 36.-, in Galbleder M. 40.-

Das Erídeinen einer Veubearbeitung des Bandes, det eine für den fadmann wie

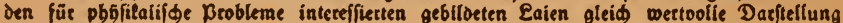
gibh, wiro bei det 3unebmenden Bedeutung, die die Bhöfil für viele Gebiete wie für die Rusgeftaltung und Dereinbettlibung unferes weltbildes gewonnen bat, befonders begrüpt

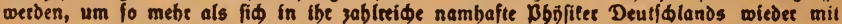

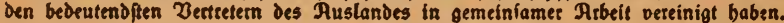

\section{Teubners Raturwiffenidaftlide Bibliotbek}

"Die zönde diefer oorzüglid geleitreten Gammlung fiteben wifrenimajtlid fo bod und find in der form fo gevflegt und fo anipredend, daf fie mit zum Beften geredsnet werden

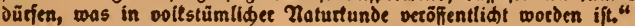

Betseidnis vom Werlag, Ecipzig, Bofifittaße 3, ethättili.

\section{Mathematifd:Bbýfikalifde Bibliothek}

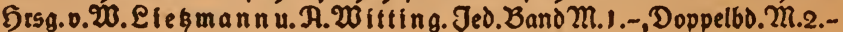
Band 50

Der (Begenftand Der 2latbematif im Eidte ibrer Entwidtung Bon Oberitudientat Dr. 6. Wi eleftner

Das So. Bandien der Bibliothet will einen uberblia über das Befamtgebiet geben, füt bas fie leinerzeit begründet wurde. Es will aujzeigen, wie die beutige Matbematil ges worben ift und was fit will. Det biersu befondecs becufene Berfaffec weî in anidaulliber

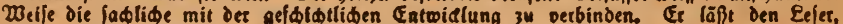

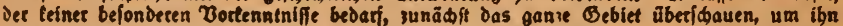
dann, oon der fa faton bad entwidelien Matbematil der OBrieden ausgebend, der modernen

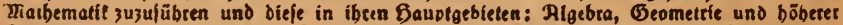

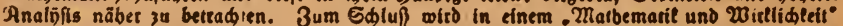

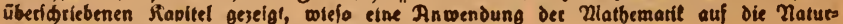

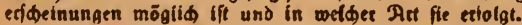

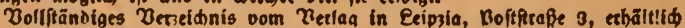

Zerlag von 3 . $\mathfrak{O}$. Ieubnet in Eeipzig und Bexlin 


\section{Rünftlerifðer Wandjømud für Gaus und Бळule}

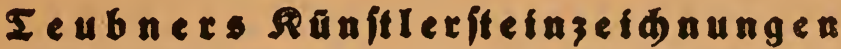

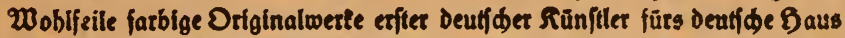
Dhe Gammlang eatbalts jett abet 200 bildet in ben Grbien $100 \times 70 \mathrm{~cm}(2 \pi, 10,-), 75 \times 55 \mathrm{~cm}$ (2., 9.-), $103 \times 44) \mathrm{cm}$ b3w. 93><4) cm $(21,0 .-), 60 \times 50 \mathrm{~cm}(22 ., 8 .-), 55 \times<4 \mathrm{~cm}$

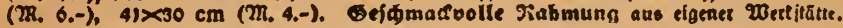

\section{Teu: Rleine $\mathfrak{R}$ unftblät ex}

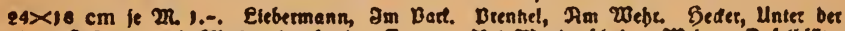

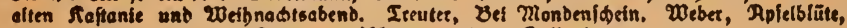
Bertmann, Blumenmatt in Gollend.

\section{Edat ten bitder}

ค. ข3. Diefenbad „Per aspera ad astra". Album, Die 34 Ieffb. Des pollif.

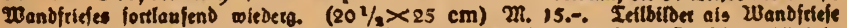

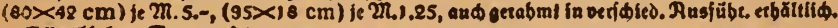

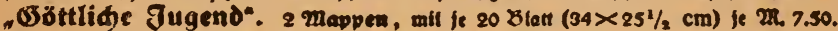

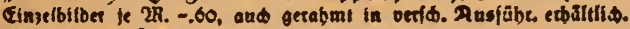

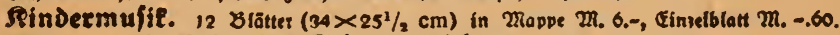

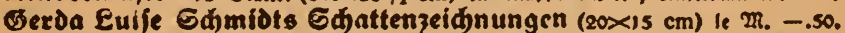

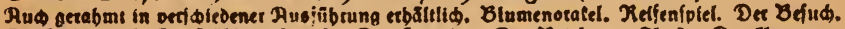
Det Eiebesbrtef. EIn Stüblingsftraupi. Die Steunie. Det Brtef an . Obn". Annäbetungs: otrud. Rm Epinet. Beim Wein. Ein 2rather. Det Debuttstag.

friefe zur $\mathfrak{A} u s j$ mmüdung von Rinderzinmern

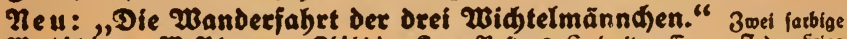

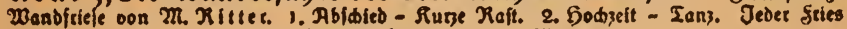
mit 2 Bilidern $(103 \times 41 \mathrm{~cm}) 2 n, 0 .-$

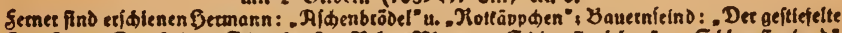
Ratet" a. Die fieben Gdwaben", Rehmsvietor: Edatarafienleben", Edlatafientano"

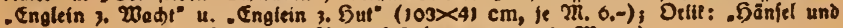
Gretet" u. . Rübezabl" (75><5s cm fe 22.9.-)

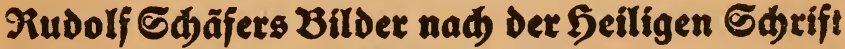

Det bermberige Gamadter, Jejus Det findetiteund, Das Rbendmabl, Godseit zu fana,

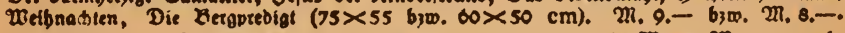

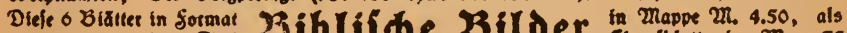

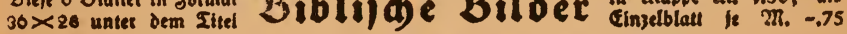
Raxl $\mathfrak{B}$ a uexs federzeidnungen

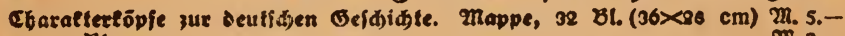
12 Bl. . . . . . . . . . . . . 2. 2.Rus Deutiajlands grotier Beit 1813, In mappe, 16 8i. (36>2s cm) 21.2 .50

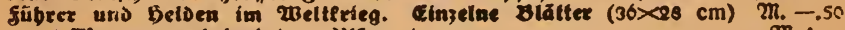
2 giappen, entbaltenb ie 12 Blatter, te................ U. 1.-

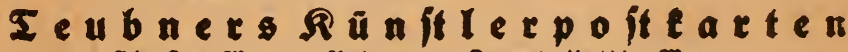

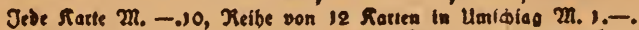

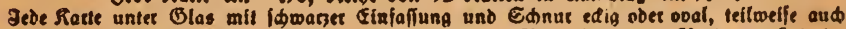

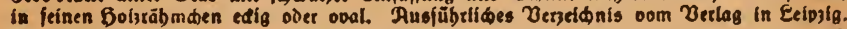

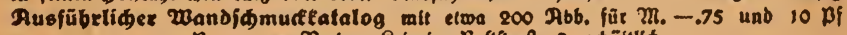
Botto vom Betieg, Eetpzig, Boftftraße 3, etbältliф.

Werlag von B. (5. Ieubner in Eeipzig und Berlin 


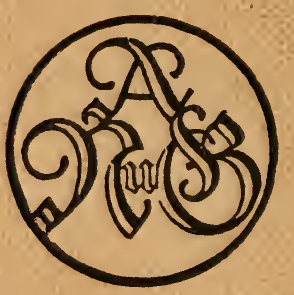

